\title{
ASSESSMENT OF LOAD BEARING CLAY BRICK MASONRY FOR ANALYZING LONG-TERM DURABILITY THROUGH FIELD MEASUREMENT AND VISUAL REVIEW
}

by

Blair Everett Williams

A thesis presented to Ryerson University

In partial fulfillment of the

requirements for the degree of

Master of Applied Science

on the Program of

Building Science

Toronto, Ontario, Canada, 2015

(C) Blair Williams 2015 


\section{AUTHOR'S DECLARATION}

\section{AUTHOR'S DECLARATION FOR ELECTRONIC SUBMISSION OF A THESIS}

I hereby declare that I am the sole author of this thesis. This is a true copy of the thesis, including any required final revisions, as accepted by my examiners.

I authorize Ryerson University to lend this thesis to other institutions or individuals for the purpose of scholarly research.

I further authorize Ryerson University to reproduce this thesis by photocopying or by other means, in total or in part, at the request of other institutions or individuals for the purpose of scholarly research.

I understand that my thesis may be made electronically available to the public. 


\begin{abstract}
Blair Williams, 2015. Assessment of Load Bearing Clay Brick Masonry for Analyzing LongTerm Durability Through Field Measurement and Visual Review. A thesis presented to Ryerson University in partial fulfillment of the requirements for the degree of Master of Applied Science in the Program of Building Science.
\end{abstract}

This thesis examines a load bearing clay brick century home research house in Toronto (Canada) which has recently undergone the addition of polyurethane foam insulation on all interior sides of the exterior clay brick load bearing walls, increasing the insulating value in areas to RSI $7.9 \mathrm{~W} / \mathrm{m}^{2} \mathrm{~K}$, on average.

This study introduces and advances techniques to create high-resolution stitched mosaic images of the elevations to visually document the current physical condition of the brick. The critical saturation point was used to determine the capabilities of the clay brick masonry to resist freeze-thaw damage by way of frost dilatometry testing, and compared to measurements taken by in-situ moisture content sensors in the brick masonry. This project also reveals how bricks expand and deteriorate in a non-uniform manner during saturated three-dimensional dilatometry testing. 


\section{ACKNOWLEDGEMENTS}

I would like to thank BASF, the industrial partner company, for their financial support and industrial partnership, as required for the NSERC Engage Grant program. Particularly at BASF, I would like to thank Robert Armstrong, Joe Innocente and Sharon Lishman. I would like to thank NSERC Engage Grant program for their financial support for this research project.

I would like to thank the members of the Faculty at Ryerson University for assistance with equipment and supplies. In particular I must thank Dr. Russell Richman, and his Sustainable Building Group at Ryerson for all the support, assistance, and for listening to my presentations. I must also thank Dr. Miljana Horvat, for her encouragement and the generous and extensive use of her NSERC funded Laboratory Drying Oven. Thanks to Dr. Vera Straka, for the kind use of her spare OnSet U10 data logger, when I was in need of an extra. Thanks to Dr. Hua Ge for her time and assistance with my research refinement. And thanks to Frank Bowen and Blaine Evans for their assistance with equipment in the Building Science Lab.

Thank you to Paul Van der Zalm and Rick Minion from Heraeus for the loan of Vaccon vacuum pump equipment.

And last but not least, I would not have been able to complete this thesis without the amazing support of my parents Vic \& Linda, my family, my friends and Daniel. 


\section{DEDICATION}

I would like to dedicate this fun little paper to my grandmothers. I certainly wouldn't have had the courage to take on this project without their many years of love, encouragement and support. 


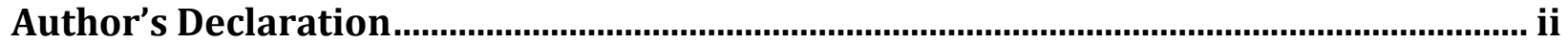

Abstract ................................................................................................................................. ii

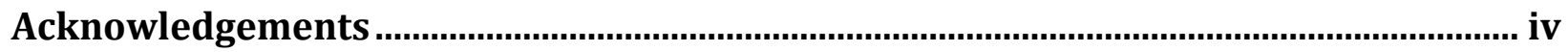

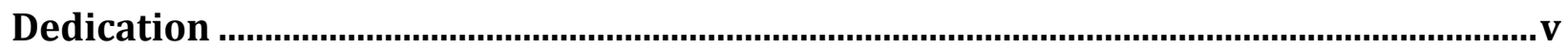

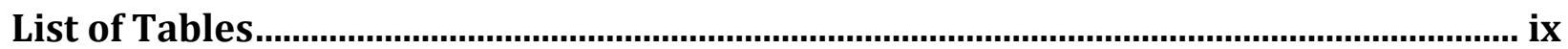

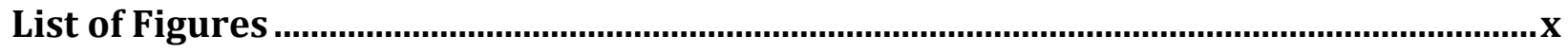

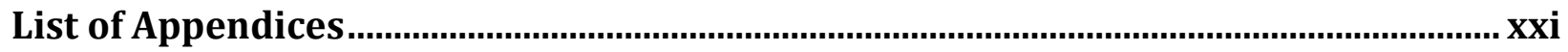

List of Abbreviations........................................................................................................ Xxii

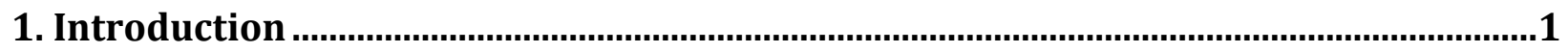

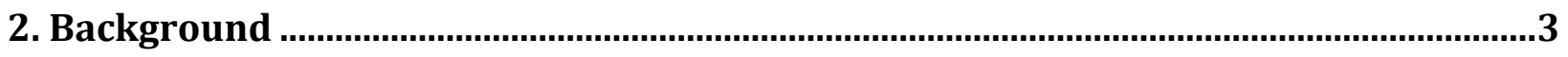

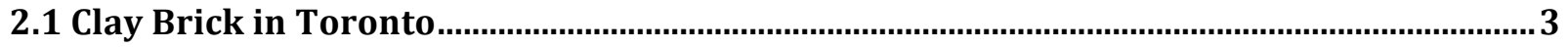

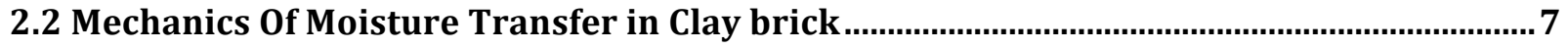

2.3 Moisture Content VS. Relative Humidity in Porous media ............................................... 10

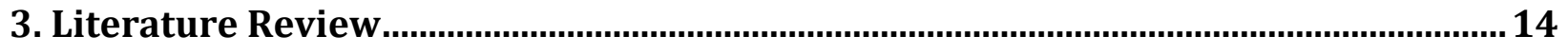

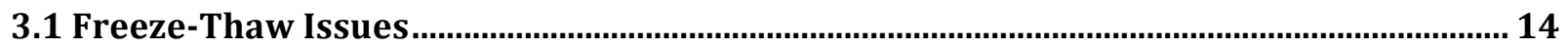

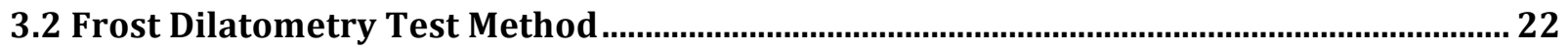

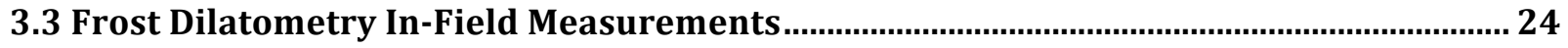

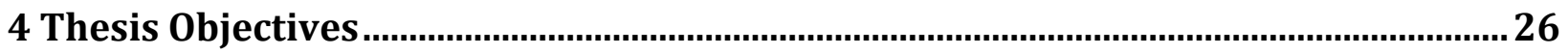




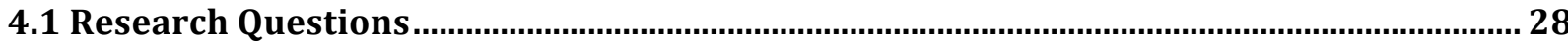

5. Methodology

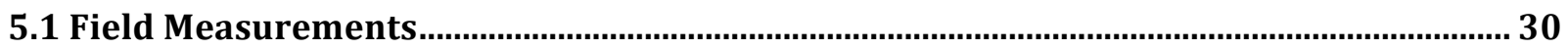

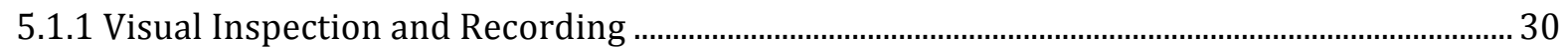

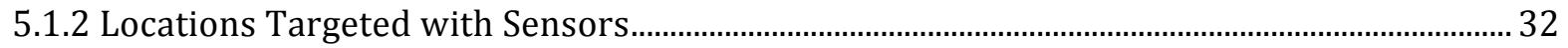

5.1.3 Measuring Clay brick Moisture Content In Situ ............................................................................. 49

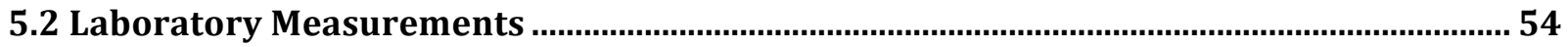

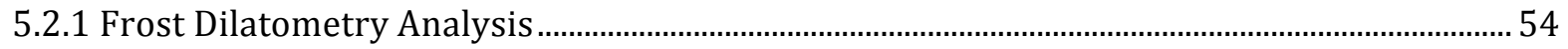

5.2.2 Absorption Curve Value Determination ......................................................................................... 71

5.2.3 Correlating Moisture Content to Relative Humidity ................................................................... 72

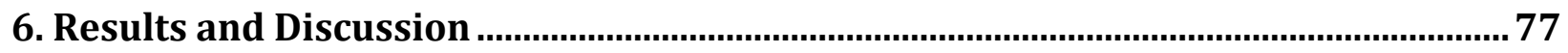

6.1 Photo-Documenting Elevations of the Test House .............................................................. 77

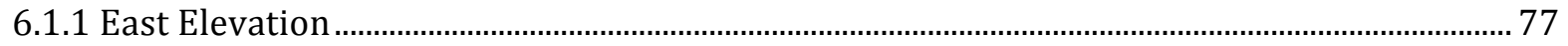

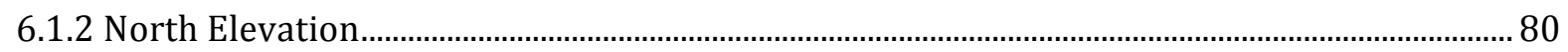

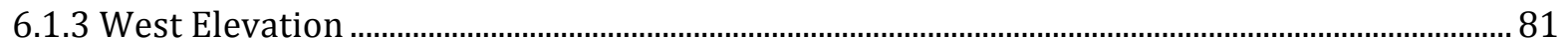

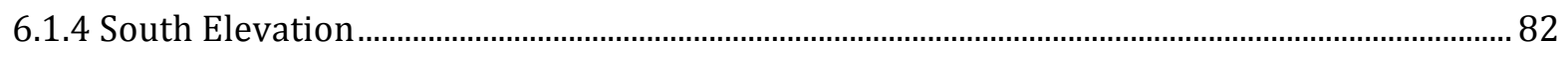

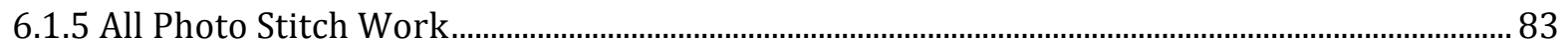

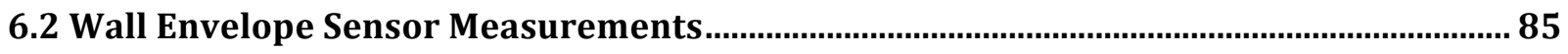

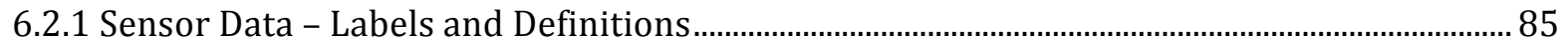

6.3 Frost Dilatometry Results - General Notes ....................................................................105

6.3.1 Plotted Results of 2-Dimensional Frost Dilatometry ...............................................................107

6.3.2 Plotted Results of 3-Dimensional Frost Dilatometry ..............................................................118

6.3.3 Plotted Results of 3-Dimensional Frost Dilatometry …….........................................................119

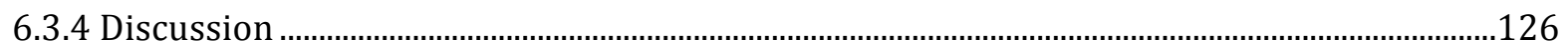

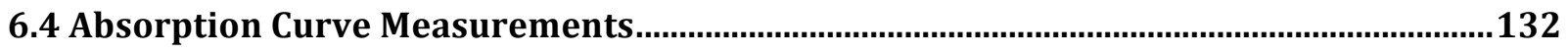




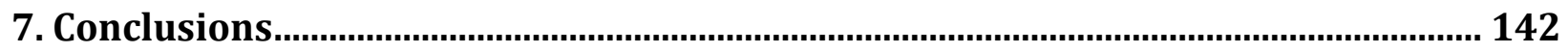

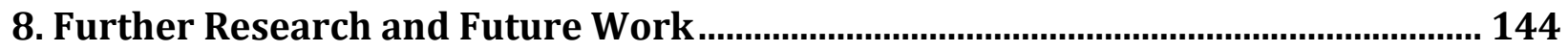

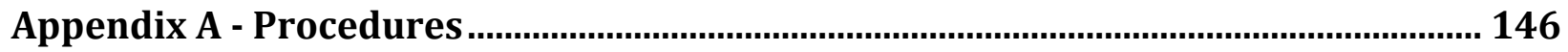

Procedure \# 1: Frost Dilatometry Procedure.................................................................................147

Procedure \#2: Making Wood Surrogate RH Sensors.................................................................153

Procedure \#3: Installation of Temperature/RH Sensors .......................................................157

Procedure \#4: Clay brick Specimen Extraction \& Reinstallation ...........................................160

Procedure \# 5: Installation of Moisture Content Sensors in Clay brick................................163

Procedure \#6: Photo-journaling an Elevation for Autopano Giga.............................................167

Procedure \# 7: Determining the Water Absorption Coefficient (A-value) for Clay brick

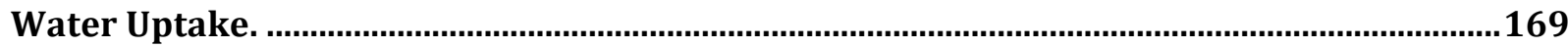

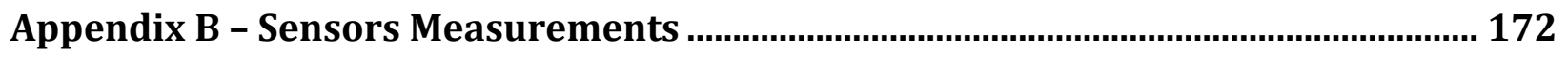

Location "P" - East Elevation, Lower Wall.......................................................................................173

Location “Q” - East Elevation, Upper Wall ..........................................................................................190

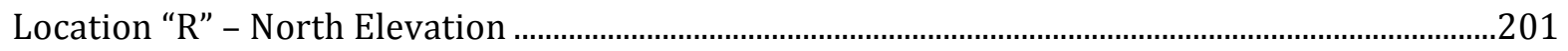

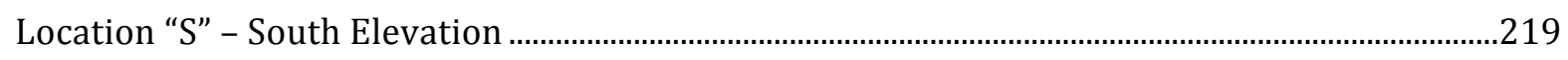

Appendix C - Moisture Content Sensor Correction Coefficients .................................... 237

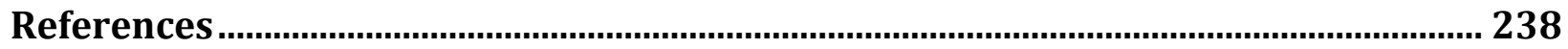




\section{LIST OF TABLES}

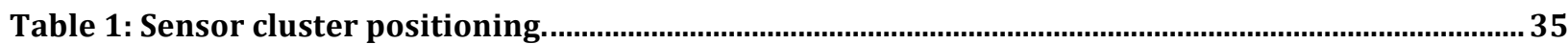

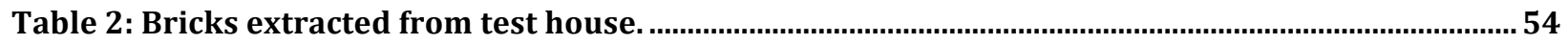

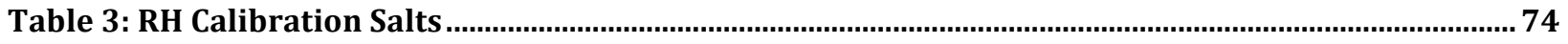

Table 4: Freeze-thaw cycles measured over one winter $(2012 / 2013):$.................................................103

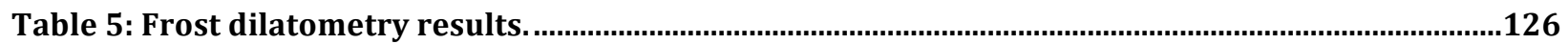

Table 6: Boil saturation vs. vacuum saturation. (Partial data set.) …......................................................129

Table 7: RH to Gravimetric Clay brick Moisture Content Relationship................................................135

Table 8: WUFI extrapolated sorption isotherm values for red brick. ....................................................136

Table 9: WUFI extrapolated sorption isotherm values for beige brick....................................................136

Table 10: Sample of MC measurements and corrected/predicted MC at sensors location P................139

Table 11: Moisture content sensor calibration coefficients. ......................................................................237 


\section{LIST OF FIGURES}

Figure 1: Scanning electron microscope image of internal pore structure of clay brick(Kavenagh \& Wheeler, 2003). 8

Figure 2: Illustration of different pore aspects within a porous media such as brick (Straube \& Burnett, 2005). . .8

Figure 3: As relative humidity increases, surface diffusion lines the pore walls with water molecules

(Straube \& Burnett, 2005) . .9

Figure 4: Sorption isotherms: Moisture storage in porous materials (Hutcheon \& Handegord, 1995).... 10

Figure 5: The Toronto test house, with adjacent neighbouring houses (Richman, 2009)........................... 32

Figure 6: Toronto test house Site plan (Russell Richman Consulting Limited, 2010) .................................... 33

Figure 7: Test house with sensor cluster locations "P", "Q" and "S."............................................................. 34

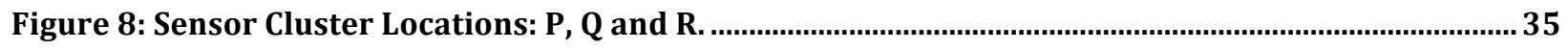

Figure 9: Gate installed between test house and one neighbouring property appears to be stagnating the air flow, and preventing brick masonry walls from drying (Google Maps, 2014) ....................... 37

Figure 10: A typical sensor positioning within the wall at each sensor cluster.......................................... 38

Figure 11: OmniSense Temperature/RH sensors (OmniSense LLC, 2014) ................................................ 39

Figure 12: Onset Temperature/RH Smart Sensor (Onset Computer Corporation, 2014d)...........................40

Figure 13: Hobo Micro Station Data Logger (Onset Computer Corporation, 2014a). ................................ 41

Figure 14: Onset HOBO Mirco Station Installed at the Research House. .................................................... 41

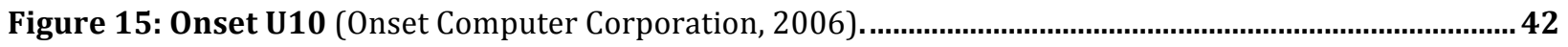

Figure 16: Onset USB data shuttle(Onset Computer Corporation, 2014b)...................................................... 42

Figure 17: SMT Moisture Content sensor (SMT Research Ltd., n.d.). ……..................................................... 43

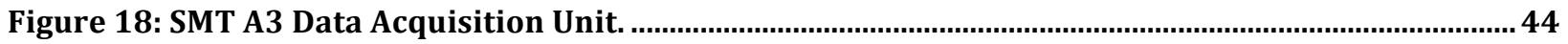

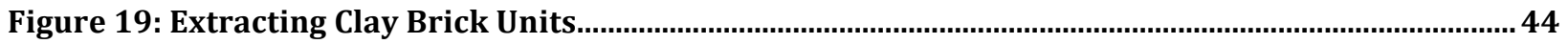

Figure 20: Bore hole being made in bottom of an inverted clay brick from the exterior wythe in

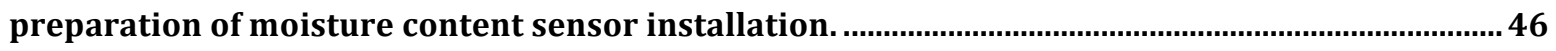

Figure 21: Sensor embedded into clay brick with dust from drilling process...............................................46 
Figure 22: Sensor Sealed in Place with Epoxy.

Figure 23: Sensor installed through the face of the interior wythe of brick.

Figure 24: Section of the test building's clay brick wall shows typical moisture content sensor arrangement. (Exterior side is on the left.). 47

Figure 25: Sliced century old clay bricks reveal the visibly inhomogeneous swirl pattern within, as well as pockets, voids and inclusions Note the "marble" swirl pattern. 49

Figure 26: Resistance vs. Moisture Content Curve for Wood. - redrawn from SMT technical literature, EMS Sensor. (SMT Research Ltd., n.d.) 50

Figure 27: Moisture Sensor cables routed around the exterior of the house. 52

Figure 28: 1 of 4 SMT Moisture Content data loggers during installation. 53

Figure 29: Cored contemporary clay brick only yields 4 specimens of appropriate size for comparison. .55

Figure 30: Whole clay bricks and clay bricks sliced in a "bread loaf" manner to create specimens ...... 57

Figure 31: Wear-pins installed into clay brick specimens for micrometer measurements. .................. 58

Figure 32: Clay brick specimens measurement axes. 59

Figure 33: Micrometer calliper measurement of wear pins. 60

Figure 34: Pins must be positioned at dead centre of fixed anvil during measurement for consistency.

Figure 35: Pins must be positioned at dead centre of adjustable anvil during measurement for consistency.

Figure 36: 0.1 g Resolution Scale. 62

Figure 37: 0.5 g Resolution Scale. 63

Figure 38: Boil method for saturation of clay brick specimens. 65

Figure 39 Clay brick stacked inside the inverted upper hemisphere of a vacuum desiccator

(foreground). They are to be positioned on the platform in the lower hemisphere of the desiccator before it is filled with water (background).

Figure 40: Vacuum desiccator assembled, clay bricks in the upper hemisphere.

Figure 41: Lower hemisphere of desiccator filler with distilled water. 
Figure 42:Peristaltic Pump system used to evacuate atmosphere from vacuum desiccator.

Figure 43: Peristaltic pump in the Building Science Lab at Ryerson University was capable of producing 28 inHg of vacuum.

Figure 44: 9-cycle cooling and heating profile for freeze-thaw chamber. ............................................ 69

Figure 45: Wrapped brick specimens inside the freeze-thaw chamber............................................. 70

Figure 46: Visibly inhomogeneous clay brick constitution. (blown up to show texture.) ....................... 73

Figure 47: Air pocket in clay brick sample 73

Figure 48: RH Vessel with brick specimen (with Moisture Content Sensors installed), salt solution

(below brick), Temp/RH data logger, and airtight lid.................................................................... 75

Figure 49: East elevation gigapixel images. Note Sensor locations “P” and “Q” at this elevation. .......... 77

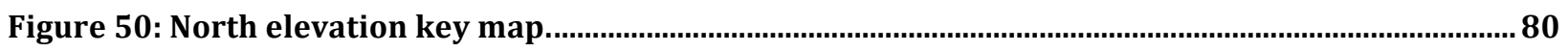

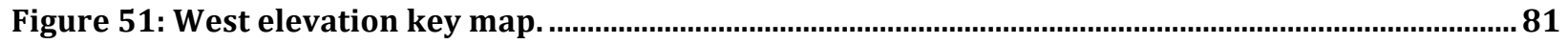

Figure 52: West corner of South elevation - location of sensor installation "S". .................................... 82

Figure 53: Sensor Measurements from Location "Q" - East elevation 3 m above grade. February 26 March 4, 2013.

Figure 54: Sensor Measurements from Location "Q" - East elevation 3 m above grade. March 5 - 11,

2013 91

Figure 55: Sensor Measurements from Location "Q" - East elevation 3 m above grade. March 12 - 18, 2013.

Figure 56: Sensor Measurements from Location "Q" - East elevation 3 m above grade. March 19 - 25, 2013 93

Figure 57: Sensor Measurements from Location "P" - East elevation 0.5 m above grade. January 29 February 4, 2013.

Figure 58: Sensor Measurements from Location "Q" - East elevation 3 m above grade. January 29 -

February 4, 2013. 96

Figure 59: Sensor Measurements from Location "R" - North elevation at porch. January 29 - February

4, 2013. 
Figure 60: Sensor Measurements from Location "S" - South elevation at second storey. January 29 -

February 4, 2013.

Figure 61: Sensor Measurements from Location "Q" - East elevation 3 m above grade. April 9 - 15,

2013.

Figure 62: 2-Dimensional Frost Dilatometry results - Brick Specimen 1R - X Axis average $s_{\text {crit }}$ measurements.

Figure 63: 2-Dimensional Frost Dilatometry results - Brick Specimen 1R - Y Axis average $s_{\text {crit }}$ measurements.

Figure 64: 2-Dimensional Frost Dilatometry results - Brick Specimen $1 \mathrm{~W}-\mathrm{X}$ Axis average $\mathbf{s}_{\text {crit }}$ measurements.

Figure 65: 2-Dimensional Frost Dilatometry results - Brick Specimen $1 \mathrm{~W}-\mathrm{Y}$ Axis average $s_{\text {crit }}$ measurements.

Figure 66: 2-Dimensional Frost Dilatometry results - Brick Specimen 2R - X Axis average $s_{\text {crit }}$ measurements.

Figure 67: 2-Dimensional Frost Dilatometry results - Brick Specimen 2R - Y Axis average $s_{\text {crit }}$ measurements.

Figure 68: 2-Dimensional Frost Dilatometry results - Brick Specimen $2 \mathrm{~W}-\mathrm{X}$ Axis average $\mathbf{s}_{\text {crit }}$ measurements.

Figure 69: 2-Dimensional Frost Dilatometry results - Brick Specimen $2 \mathrm{~W}-\mathrm{Y}$ Axis average $\mathbf{s}_{\text {crit }}$ measurements.

Figure 70: 2-Dimensional Frost Dilatometry results - Brick Specimen $4 R$ - X Axis average $s_{\text {crit }}$ measurements.

Figure 71: 2-Dimensional Frost Dilatometry results - Brick Specimen 4R - Y Axis average $s_{\text {crit }}$ measurements.

Figure 72: 2-Dimensional Frost Dilatometry results - Brick Specimen $4 \mathrm{~W}-\mathrm{X}$ Axis average $s_{\text {crit }}$ measurements.

Figure 73: 2-Dimensional Frost Dilatometry results - Brick Specimen 4W - Y Axis average $s_{\text {crit }}$ measurements. 
Figure 74: 2-Dimensional Frost Dilatometry results - Brick Specimen 5R - X Axis average $S_{\text {crit }}$ measurements.

Figure 75: 2-Dimensional Frost Dilatometry results - Brick Specimen 5R - Y Axis average $\mathbf{S}_{\text {crit }}$ measurements.

Figure 76: 2-Dimensional Frost Dilatometry results - Brick Specimen $5 W$ - X Axis average $s_{c r i t}$ measurements.

Figure 77: 2-Dimensional Frost Dilatometry results - Brick Specimen 5 W - Y Axis average $\mathbf{s}_{\text {crit }}$ measurements.

Figure 78:2-Dimensional Frost Dilatometry results - average $s_{\text {crit }}$ measurements for Modern Brick Specimens 5, 6 and 7.

Figure 79:2-Dimensional Frost Dilatometry results - average $s_{\text {crit }}$ measurements Modern Brick Specimens 8, 9 and 10.

Figure 80:2-Dimensional Frost Dilatometry results - average $\mathbf{s}_{\text {crit }}$ measurements for Modern Brick Specimen No. 11.

Figure 81: 3-Dimensional Frost Dilatometry - Pin Placement Diagram. .118

Figure 82: 3-Dimensional Frost Dilatometry results - average $s_{\text {crit }}$ measurements for Brick specimen

6n-1. .119

Figure 83: 3-Dimensional Frost Dilatometry results - average $s_{\text {crit }}$ measurements for Brick specimen

6w-1.

Figure 84: 3-Dimensional Frost Dilatometry results - average $s_{\text {crit }}$ measurements for Brick specimen

$6 w-2$ .120

Figure 85: 3-Dimensional Frost Dilatometry results - average $s_{\text {crit }}$ measurements for Brick specimen

$3 \mathbf{r}-1$.

Figure 86: 3-Dimensional Frost Dilatometry results - average $s_{\text {crit }}$ measurements for Brick specimen

$3 r-2$. 121

Figure 87: 3-Dimensional Frost Dilatometry results - average $s_{\text {crit }}$ measurements for Brick specimen

$6 r-1$. 
Figure 88: 3-Dimensional Frost Dilatometry results - average $s_{\text {crit }}$ measurements for Brick specimen

c1-1.

Figure 89: 3-Dimensional Frost Dilatometry results - average $s_{\text {crit }}$ measurements for Brick specimen

c1-2.

Figure 90: 3-Dimensional Frost Dilatometry results - average $s_{\text {crit }}$ measurements for Brick specimen

c2-1.

Figure 91: 3-Dimensional Frost Dilatometry results - average $s_{\text {crit }}$ measurements for Brick specimen

c2-2.

Figure 92: 3-Dimensional Frost Dilatometry results - average $s_{\text {crit }}$ measurements for Brick specimen

c3-1. 124

Figure 93: 3-Dimensional Frost Dilatometry results - average $s_{\text {crit }}$ measurements for Brick specimen c3-2. .124

Figure 94: 3-Dimensional Frost Dilatometry results - average $s_{\text {crit }}$ measurements for Brick specimen

c4-1.

Figure 95: 3-Dimensional Frost Dilatometry results - average $s_{\text {crit }}$ measurements and Brick specimen c4-2. .125

Figure 96: 3D frost dilatometry; uneven expansion. .127

Figure 97: 3D frost dilatometry; uneven expansion.

Figure 98: 3D frost dilatometry; clay brick experienced different internal forces and expansion on either side of the cut.

Figure 99: Absorption curve for brick specimen 3R. 132

Figure 100: Absorption curve for brick specimen 6N-1.

Figure 101: Absorption curve for brick specimen 6R .133

Figure 102: WUFI extrapolated sorption isotherm curve for red brick. .136

Figure 103: WUFI extrapolated sorption isotherm curve for beige brick. 136

Figure 104: Moisture Content Sensor Correlation to Gravimetric Moisture Content for Beige Clay brick. 
Figure 105: Moisture Content Sensor Correlation to Gravimetric Moisture Content for Red Clay brick.

Figure 106 Sensor Measurements from Location "R" - North elevation under porch. Jan 22-28, 2013.

Figure 107: Voltage divider circuit (Straube et al., 2002). .155

Figure 108: Voltage divider circuit (Straube et al., 2002). . .155

Figure 109: Sensor Measurements from Location "P" - East elevation $0.5 \mathrm{~m}$ above grade. December 18 - 24, 2012. .173

Figure 110: Sensor Measurements from Location "P" - East elevation $0.5 \mathrm{~m}$ above grade. December 25

$-31,2012$.

Figure 111: Sensor Measurements from Location "P" - East elevation $0.5 \mathrm{~m}$ above grade. January 1 - 7, 2013. .175

Figure 112: Sensor Measurements from Location "P" - East elevation $0.5 \mathrm{~m}$ above grade. January 8 -

14, 2013.

Figure 113: Sensor Measurements from Location "P" - East elevation 0.5 m above grade. January 15 -

21, 2013 .177

Figure 114: Sensor Measurements from Location "P" - East elevation $0.5 \mathrm{~m}$ above grade. January 22 -

28, 2013.

Figure 115: Sensor Measurements from Location "P" - East elevation 0.5 m above grade. January 29 -

February 4, 2013.

Figure 116: Sensor Measurements from Location "P" - East elevation $0.5 \mathrm{~m}$ above grade. February 5 -

$11,2013$. 180

Figure 117: Sensor Measurements from Location "P" - East elevation 0.5 m above grade. February 12 -

$18,2013$. .181

Figure 118: Sensor Measurements from Location "P" - East elevation 0.5 m above grade. February 19 -

25, 2013. .182

Figure 119: Sensor Measurements from Location "P" - East elevation 0.5 m above grade. February 26 March 4, 2013. . .183 
Figure 120: Sensor Measurements from Location "P" - East elevation 0.5 m above grade. March 5 - 11, 2013

Figure 121: Sensor Measurements from Location "P" - East elevation 0.5 m above grade. March 12 - 18, 2013. 185

Figure 122: Sensor Measurements from Location "P" - East elevation 0.5 m above grade. March 19 - 25 , 2013 186

Figure 123: Sensor Measurements from Location "P" - East elevation 0.5 m above grade. March 26 -

April 1, 2013.

Figure 124: Sensor Measurements from Location "P" - East elevation 0.5 m above grade. April 2 - 8, 2013

Figure 125: Sensor Measurements from Location "P" - East elevation 0.5 m above grade. April 9 - 15, 2013.

Figure 126: Sensor Measurements from Location "Q" - East elevation 3 m above grade. January 29 -

February 4, 2013

Figure 127: Sensor Measurements from Location "Q" - East elevation 3 m above grade. February 5 -

11,2013 .191

Figure 128: Sensor Measurements from Location "Q" - East elevation 3 m above grade. February 12 -

18,2013 .192

Figure 129: Sensor Measurements from Location "Q" - East elevation 3 m above grade. February 19 -

25,2013 .193

Figure 130: Sensor Measurements from Location "Q" - East elevation 3 m above grade. February 26 -

March 4, 2013. .194

Figure 131: Sensor Measurements from Location "Q" - East elevation 3 m above grade. March 5 - 11, 2013. .195

Figure 132: Sensor Measurements from Location "Q" - East elevation 3 m above grade. March 12 - 18, 2013. 196

Figure 133: Sensor Measurements from Location "Q" - East elevation 3 m above grade. March 19 - 25, 2013. .197 
Figure 134: Sensor Measurements from Location "Q" - East elevation 3 m above grade. March 26 -

April 1, 2013.

Figure 135: Sensor Measurements from Location "Q" - East elevation 3 m above grade. April 2 - 8,

2013.

Figure 136: Sensor Measurements from Location "Q" - East elevation 3 m above grade. April 9 - 15,

2013

Figure 137: Sensor Measurements from Location "R" - North elevation under covered porch.

December 11 - 17, 2012.

Figure 138: Sensor Measurements from Location "R" - North elevation under covered porch.

December 18 - 24, 2012.

Figure 139: Sensor Measurements from Location "R" - North elevation under covered porch.

December 25 - 31, 2012.

Figure 140: Sensor Measurements from Location "R" - North elevation under covered porch. January 1

$-7,2013$.

Figure 141: Sensor Measurements from Location "R" - North elevation under covered porch. January 8

$-14,2013$.

Figure 142: Sensor Measurements from Location "R" - North elevation under covered porch. January

$15-21,2013$. .206

Figure 143: Sensor Measurements from Location "R" - North elevation under covered porch. January

$22-28,2013$.

Figure 144: Sensor Measurements from Location "R" - North elevation under covered porch. January

29 - February 4, 2013.

Figure 145: Sensor Measurements from Location "R" - North elevation under covered porch. February

5 - 11, 2013.

Figure 146: Sensor Measurements from Location "R" - North elevation under covered porch. February

$12-18,2013$.

Figure 147: Sensor Measurements from Location "R" - North elevation under covered porch. February

19- 25, 2013.

.211 
Figure 148: Sensor Measurements from Location "R" - North elevation under covered porch. February 26 - March 4, 2013.

Figure 149: Sensor Measurements from Location "R" - North elevation under covered porch. March 5 -

11, 2013. .213

Figure 150: Sensor Measurements from Location "R" - North elevation under covered porch. March 12

$-18,2013$.

Figure 151: Sensor Measurements from Location "R" - North elevation under covered porch. March 19

$-25,2013$.

Figure 152: Sensor Measurements from Location "R" - North elevation under covered porch. March 26

- April 1, 2013.

Figure 153: Sensor Measurements from Location "R" - North elevation under covered porch. April 2 -

8, 2013.

Figure 154: Sensor Measurements from Location "R" - North elevation under covered porch. April 9 -

15,2013 .218

Figure 155: Sensor Measurements from Location "S" - South elevation under second floor windows.

December 11 - 17, 2012.

Figure 156: Sensor Measurements from Location "S" - South elevation under second floor windows.

December 18 - 24, 2012.

Figure 157: Sensor Measurements from Location "S" - South elevation under second floor windows.

December 25 - 31, 2012.

Figure 158: Sensor Measurements from Location "S" - South elevation under second floor windows.

January $1-7,2013$.

Figure 159: Sensor Measurements from Location "S" - South elevation under second floor windows.

January 8 - 14, 2013.

Figure 160: Sensor Measurements from Location "S" - South elevation under second floor windows.

January 15 - 21, 2013.

Figure 161: Sensor Measurements from Location "S" - South elevation under second floor windows.

January 22 - 28, 2013. 
Figure 162: Sensor Measurements from Location "S" - South elevation under second floor windows.

January 29 - February 4, 2013.

Figure 163: Sensor Measurements from Location "S" - South elevation under second floor windows.

February 5 - 11, 2013.

Figure 164: Sensor Measurements from Location "S" - South elevation under second floor windows.

February $12-18,2013$.

Figure 165: Sensor Measurements from Location "S" - South elevation under second floor windows.

February 19 - 25, 2013

Figure 166: Sensor Measurements from Location "S" - South elevation under second floor windows.

February 26 - March 4, 2013.

Figure 167: Sensor Measurements from Location "S" - South elevation under second floor windows.

March 5 - 11, 2013.

Figure 168: Sensor Measurements from Location "S" - South elevation under second floor windows.

March 12 - 18, 2013.

Figure 169: Sensor Measurements from Location "S" - South elevation under second floor windows.

March 19 - 25, 2013.

Figure 170: Sensor Measurements from Location "S" - South elevation under second floor windows.

March 26 - April 1, 2013

Figure 171: Sensor Measurements from Location "S" - South elevation under second floor windows.

April 2 - 8, 2013.

.235

Figure 172: Sensor Measurements from Location "S" - South elevation under second floor windows.

April 9 - 15, 2013 


\section{LIST OF APPENDICES}

APPENDIX A: Procedures

Procedure \#1: Frost Dilatometry Procedure

Procedure \#2: Making Wood Surrogate RH Sensors

Procedure \#3: Installation of Temperature/RH Sensors

Procedure \#4: Brick Specimen Extraction \& Reinstallation

Procedure \#5: Installation of Moisture Content Sensors in Brick

Procedure \#6: Photo-journaling an Elevation for Autopano Giga

Procedure \#7: Measuring the Water Absorption Coefficient of Brick

APPENDIX B: Sensor Measurements

1) Location "P" - East Elevation, Lower Wall

2) Location "Q" - East Elevation, Upper Wall

3) Location "R" - North Elevation

4) Location "S" - South Elevation

APPENDIX C: Moisture Content Sensor Correction Coefficients 


\section{LIST OF ABBREVIATIONS}

ASTM - American Society for Testing and Materials

BCRC - Belgian Ceramic Research Center

BBRI - Belgium Building Research Institute

CAD - Computer Aided Design

CMHC - Canada Mortgage and Housing Corporation

CSA - Canadian Standards Association

EU - European Union

HAM - Heat Air Moisture

HAMSTAD - Heat Air and Moisture Standards Development - An E.U.-initiated interlaboratory project designed to compare measurements variability observed when analyzing the hygric properties of various porous materials.

MC - Moisture Content [\%]

NSERC - Natural Sciences and Engineering Research Council

$\mathrm{R}$ - Resistance $[\Omega]$

RH - Relative Humidity [\%]

RSI - Metric Thermal Resistance $\left[\mathrm{W} / \mathrm{m}^{2} \mathrm{~K}\right]$

SPF - Spray-applied Polyurethane Foam 
USB - Universal Serial Bus

VIP - Vacuum Insulation Panels

WUFI - Wärme und Feuchte Instationär ("Transient Heat and Moisture Transport") 


\section{INTRODUCTION}

With energy costs on the rise there is great emphasis being placed on having a well insulated home. New houses are insulated by a number of different materials, and the insulation is generally installed as a component of an overall wall assembly that is designed in a way that minimizes the potential for premature deterioration of the building envelope.

There exists a great number of pre-World War II homes constructed of clay brick masonry in Canada that have minimal insulation installed, if any (CMHC, 2004). It makes sense that owners would want to insulate these older homes in order to save money on heating and cooling costs; the instances of homeowners installing insulation will increase as energy costs rise with time. Unfortunately, altering the envelope system can have a negative effect on its moisture and temperature balance (Straube \& Schumacher, 2007). Old solid clay brick masonry walls that were completely uninsulated would dry themselves out throughout the year, simply by the heat loss from the interior heat migrating through the clay brick masonry during the heating season (Straube \& Schumacher, 2007). Literature exists suggesting harmful effects result from installing closed-cell spray-applied polyurethane foam (SPF) applications on the interior of solid clay brick masonry in order to achieve modern insulating levels (e.g. approximately RSI 3.5 W/m² K to $7.9 \mathrm{~W} / \mathrm{m}^{2} \mathrm{~K}$ ) (Finch, Straube, \& Richmond, 2007; Straube, Schumacher, \& Mensinga, 2010; Straube, Ueno, \& Schumacher, 2011). However, little is known about the effects of super-insulating with SPF on the interior of load bearing clay brick masonry to increase thermal resistances beyond modern levels (i.e. above RSI $3.5 \mathrm{~W} / \mathrm{m}^{2} \mathrm{~K}$ ). 
This research project focuses on quantifying the effects of super-insulating clay brick masonry from the interior at a solid clay brick masonry case study research house in the Riverdale area of Toronto (Canada). This particular research house is a three-storey century home, of which the bottom two storeys are constructed of load bearing double-wythe clay brick masonry and is currently home to various building science research initiatives (Richman, 2009). The house has recently undergone major renovations: the interior was fully demolished to the clay brick walls during this "full gut" renovation. The original solid clay brick masonry walls were framed on the interior and insulated with $125 \mathrm{~mm}$ to $175 \mathrm{~mm}$ (5" to 7") of $900 \mathrm{~g}$ (2-lb) closed cell spray applied polyurethane foam. As part of this thesis, temperature, relative humidity and embedded moisture content sensors were installed at various locations throughout the exterior walls, and the in-situ hygrothermal regime were recorded through a 2 year period; data over the winter of 2012 was focussed upon, as all sensors were simultaneously operational during this period. Sample clay bricks were removed from the walls of the house and analysed in a laboratory using standard techniques and also advancing novel techniques to obtain essential material characteristics that could be used to create a highly tuned computer model of the wall assembly using WUFI. 


\section{BACKGROUND}

\subsection{CLAY BRICK IN TORONTO}

In the 1870's an industrious paper mill owner discovered that the clay along Toronto's Don River was ideal for making clay bricks. A clay brick manufacturing operation started shortly thereafter. Toronto had a number of early clay brick manufacturers: "Robert Goodings' Brick Works" at Broadview Avenue and Bloor Street began its operations around 1872 (City of Toronto, 2011b). “James Pears Brick Manufacturer" (also run under different names) on Eglinton Avenue operated from about 1880 to 1923 (City of Toronto, 2011a). And most notably due to its longevity, the Don Valley Brick Works operated in the Don lands along Bayview Avenue from 1889 to 1984 (Evergreen Brick Works, 2013).

Toronto experienced its Great Fire in 1904 (City of Toronto, 2011). At the time, much of the city's downtown was constructed of a mix of wooden timber frame and masonry buildings. They were built closely together, so the flames spread quite easily. The result of the fire were new city by-laws which required most buildings to be constructed of masonry to reduce the chance of fire spreading beyond a single building (Evergreen Brick Works, 2011). With at least three significant clay brick suppliers in the immediate area, the majority of residents would have used locally manufactured materials to construct their homes rather than pay premiums to import clay brick by rail from outlying areas. 
Clay brick units produced at the turn of the century have very different characteristics compared to clay bricks that are produced today. Clay brick produced up until the middle of the 20th century was highly variable in dimension, hardness and strength. This was primarily due to the clay type, and the type of kiln processes used to fire the older brick (Laefer, Boggs, \& Cooper, 2004). There was so much variability of quality from a single kiln, that clay brick manufacturers would classify the clay brick into different grades: best class, first class, second class and third class. Clinkers (over-fired clay brick) and salmons (under-fired clay brick) were also sold, but not for structural purposes (Laefer et al., 2004).

At the time, there were no standards for measuring the strength of these clay bricks, but generally were measured by their compressive strength (Laefer et al., 2004). Today's ASTM standard C62-11 classifies clay brick into three general grades: Severe weathering, moderate weathering, and negligible weathering clay brick (American Society for Testing and Materials, 2010). The Canadian equivalent to this standard classifies clay brick into two general grades: interior grade and exterior grade (CSA Standards, 2007). The testing processes used to develop these classifications analyze the performance characteristics of the clay brick, including compressive strength, water absorption and saturation limits, and also irreversible dimensional change as a result of freeze-thaw damage (Laefer et al., 2004). According to the CSA, all clay brick used for exposed application in Canada must be severe weathering (CSA Standards, 2007).

The kiln type and firing process play an important role in determining the final qualities of clay brick. The clay brick in Toronto's historic buildings would have been fired in traditional 
"stationary" type kilns. Batches of clay bricks were placed inside the kiln, and would not move inside the vessel during their firing process. The fuel (wood or coal) had to be attended to by men, and was heated only to about $540^{\circ} \mathrm{C}$. "Non-stationary" (or "Tunnel”) kilns were invented in the 1700s, but were not well developed until the early to mid twentieth century. In these types of kilns the clay bricks are rolled successively between preheating, heating and cooling stages. The fuel for these more modern kiln type is typically gas, oil or electricity, and with the assistance of computers and blowers, the temperatures are consistently and uniformly maintained up to $1090^{\circ} \mathrm{C}$ during the firing process, which ensure much less variability in the quality of the clay brick exiting the firing process (Laefer et al., 2004).

Most historic clay brick masonry typically cannot meet today's freeze-thaw test requirements (Straube et al., 2010). Historic buildings were constructed of clay brick that was manufactured well before the creation of ASTM or CSA standards. The only real measure of durability for old clay brick has been the test of time: clay bricks used that had inferior freeze-thaw capabilities have simply not survived. If a clay brick wall assembly degraded relatively soon after construction, the building would have likely been demolished decades ago. Any historic brick buildings that remain today are of the highest quality, and have survived due to their tolerant characteristics, and are also aided by the inefficiency of old wall assemblies that kept them warm and dry in the winter.

Although Toronto and other cities are seeing drastic changes in their skylines, there still exist a tremendous number of these historic clay brick buildings in many neighbourhoods in and around the city. Structurally speaking, these longstanding buildings are very different than ones built today; the clay brick masonry walls in buildings constructed at this time served as 
both the barrier to the elements, and also as the load bearing structure for the floors and roof. The clay brick masonry walls typically ranged from two to five wythes thick; the great volume of brick of which these walls massive walls were comprised was capable of holding a greater amount of moisture simply due to their thickness. Rain events and surface condensation combined with capillary moisture transport and the assistance of the sun-driven moisture phenomenon would cause moisture to travel toward the interior side of these massive walls.

Contemporary buildings use a completely different technique: clay brick veneer cavity walls are only a single wythe deep, and hang from the structure of the building. They serve to impede rainwater entering the wall, and also offer a "traditional" aesthetic appearance. A cavity exists behind the brick veneer to serve as a capillary break between the clay brick rain screen and the backup wall; the cavity serves as a water drainage plane as well as a vented space to promote drying on the interior side of the brick. Furthermore, the characteristics of the clay brick have changed over the years. Today clay bricks used for exterior purposes in Canada and northern U.S. must be certified to CSA "Exterior grade" and ASTM specification "Severe Weathering" respectively, in an attempt to control freeze-thaw damage in buildings.

Different building practices existed at the turn of the century compared to the practices of today. There was less of a concern for energy efficiency, and as such, the installation of insulation did not exist in the same sense as it does today. This lack of concern for energy efficiency was of tremendous benefit for the clay brick building structure. No (or little) insulation in the walls meant heat would escape through the wall assembly during the cold winter months. Any water coming into contact with and saturating the exterior side of the clay 
brick would tend to self-dry, or at the very least remain in an unfrozen state due to the wintertime heat loss through the envelope.

\subsection{MECHANICS OF MOISTURE TRANSFER IN CLAY BRICK}

Clay bricks are a porous material containing thousands of microscopic holes as small as onehundredth of a millimeter wide (Figure 1). They have an open pore structure that winds throughout, as well as many dead-end pores that are closed off from the continuous network of pore caverns. These tiny caverns interconnect throughout the clay brick causing them to have a very large internal surface area (Straube, 2006).

In hydrophilic porous material, such as clay brick, moisture travels by a number of methods. Bricks are comprised of a fired clay material, which melts together during the firing process and also creates massive network of pores and microscopic tunnels. These pores provide an internal volume of space that can be occupied by air or water (Figure 1 and Figure 2). When a

pore is fine enough (approximately 10-100 nanometers) water vapour in the air condenses on the sides of the pore walls, and forms a small amount of liquid water. Once the water is out of vapour form, and in liquid form it travels through the pore of the material via a phenomenon called capillary suction (Straube \& Burnett, 2005). This phenomenon occurs when water molecules are more attracted to the molecules of the pore wall than the molecules of the air, and creep up the pore, causing a meniscus (Hugo Hens, 2007). This creeping up of water molecules occurs in practically all stony and wood materials, and are therefore called "hydrophilic" effect (Hugo Hens, 2007). 


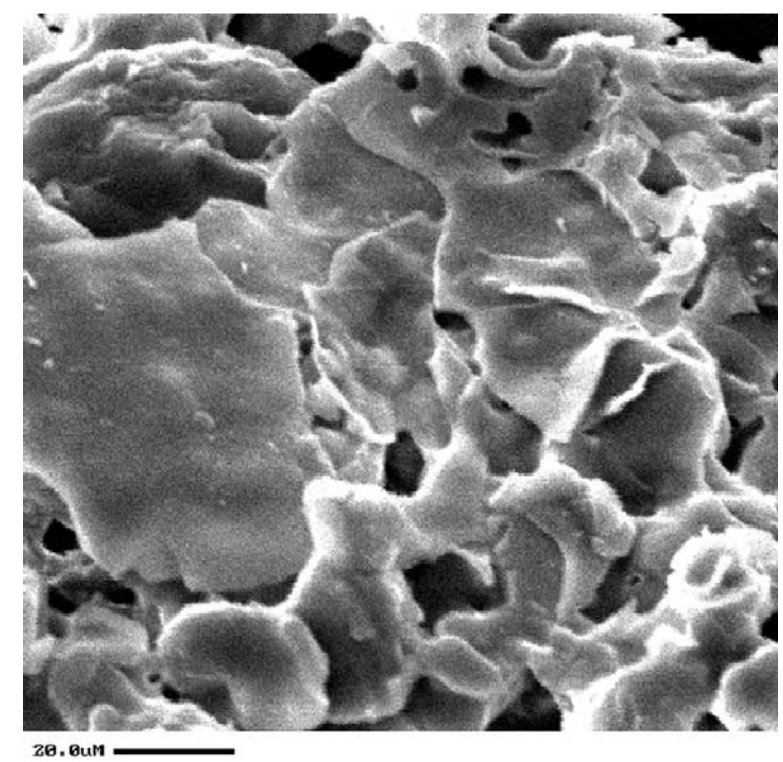

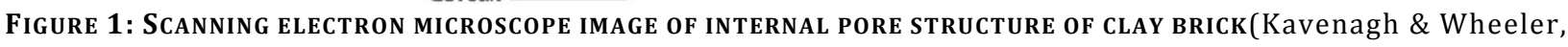
2003).

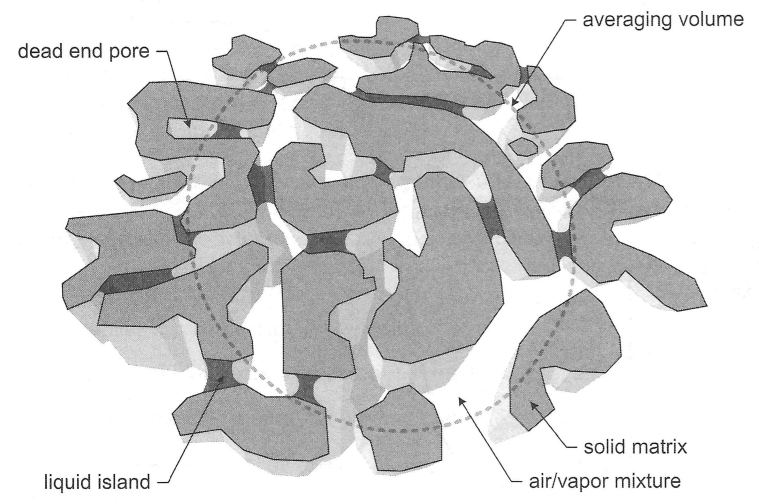

Figure 2: Illustration of Different pore ASPECts Within a POROUS MEdia SUCh AS BRick (Straube \& Burnett, 2005).

At a high ambient relative humidity, enough moisture condenses inside the pores of the brick that it can reach a point of capillary saturation (Figure 3). That is, the point where the brick cannot absorb any more moisture from the air. In order to add more moisture to a brick at this point, it must be supersaturated with water. The network of pores is not entirely interconnected; some are isolated and many are dead-ended. In order to fill these dead ends with water, Hall and Hoff (2012) note that super saturation is "not easy to achieve and not 
always attained." Brick specimens must use a 5-hour boil method or z vacuum saturation method to fully saturate the pores.

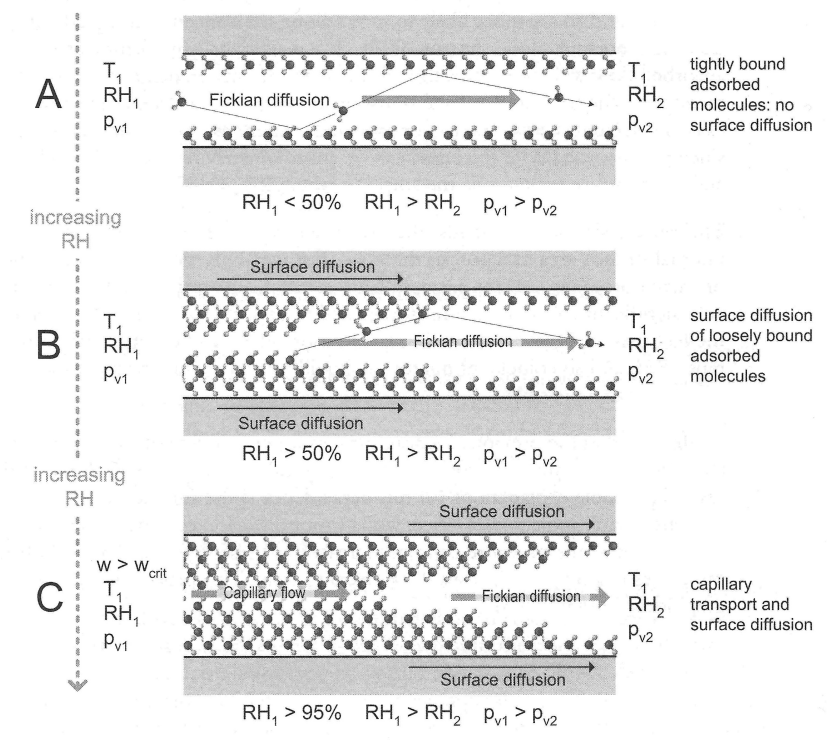

FigURE 3: AS RELATIVE HUMIDITY INCREASES, SURFACE DifFUSION LINES THE PORE WALLS WiTh WATER MOLECULES (Straube \& Burnett, 2005). 


\subsection{MOISTURE CONTENT VS. RELATIVE HUMIDITY IN POROUS MEDIA}

Various porous materials store moisture differently from one another. As the relative humidity fluctuates, the moisture content that fills the pores of a given material change at different proportions. As the sorption isotherms show in Figure 4, the moisture content of brick remains fairly unchanged until a very high relative humidity is achieved. Conversely, the moisture content of wood follows the relative humidity very closely, as is depicted by the near 45degree slope of the graph. The fact that wood has such a gentle slope in this situation proves useful: wood can be used as a surrogate material inside a porous material that has a much more flat sorption isotherm, in order to accurately relate moisture content to relative humidity.

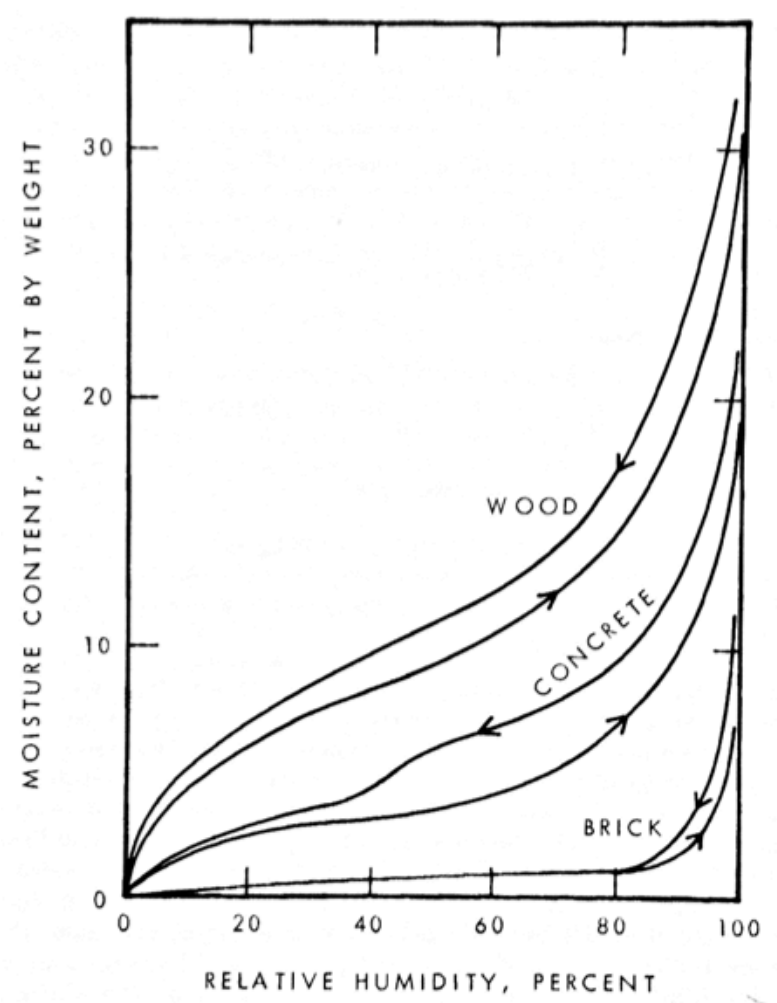

Figure 4: Sorption isotherms: Moisture Storage in porous materials (Hutcheon \& Handegord, 1995). 
The actual damage caused to a clay brick by the expansion of freezing water inside its pores is not yet completely understood (Mensinga, 2009). There are a number of theories that have been brought forward, but it will likely be a number of years before the matter is studied with great detail and an outcome determined. Nevertheless, even with the reasons not fully understood the fact still remains that clay bricks undergo irreversible expansion when they freeze above critical moisture contents; this is known as freeze-thaw damage. The internal pressures of the freezing water can be enough to slowly cause micro-cracks within the pore matrix. With each cycle of freezing and thawing, the cracks can become larger, resulting in the clay brick slowly increasing in size. With each freeze-thaw expansion, the structural integrity of the clay brick degrades and physical signs of damage become visible to the naked eye. This irreversible expansion caused by the freezing process is called frost dilatometry. It is becoming a useful means of testing the durability of clay brick. Susceptibility to frost dilatometry varies greatly in the various types of clay brick. Some clay bricks can tolerate undergoing freezing with very high moisture content, that is, water filling the pores of the clay brick, without much expansion at all. Other types of clay brick crumble apart quickly with only having small moisture content.

However, pouring water onto a clay brick does not necessarily mean it will become saturated with water. Because the pores of the clay brick are both plentiful and very fine, the tiny internal cavities create a large internal surface area. Many of these dead-ends caverns do not easily fill with water (Figure 2). The internal surface areas of the clay brick also have the ability to take on and hold moisture from water vapour in the air, by way of adsorption. That is, water molecules cling to the extensive surface areas of the pore cavities. As the relative humidity of the air increases, so do the layers of water molecules clinging to the surfaces of the pores. At locations within the clay brick where the pores taper and bottleneck, water molecules layer on 
top of one another until the air is forced out and a small about of liquid water becomes present. Mensinga discusses this moisture transport phenomenon to great detail (Mensinga, 2009).

When the relative humidity of the air is very high, water molecules build up on these internal surfaces in layers. The pores adsorb layers of water molecules. If the Relative Humidity (RH) is large enough (or the pore diameter is fine enough), water molecules fill them entirely. They essentially become a tube filled with liquid water that travels by capillary suction. "When a material has adsorbed all the moisture it can, further moisture will be stored in the pores and cracks within the material by capillary suction, or by absorption" (Straube, 2006). Water can be adsorbed by the pores of the clay brick until capillary saturation is reached; at this point saturation enters a "supersaturated" realm (Straube \& Burnett, 2005). Depending on the type of clay brick and the size of the pores, in the capillary saturation region the brick holds about 95-99\% of its maximum possible water storage. Super-saturating the clay brick beyond this quantity requires immersion into boiling water, or the use of vacuum to draw out the remaining air.

Water is not detrimental to the integrity of clay brick masonry brick on its own; the bricks are fired in a kiln until the clay particles have fused together. Water alone will not dissolve them (Ibstock, 2005). The problem comes when such a water-saturated clay brick freezes. Water achieves its maximum density at $4^{\circ} \mathrm{C}$; once it is cooled beyond this temperature it expands and decreases in density (Hutcheon \& Handegord, 1995). When frozen water inside a saturated pore of a clay brick increases in size, the forces exerted within the pore of the clay brick may become too great and the structure of the clay brick will give way in a tensile failure. When these freeze-thaw cycles are repeated, the water within the pores may warm, melt back into 
liquid form, and fill any new fissure the previous freeze may have created, refreeze and cause further cracking - essentially a "snow ball effect." This is known as freeze-thaw expansion or frost dilatometry: clay bricks saturated with water to a particular degree and exposed to cycles of freeze-thaw reveal irreversible dimensional change.

Different tests are performed on clay brick to categorize them and reduce the chance of failure in the field by using freeze-thaw resistant clay bricks. The Canadian standard for testing the freeze-thaw capability of clay brick is standard number CSA-A82-06. It is very similar in procedure to its American equivalent, ASTM C62-13a in conjunction with ASTM C67-13a. If compressive strength and porosity criteria are not met, then specimens of clay brick must undergo 50 cycles of freeze-thaw testing. The current recognized method for testing clay brick is flawed and has documented shortcomings; clay brick that have passed the CSA and ASTM tests have failed in the field, and clay bricks that have performed well in constructed buildings do not meet the criteria of the test (Straube et al., 2010). New techniques are being developed such as frost dilatometry testing, which would predict how a particular clay brick material would thermally contract or dilate, and generate a "strength estimate" based on existing freeze-thaw threshold data(Straube et al., 2010). 


\section{LITERATURE REVIEW}

\subsection{FREEZE-THAW ISSUES}

Several papers have been written about clay brick masonry and potential negative effects that can occur once a load bearing clay brick wall is insulated on the interior (Straube et al., 2010, 2011; Straube \& Schumacher, 2007). However, this is a relatively current topic and there is room for more research on the matter.

Straube et al. (2011) discuss insulation retrofits. The study contains much more than just issues with insulating load bearing clay brick. It also covers cost effectiveness questions of adding insulation to walls, discusses interior vs. exterior insulation systems, all the major insulation types, and also shows many "problem areas" and illustrates how to address them with various detail drawings and flashing solutions. This paper only discusses insulation up to traditional levels of RSI $3.52 \mathrm{~W} / \mathrm{m}^{2} \mathrm{~K}(\mathrm{R}-20)$ as do the others. There appears to be little known of the effects of super-insulating load bearing clay brick beyond this level using $900 \mathrm{~g}(2 \mathrm{lb}$.) closed-cell SPF insulation.

Smits, Gregoire, Tirlocq, Lefort, \& Andre (2010) discuss a European method for determining the frost resistance of clay brick that was established in 2006, and compare it to the complex pre-existing Belgium method. The purpose of this analysis is to reveal the differences in measurements obtained from the two different procedures that cause problems for brick manufacturers and builders. 
The report establishes that the existing Belgium test method uses a complex calculation method to determine the porometric moisture distribution within a brick, which is based on water absorption slopes. Smits explains that limited information exists on how water is absorbed into bricks in situ, especially when factoring in general exposure severity. The moisture taken on from wind driven rain, moisture distribution within massive walls, and the effects of protected areas play an essential part of analyzing the severity of exposure that a brick must endure, so the Belgium Building Research Institute (BBRI) and Belgian Ceramic Research Center (BCRC) built exposure test sites to help provide analysis.

The paper briefly explains the Belgium "direct frost test method" (NBN B27-009+Add.2) which varies greatly from the CSA and ASTM test methods for bricks used in North America. Five bricks must be tested, one outfitted with thermocouples to measure temperature levels on two adjacent sides of a brick. The bricks are buried $3 \mathrm{~cm}$ deep in sand, and then exposed to 20 freeze-thaw cycles. The rate and duration of the freeze-thaw cycles are dynamic and vary depending on the rate of temperature change between the two thermocouples. Each thaw cycle is accomplished by immersing the bricks and sand in $15^{\circ} \mathrm{C}$ water until the bricks reach $10^{\circ} \mathrm{C}$.

The European test method calls for clay bricks to be tested as constructed, so tests must be performed with brick units mortared into position in a section of a test wall assembly. Both Belgium and European test methods evaluate frost damage by way of visual inspection only. Attempts have been made by the BBRI and BCRC to quantitatively measure the effects of freeze-thaw damage by determining loss of dynamic elasticity modulus, also known as the 'pull-off adhesion test.' 
This paper does not address the critical saturation point of brick; it only identifies bricks as pass or fail by the Belgium and European methods. The purpose of this paper is solely to compare the differences of the existing Belgium method and the newer European test method. Visual inspection for damage to clay masonry caused by cycles of freeze-thaw is one of the test procedure still performed according to the Belgium procedure. However, it appears to only be performed on laboratory specimens, and not on a scale that involves all surfaces of an entire building.

In North America there are currently two standard test methods for determining the freezethaw capabilities of clay brick. ASTM C62-13a "Standard Specification for Building Brick" is used in conjunction with ASTM C67-13a "Standard Test Methods for Sampling and Testing Brick and Structural Clay Tile" and they are the international test criteria established by the United States, while Canada uses its own CSA A82-06 "Fired masonry brick made from clay or shale." Both procedures have essentially the same requirements, and as noted above, both have been found to have their flaws. The criteria for a brick to pass the CSA freeze-thaw durability test requires the brick to have a 5 hour boiling water absorption of no more than $17 \%$, a maximum saturation coefficient of 0.78 , an individual brick compressive strength of at least 17.2 MPa, and a 5-brick-average compressive strength of at least $20.7 \mathrm{MPa}$. The criteria for a brick to pass the ASTM freeze-thaw durability tests are essentially identical to those of the CSA requirements. (The 5-brick average values must demonstrate a 5-hour boiling water absorption of no more than $17 \%$, a maximum saturation coefficient of 0.78 , and a compressive strength of $20.7 \mathrm{MPa}$, and an individual brick compressive strength of 17.2 MPa.) For both the ASTM and the CSA standards, if the brick specimens do not conform to these established 
absorption and compressive strength requirements, then the brick must then be tested for 50 cycles of freeze thaw.

Hall (1977) quantitatively discusses moisture flow within porous media, and the drying effect caused by the exposure of a wetted porous medium to moving air. His paper discusses the energy transfer and technical mechanics of adsorption, capillary condensation and internal moisture flow that occur within porous media. The hysteresis effect of sorption isotherms (i.e. the difference in rates of adsorption and desorption at which a porous medium takes on and releases moisture) is also discussed and explains how moisture sorption occur at different rates depending on a number of factors such as partial vapour pressure of the air in which moisture is moving into, the pore structure of the porous medium, etc. The paper limits its discussion to moisture flow, and does not venture much beyond this topic; the problems resulting from moisture flow in building materials (i.e., mould, and freeze-thaw damage) are not covered.

The discussion by Roels et al. (2004) concerning the variability of measurements recorded by 6 different laboratories in the HAMSTAD-project in the European Union. The HAMSTAD project was an initiative of the European Union designed to compare measurement variability observed when analyzing the hygric properties of various porous materials between various laboratories. It is a reminder of how laboratory variability exists. Great care must be taken whenever analysing laboratory specimens. The report compares measurement variability of moisture capacity and moisture transport of only three different porous materials: calcium silicate plate, fired clay brick and cellular concrete. The discussion covers simple measurement 
techniques (such as vacuum saturation testing, and free water uptake testing) and more complex methods (such as mercury intrusion experiments) without going into any measurement procedures. The report does not mention any aspects of freeze-thaw testing as part of their variability comparison.

Künzel (1998) compares interior side insulation vs. exterior side insulation on brick and stone masonry exterior wall retrofit projects by using an early rendition of the WUFI computer program. The paper states "elevated moisture...on exposed walls can lead to frost damage" but Künzel does not elaborate upon or quantify the "damage" beyond this point. The paper does state that by adding insulation to the interior side of the wall, the drying capacity is reduced due to lowering the temperature. Exterior-side insulation retrofits are effective from a technical standpoint, as they not only keep the brick wall warm, they can provide a barrier to rain-driven moisture, reducing the moisture within the brick masonry wall depending on the type of insulation used.

Delghust, Janssens, \& Rummens (2010) investigate retrofitting brick cavity walls with various types of insulation, as a method of reducing energy use in the great number of Flemish (Northern Belgium) post-war residential houses. The paper is regionally specific to northern Belgium due to the large number of uninsulated cavity-wall houses, and therefore only focuses on cavity-wall retrofits. Research measurements include in-situ heat flux measurements, and do not include any moisture measurements. Since moisture is not measured, the effects of freeze-thaw damage on brick are not considered in this paper. 
Brocken (1998) discusses moisture transport in porous brick and mortar, and goes into great depth examining pore structure within these media. The primary focus of Brocken's book is the moisture transport mechanisms between brick units and the mortar that hold the bricks in position in brick masonry walls. The pore structure of a brick, and its moisture transport characteristics begin having an effect on brick masonry the moment the wall is constructed: the quality of the mortar joint is partially determined during the construction process. The brick can draw moisture out of the mortar before it properly cures, creating a mortar that is not optimally hydrated. Conversely, a porous brick that is wetted prior to installation can overhydrate the mortar joint during the curing process, creating a weak layer in the mortar. Brocken goes into these relationships in great detail, and explains the different chemical contents within the mortar joint at various depths away from the brick-mortar joint interface. Brocken iterates how moisture transport is an important aspect of brick masonry, as it is the mechanism for many destructive phenomena, including frost damage. However, frost damage is a topic that is not explored to any detail in this book, other than mention of the frost resistance of air-entrained mortars.

Abuku, Janssen, \& Roels, (2009) discuss in their paper the effects of wind-driven rain on historic brick masonry wall construction. The research is based on a building situated in a cool climate and with high interior humidity to analyze the hygrothermal characteristics of the wall assemblies. The ultimate reasoning for the research is for the control of mould growth on the interior side of the wall, and energy load on the building being tested. Damage to the brick masonry as a result of saturated freeze-thaw was not within the scope of this research project. 
Adan et al. (2004) discuss how moisture problem tolerant building can reduce health related issues and reduce repair costs, and also can increase energy consumption. The paper discusses how the "Glaser method" is used to determine if vapour diffusion will lead to interstitial moisture problems within a building envelope, and that it does not allow for capillary moisture flow. Porous exterior materials, such as brick and concrete, are misrepresented by the old calculation method. The paper refers to the 2001 "HAMSTAD" project in the European Union as an attempt to standardize the process for determining moisture transfer methods in building envelopes. This paper does not go into any specific calculations. The effects of freezethaw are beyond the content of this paper.

Carmeliet \& Roels (2002) focus on comparing different analytical functions that have been established in various pieces of building science literature to assess the moisture permeability and moisture storage function of porous media. They point out there is no agreement of the form of these functions, or any consensus on the experimental procedures for determining the input data for such moisture functions. As a result, calculation of moisture storage can be oversimplified, or may require a great deal of effort to determine a precise figure. Carmeliet and Roels discuss critical moisture content and introduce it as the transition point where moisture inside capillaries changes from "enhanced vapour flow" to "dominant liquid flow." The paper solely discusses pores filling with liquid or vaporous moisture. Freezing pores above or below the critical saturation point is not a topic discussed in this paper.

Klõšeiko, Arumägi, \& Kalamees (2003) report on a study of four different insulation types (calcium silicate, aerated concrete, polyurethane board, and polyisocyanurate board) to 
insulate on the interior side, an area of load bearing brick wall of a historic school building in central Europe. The brick wall was outfitted with sensors to monitor temperature and relative humidity levels. The performance of the four different insulation types were monitored and compared. Klõšeiko et al. briefly discuss freeze-thaw in this report, and mention that freezethaw damage can begin to occur in brick when saturated areas fall below the freezing point to as low as $-5^{\circ} \mathrm{C}$. Freeze-thaw damage is not elaborated upon beyond this, and there is no discussion of the amount of moisture that constitutes the saturation of a brick.

In his paper, Hens (1998) focuses on retrofitting "traditional" (massive) masonry walls with interior side insulation. The paper addresses airtightness of the masonry, prediction of the Uvalue of the wall assembly, which includes the hygric analysis of "T-junctions" in the wall where the interior wood studs are positioned directly adjacent to the brick masonry. The only topic of concern regarding cold temperatures in this paper is the occurrence of interstitial condensation within the wall envelope. The occurrence of freeze-thaw damage is a topic not discussed in this paper, other than a sudden suggestion in the conclusion to face-seal brick masonry only where not exposed to cycles of freeze-thaw. 


\subsection{FROST DILATOMETRY TEST METHOD}

Mensinga (2009) investigates using a new procedure to determine the maximum degree of water saturation a material can have before it undergoes irreversible expansion from freezing and thawing - critical saturation testing. Much of the procedure stems from work by Fagerlund (1977) who wrote a procedure for measuring the critical saturation point of concrete.

Knowing this critical saturation point of porous materials such as clay brick or concrete help to accurately determine the maximum safe moisture load such a material can endure, and is arguably a more reliable measure of how a porous material like clay brick will perform in the field. Mensinga (2009) outlines in detail how the frost dilatometry procedure was performed all work was completed in a lab. The scope of this paper does not go on to measure the in situ moisture content of the tested clay bricks in service in a real building. Also, the dilatometry expansion of the clay brick samples was only measured along one axis. (The $100 \mathrm{~mm}$ "width"

of the clay brick; not along the length or height.) The need exists to conduct multi-dimensional frost dilatometry in order to further advance this novel method of estimating resistance to freeze thaw deterioration.

Fagerlund (1977) presents the new procedure for testing the freeze-thaw capabilities of concrete in this procedure. The procedure introduces the critical saturation point as being the key to frost dilatometry analysis. The procedure outlines two methods of testing: a full test and a shortened test. This is the original frost dilatometry testing procedure, and is the one used by Peter Mensinga in his 2009 thesis. 
Johansson et al. (2014) consider potential problems that arise when installing energy retrofits (insulation) in existing building stock. Their particular research involves using VIPs as a retrofit insulation material, and study the moisture related effects that their introduction to the wall has on wooden beam ends embedded in the load bearing brick masonry walls. The study is limited to wind-driven rain onto the surface, capillary moisture flow through and saturation of various brick types, and the accumulation of moisture in the interior side of the wall against the VIPs using accelerated aging experiments on the VIPs, and by using one- and two-dimensional hygrothermal analysis to determine moisture accumulation at the interface where the wood structure connects to the brick masonry wall. This is where moisture could be a problem for the longevity of the wood structure.

The paper stops short of investigating any effects of freezing of the capillary saturated bricks. Mention is made of previous research being performed in the US by Straube et al. in North America, showing increased moisture content and RH within the wall, which can also increase the rick of freeze-thaw damage. The paper also briefly discusses how capillaries within brick that are over-saturated with water and then exposed to multiple freeze-thaw cycles can lead to freeze-thaw damage, and refers to work performed by Mensinga et al (2010) and their development of the frost dilatometry technique to determine critical saturation point. 


\subsection{FROST DILATOMETRY IN-FIELD MEASUREMENTS}

Wilkinson et al (2009) present a field study similar in nature to the Toronto test house being studied with this thesis. Instead of a century house, the subject building was a 1950s school. The clay brick analysis was performed to CSA-A82-06 test methods (Wilkinson et al., 2009) - a test procedure with known flaws. The flaws are acknowledged in the paper: CSA testing requires a clay brick not be highly absorptive, and also must pass 50 saturated freeze thaw cycles without swelling (Wilkinson et al., 2009). Clay bricks have been known to pass the CSA tests given these requirements, and then fail in the field and vice versa (Straube, Schumacher, \& Mensinga, 2010).

Wilkinson et al., (2009) also acknowledge challenges with use of wood surrogate moisture content sensors that they embedded in the brick. The authors felt the sensors were too large, and provided a slow response to wetting events from rain. During a rain-wetting event, water is absorbed through the face of the clay brick via capillary suction, a process that could take minutes to hours depending of the characteristics of the clay brick. When the wetting event ends, the clay brick dries as water vapour is released from the clay brick back into the air - the drying time can take much longer especially if the relative humidity is high or if there is little airflow around the clay brick. The tight fit of the wooden surrogate sensor within the clay brick plays a role in the measurement time: any extra gaps slow the time it takes for the moisture content to equilibrate between clay brick and wood sensor. Any extra gap means moisture will not travel by capillary flow alone - there would also be a component of slower vapour transport through the airspace, and adsorption into the wooden sensor. For these reasons, embedded moisture content sensors provide a slow response time, and the problem may be exacerbated by the dynamic nature of an outdoor wall exposed to the elements. 
Finally, Ueno \& Straube (2008) outline the calibration of Wood Surrogate Moisture Content Sensors for measuring moisture content of brick in situ. This paper was likely written for calibrating "home made" sensors, however some steps from this paper may be useful for correlating our measurements with the actual moisture content of clay bricks from our Toronto test house.

There is room for more research in the area of interior-insulated load bearing clay brick walls. Firstly, past work has only been performed on walls insulated up to traditional levels of RSI 3.5 $\mathrm{W} / \mathrm{m}^{2} \mathrm{~K}(\mathrm{R}-20)$. Little is known about the effects of super-insulated clay brick walls, such as RSI $7.9 \mathrm{~W} / \mathrm{m}^{2} \mathrm{~K}$ (R-45) walls in retrofitted structural brick buildings. Secondly, much of the past clay brick testing was performed in accordance with CSA (or ASTM) standards -both of which have known flaws. Research using frost dilatometry testing to determine the critical saturation point of the clay brick better demonstrates how susceptible they are specifically to freeze-thaw damage.

In this project, frost dilatometry tests are performed on clay brick units from the a Toronto research house, and frost dilatometry expansion is measured over three axes to reveal how uniformly clay bricks expand with freeze-thaw cycling, while advancing the frost dilatometry method recently proposed by Straube et al (2010) and Mensinga (2009). Lastly, this research project includes in-situ moisture content measurements from sensors installed at various locations in the load bearing clay brick walls. These factory-calibrated and tuned sensors were installed in various brick masonry units around the test house. 


\section{THESIS OBJECTIVES}

A house in Toronto has recently been renovated and insulated on the interior side, creating a unique opportunity to measure how moisture transports within a recently-insulated load bearing brick masonry wall, which was in serviceable condition at the time of renovation. This Toronto test house presents the opportunity to measure how temperature and moisture are stratified throughout the entire building envelope assembly. By using sensors and instrumentation, the temperature and moisture content can be measured in the clay brick units, and temperature and relative humidity can be measured through the rest of the building envelope. The sensor measurements can then be correlated to weather conditions at the exterior, and also climate conditions on the interior. Such information is useful for determining the drying characteristics of brick masonry walls, their moisture content during freeze-thaw cycles, and the number of freeze-thaw cycles experienced during the winter. If the critical saturation point on the brick is also known, the use of sensors could be used to warn of potential damage in critical locations of a building. At the very least, information from sensors can provide a benchmark that would allow for the future creation of a precision-tuned WUFI computer model to predict the drying capabilities of an exterior wall.

The primary objectives of this thesis are to:

1. Contribute to the existing knowledge of historic clay brick freeze-thaw deterioration resistance of interior super-insulated load bearing clay brick walls,

2. Further develop the use of frost dilatometry as a viable test method for measuring the durability of clay brick in situ, 
3. Contribute towards a method of determining whether load bearing clay brick of a particular building can safely be insulated on the interior side, and

4. Because the project will require invasive installation techniques to install sensors into the brick wythes, additional sensors will be installed in order to obtain a complete temperature and moisture profile of the complete building envelope. This would allow for the creation a finely tuned WUFI model in the future as a project beyond the scope of this thesis. The project will also require the determination of the critical saturation point of the clay brick, which is value that can be used to create a high precision WUFI model. The determination of the brick A-value is also of great importance when creating a finely tuned WUFI computer model, and can easily be determined in the lab with brick specimens that are already available. 


\subsection{RESEARCH QUESTIONS}

From the thesis objectives, and review of previously written papers in this area, the following objectives have been developed for this case study:

1. Is it possible to create a simple reference tool for future visual inspection of insulated load-bearing brick walls?

2. Does the recently installed RSI $7.9 \mathrm{~W} / \mathrm{m} 2 \mathrm{~K}$ levels of interior insulation cause the wall to cool to the point where it tends to freeze and stay frozen in the winter, reducing the number of freeze/thaw cycles?

3. In terms of frost dilatometry of the clay brick at the Toronto test house, is the expansion greater along any particular dimension, or is expansion equal and uniform in all directions?

4. Is it possible to use sensors embedded in the brick wall in situ to accurately determine the moisture content of the brick in real time, without the need for destructive testing? 


\section{METHODOLOGY}

This research project has been split into sections: field measurements and laboratory research. Field measurements include everything to do with the visual documentation of existing conditions of the test building, as well as in-field sensors work. Laboratory research was performed in the Building Science Laboratory at Ryerson University. The work undertaken in the lab included preparing and analyzing brick specimens.

Visual documentation and field measurements were generally performed at the beginning of the project, while research and lab work were generally performed in the latter half of the project. 


\subsection{FIELD MEASUREMENTS}

\subsubsection{VISUAL INSPECTION AND RECORDING}

If the brick units at the Toronto test house begin to degrade and spall in the future, one method to visually quantify the deterioration of brick is to compare the then-and-now conditions by referring to a photo journal of the elevation surfaces. High-resolution photographs taken at close proximity to the brick surface are required to make this possible. The problem is that a single family home with two stories of brick masonry on all four elevations produces hundreds of photographs when taken at close proximity to the wall. Furthermore, photographs of brick masonry look very similar to one another. This can present a challenging task of managing and cataloguing the hundreds of exterior wall photographs. It can be cumbersome to locate the correct photograph with the desired area of interest of wall elevation through the use of a photograph database and a key map system.

In order to simplify the organization of these photographs, a new method is being used: the generation of large composite images from hundreds of high-resolution photographs taken of the elevations. This process involves stitching the hundreds of photographs into a few very large "giga-pixel” images. For this task AutoPano Giga computer software was utilized (Kolor SARL, 2014). This advanced image stitching software is intended to stitch together photographs from a single capture point, however with some effort a linear progression of individual photographs taken along a plane can also be stitched together. The software has a detection engine that locates similar reference points amongst the overlapping areas of two or more images, and then automatically joins them together into a single rendered image. Other 
pieces of software are also available, however AutoPano Giga was chosen as it appeared to be one of the most advanced pieces of software capable of stitching large quantities of highresolution photos at the time of this project.

All elevations of the building have been thoroughly surveyed up close at each storey. Photographs were taken approximately every $0.75 \mathrm{~m}^{2}$ using a 10 megapixel point-and-shoot camera. Photos were taken from grade, and then slowly up each of the elevations. Scaffolding and a boom-mounted camera were utilized to access and record the condition of the brick at upper levels of the Toronto test house. Individual images were input into the AutoPano Giga software, and were stitched into 2-dimensional quilts of large high-resolution images. Given the current limitations of JPG file sizes and Adobe Photoshop file limitations, each elevation had to be broken into multiple images. A total of 13 giga-pixel composite images were rendered for this project, and are available online (Section 6.1 Photo-Documenting Elevations of the Test House). Areas of these giga-pixel elevation images can be analysed and compared to sensor measurements recorded around the house, and also provide a reference point for potential future work studying long-term effects of interior-side insulation of load bearing clay brick. The current condition of all exterior clay brick surfaces has been documented, and may be reviewed for signs of deterioration over the upcoming years. 


\subsubsection{LOCATIONS TARGETED WITH SENSORS}

The one hundred year-old solid clay brick masonry research house is typical for the period.

The loadbearing clay brick masonry walls are 2 wythes deep, with the inner wythe supporting the floor joists and the roof structure. It is very close in proximity to the neighbouring houses (Figure 5 and Figure 6).

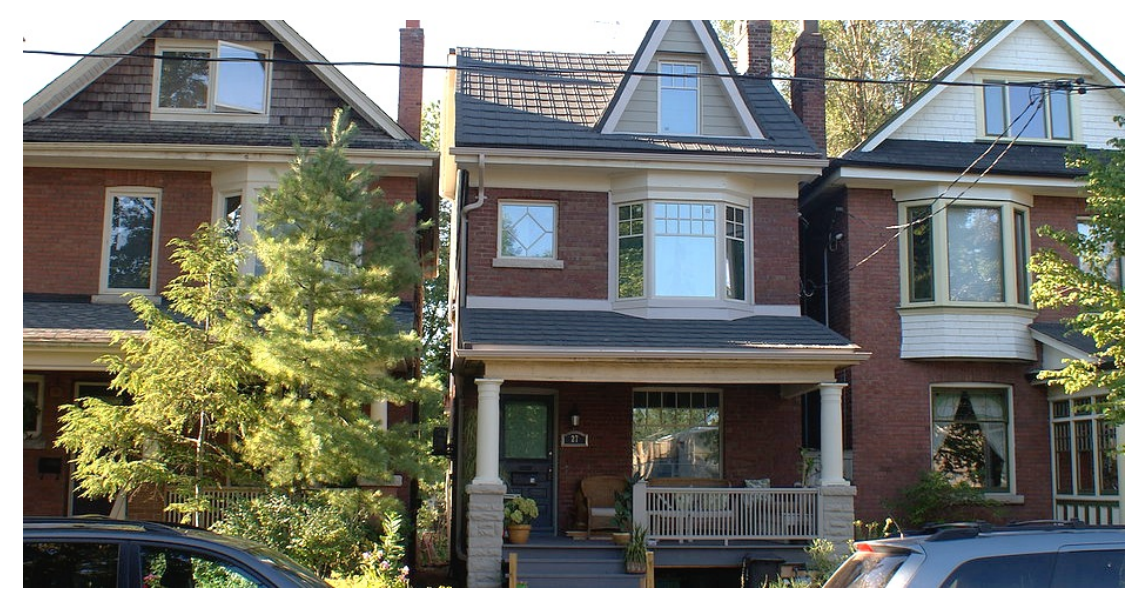

Figure 5: The TORONTO TEST HOUSE, WITH ADJACENT NEIGHBOURING HOUSES (Richman, 2009). 

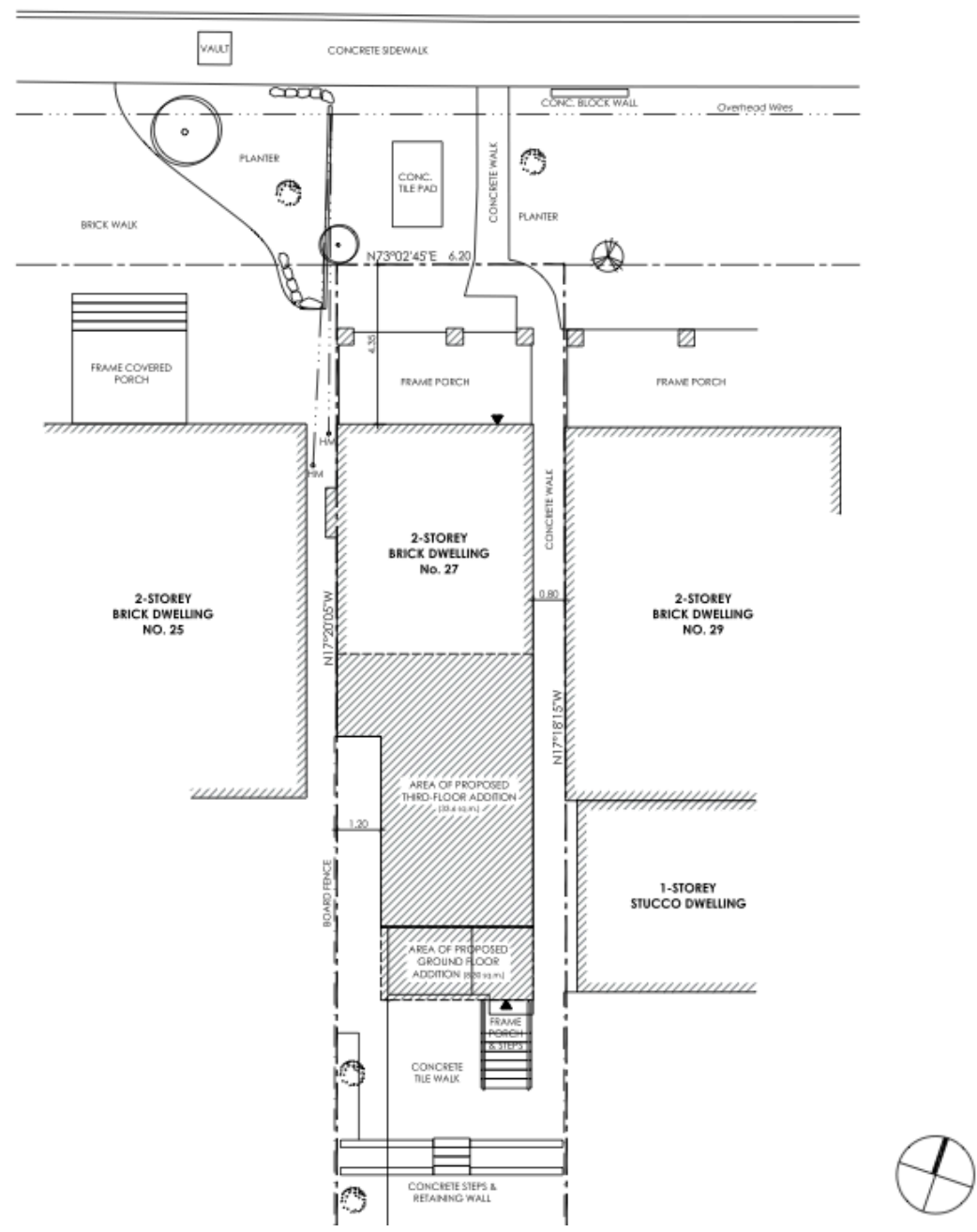

Figure 6: Toronto test house Site Plan (Russell Richman Consulting Limited, 2010).

What makes this particular dwelling unique and well suited to this project is that it underwent a deep retrofit in 2009. The interior of the building was stripped down to the clay brick masonry (only floor joists remained); floors and interior walls were reconstructed to allow for the installation of $138 \mathrm{~mm}$ to $190 \mathrm{~mm}$ (5.5 to 7.5 inches) of $900 \mathrm{~g}$ (2-lb) closed-cell sprayapplied polyurethane foam insulation directly on the interior face of the exterior clay brick masonry walls. The envelope of the building went from being essentially uninsulated solid clay brick masonry to having an average insulating value of RSI $7.9 \mathrm{~W} / \mathrm{m}^{2} \mathrm{~K}(\mathrm{R}-45)$ for the walls, completely changing the moisture transport/storage characteristics of the building. 
Hygrothermal data collection began after the renovations had been completed in January of 2012.

Clusters of Temperature/RH and Moisture Content sensors have been installed at four locations of the building to measure conditions through the depth of the building envelope. The locations of these clusters of sensors were labeled: "P", "Q", "R" and "S." Locations are of these clusters of sensors are illustrated in Figure 7 and Figure 8.

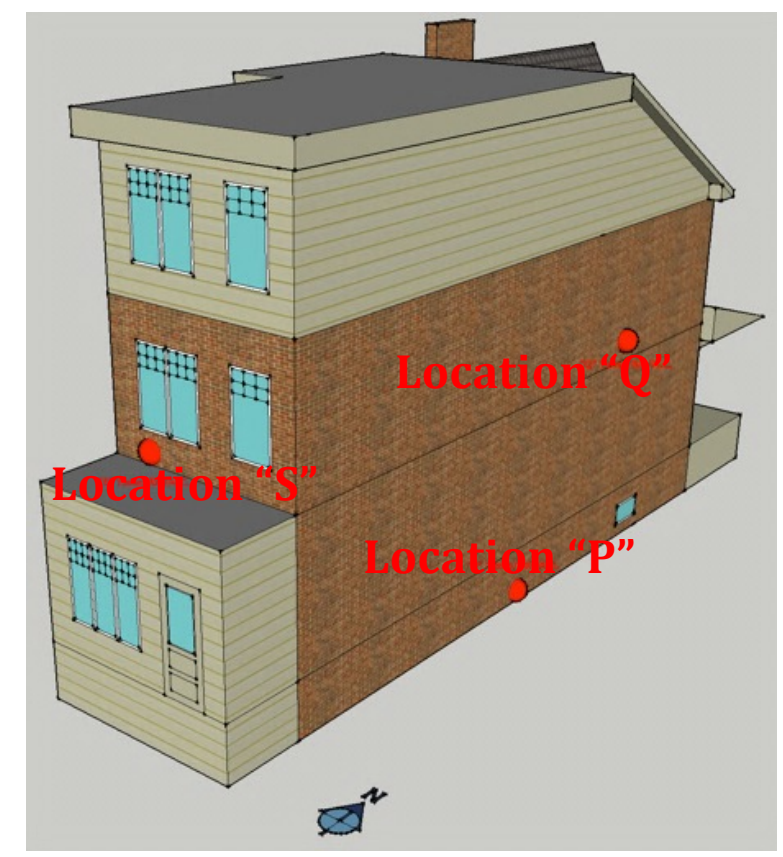

Figure 7: Test house With SEnSor Cluster locations "P", "Q" AND "S." 


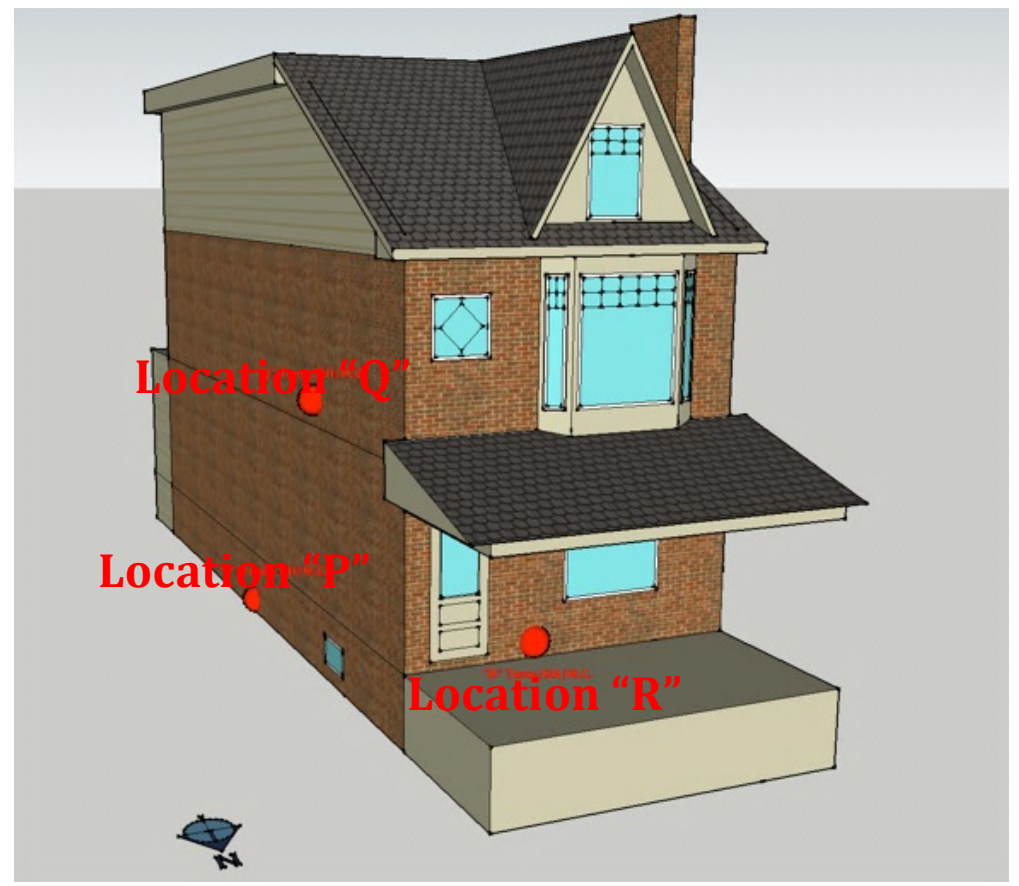

Figure 8: Sensor Cluster locations: P, Q and R.

Each cluster contains a number of Temperature, $\mathrm{RH}$ and Moisture Content sensors installed at various depths of the well assembly.

TABle 1: Sensor CluSter positioning.

\begin{tabular}{|c|l|l|}
\hline Sensor Cluster & Location & Reasoning for location \\
\hline $\mathrm{P}$ & East Wall, 1 m above grade. & $\begin{array}{l}\text { Located in a position far below the } \\
\text { protection of the eaves. Installed with } \\
\text { the possibility of measuring a damp } \\
\text { area of wall due to proximity to grade. }\end{array}$ \\
\hline $\mathrm{Q}$ & $\begin{array}{l}\text { East wall, at base of second } \\
\text { storey } 3 \mathrm{~m} \text { above grade. }\end{array}$ & $\begin{array}{l}\text { Located on the same elevation as sensor } \\
\text { cluster P, but at a higher position in } \\
\text { order to measure the effects of different } \\
\text { microclimates caused by different } \\
\text { proximity to the eaves of both buildings. }\end{array}$ \\
\hline $\mathrm{R}$ & $\begin{array}{l}\text { North wall, under veranda } \\
\text { overhang. }\end{array}$ & $\begin{array}{l}\text { Located on the North wall under the } \\
\text { protection of the veranda roof, this } \\
\text { location should never see rain wetting. } \\
\text { Also being on the North elevation, there } \\
\text { should be no direct solar radiation to } \\
\text { dry the clay brick in winter. }\end{array}$ \\
\hline $\mathrm{S}$ & $\begin{array}{l}\text { South wall, at base of second } \\
\text { storey above rear addition. }\end{array}$ & $\begin{array}{l}\text { Location is fully exposed to the } \\
\text { elements. The South side of the building } \\
\text { experiences year round solar radiation } \\
\text { and is unsheltered from the rain. }\end{array}$ \\
\hline
\end{tabular}


Sensor cluster "P" is installed low on the East wall of the house, approximately $1 \mathrm{~m}$ from grade. This east wall is a $0.75 \mathrm{~m}$ wide corridor that provides access from the street to the back yard. With the neighbouring house so close, the eaves of the two buildings provide enough overhang to shelter the walls from the majority of rainfall and sunlight.

Sensor cluster "Q" is installed mid-height of the East wall at the second storey. The different vertical position is intended to reveal different results caused by moisture wicking up from the foundation and also from wind-carried precipitation blown through the corridor.

Sensor cluster "R" is installed on the north wall of the house: it is covered by a deep overhang that protects the front porch from rainfall. Also, this North wall is never exposed to direct sunlight in the wintertime, so will provide a benchmark free of direct solar radiation.

Sensor cluster "S" is installed on the south wall; this area of wall is exposed to the most rain, and also to the most direct solar radiation. Location $S$ is where we expect to see the greatest extremes of wetting, drying, daytime heating, and night-time cooling.

Sensor clusters are not installed on the West wall. A solid gate at the south end of the buildings block the lower portion of the west corridor (Figure 9). The gate appears to impede airflow as the clay bricks are drying inadequately on both this test house as well as the neighbouring building at this location. The clay brick walls are generally damp to the touch, and there are signs of moss growth beginning on areas of the walls. It was decided this microclimate is not representative of the overall exposure experienced by the clay brick masonry at this site. As such, the various sensors of cluster " $Q$ " were installed on the East at $2^{\text {nd }}$ floor height, instead of on the West wall. The added benefit of this positioning the sensor clusters in this manner allowed for the comparison of two different areas of the same East wall. 


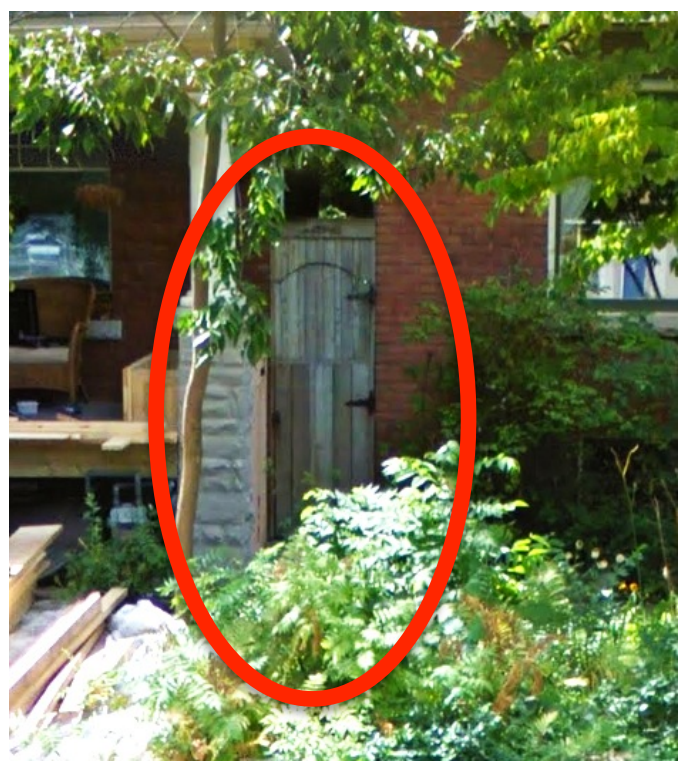

Figure 9: GATE INSTALLED BETWEEN TEST HOUSE AND ONE NEIGHBOURING PROPERTY APPEARS TO BE STAGNATING THE AIR FLOW, AND PREVENTING BRICK MASONRY WALLS FROM DRYING (Google Maps, 2014). 


\subsubsection{TEMPERATURE, RELATIVE HUMIDITY \& MOISTURE CONTENT SENSOR INSTALLATION}

Each cluster of sensors at the "P," "Q," "R," and "S" location have six temperature/relative humidity sensors at various depths in the wall (Figure 10). Each location also have three wooden surrogate Moisture Content sensors embedded at various depths within the wythes of clay brick (Figure 10). These wooden surrogate Moisture Content sensors measure the moisture content of the brick units. By using three of these sensors at a single location, stratification of the Moisture Content can be measured through the brick masonry wall assembly, and be compared to relative humidity levels. Although temperature/relative humidity sensors were installed and collected data beginning January 2012, the moisture content sensor and instrumentation installation was not complete at the Toronto test house until December 2012. The data presented in this study includes data collected over the winter of 2013, approximately December 2012 until April 2013

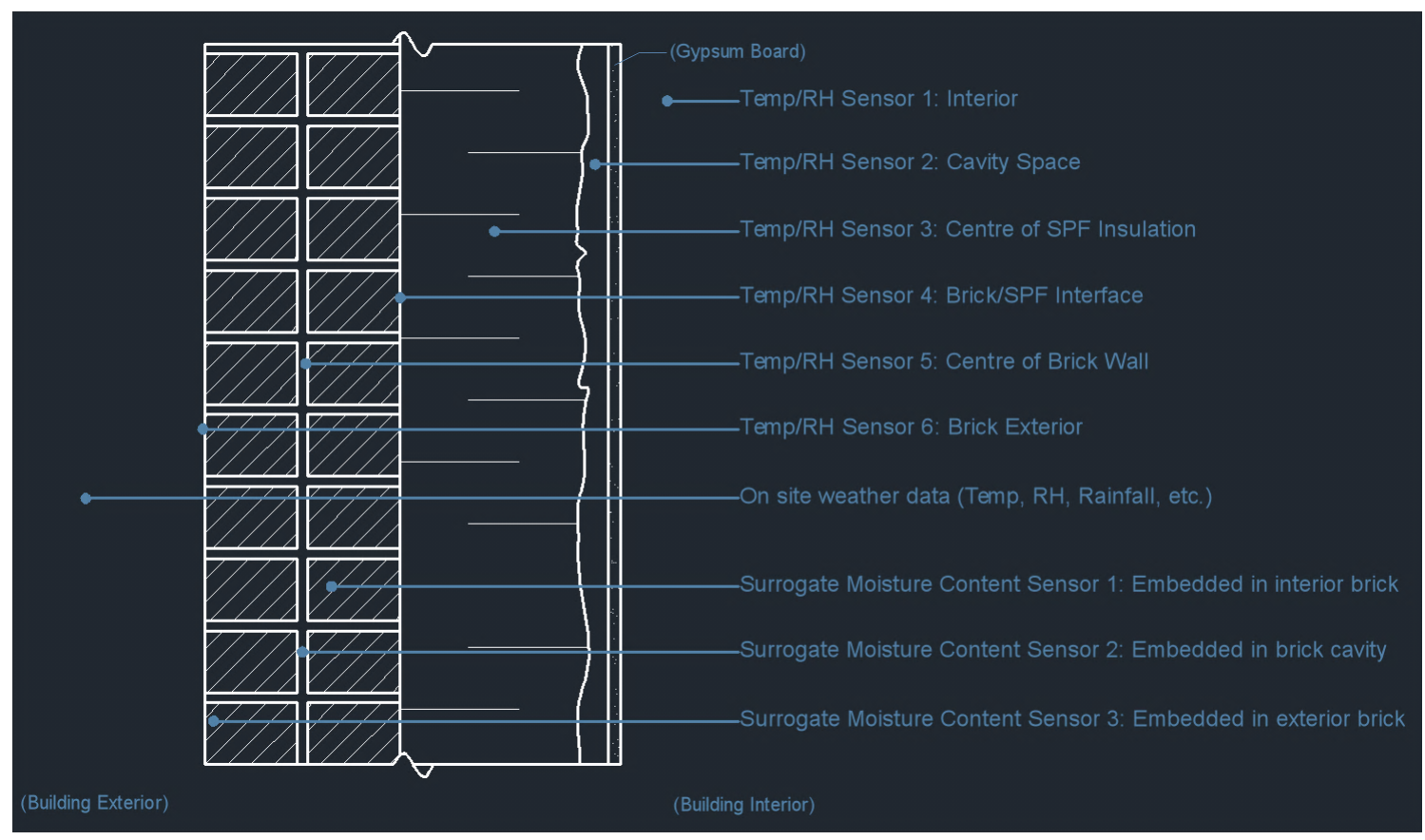

Figure 10: A typical SENSOR POSITIONing Within THE WALl AT EACH SENSOR CluSter. 


\subsubsection{INTERIOR TEMPERATURE RH SENSOR}

The interior ambient temperature and relative humidity sensors (see "Temp/RH Sensor 1" in Figure 10) are used to wirelessly measure conditions at each location, shown in Figure 11 (OmniSense LLC, 2014). These OmniSense interior temperature/RH sensors had been installed in the test house for other research projects, and logged measurements at the same time as measurements recorded specifically for this project. Some of this OmniSense interior Temperature/RH data has been generously contributed to this research project. A project investigating cooling zones and comfort at the test house has subsequently been written by Anthony Guadagnoli (2014) which is based on data from the OmniSense sensors.

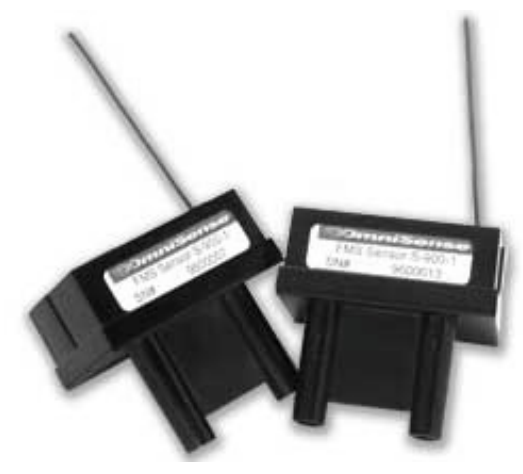

Figure 11: OMniSense Temperature/RH Sensors (OmniSense LlC, 2014). 


\subsubsection{INTER-WALL TEMPERATURE RH SENSORS}

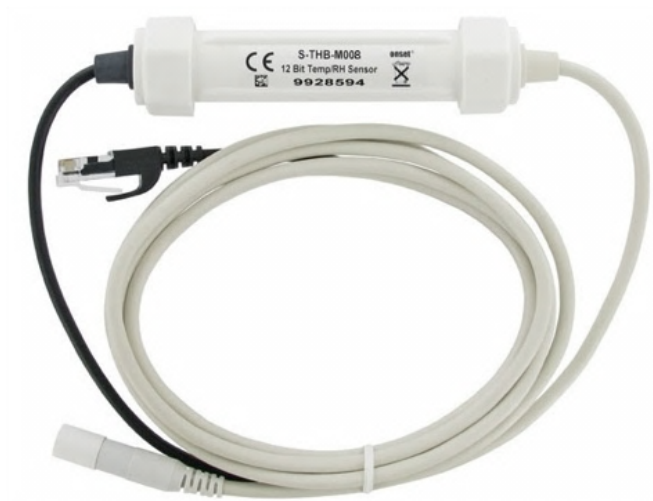

Figure 12: Onset Temperature/RH Smart Sensor (Onset Computer Corporation, 2014d).

Temperature/RH data is measured at four points inside the wall assembly at each location using four 12-bit Temperature/RH sensors (Onset Computer Corporation, 2014d). These sensors have an accuracy of $0.2^{\circ} \mathrm{C} / \pm 2.5 \% \mathrm{RH}$ and a resolution of $0.02^{\circ} \mathrm{C} / \pm 0.1 \% \mathrm{RH}$. The sensors are designed for indoor and outdoor use; our application falls well within their range of operation. Sensor positions are shown in Figure 10; these sensors are:

"Temp/RH Sensor 2" - Positioned in the small air cavity between the gypsum board and the surface of the SPF insulation. The data collected from this position compares relative humidity inside the cavity space to the relative humidity in the room.

"Temp/RH Sensor 3" - The tip of the sensor is positioned half way through the SPF insulation layer. The thickness of SPF ranges from $127 \mathrm{~mm}\left(5^{\prime \prime}\right)$ to $178 \mathrm{~mm}$ (7") depending on the wall of the house.

"Temp/RH Sensor 4" - The tip of the sensor is positioned against the clay brick on the inside wythe. 
"Temp/RH Sensor 5" - The hole for the sensor was drilled through the inside wythe of clay brick into the collar joint/cavity space. The space between the two wythes of clay brick in this house consists of a mix of cavities and mortar infill. One sensor had to be slightly repositioned, as it seemed to be measuring exterior conditions from within the wall.

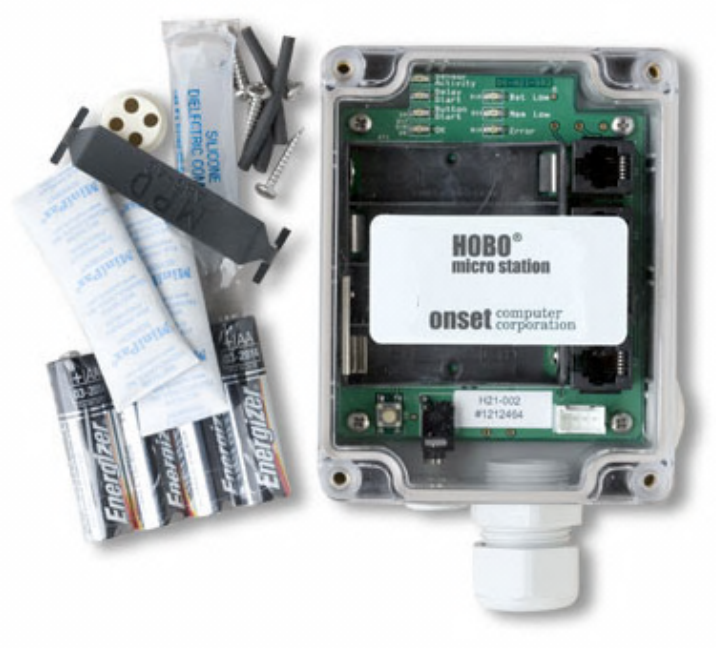

Figure 13: Hobo Micro Station Data logger (Onset Computer Corporation, 2014a).

The Temperature/RH sensors connect to a four Channel OnSet Hobo Micro Station (

Figure 13.) Each Micro Station can log data from four separate Temperature/RH sensors. They are been configured to log measurements every 5 minutes. At this rate of sampling, the device's onboard flash memory has enough room for almost 3 months of data. The Micro Stations are mounted indoors at each location (Figure 14).

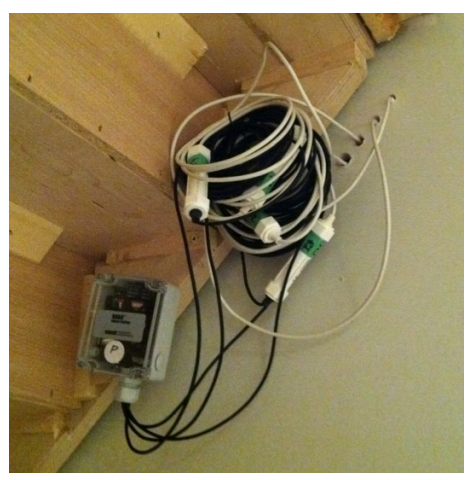

Figure 14: Onset Hobo Mirco Station Installed at the Research House. 


\subsubsection{EXTERIOR TEMPERATURE RH SENSORS}

"Temp/RH Sensor 6" - Onset HOBO U10 Temp/RH Data Loggers: small battery operated all-inone sensor plus data loggers (Figure 15). They recorded temperature and humidity on the exterior side of the clay brick at each of the locations (Figure 10). These U10 sensors were mounted at each location, and measured the local microclimate directly at the clay brick face. The U10s were synchronized with the Micro Stations on the interior, and were also programmed to record measurements every 5 minutes. Like the Micro Stations, data was offloaded to a portable USB shuttle, and then uploaded to a computer.

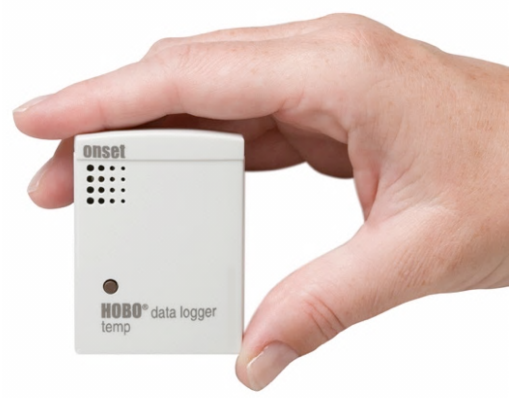

Figure 15: OnSET U10 (Onset Computer Corporation, 2006).

A USB Shuttle (

Figure 16) is used to collect data from each of the Micro Stations, and upload all of the information to a computer.

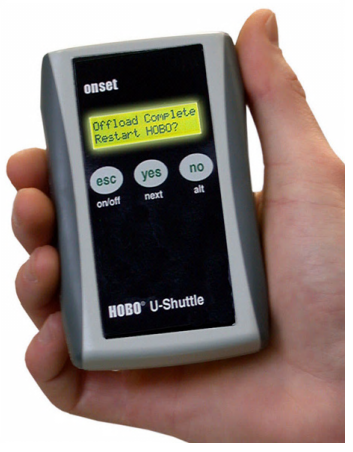

Figure 16: OnSET USB data Shuttle(Onset Computer Corporation, 2014b). 


\subsubsection{MOISTURE CONTENT DATA COLLECTION}

The lower three sensors in Figure 10 "Surrogate Moisture Content Sensor 1, 2 and 3" measure in-situ moisture content of the clay brick. These moisture content sensors (SMT Research Ltd., n.d.), consist of a laboratory-calibrated hemlock wood surrogate dowel and a thermistor (Figure 17).

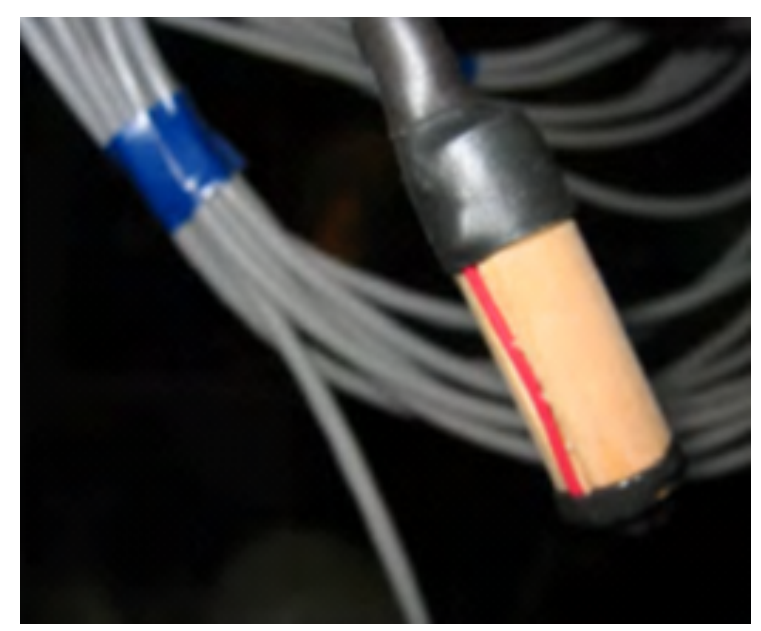

Figure 17: SMT Moisture Content Sensor (SMT Research Ltd., n.d.).

These sensors rely on moisture transferring from the clay brick into the $12 \mathrm{~mm}$ diameter hemlock dowel via capillary transport and/or vapour diffusion. As the moisture content of the wood increases, so does its resistance (Straube, Onysko, \& Schumacher, 2002). The moisture content of the wood embedded in the clay brick (and therefore the moisture content of the clay brick) can be predicted as a function of resistance and temperature. High precision 24-bit SMT data acquisition units (SMT Research Ltd., n.d.) are programmed to record the moisture content ("\%MC") every 15 minutes. 


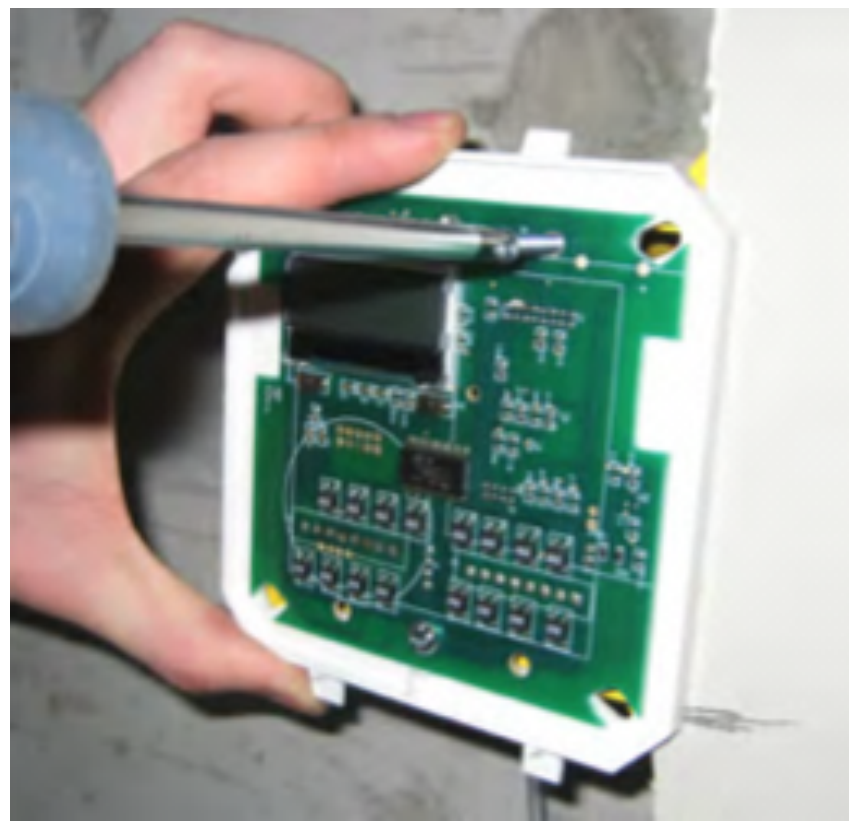

Figure 18: SMT A3 Data Acquisition Unit.

The installation process for the wood surrogate moisture sensors involved using a hammerdrill to carve out mortar joints, and then extracting clay bricks from the wall (Figure 19).

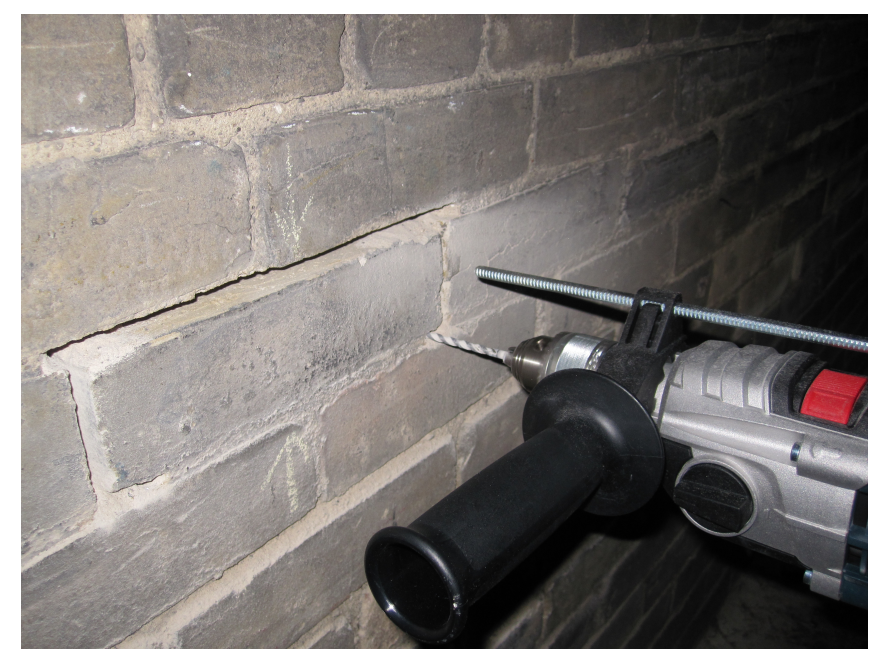

Figure 19: Extracting Clay Brick Units

Sensors installed in the exterior wythe of brick are inserted vertically and parallel to the exterior face through holes drilled through the bottom of the clay bricks; the sides of the 
sensors are positioned $7 \mathrm{~mm} \pm 2 \mathrm{~mm}$ from the exterior face of the bricks (Figure 20 and Figure 21). A second sensor is also installed in the interior wythe of brick, inserted through the exposed clay brick face through a horizontal hole made at an accessible area of the brick. (The interior wythes of brick were not extracted from the wall for sensor installation; holes were made at the most convenient location to avoid areas of collar joint.) A third sensor is inserted into gaps in the collar joint between the two wythes. (Figure 23 and Figure 24.) As suggested by the Moisture Content sensor manufacturer, clay brick dust was saved from the drilling process and used inside the hole to provide an intimate contact between the sensor and the clay brick (SMT Research Ltd., n.d.). A tight fitting sensor inside the borehole combined with a tamped intermediate layer of clay brick dust provides a continuous connection of media (i.e. porous brick, to brick-dust, to wooden moisture content sensor). By providing this porous path between the brick and the sensor, the moisture transport mechanism should primarily occur though capillary suction, and not the slower mechanism of vapour diffusion, which would make the sensors less responsive to moisture content changes in the brick. There are, however, limitations to this approach. The brick dust, which is essentially pulverized clay brick, no longer has the same pore structure it once did before drilling. The brick dust only offers the fine space between each of the particles, which may be nowhere near the size of the original interconnected brick pore structure. Another issue is adequately installing this brick dust between the sensor and the borehole of the horizontally installed sensors at the interior wythe of brick. For this situation, the dust is placed inside the holes, and the sensors are tapped and vibrated into place so to shift the brick dust between the wooden sensor and the borehole - a less than ideal approach compared to the exterior wythes of bricks, which had the luxury of using gravity combined with vibration to install the brick dust into the sensor holes. 
Each of the sensors installed in the clay brick are also sealed in place with epoxy. Once the sensors were installed, the clay bricks were replaced into their original locations, and the mortar joints were replaced with a type-N mortar mixture.

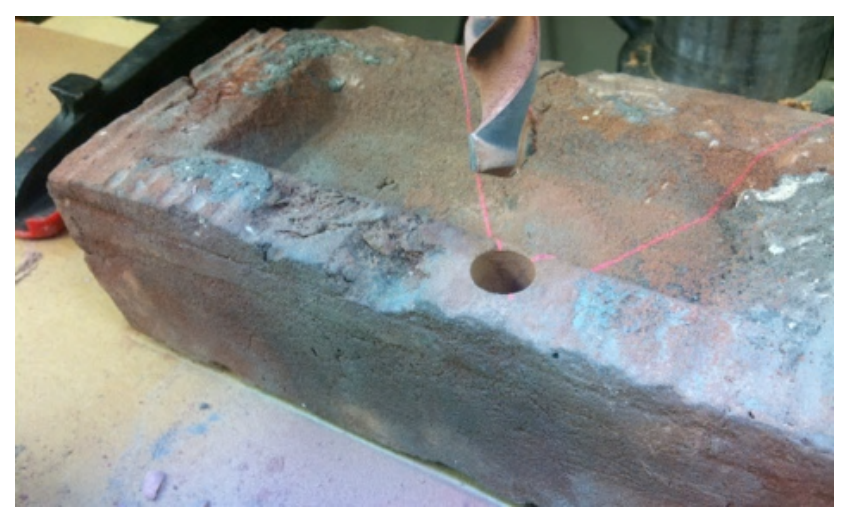

FIGURE 20: BORE HOLE BEING MADE IN BOTTOM OF AN INVERTED CLAY BRICK FROM THE EXTERIOR WYTHE IN PREPARATION OF MOISTURE CONTENT SENSOR INSTALLATION.

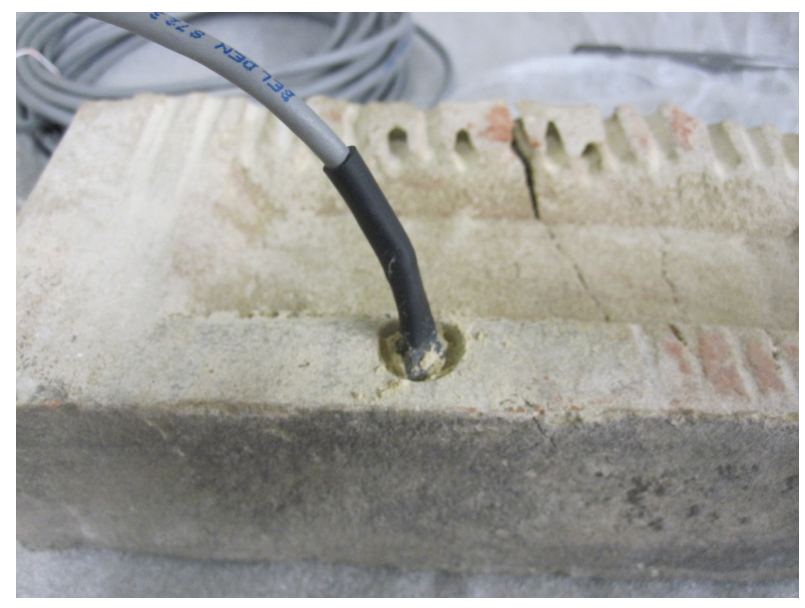

Figure 21: SENSOR EMBEDded INTO CLAY BRICK WITH DUST FROM DRILLING PROCESS. 


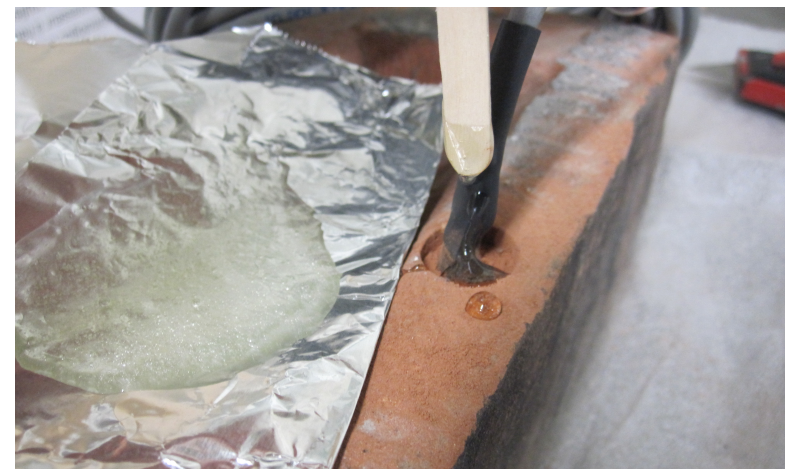

Figure 22: Sensor Sealed in Place with Epoxy.

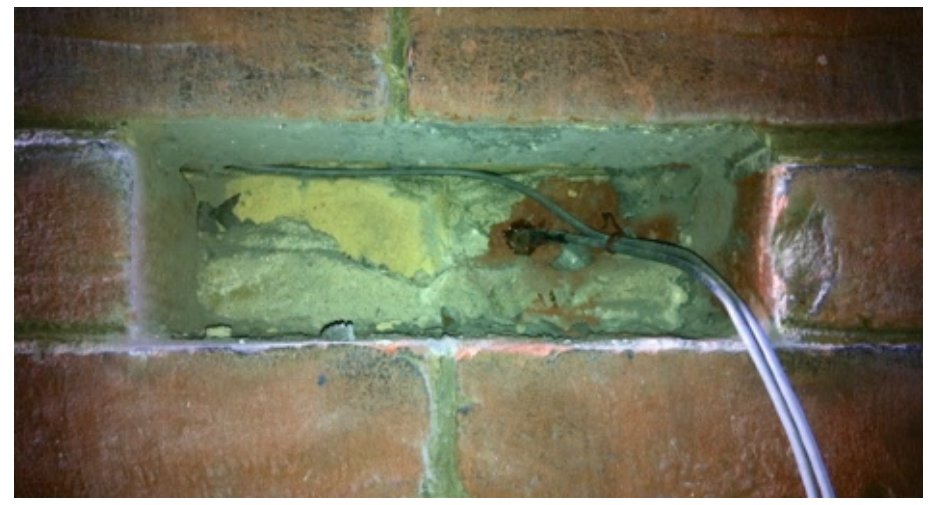

FIGURE 23: SENSOR INSTALLED THROUGH THE FACE OF THE INTERIOR WYTHE OF BRICK.

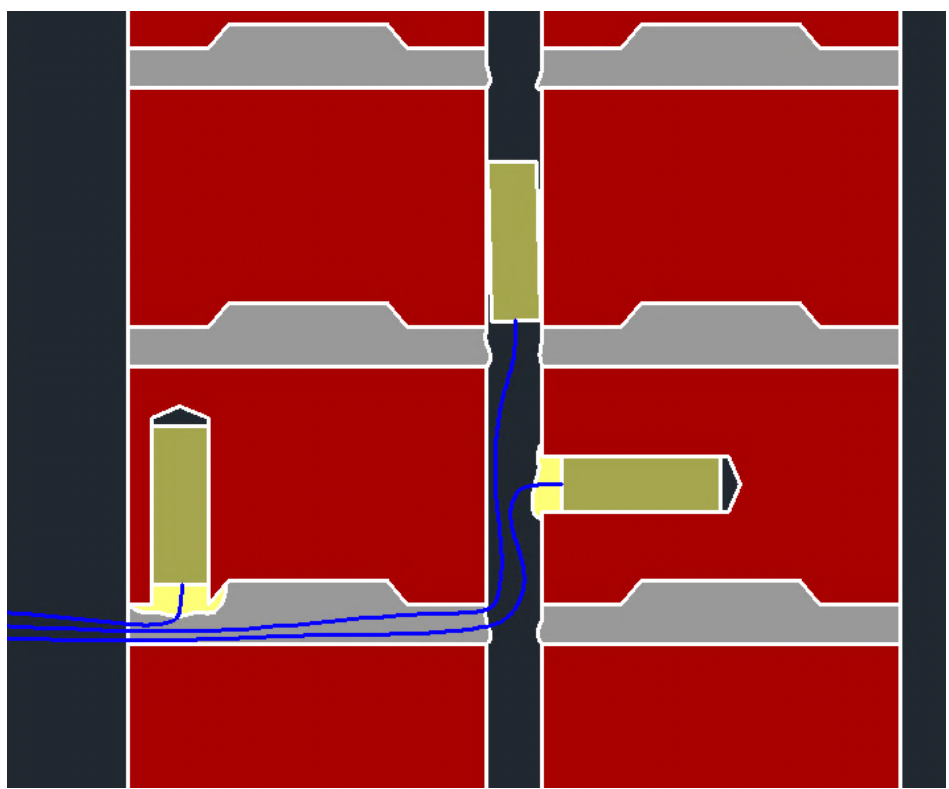

FigURE 24: SECTION OF THE TEST BUILDING'S CLAY BRICK WALL SHOWS TYPICAL MOISTURE CONTENT SENSOR ARRANGEMENT.

(EXTERIOR SIDE IS ON THE LEFT.) 
It should be noted that all the Moisture content sensors were installed through the exterior side of the wall. All wires protruding from mortar joints exit the wall at a downward $45^{\circ}$ angle to reduce bulk rainwater entry into the wall via water cohesion to the cable. 


\subsubsection{MEASURING CLAY BRICK MOISTURE CONTENT IN SITU}

Measuring moisture content of clay brick in real-time, in situ, outside of a laboratory is a challenging task (Ueno \& Straube, 2008). The problem is that no sensor currently exists that can directly measure the moisture content of clay brick, given two fundamental physical characteristics: (1) the physical makeup of clay brick is not necessarily homogenous and uniform, and (2) clay brick has varying degrees of porosity. As a result the measurement of moisture content in clay brick by electrical resistance alone is not a reliable method. This variation is visually evident in Figure 25.

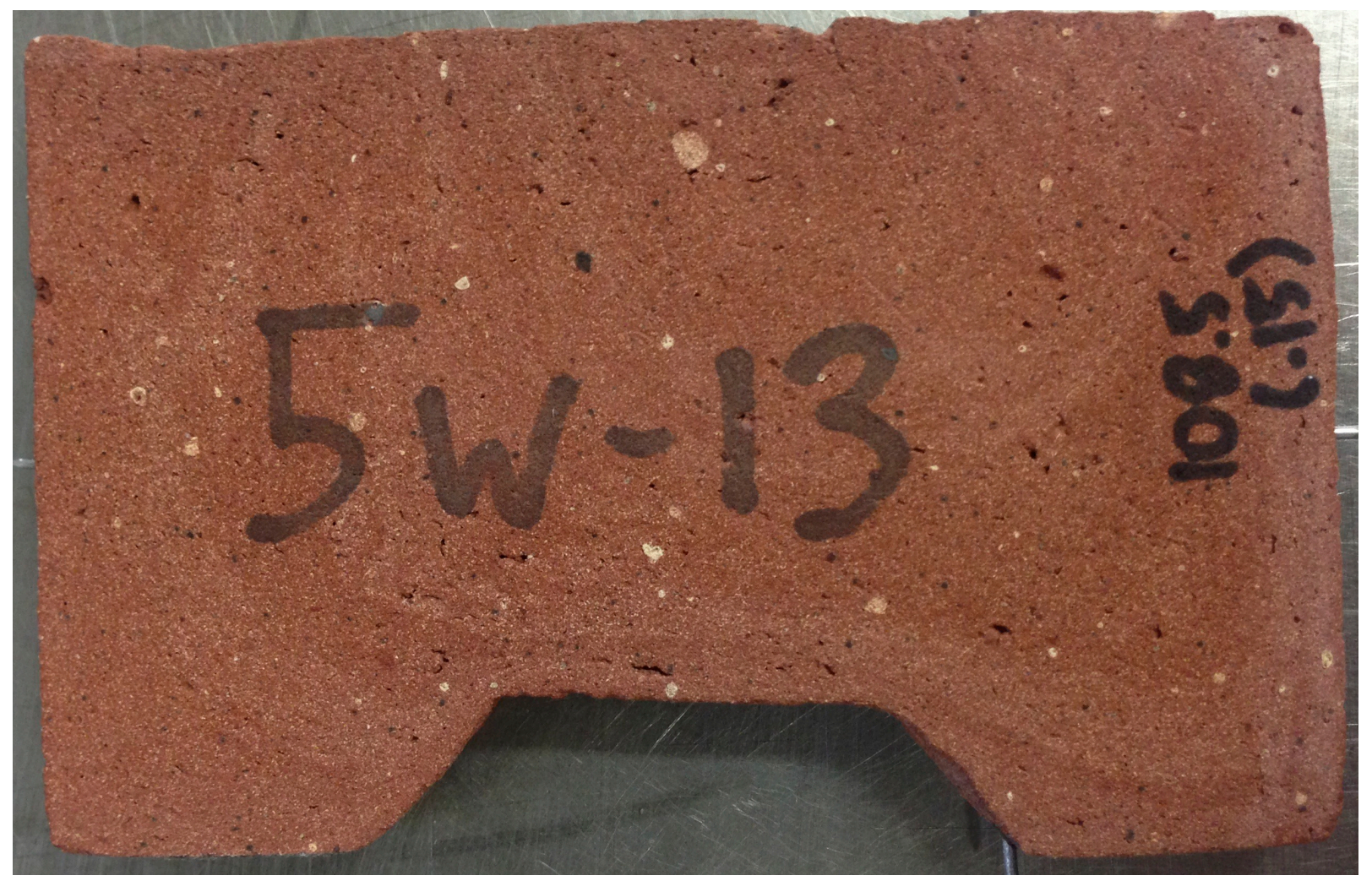

FigURE 25: SLICED CENTURY OLD CLAY BRICKS REVEAL THE VISIBLY INHOMOGENEOUS SWIRL PATTERN WITHIN, AS WELL AS POCKETS, VOIDS AND INCLUSIONS NOTE THE “MARBLE" SWIRL PATTERN.

The most reliable way to measure moisture content in clay brick masonry is by gravimetric measurement in a laboratory (Fagerlund, 1977). By thoroughly drying a clay brick specimen 
for a few days in a drying oven, its dry weight can be determined and used calculate the weight of water content at any point in time thereafter (Appendix A, Procedure 1). Unfortunately, this is not an option when clay bricks are mortared in place in a wall as part of a building.

An alternate method to measure moisture content in clay brick is to use a surrogate material that has characteristics that lends well to electrical resistance measurements. One of the natural characteristics of wood is that its electrical resistance changes depending on the amount of moisture contained within the pores of the wood. This characteristic is true of most woods, however certain species such as hemlock are better for this application than others. The resistance is consistent in clear (free of knots) wood specimens, and its resistance-tomoisture content curve is relatively linear. As the moisture content of wood increases, its measurable resistance drops (Figure 26). Also the sorption isotherm for wood has a slope that makes it easier to relate the moisture content to the relative humidity than a sorption curve for a material such as brick (Refer to Section 2.3 Moisture Content VS. Relative Humidity in Porous media).

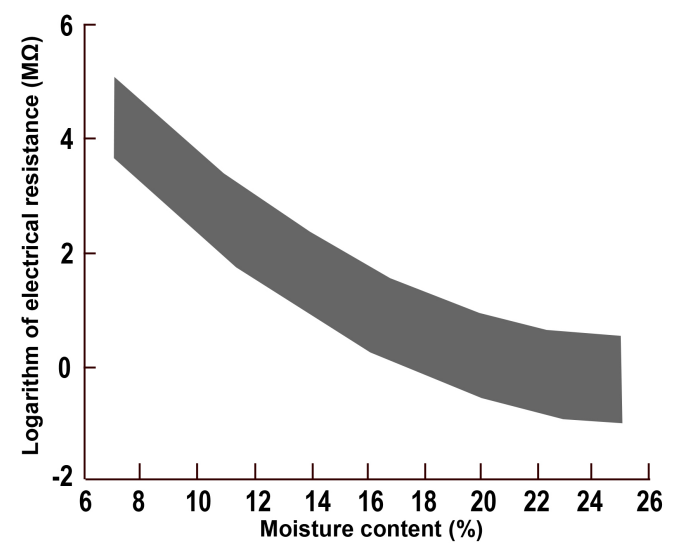

Figure 26: Resistance vs. Moisture Content Curve for Wood. - REDraWn From SMT TeChniCal Literature, EMS SENSOR. (SMT RESEARCH LTD., N.D.) 
Wood surrogate Moisture Content sensors are commercially available and include custom instrumentation designed to measure the high resistance of wood. Moisture Content sensors (SMT Research Ltd., n.d.) were used for data collection at the Toronto test house (Figure 17). The wood surrogate sensor consisted of a western hemlock hardwood dowel that is $12.7 \mathrm{~mm}$ $(1 / 2 ")$ in diameter by $51 \mathrm{~mm}(2 ")$ long. Each sensor has electrodes at each end of the dowel to measure the resistance along the length, as well as an internal thermistor to measure the temperature. The resistance measurement of clear wood material (i.e. free of knots and with consistent grain) produce consistent resistance curves with respect to moisture content. The moisture content calculation used by SMT equipment is based on the equation based on the work of Pfaff \& Garrahan (1988):

$$
M C=\left[\frac{R+\left(0.567-0.0260 x+0.0000051 x^{2}\right)}{0.811\left(1.0056^{x}\right)}-b\right] \div a
$$

EQUATION 1

Where,

$$
\begin{aligned}
& M C=\text { Moisture Content at } 23^{\circ} \mathrm{C} \\
& R=\text { Measurement resistance, } \Omega \\
& x=\text { Temperature of the wood, }{ }^{\circ} \mathrm{C}
\end{aligned}
$$


$a, b$ : Correction coefficients for each tuned sensor. ${ }^{1}$ The coefficients used at the Toronto test house are listed in Appendix C - Moisture Content Sensor Correction Coefficients.

A total of 12 sensors are permanently installed into the exterior-wythe clay brick units, the collar joints, and the interior-wythe clay brick units at the four measurement locations. As a method of increasing capillary flow between the clay brick and the wood surrogate sensor, the boreholes for the M.C. sensors are sized as closely as possible to the diameter of the sensor body. Also, clay brick dust recovered from the drilling process is packed between the borehole and the wooden sensor body, as recommended by the manufacturer as the best procedure for increasing capillary flow into the sensor. All cables from the moisture content sensors are routed along the exterior of the building, and into an instrumentation room in the basement of the house where four SMT 24-bit data loggers were centrally positioned (Figure 27 and Figure 28).

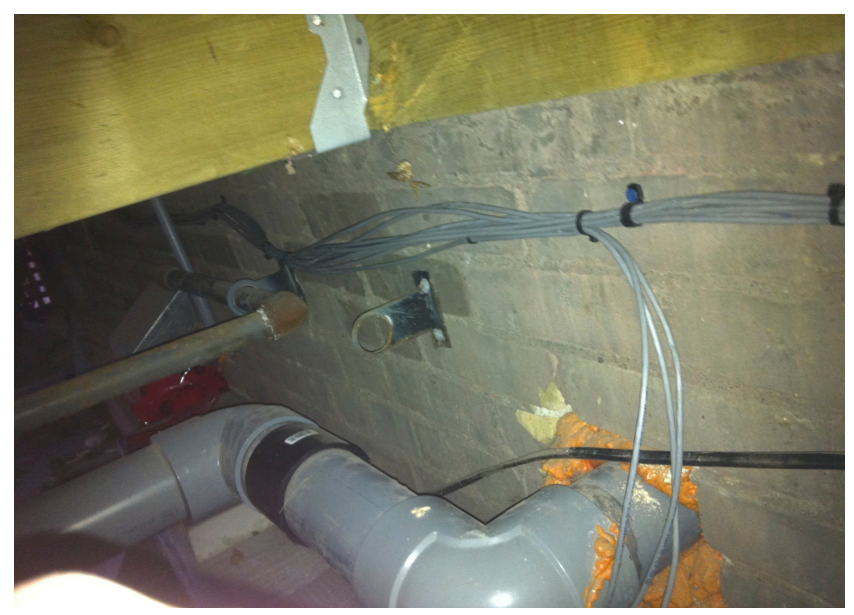

Figure 27: MOISTURE SENSOR CABLES ROUTED AROUND THE EXTERIOR OF THE HOUSE.

\footnotetext{
1 The correction factors are instrument specific and are typically provided by SMT, the Manufacturer
} 


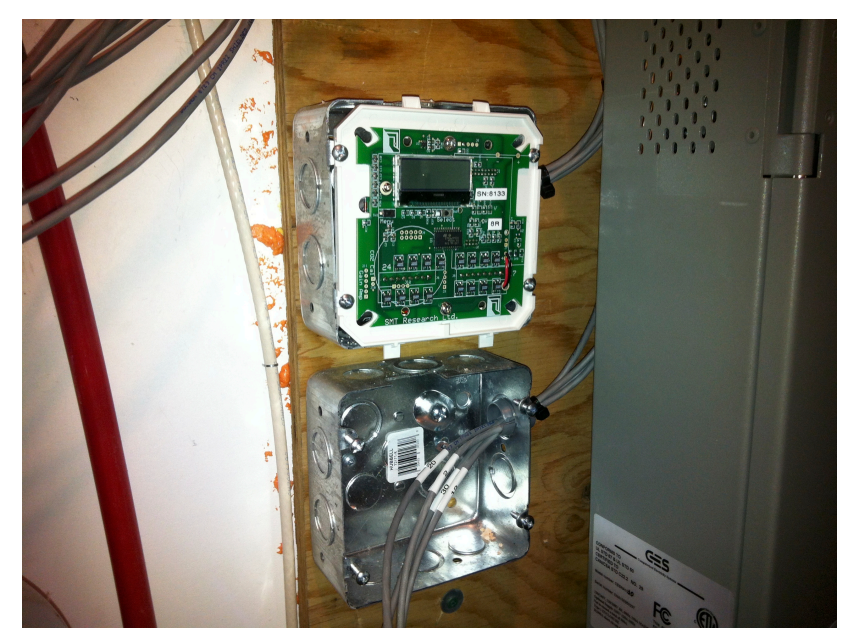

Figure 28: 1 of 4 SMT Moisture Content data loggers during installation.

An additional moisture content sensor is used to create a calibration curves and correlate relative humidity levels to measured moisture contents within clay brick specimens inside of a controlled relative humidity chamber, as outline in Section 5.2.3 Correlating Moisture Content to Relative Humidity. 


\subsection{LABORATORY MEASUREMENTS}

\subsubsection{FROST DILATOMETRY ANALYSIS}

A total of 18 clay bricks were removed from various locations of the Toronto test house so that aspects of their physical characteristics could be quantified in a lab (Table 2). A few were discarded due to fissures and damage that made them unsuitable for testing.

TABLE 2: BRICKS EXTRACTED FROM TEST HOUSE.

\begin{tabular}{|c|c|c|c|}
\hline Brick No. & Type & Extraction Location & Reasoning \\
\hline $1 \mathrm{~N}$ & Black/Fire brick & \multirow{2}{*}{$\begin{array}{l}\text { North elevation, below porch deck, } \\
\text { mid-wall, } 0.7 \mathrm{~m} \text { above grade. }\end{array}$} & \multirow{2}{*}{$\begin{array}{l}\text { Area completely obscured by porch. Also, bricks at this elevation } \\
\text { have not been exposed to solar radiation temperature cycling. }\end{array}$} \\
\hline $2 \mathrm{~N}$ & Beige & & \\
\hline $1 R$ & Red & \multirow{6}{*}{$\begin{array}{l}\text { West elevation, south end. } 0.7 \mathrm{~m} \\
\text { from rear addition and } 1.3 \mathrm{~m} \text { above } \\
\text { grade. }\end{array}$} & \multirow{6}{*}{$\begin{array}{l}\text { Open location where airflow not stagnated by side-gate. Out of sight } \\
\text { from the rear access way to the yard. Bricks were removed without } \\
\text { need for ladder. }\end{array}$} \\
\hline $2 R$ & Red & & \\
\hline $3 R$ & Red & & \\
\hline $4 R$ & Red & & \\
\hline $5 R$ & Red & & \\
\hline $6 R$ & Red & & \\
\hline $1 \mathrm{~W}$ & Beige & \multirow{3}{*}{$\begin{array}{l}\text { West elevation, } 2 \mathrm{~m} \text { North of step- } \\
\text { in, } 0.6 \mathrm{~m} \text { above grade. }\end{array}$} & \multirow{3}{*}{$\begin{array}{l}\text { Location where airflow not terribly stagnated by side-gate. Out of } \\
\text { sight from the rear access way to the yard. Bricks were removed } \\
\text { without need for ladder. }\end{array}$} \\
\hline $2 W$ & Beige & & \\
\hline $3 \mathrm{~W}$ & Beige & & \\
\hline $4 W$ & Red & \multirow{3}{*}{$\begin{array}{l}\text { West elevation, } 4 \mathrm{~m} \text { North of step- } \\
\text { in, } 1.7 \mathrm{~m} \text { above grade. }\end{array}$} & \multirow{3}{*}{$\begin{array}{l}\text { Location where airflow not terribly stagnated by side-gate. Out of } \\
\text { sight from the rear access way to the yard. Bricks were removed } \\
\text { without need for ladder. }\end{array}$} \\
\hline $5 \mathrm{~W}$ & Red & & \\
\hline $6 \mathrm{~W}$ & Red & & \\
\hline
\end{tabular}

These clay bricks were analysed for two- and three-dimensional frost dilatometry, water absorption uptake (A-value), moisture storage curves and also to generate calibration curves for the moisture content sensors. Porosity and density can easily be calculated using data obtained during the frost dilatometry analysis. Most of these pieces of data are required for any future WUFI analysis to take place. In addition to the century old clay bricks from the Toronto test house, 12 contemporary clay bricks from a Canada wide manufacturer (Hanson Building Products, 2014) were also cut into $10 \mathrm{~mm}$ wide specimens. They were tested for 2dimensional frost dilatometry to compare against the century old clay brick, and to help establish a benchmark of acceptable frost-dilatometry results. These contemporary clay bricks 
did not have "frog" indentations in the bottoms; they had hollow cores that passed clear through the clay brick. As a result, each of the contemporary clay bricks yielded only 4 specimens, whereas the century old clay brick yielded 12 to 17 specimens (Figure 29).

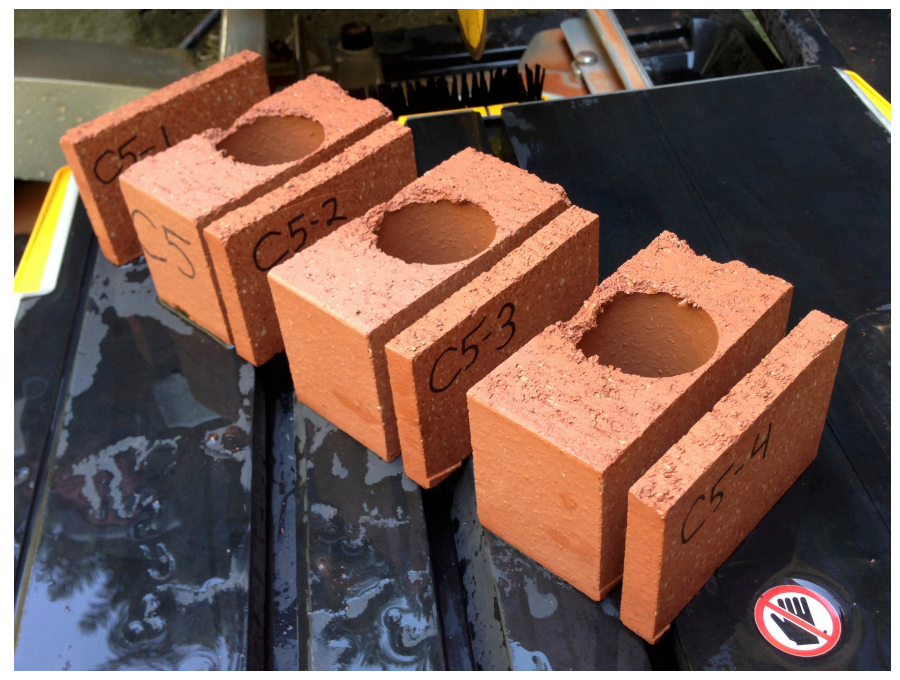

FIGURE 29: CORED CONTEMPORARY CLAY BRICK ONLY YIELDS 4 SPECIMENS OF APPROPRIATE SIZE FOR COMPARISON.

The Critical Saturation point has been determined by way of frost dilatometry analysis. As well, the determination of their A-value (water absorption curve) has also been measured. (Refer to Appendix A - Procedures for the process used for measuring frost dilatometry and A-value.) Knowing the critical saturation point and A-value allows for the future creation of a finely tuned WUFI computer model of the Toronto test house wall assembly. A WUFI model could be calibrated against the results measured from the actual walls. With an accurate computer model in place, long-term analysis of the wall could be projected. 


\subsubsection{DIMENSIONING THE CLAY BRICK SPECIMENS}

Frost dilatometry is the process being used to identify the critical saturation point of the clay brick specimens. The process for pinpointing the critical saturation point is an iterative one. Once a clay brick specimen with a particular moisture content shows signs of frost dilatometry (i.e. permanently expansion), it must be discarded. A new clay brick specimen with a different moisture content must then be analysed. This process is repeated until the critical saturation point of the clay brick specimen has been narrowed in upon (Mensinga, 2009). Refer to Appendix A - Procedures for the process steps that have been followed.

\section{Slicing the Brick Specimens}

The whole clay bricks of the Toronto test house are true $2-1 / 2$ " x 4" x 8-3/4" in dimension (64 mm x $102 \mathrm{~mm}$ x $222 \mathrm{~mm}$ ). The clay bricks are sliced into small specimens using a tile-cutting wet saw (American Society for Testing and Materials, 2014b). The ends of the clay bricks are discarded, and then they are sliced up like a loaf of bread, into $10 \mathrm{~mm}$ thick specimens (Figure 31). The clay bricks are typically $10 \mathrm{~mm}$ x $64 \mathrm{~mm}$ x $102 \mathrm{~mm} .\left(3 / 8^{\prime \prime}\right.$ x 2-1/2" x 4") and each clay brick produces about 17 samples (Figure 30). 


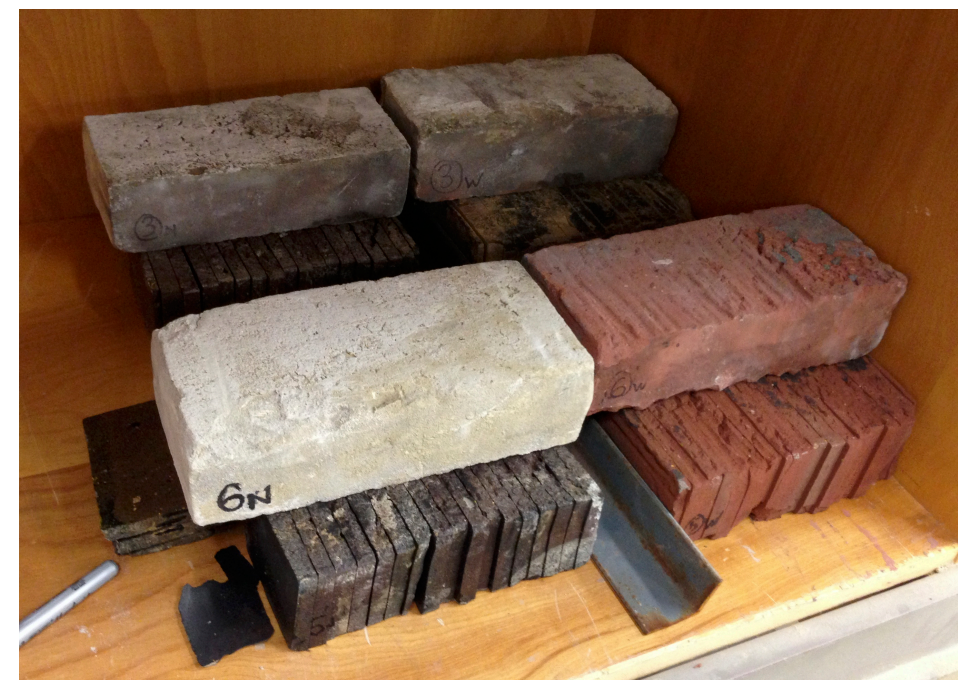

FigURE 30: WHOLE CLAY BRICKS AND CLAY BRICKS SLICED IN A "BREAD LOAF" MANNER TO CREATE SPECIMENS

\section{Dimensioning the Specimens}

In order to accurately measure the amount of expansion in the clay brick samples, ratchet micrometers accurate to $\pm 0.00381 \mathrm{~mm}( \pm 0.00015 ")$ are used to measure the samples along three axes (Figure 32). To reduce wear on clay brick from the rotating anvil of the micrometer, metal pins are installed $4 \mathrm{~mm}$ deep into the clay brick, along the length and the width of the samples (Figure 31). Pins are not installed in the face of the $1 \mathrm{~cm}$ thick clay brick samples; if pins were set into these samples to a depth of $4 \mathrm{~mm}$, there would have been insufficient clay brick between the pins to accurately measure any strain. Instead, accurate measurement along the third "z-axis" are limited to the half-brick samples (Figure 32). Eight half sized clay bricks (64 mm x $100 \mathrm{~mm} \times 100 \mathrm{~mm}$ ) are set aside for this expansion comparison. The thickness ("zaxis") measurement of the $10 \mathrm{~mm}$ samples is attempted with 0 " to 1 " ratchet micrometer calliper, but the measurements obtained seemed to have large erroneous numbers; this is likely due a few factors. The wear on the clay brick surface by the rotation of the closing calliper, the soft constitution of the clay brick, the fact that the faces of the clay bricks were not 
necessarily perfectly parallel, and the thin $10 \mathrm{~mm}$ samples expanding only a minute amount. The error from these small specimen "z-axis" thickness measurements is far greater than the strain expansion across the other two axes.

The first step in the process is to measure the starting dimensions of the clay brick samples.

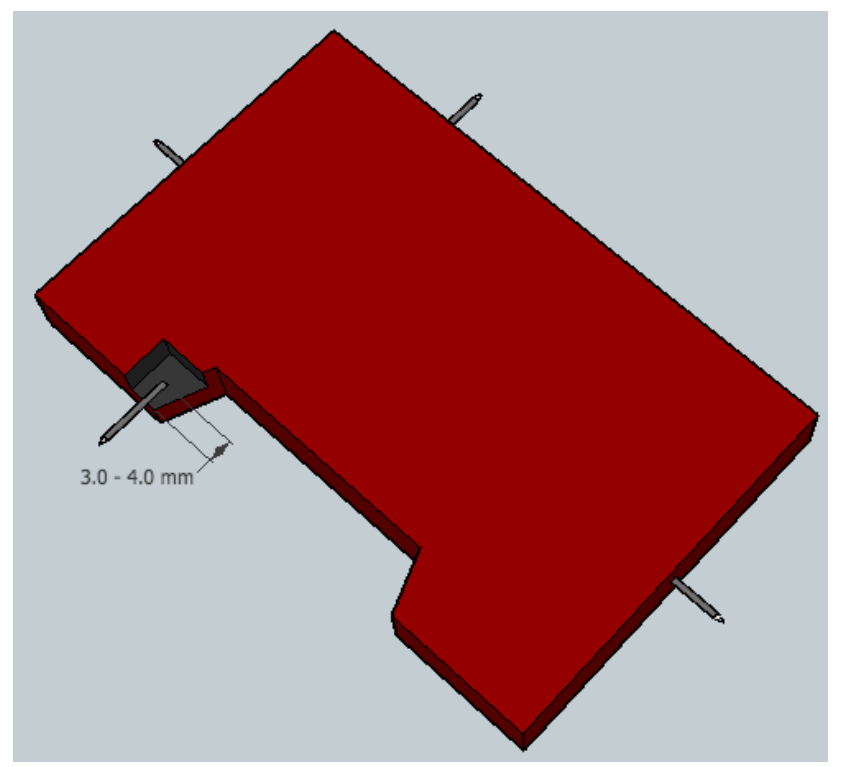

FIGURE 31: WEAR-PINS INSTALLED INTO CLAY BRICK SPECIMENS FOR MICROMETER MEASUREMENTS.

FreEze THAW STRAin/EXPANSION IS MEASURED IN THE SAMPLES ALONG THREE AXES (X, Y AND Z) IN THE LARGER 100 MM X LARGER 100 MM X 100 MM X 50 MM SPECIMENS, BUT ONLY MEASURED ALONG TWO AXES (X AND Y) IN THE SMALL 100 MM X THE SMALl 100 MM X 50 mM X 10 mM SAMPLES. (

Figure 32 below.)

This is performed using a "large" Mitutoyo $101 \mathrm{~mm}-127 \mathrm{~mm}$ (4" to 5") manual ratchet-stop micrometer, a "medium" Mitutoyo $51 \mathrm{~mm}-76 \mathrm{~mm}$ (2" to 3") manual ratchet-stop micrometer, and a "small" Chaun-Brand $0 \mathrm{~mm}-25 \mathrm{~mm}$ (0" to 1") ratchet-stop micrometer. The Mitutoyo 
micrometers have specified tolerances of $\pm 0.00381 \mathrm{~mm}( \pm 0.00015 ")$ and $\pm 0.00254 \mathrm{~mm}$ $( \pm 0.0001 ")$ respectively. The Chaun-Brand micrometer does not have a manufacturer specified tolerance, although standard JIS B7502 specifies that micrometers of this size should have overall error of no more than $\pm 0.002 \mathrm{~mm}$. ( \pm 0.00008 ").

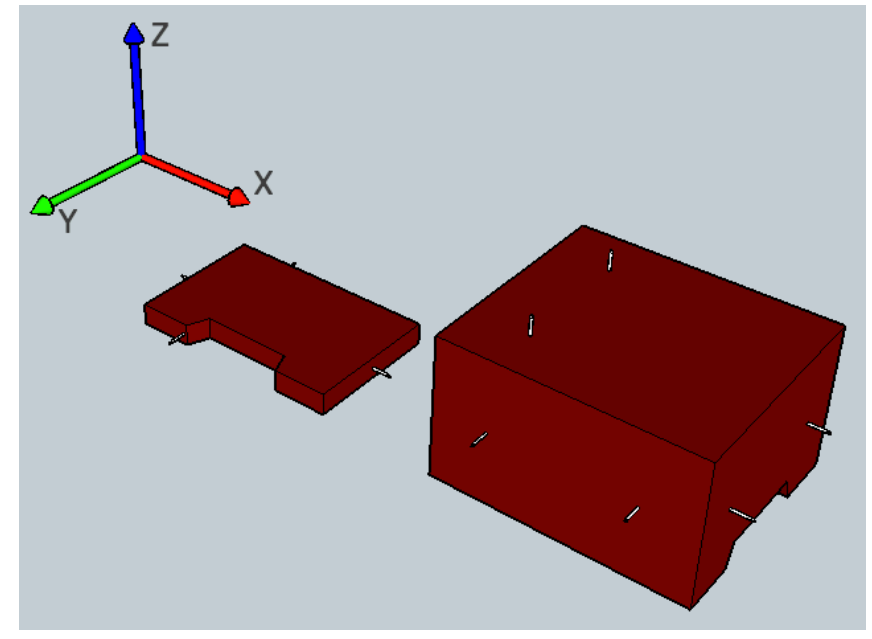

FiguRE 32: ClAY BRICK SPECIMENS MEASUREMENT AXES.

Using the same approach as Mensinga (2009), the minimum strain measurement of the clay brick samples is determined by the tolerance of the instruments used for measurements. That is, $0.00381 \mathrm{~mm}$ tolerance of the large micrometer, and $0.00254 \mathrm{~mm}$ for the medium micrometer, are considered the amount of expansion required before being recognized as frost dilatometry expansion. This equates to approximately 100 microstrain. Strain measurements occurring in the Z-axis of the $10 \mathrm{~mm}$ thick specimens was abandoned: the amount of strain that occurs is too small to measure with this type of equipment. Also, accuracy was hindered along the thin width dimension, due to the lack space to install wear pins into the sample in this dimension. The rotating action of the closing micrometer callipers provided enough abrasion against the soft sandstone-like characteristic of the historic clay brick, to slightly wear the 
surface away at each measurement. Wear pins were not embedded into $10 \mathrm{~mm}$ dimension because they require at least $3 \mathrm{~mm}$ of depth. Had they been installed, there would only have been approximately $4 \mathrm{~mm}$ of clay brick between the pins for frost dilatometry measurement.

Each micrometer measurement is taken twice: once in a forward direction (Figure 33), once in a reverse direction, and then averaged. This approach helps eliminates measurement error, both user error and instrument error. Great care must also be taken to position each pin at the very center of the calliper anvils when measuring specimen length in order to minimize user error (Refer to Figure 33, Figure 34 and Figure 35). This approach helps ensure repeatable measurements. Otherwise, measuring the span between pins with the callipers off-centre would introduce a measurement angle that is not a perfect right angle between the pins. Even if the wear pins are not installed at perfect right angles to into the clay brick, they can still produce repeatable measurements when measured at the centre of the micrometer anvils.

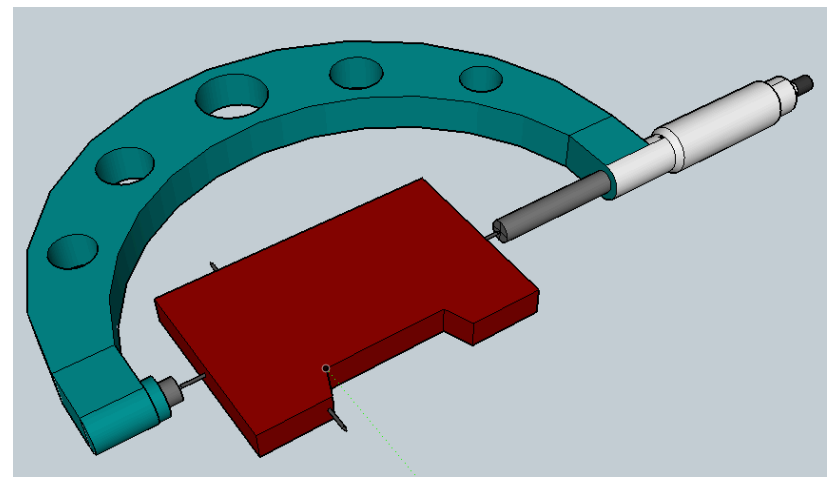

FiguRE 33: Micrometer CALLIPER MEASUREMENT OF WEAR PINS.

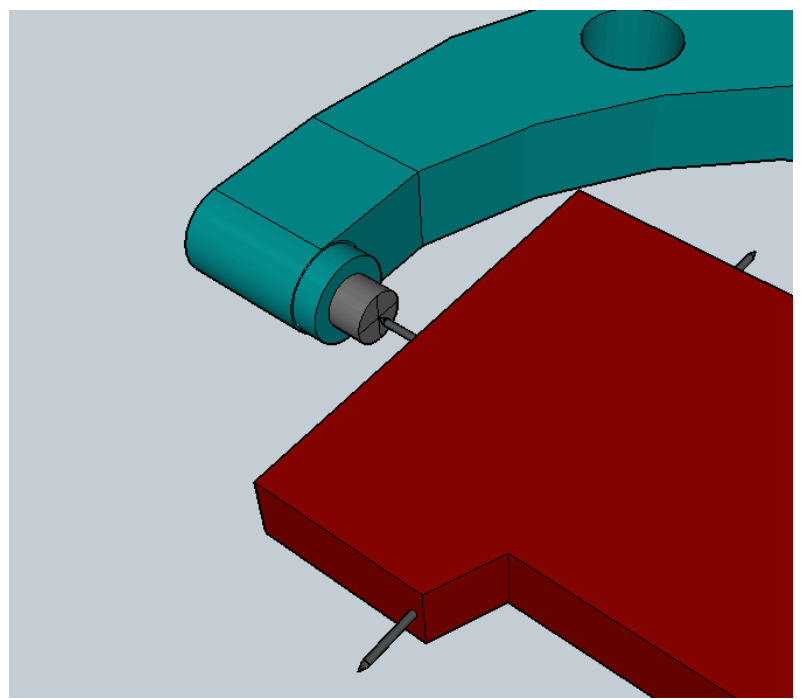

Figure 34: Pins MUST Be Positioned at deAd CENTRE OF FIXED ANVIL DURING MEASUREMENT FOR CONSISTENCY. 


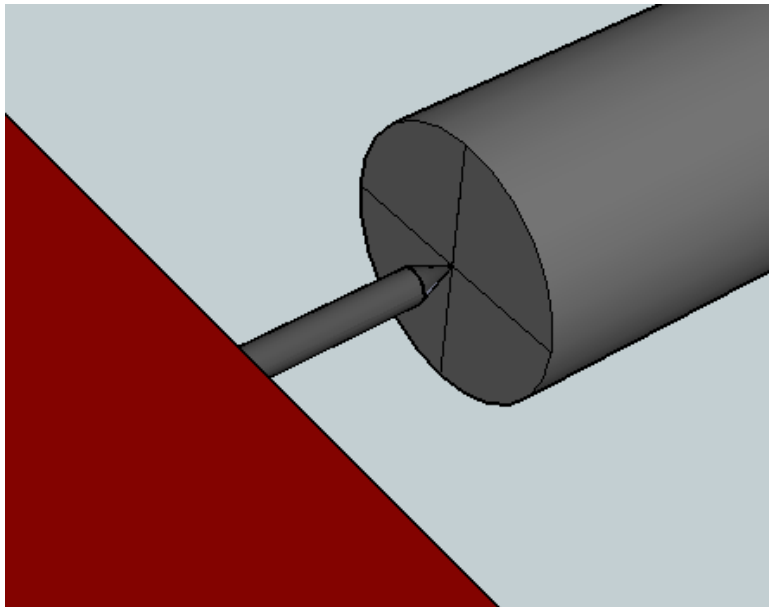

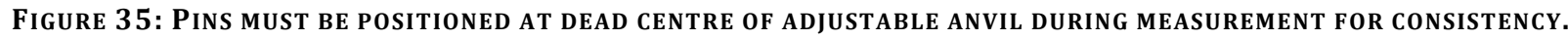




\subsubsection{DETERMINATION OF DRY CLAY BRICK SPECIMEN MASS}

Each of the specimens is tested to determine their maximum and minimum possible moisture content. The procedure for this process is adapted from previous work by Peter Mensinga (Mensinga, 2009) as well as CSA and ASTM standard Test Procedures (American Society for Testing and Materials, 2014b; CSA Standards, 2007). The mass of each specimen is measured using a digital scale with a precision of $0.1 \mathrm{~g}$ for the small samples (Figure 36), and a precision of $0.5 \mathrm{~g}$ for the larger half-clay brick samples (Figure 37). To begin, the samples are placed in a drying oven with a stable temperature of $110^{\circ} \mathrm{C}$ until they were thoroughly dried of moisture and their mass stabilized, a minimum of 48 hours, and their final weights were recorded.

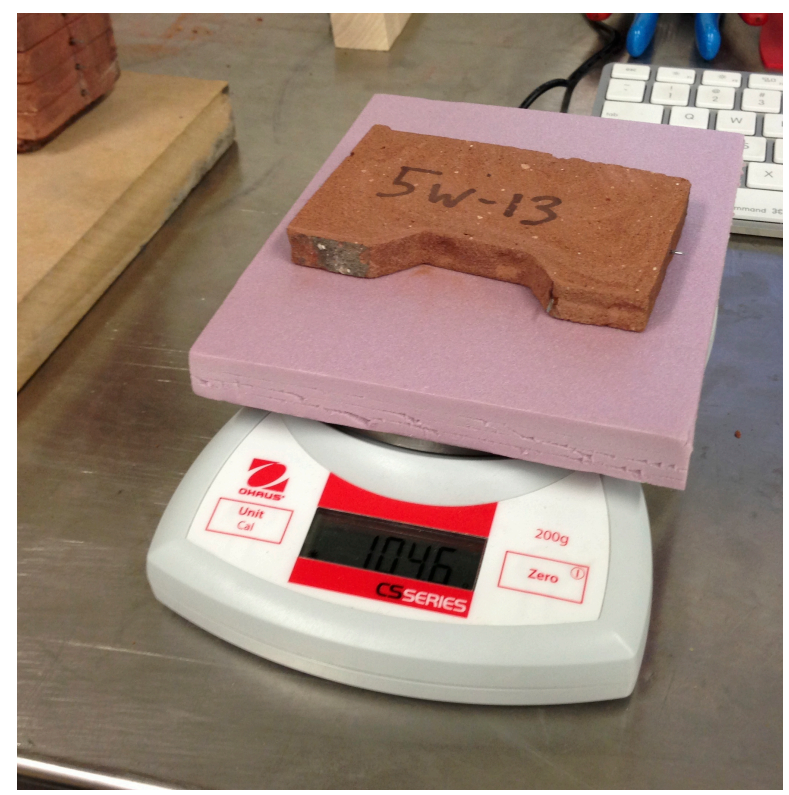

Figure 36: 0.1 g Resolution Scale 


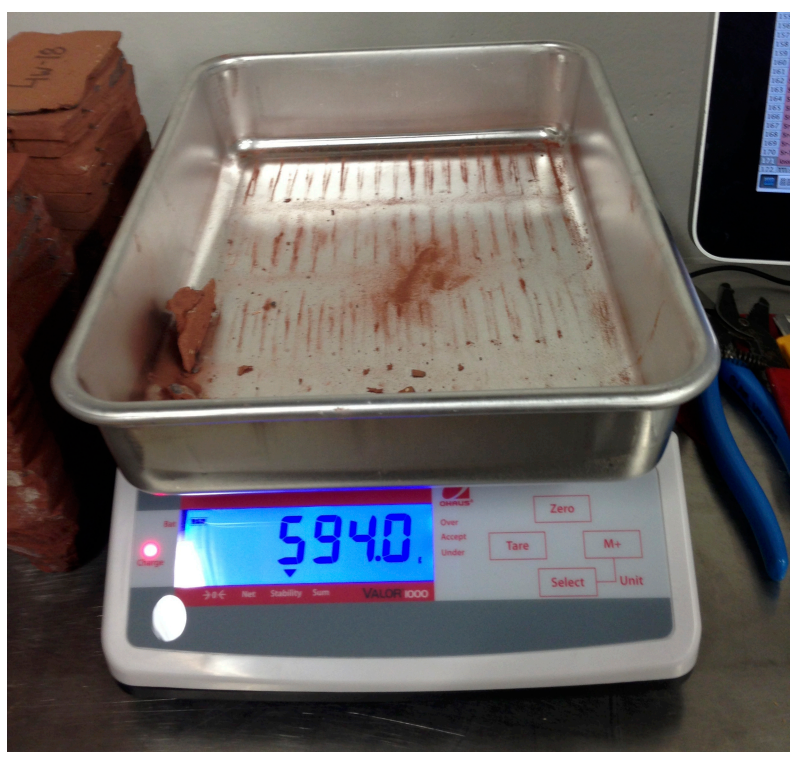

Figure 37: 0.5 g Resolution Scale 


\subsubsection{DETERMINATION OF SATURATED CLAY BRICK SPECIMEN MASS - COLD SOAK}

To determine the water saturation point at which the clay brick specimens begin to expand, the dry and fully saturated weights of the clay brick specimens must first be measured. Dry specimens are placed in a vessel and covered with room temperature $\left(25^{\circ} \mathrm{C}\right)$ distilled water. The samples are left to absorb the water for a 24 -hour period. Samples are then removed from the bath, and the remaining liquid water on the outer surface is wiped with a damp cloth. Samples are weighed and placed back in the cold-water bath.

\subsubsection{DETERMINATION OF SATURATED CLAY BRICK SPECIMEN MASS - BOIL METHOD}

After the cold soak weights are recorded, the samples are put back in the cold distilled water bath, and placed on a hot plate (Figure 38). The water is slowly brought to a boil, and the boil is maintained for a period of five hours (American Society for Testing and Materials, 2014b; CSA Standards, 2007). At the five-hour mark, the bath is removed from the heat, and allowed to cool slightly. Samples are individually removed, wiped with a damp cloth, weighed and recorded. 


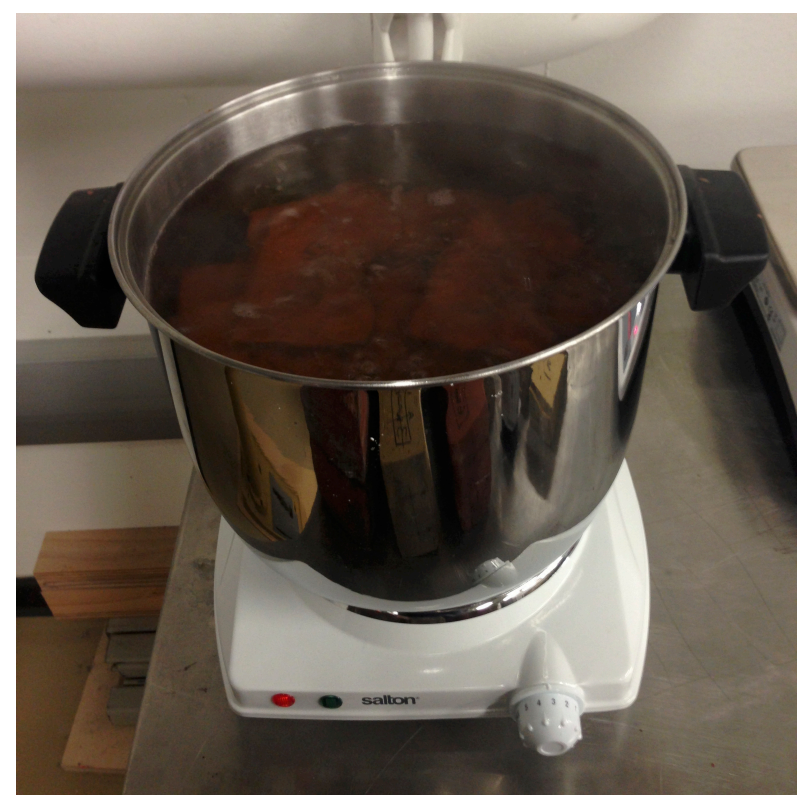

FIGURE 38: BOIL METHOD FOR SATURATION OF CLAY BRICK SPECIMENS.

\subsubsection{DETERMINATION OF SATURATED CLAY BRICK SPECIMEN MASS - VACUUM SATURATION METHOD}

Wet clay brick samples are dried once again in the drying oven with a stable temperature. To start, a temperature of $80^{\circ} \mathrm{C}$ is maintained for half a day to allow the bulk of the water to dissipate from the specimens. The drying oven temperature is then raised to $110^{\circ} \mathrm{C}$, and the samples are allowed to dry for 48 hours. After 48 hours in the drying oven, the dry masses of the specimens are stabilised, signifying they are thoroughly dry.

A vacuum desiccator vessel is outfitted with a plastic and wooden platform to allow the for the positioning of the clay brick specimens in the upper hemisphere of the vessel, while allowing the lower half of the vessel to be filled with distiller water (Figure 39, Figure 40 and Figure 41). The top half of the desiccator is then positioned over the stack of bricks on top of the platform, and sealed on the lower half of the desiccator vessel. The atmosphere is then evacuated from the desiccator vessel using a peristaltic pump (Figure 42). A "Vaccon" air-driven venturi vacuum pump is also utilized for a portion of the depressurization, and then switched to the 
peristaltic pump in order to achieve the deepest vacuum. A vacuum of $-94 \mathrm{KPa}(7.35 \mathrm{KPa}$ absolute pressure) (-27.75 inHg) is achieved using this method (Figure 43). The vacuum is maintained for 30 minutes and then the vacuum desiccator vessel is inverted, allowing the dry clay brick specimens to be submerged under the distilled water inside the vessel. The valve on the desiccator vessel is then opened; air re-enters the vessel and re-pressurizes the inside of the vessel back to that of atmospheric pressure. In the process, evacuated pores within the clay brick are completely filled with water, pushed in by atmospheric pressure. Specimens are immediately removed from the vessel, wiped with a damp cloth, and weighed.

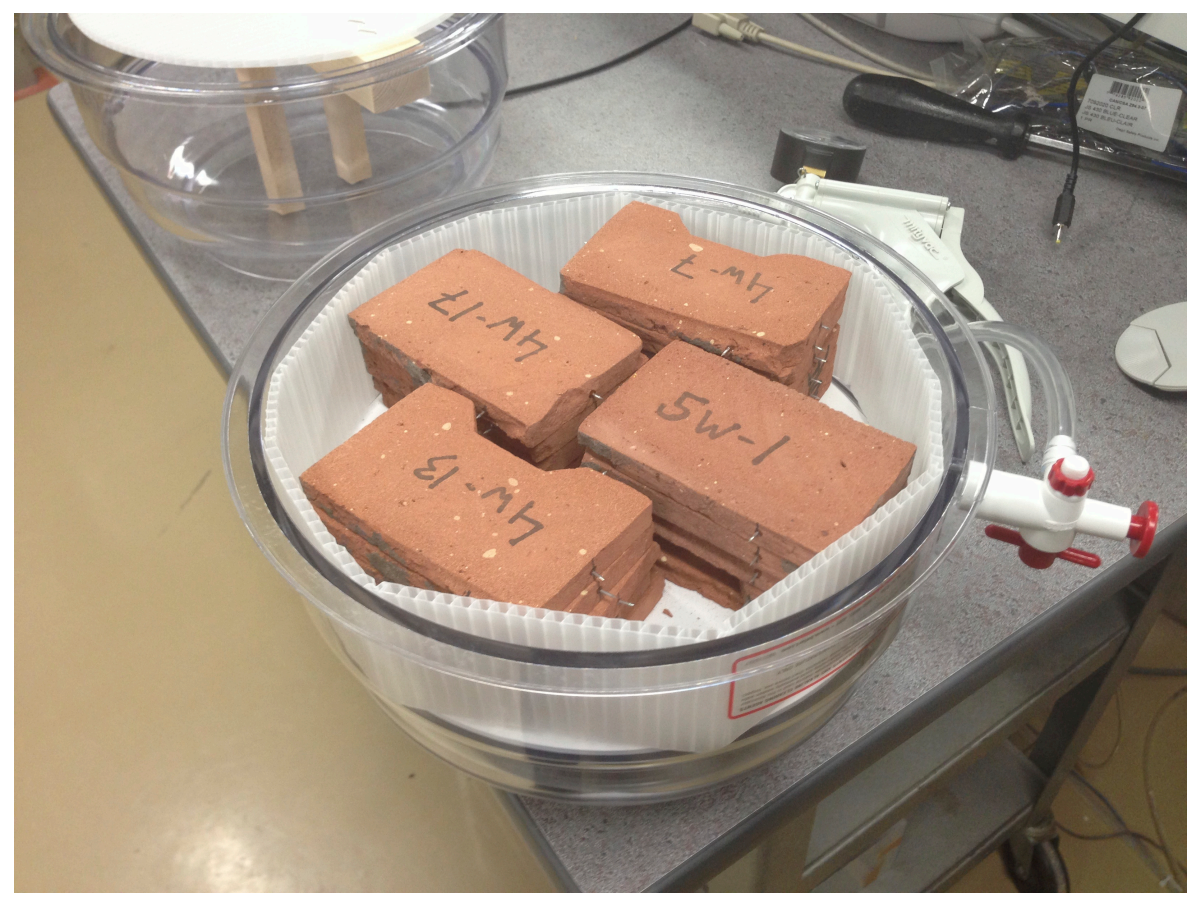

FIGURE 39 CLAY BRICK STACKED INSIDE THE INVERTED UPPER HEMISPHERE OF A VACUUM DESICCATOR (FOREGROUND). THEY ARE TO BE POSITIONED ON THE PLATFORM IN THE LOWER HEMISPHERE OF THE DESICCATOR BEFORE IT IS FILLED WITH WATER (BACKGROUND). 


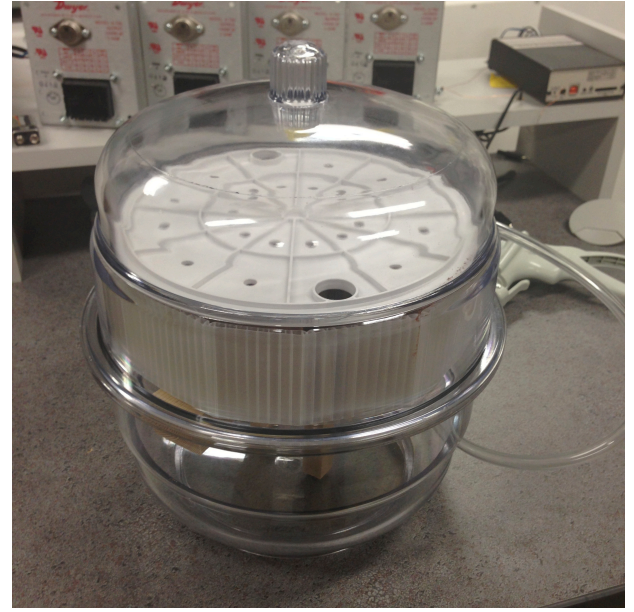

Figure 40: VACUUM DESicCator ASSEMBLED, CLAY BRICKS IN THE UPPER HEMISPHERE.

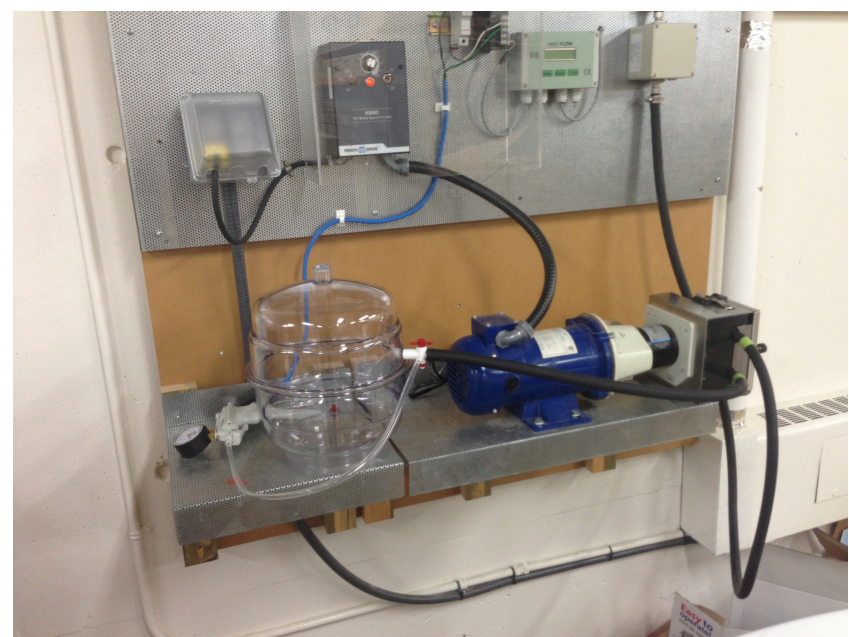

Figure 42:Peristaltic Pump system used to evacuate ATMOSPHERE FROM VACUUM DESICCATOR.

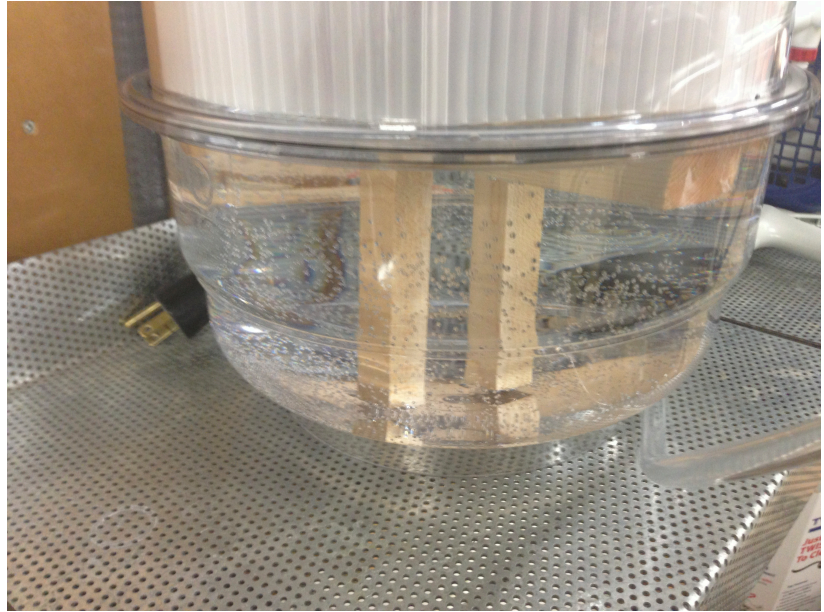

FIGURE 41: LOWER HEMISPHERE OF DESICCATOR FILLER WITH DISTILLED WATER.

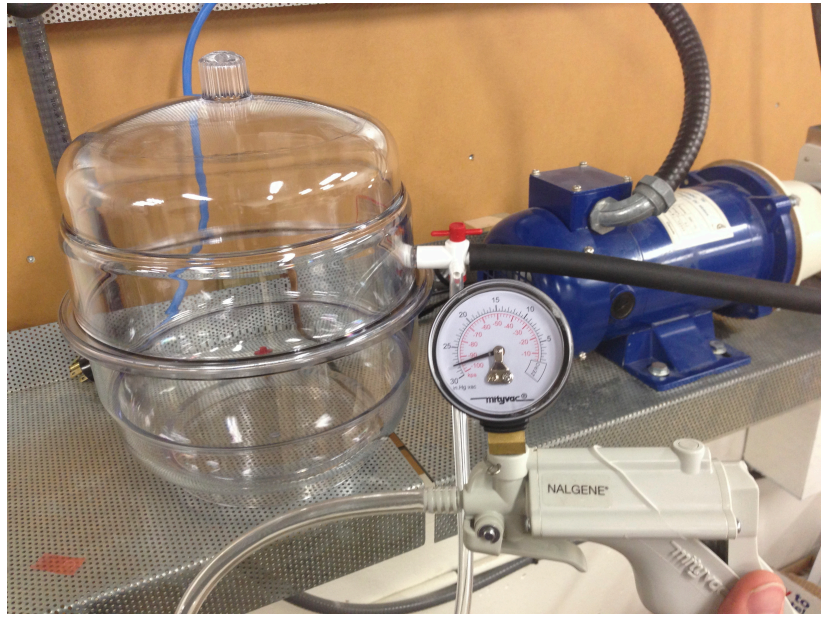

Figure 43: Peristaltic Pump in the Building Science

LAB AT RYERSON UNIVERSITY WAS CAPABLE OF PRODUCING 28 InHg OF VACUUM. 


\subsubsection{CRITICAL SATURATION POINT ANALYSIS}

Once the minimum and maximum water saturation points are known for each specimen, the freeze-thaw testing is performed to determine the critical saturation point, $S_{\text {crit }}$ - the point at which the specimen experiences frost dilatometry. Before the brick specimens are saturated, each specimen must be dimensioned across the installed wear pins and recorded. Specimens are measured twice, at the centre-points of the micrometer callipers, and the average of the two measurements must be used. The specimens are then saturated with water to: $20 \%, 40 \%$, $60 \% 80 \%$ and $100 \%$ of their maximum. Water is added to specimens with an eyedropper where under $60 \%$ saturation is desired. Samples requiring greater saturation than $60 \%$ must be saturated beyond the desired amount by either boil or vacuum saturation methods, and then dried to the desired level of saturation. Once achieved, the specimens are wrapped in multiple layers of plastic cling wrap, and then in layers of aluminum foil to prevent moisture from escaping. Clay brick specimens are then left to sit to allow the water to equally distribute throughout for a period of 24 hours.

Once the 24 hour distribution period had passed, the specimens are placed into an automatic freeze-thaw chamber. The chamber automatically cycles between freezing and thawing every 12 hours: each freeze cycle is 12 hour in duration, and drops beyond $-30^{\circ} \mathrm{C}$. The freeze cycle is followed by a 12 hour thaw period where the temperature inside the freeze-thaw chamber reaches $+30^{\circ} \mathrm{C}$ (Refer to Figure 44). A total of 9 freeze-thaw cycles are performed on each specimen. Previous work by Peter Mensinga exposed the brick specimens to 6 cycles of freeze thaw (Mensinga, 2009). Since this equipment for cycling freeze -thaw is automatic, a few extra cycles have been added in an attempt to make any dilatometry occurring in the specimens more evident. 


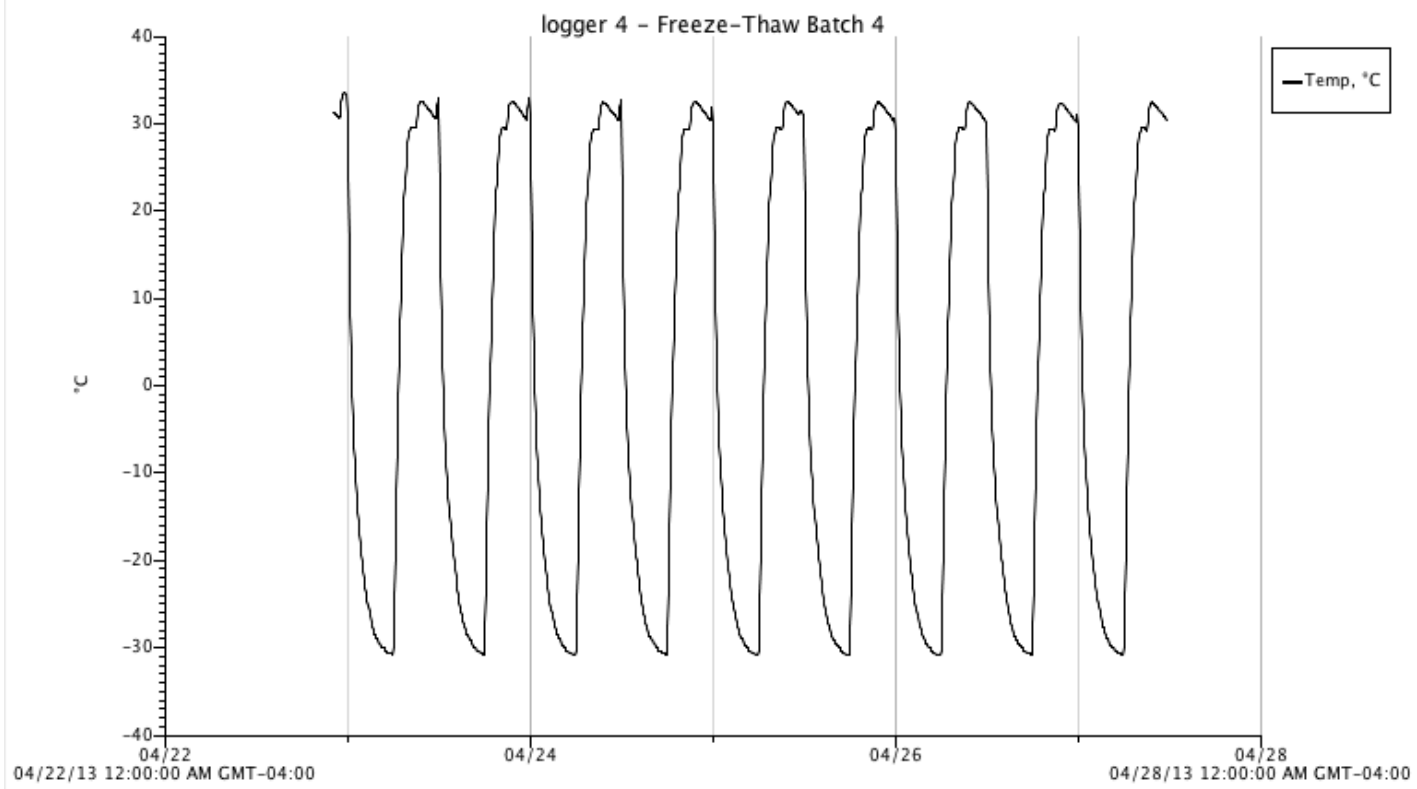

FigURE 44: 9-CYCLE COOLING AND HEATING PROFILE FOR FREEZE-THAW CHAMBER.

Specimens are placed flat directly onto the refrigerated shelves of the freeze-thaw chamber, so that the maximum surface area of the specimen is in contact with shelves where the cooling lines were located (Figure 45). During the cooling cycle, the samples are chilled by a combination of conductive heat flow to the shelves, and convection within the chamber. During the heating cycle, the specimens are warmed convectively by a small heater-fan that circulates warm air throughout the chamber. Once the 9 freeze-thaw cycles complete, specimens are removed from the chamber, dimensioned with the micrometers in both directions and the average measurement taken. Measurements are logged into a spreadsheet, and analysed. 


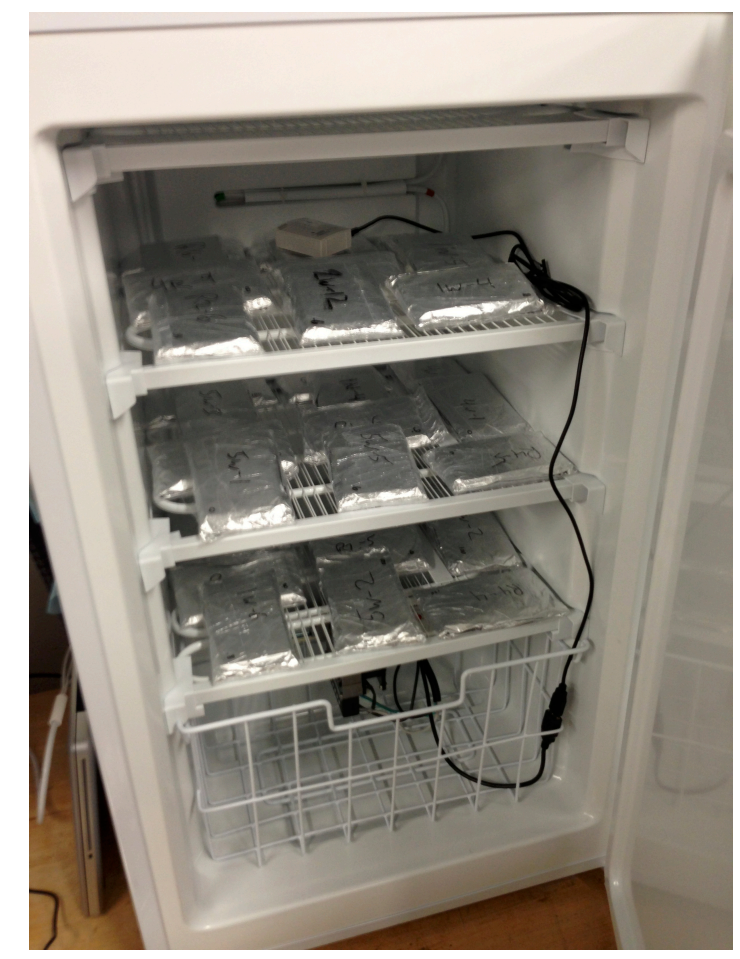

FIGURE 45: WRAPPED BRICK SPECIMENS INSIDE THE FREEZE-THAW CHAMBER.

This process for freeze-thaw differs from that outlined in the procedure for ASTM C67, which calls for the brick specimens to be partially submerged in a bath of water during the freezethaw cycles. This step is not possible when testing for frost dilatometry. When narrowing in on the critical saturation point of a specimen, the precisely measured amount of water it contains must be known when freeze-thaw expansion begins to occur. 


\subsubsection{ABSORPTION CURVE VALUE DETERMINATION}

The initial rate of absorption, or the A-value, is an important piece of information: it identifies how quickly water moisture transfers though a porous medium by way of capillary suction, and is a necessary value for producing a precise WUFI computer model. For this measurement, oven dried bricks are allowed to cool. The bricks are stood on one end so that the end in a shallow bath of water. Racks are position to support the brick, so that only the end face comes in contact with the water, and the brick is not submerged more than approximately 3 millimeters. The A-value water uptake is only measured in one dimension along the width of two full brick units, and one half-width brick specimen. The brick is removed from the bath every minute, the wet surface is wiped with a damp cloth, the brick is weighed, and then quickly put back in the bath where it continues to uptake water for another minute. The measurement cycle is repeated until enough data has been recorded to create a curve. The procedure for determining the A-value of bricks are outlined in CSA-A82-06 (CSA Standards, 2007) and in ASTM C67-13 (ASTM, 2014b). 


\subsubsection{CORRELATING MOISTURE CONTENT TO RELATIVE HUMIDITY}

Precisely correlating the moisture content of the SMT wooden moisture content sensors to the M.C. of the clay brick is performed in the lab. It should be noted that only a limited number of bricks are available for testing. Of the bricks extracted from the walls, a total of 5 beige bricks and 8 red bricks were undamaged and suitable for laboratory analysis. (Several bricks extracted from the walls were discarded due to fissures and voids in the clay.) The remaining bricks were divided up amongst the various sections of lab work for this project. A single red clay brick (upper wall) and a single beige clay brick (foundation), chosen at random, are used for this portion of the analysis, to correlate the R.H. to M.C. data. A brick of each type was chosen to identify what effect the type of brick might have on correlating the moisture content to the relative humidity. Any measurement error resulting from the inhomogeneous constitution of the clay brick may be offset by the large size of the SMT Moisture Content sensors. Figure 46 and Figure 47 show examples of clay brick with visible signs of inhomogeneity: marbling within the clay, as well as inclusions and air pockets can be seen. The $12.7 \mathrm{~mm}$ diameter by $65 \mathrm{~mm}$ depth of the borehole for the sensors requires a relatively large amount of surface area for the Moisture Content sensor to make contact, inside of the clay brick, and bisects multiple zones of clay brick composition. 


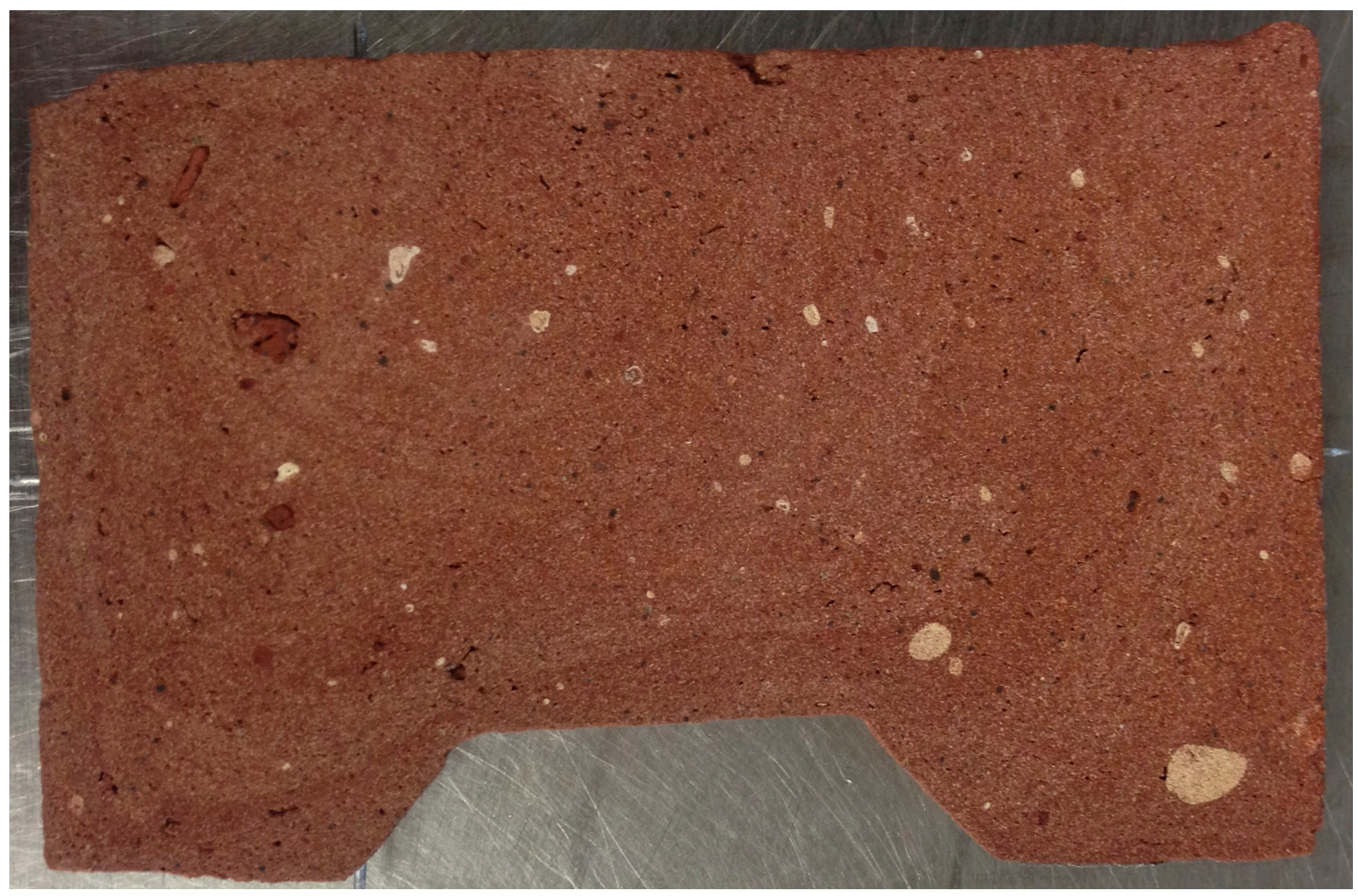

FigURE 46: VISIBLY INHOMOGENEOUS CLAY BRICK CONSTITUTION. (BLOWN UP TO SHOW TEXTURE.)

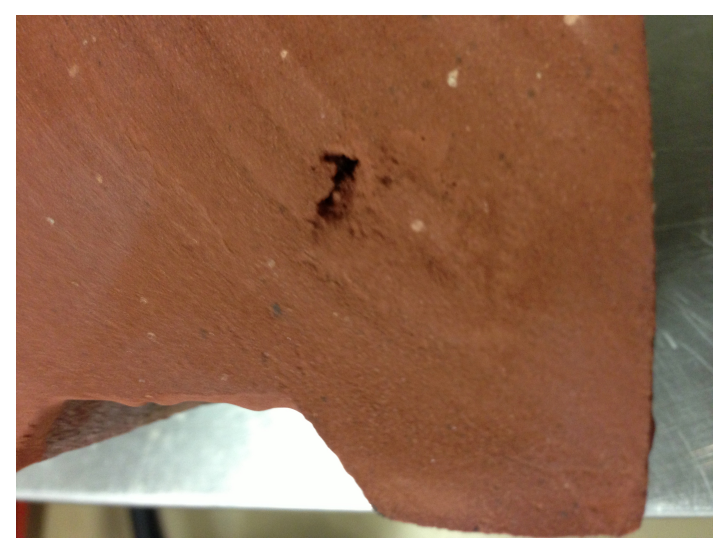

FIgURE 47: AIR POCKET IN CLAY BRICK SAMPLE

Clay bricks are chosen based on their appearance; they are cut in half to reduce them to a manageable size, and also to make visible their inner composition. The two clay bricks chosen for this portion of the analysis do not appear to have any cracks or damage, and appear be representative samples. 
A controlled relative humidity environment is achieved inside an airtight vessel by using water and supersaturated salt solutions. Different types of salts, when mixed in a supersaturated solution, create stable and documented RH levels (Wexler \& Hasegawa, 1954). For safety reasons, only Potassium Carbonate and table salt are used to obtain mid-range levels of humidity (Refer to Table 3). A variety of other salts can produce a range of RH levels, however many are listed as hazardous through the Workplace Hazardous Material Information System (WHMIS), and the benefit of additional relative humidities inside the control chamber was unnecessary and would have required the use of an updraft (OSHA, 2001).

Table 3: RH Calibration Salts

\begin{tabular}{|c|c|c|}
\hline Desired R.H. Level [\%] & Salt, supersaturated in $\mathrm{H}_{2} \mathrm{O}$ & Note \\
\hline 0 & (no solution) & Dry weight \\
\hline 45 & $\mathrm{~K}_{2} \mathrm{CO}_{3}$ & Potassium Carbonate \\
\hline 76 & $\mathrm{NaCL}$ & $\begin{array}{c}\text { Table salt (non- } \\
\text { iodized, lab grade) }\end{array}$ \\
\hline 100 & - & Pure distilled water \\
\hline
\end{tabular}

To ensure the salts are properly in a super saturated solution, they must be mixed with boiling water and allowed to cool. The extra salt crystalizes out of the solutions as the liquids cool. The crystalized salts remain at the bottoms of the solutions in a solid state. Maintaining this extra solid salt is crucial to creating a stable RH inside a sealed vessel.

First, gravimetric analysis is performed on the clay bricks in the vessel without the sensor in place so that the clay bricks can be accurately weighed without the interference from weight of any attached sensor cable. The salt solution is placed in the bottom of the airtight vessel (Refer to Figure 48). The clay brick (without sensor) is then placed in the same container, on top of a rack, which keeps the clay brick elevated above the salt solution. An OnSet U10 temperature/RH data logger is also placed inside the vessel to monitor the humidity 
conditions. The U10 is wired to a computer so that conditions can be monitored without disturbing the measurement by opening the vessel.

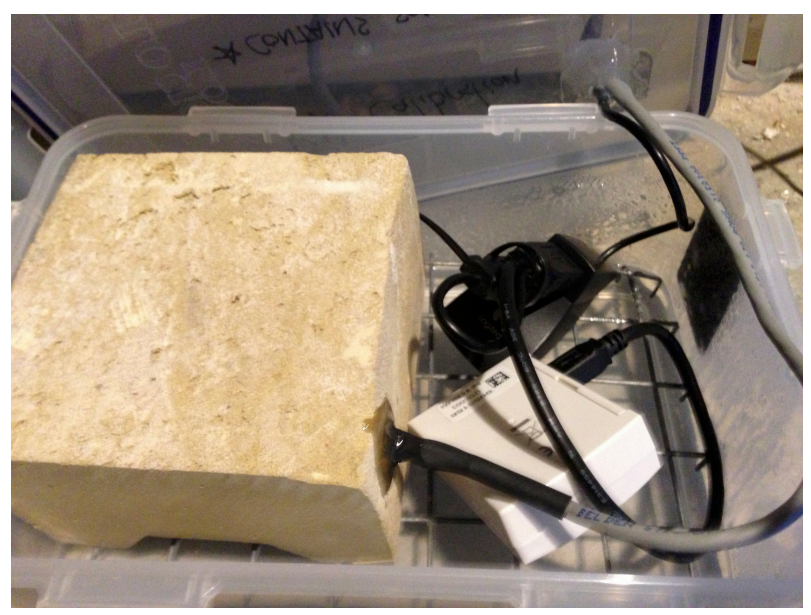

Figure 48: RH Vessel With brick SPecimen (With Moisture Content Sensors installed), Salt solution (below BRICK), TEMP/RH DATA LOGGER, AND AIRTIGHT LID.

Both clay brick types were allowed to acclimatize over each salt solution listed in Table 3 for over one week. After a seven-day period, the vessel was opened, and the clay brick specimens were weighed.

The next step requires repeating the above procedure, but with the moisture content sensor installed in each clay brick. A $12.7 \mathrm{~mm}(1 / 2$ ") hole is drilled squarely into the face near a corner of the clay brick to a depth of $75 \mathrm{~mm}\left(3^{\prime \prime}\right)$. The hole is positioned near a corner such that the outside diameter of the hole is approximately $6 \mathrm{~mm}(1 / 4 ")$ from the faces of two sides of the clay brick (Figure 48). The intention of positioning the sensor close to the edge is to speed the measurement time, by reducing the distance through the clay brick that moisture must travel to reach the sensor. The distance between the wall of the borehole and any brick face is kept at a distance greater than $6 \mathrm{~mm}$ in order to prevent the soft and brittle 100-yearold clay brick from cracking. 
Dust from the clay brick drilling process is saved and reused as an intermediate medium to tightly bridge the sensor to the wall of the borehole for each respective clay brick.

Approximately $1 \mathrm{cc}$ of clay brick dust is placed into the bottom of the borehole. Once the sensor is inserted, more clay brick dust is placed on top. A combination of tamping, taping and vibrating is performed to pack the dust in tightly. Once complete, the sensor hole is topped off with epoxy to seal all the components in place, and to prevent water vapour from simply entering the sensor through the top.

Cables for both the M.C. sensor and the temperature/RH data logger are routed out of a hole in the vessel (and sealed airtight with sealant). Conditions can be monitored in real-time without disrupting the measurement (Figure 48). As before, each clay brick is placed inside the sealed vessel, above the super saturated salt solution. The two cables exiting the sealed vessel are for a U10 temperature/RH and a SMT Moisture Content sensor, are connected to a PC computer and a SMT data logger, respectively. 


\section{RESULTS AND DISCUSSION}

\subsection{PHOTO-DOCUMENTING ELEVATIONS OF THE TEST HOUSE}

Visual documentation and Giga Pixel imagery are the stitched-together work of many individual photos, taken approximately $0.75 \mathrm{~m}$ from the wall of the house. In order for many of these photos to be taken, the camera was placed against the neighbouring houses as the shutter was snapped. Taking a single overall picture of the east and west elevations was not possible, as these neighbouring buildings are in the way.

\subsubsection{EAST ELEVATION}
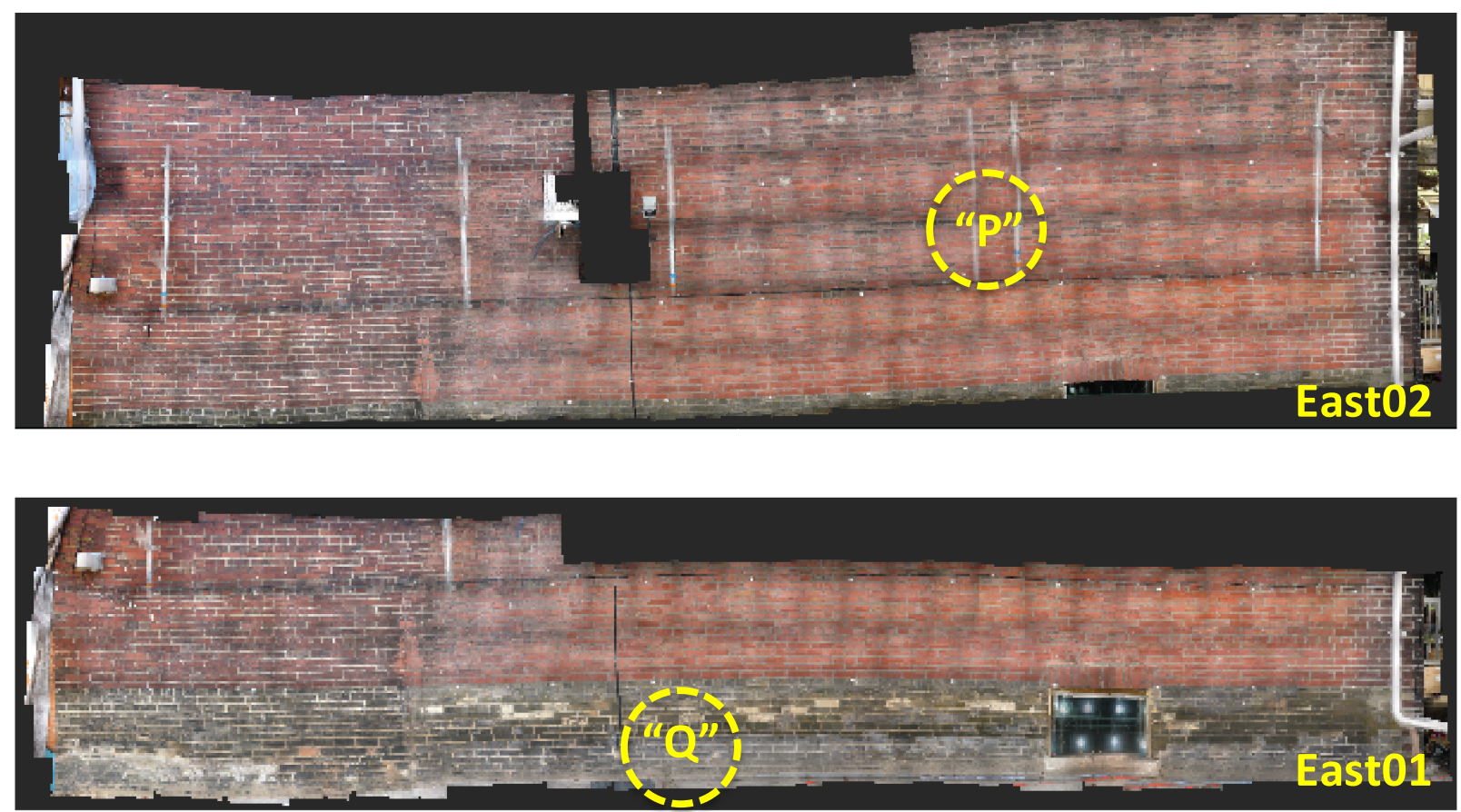

Figure 49: East elevation gigapixel images. Note Sensor locations “P” and “Q” at this elevation. 
The east wall was divided into two gigapixel images, as the size and similarity of all the individual photos which make up these gigapixel images were pushing the limits of the software. In Figure 49, the upper photo is the upper portion of the wall, and the lower photo is the lower portion of the wall where it meets grade. Note the the grey vertical lines in the upper portion of the image: these are the uprights of the scafolding that were caught in the perifery of the individual photos before stitching. The void area in the centre of image "East02" is the location of the wall mounted air conditioning condenser; because it was not along the same plane as the brick faces, the paralax prevented the images being stitched together in this area. The siding of the third storey addition are directly above image "East02." All high-resolution imagry are available for download at the website for the toronto test house. In an internet browser, go to: http://renovation2050.wix.com/renovation2050\# and navigate to the "Brick Study" section of the website. With the high resolution gigapixel imagry from the website, images can be zoomed in upon to reveal the sand-like texture of the clay brick units and mortar joints.

These photographs reveal quite interesting weathering characteristics. The left third of the images (south end) shows the bricks are dirty and the mortar joints are weathered. This portion of the wall does not have a neighboring building directly adjacent. Conversly, the right two-thirds of the photos (north end) show the bricks appearing almost "salmon" in colour, and are not weathered to the extent of the south end. This north portion of the east elevation has been partially sheltered by the neighboring house which is less that $1 \mathrm{~m}$ away. Also the eaves of the two houses providing considerable shelter from the elements in this area as they overlap in along their length. Sensor location "P" is essentially in the centre of this protected area of wall. The visual reviewed condition of the wall at this location generally reflects the 
measurements recorded by the moisture content senors at this location. The wall is able to dry, especially at the exterior surface.

The entire length of brick wall at grade appears damp, and is exhibiting some signs of deterioration, with the brick unit faces spawling at a few locations in a line approximately $1 \mathrm{~m}$ above grade. The foundaton brick is beige, and changes to red brick approximately $0.5 \mathrm{~m}$ above grade. However this interface is not easily visible, due to years of dampness in this zone, which has caused years of soil and pollution to stick to the area. Moisture from below grade is wicking up through the foundation wall, and is drying at the brick masonry surface above grade. There are a dozen or so bricks at the top of this band on the east elevation which have spalled faces. Because the spall is isolated to this high moisture band, the damage could be a result of ground salt and minerals being drawn through foundation wall, which cause the bricks to spawl as the minerals deposit beneath the brick surface as the moisture dries. The sensors at location " $Q$ " were installed in this damp region in the centre of the east wall, and confirm damp conditions, particularly in the interior wythe of the of brick masonry wall. This topics is discussed further in the Moisture Content sensor results in section 6.2.1 Sensor Data Labels and Definitions. 


\subsubsection{NORTH ELEVATION}

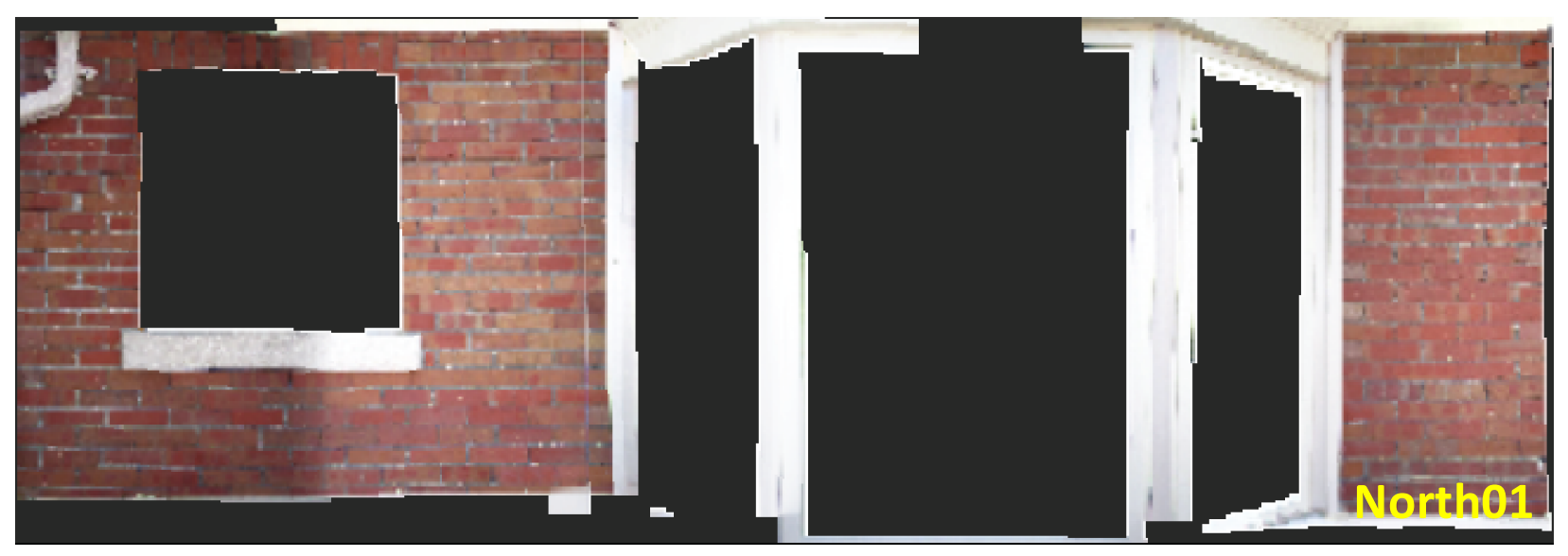

FigURE 50: NORTH ELEVATION KEY MAP.

The north elevation is only photo journaled at the second storey above the veranda roof. The windows have been digitally masked out in order to help the software stitch the individual photos together. Clay brick masonry at the first storey of the north elevation were obscured by porch furniture and were not included in the gigapixel portion of this paper. The brick at the north elevation, especially where it is covered and protected, is very dry. Sensor location " $R$ " is located in the first storey wall near the centre of the porch, and confirms this is a wall with a relatively low mositure content with respect to the other locations around the house. 


\subsubsection{WEST ELEVATION}
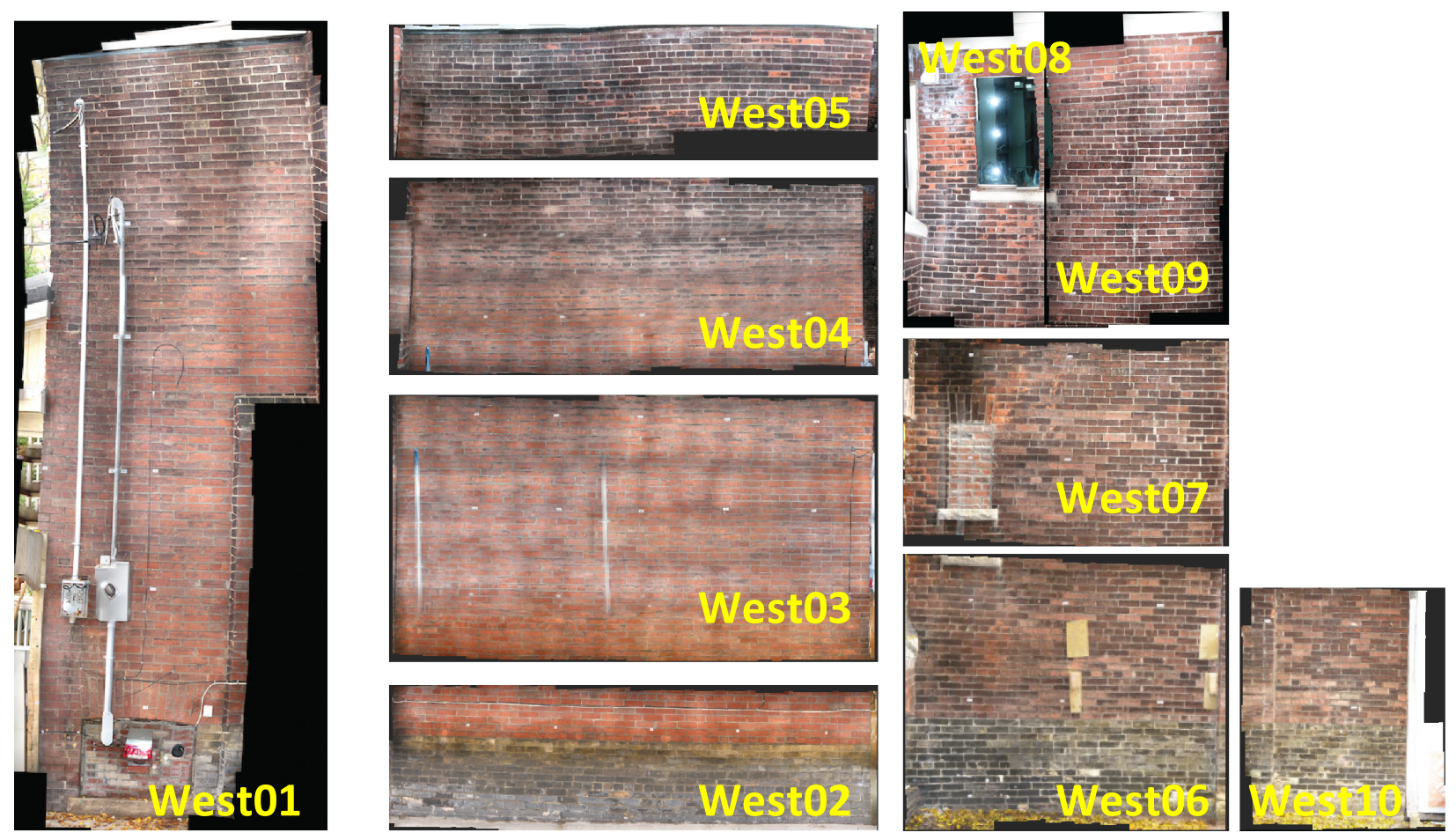

FIGURE 51: WEST ELEVATION KEY MAP.

The west elevation was visually reviewed and photo journaled with gigapixel imagery, however sensors were not installed at this elevation. The wall is very damp, and in image "West02" in Figure 51, a green line of algae growth is visible. The south end of the building steps back away from the neighboring building ("West08" to "West10" in Figure 51) and the brick shows a more weathered appearance, as it is less protected from the elements; this same phenomenon occured on the east elevation as the west. 


\subsubsection{SOUTH ELEVATION}

The south elevation has very little exposed brick: an addition to the south end of the house at the first floor covers all the original exposed brick at this level. The second storey has some of the original brick exposed, however this portion of wall is primarily window fenestration; there is not enough brick area for the photo-stitching software to successfully match enough converging pixels within the images to make a successful rendering. The brick at the second storey south elevation are therefore best shown with a few full regular camera images. The third storey at this south end of the house is new; this upper addition is clad with clapboards and has no exposed brick.

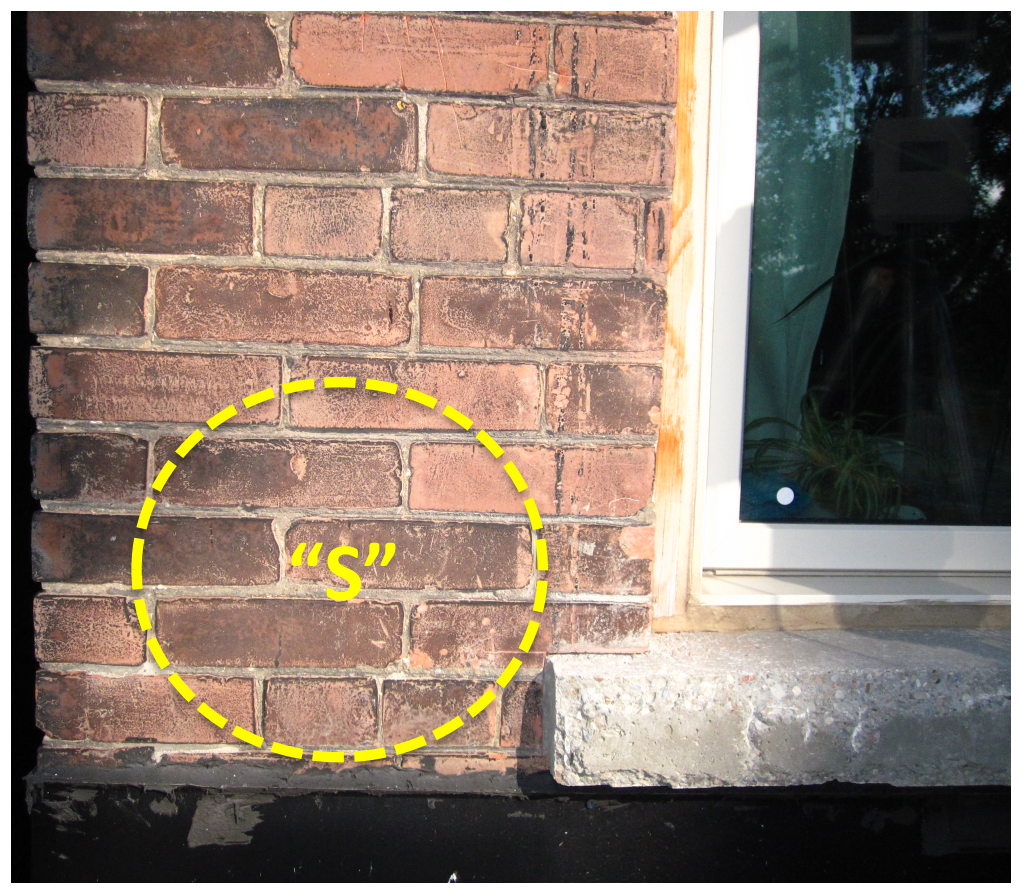

FigURE 52: WEST CORNER OF SOUTH ELEVATION - LOCATION OF SENSOR INSTALLATION "S". 


\subsubsection{ALL PHOTO STITCH WORK}

Stitching the photographs together into larger images for this particular application is not a simple task. Given the state of current photo-stitching technology available, the process of merging high-resolution photographs is extremely time consuming and involves continuously coaxing the software into producing the desired outcome. The problem is that this type of application is not well suited to the software, which was likely never intended for this purpose. The software is designed for stitching together panoramic photographs of scenes differing in colours, textures, and also with photos taken from a single camera position. For this project, the image stitching software was used to stitch together hundreds images, which all essentially looked the same. They all shared the same pattern (brick and mortar joints) but with every photo containing subtle differences in colour, shades and texture. Also, the photos were taken in a linear fashion by moving the camera along a plane. Since the software looks for similar points between the different images, the software would often erroneously identify control points that did not actually exist between photographs. It would link together individual photographs that it thought were portions of the same position on the elevation, but in fact were not. The result was a mosaic of photos that were not stitched together in linear fashion the software had a tendency to attempt to bend the photographs in a sort of 4-dimensional nonsensical assembly. A great deal of manual control-point editing was required to create these large images.

In the end, it was possible to create the large giga-pixel images of areas of the elevations. The benefits of this approach are evident as discussed in the above Sections and could serve as an excellent method to provide visual reference for exterior cladding in the future, however, 
currently the effort required to do so is substantial considering current technology and this method should be evaluated on a project specific basis. 


\subsection{WALL ENVELOPE SENSOR MEASUREMENTS}

\subsubsection{SENSOR DATA - LABELS AND DEFINITIONS}

Listed in this section are representative samples of the data collected from various sensors installed within the building envelope at various depths, and 4 different locations at the Toronto test house. (The complete measurement sets of graphs for the winter of 2012/2013 are included in "Appendix B - Sensors Measurements."

All temperature measurements have been grouped together, as have all relative humidity measurements, and wood surrogate moisture content measurements. Additional weather data from an onsite weather station has also been included and aligned with the temperature, $\mathrm{RH}$, and moisture content data. In the interests of simplifying the charts, the time scale (x-axis) is located on the bottom-most chart on each page. The time reference is continuous for the charts on each page; all charts on a given page have been aligned with respect to time and date. A variety of contrasting graph colours were chosen to help distinguish the trend lines from one another. It should be noted that the colour scheme was randomly chosen, and lines on the same page with similar graph colours have no interconnection to other line colours.

Chart data label definitions:

T-Cavity,Onset $\left[{ }^{\circ} \mathrm{C}\right]:$ Temperature measurement from an Onset S-THB-M002 Temperature/RH Smart Sensor installed in the cavity space between the drywall and the polyurethane foam insulation. Measurements are in degrees Celsius; the graduated scale is on the left side of the chart. 
T-InsulCtr,Onset $\left[{ }^{\circ} \mathrm{C}\right]$ : Temperature measurement from an Onset S-THB-M002

Temperature/RH Smart Sensor installed in the centre of the polyurethane insulation

Measurements are in degrees Celsius; the graduated scale is on the left side of the chart.

T-InsulBrick,Onset $\left[{ }^{\circ} \mathrm{C}\right]:$ Temperature measurement from an Onset S-THB-M002

Temperature/RH Smart Sensor installed against the interior side of clay brick masonry wall, behind the insulation. Measurements are in degrees Celsius; the graduated scale is on the left side of the chart.

T-BrickCtr,Onset $\left[{ }^{\circ} \mathrm{C}\right]$ : Temperature measurement from an Onset S-THB-M002

Temperature/RH Smart Sensor installed at the centre of the clay brick wall approximately at the collar joint between the two withes of clay brick masonry wall. Measurements are in degrees Celsius; the graduated scale is on the left side of the chart.

T-Exterior,Onset $\left[{ }^{\circ} \mathrm{C}\right]$ : Temperature measurement from an Onset U10-003 Temperature/RH Data Logger installed on the exterior side of the clay brick masonry wall. Measurements are in degrees Celsius; the graduated scale is on the left side of the chart.

T-OuterWythe,SMT [ ${ }^{\circ}$ C]: Temperature measurement from an SMT Research EMS-011-030-01 Embedded Moisture/Temperature Sensor installed vertically inside the exterior clay brick unit near the exposed face of the clay brick. Measurements are in degrees Celsius; the graduated scale is on the left side of the chart.

T-InnerWythe,SMT [ ${ }^{\circ}$ C]: Temperature measurement from an SMT Research EMS-011-030-01 Embedded Moisture/Temperature Sensor installed horizontally inside the interior clay brick unit into the collar-joint face of the clay brick. Measurements are in degrees Celsius; the graduated scale is on the left side of the chart. 
T-Collar,SMT [ $\left.{ }^{\circ} \mathrm{C}\right]$ : Temperature measurement from an SMT Research EMS-011-030-01

Embedded Moisture/Temperature Sensor installed horizontally inside the interior clay brick unit into a void in the collar-joint between the two withes of the clay brick. Measurements are in degrees Celsius; the graduated scale is on the left side of the chart. Note: This data was not available at the beginning of the measurement period so is not on some charts.

RH-Cavity,Onset [\%]: Relative Humidity measurement from an Onset S-THB-M002 Temperature/RH Smart Sensor installed in the cavity space between the drywall and the polyurethane foam insulation. Measurements are in \% $\mathrm{RH}$; the graduated scale is on the left side of the chart.

RH-InsulCtr,Onset [\%]: Relative Humidity measurement from an Onset S-THB-M002 Temperature/RH Smart Sensor installed in the centre of the polyurethane insulation Measurements are in \% RH; the graduated scale is on the left side of the chart.

RH-InsulBrick,Onset [\%]: Relative Humidity measurement from an Onset S-THB-M002 Temperature/RH Smart Sensor installed against the interior side of clay brick masonry wall, behind the insulation. Measurements are in \% RH; the graduated scale is on the left side of the chart.

RH-BrickCtr,Onset [\%]: Relative Humidity measurement from an Onset S-THB-M002 Temperature/RH Smart Sensor installed at the centre of the clay brick wall approximately at the collar joint between the two withes of clay brick masonry wall. Measurements are in \% RH; the graduated scale is on the left side of the chart.

RH-Exterior,Onset [\%]: Relative Humidity measurement from an Onset U10-003

Temperature/RH Data Logger installed on the exterior side of the clay brick masonry wall. Measurements are in \% RH; the graduated scale is on the left side of the chart. 
MC-OuterWythe,SMT [\%]: Moisture Content measurement from an SMT Research EMS-011030-01 Embedded Moisture/Temperature Sensor installed vertically inside the exterior clay brick unit near the exposed face of the clay brick. Measurements are in \% MC; the graduated scale is on the left side of the chart.

MC-InnerWythe,SMT [\%]: Moisture Content measurement from an SMT Research EMS-011030-01 Embedded Moisture/Temperature Sensor installed horizontally inside the interior clay brick unit into the collar-joint face of the clay brick. Measurements are in \% MC; the graduated scale is on the left side of the chart.

MC-Collar,SMT [\%]: Moisture Content measurement from an SMT Research EMS-011-030-01 Embedded Moisture/Temperature Sensor installed horizontally inside the interior clay brick unit into a void in the collar-joint between the two withes of the clay brick. Measurements are in \% MC; the graduated scale is on the left side of the chart. Note: This data was not available at the beginning of the measurement period so is not on some charts.

Solar Rad-Roof [W/ $\left./ m^{\wedge} 2\right]$ : Solar radiation measured from an Onset rooftop weather station system model U30-NRC-SYS-B (Onset Computer Corporation, 2014c). Measurements are in Watts/square metre; the graduated scale is on the left side of the chart. Note the graduated scale for this chart is dynamic, and changes according to solar intensity.

Rain-Roof [mm]: Rain fall is measured from an Onset rooftop weather station system model U30-NRC-SYS-B (Onset Computer Corporation, 2014c). Measurements are in mm; the graduated scale is on the left side of the chart. Note the graduated scale for this chart is dynamic, and changes according to rainfall intensity. 


\section{Moisture Content Sensor Measurements}

At four locations around the house, the moisture content sensors are positioned at three depths within the brick masonry portion of the envelope: one is in the exterior wythe, the second is at the collar joint, and the third at each location is in the interior wythe of brick. The measurement trend lines are generally stratified and follow each other. When compared to the exterior wythe moisture content measurements, there is generally a delay in the collar joint measurement, and even more of a delay of the interior wythe measurement. This is a result of the time it takes for moisture to travel through the pores of the brick masonry envelope after a rain event. The sensor measurements show that the moisture content sensor in the exterior wythe can respond to moisture from a rain even in only a few hours (Refer to Figure 53). But for the interior wythe Moisture Content Sensor, it can take several days to respond and the reaction is less severe (Refer to MC measurements in Figure 53, Figure 54, Figure 55 and Figure 56). This demonstrates the time it takes for moisture to transfer from the exterior face of the clay brick by way of capillary suction. What is unknown is the additional time it takes for the moisture to travel from the brick to the Moisture Content sensor by way of vapour diffusion. However, because the wooden Moisture Content sensors are at least in partial contact with the boreholes in which they have been inserted, and the then tightly packed with brick dust, at least a partial path for moisture to travel to the sensors by way of capillary suction exists. Note that the exterior RH measurement reached a ceiling of approximate $92 \%$ for two days (Refer to Figure 53). This is most likely caused by a wind blown rain/snow event, with water coming into contact with the surface-mounted sensor on the east elevation. The 92\% RH measured by the instrument is the maximum it measures, and the length of the plateau indicates that it was wet for several days. 


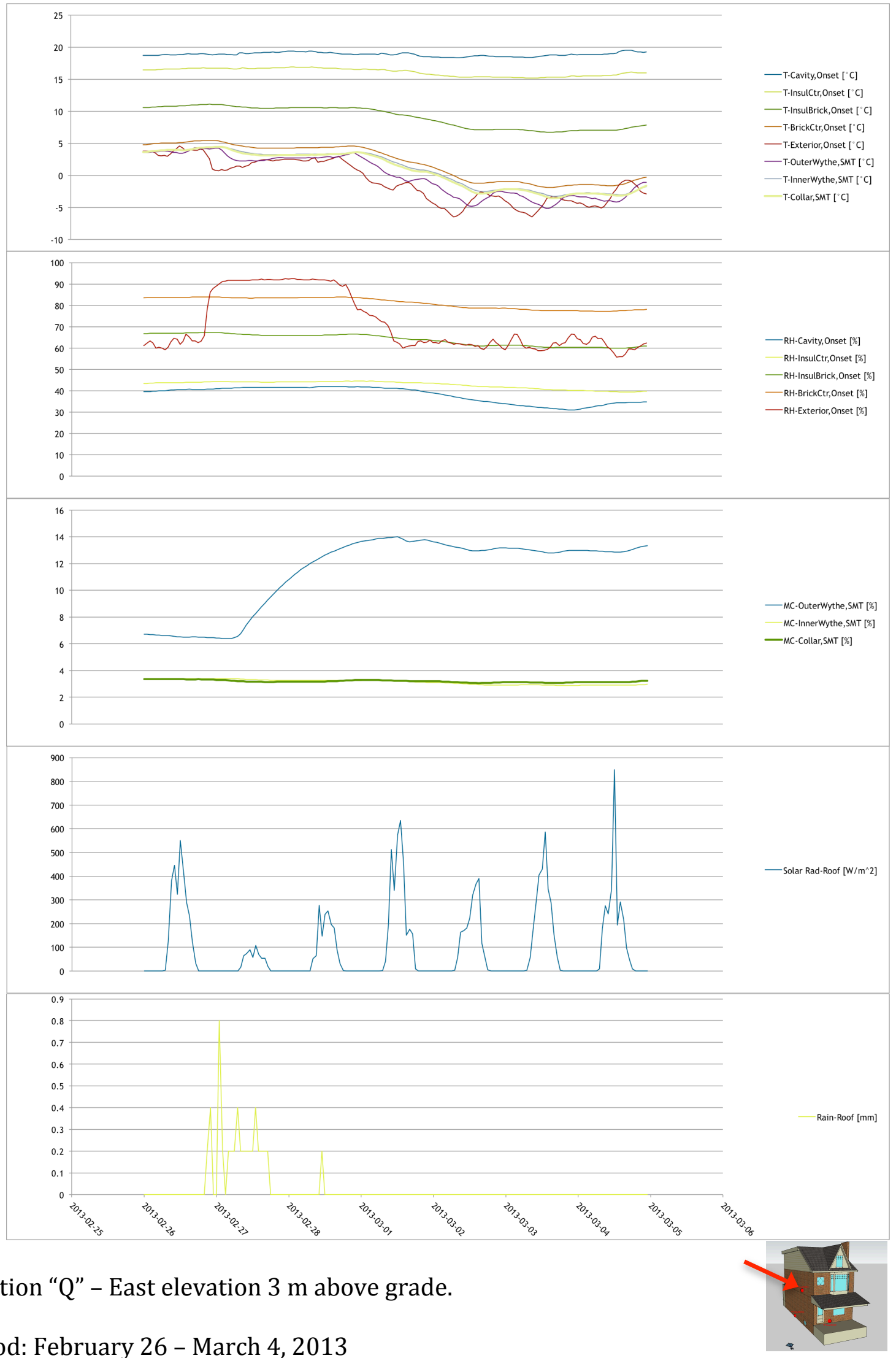

Period: February 26 - March 4, 2013

Figure 53: Sensor Measurements from location "Q" - East elevation 3 m above grade. February 26 - March 4, 2013. 


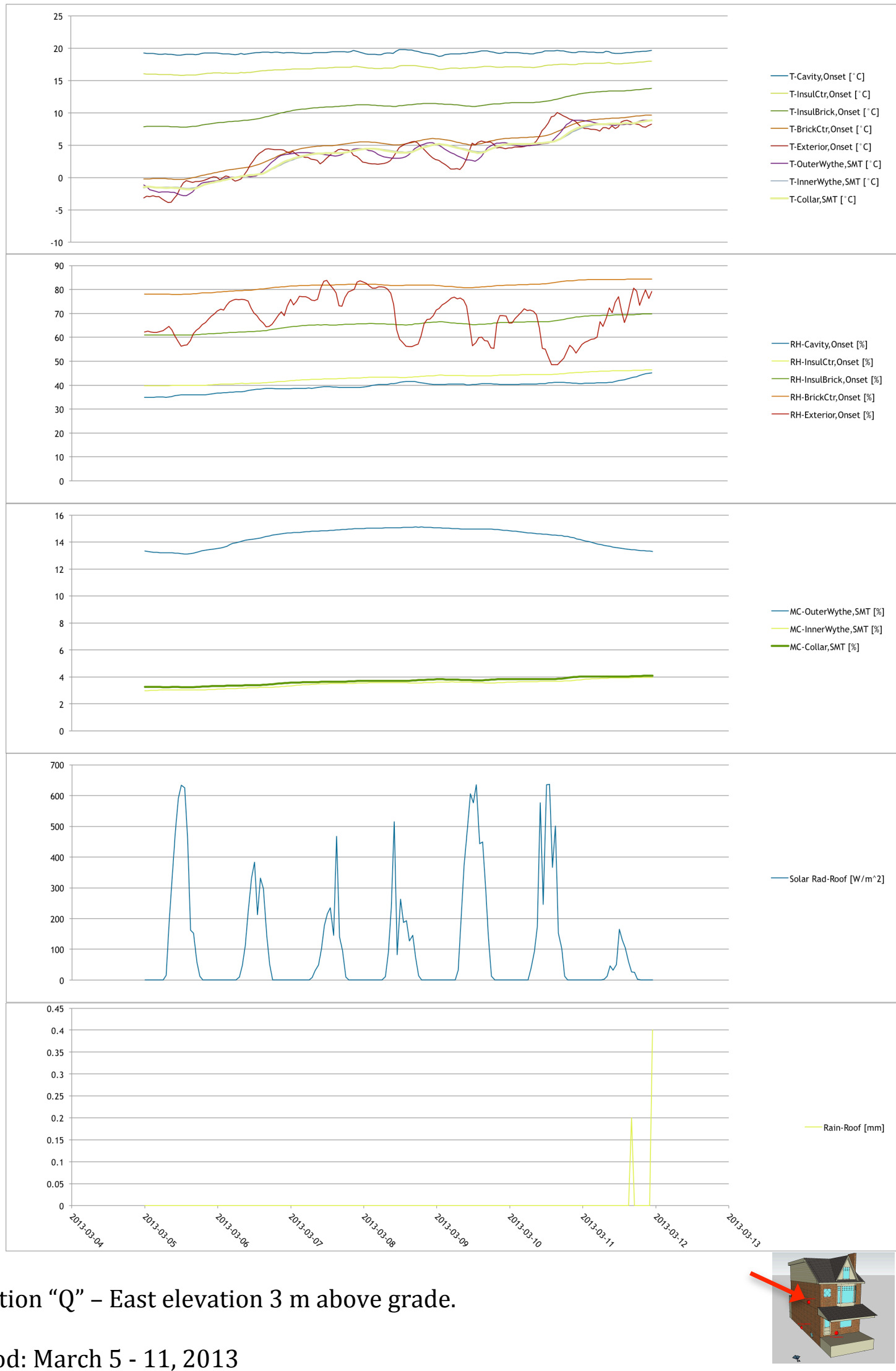

Period: March 5 - 11, 2013

Figure 54: Sensor Measurements from location "Q" - East elevation 3 m above grade. March 5 - 11, 2013. 


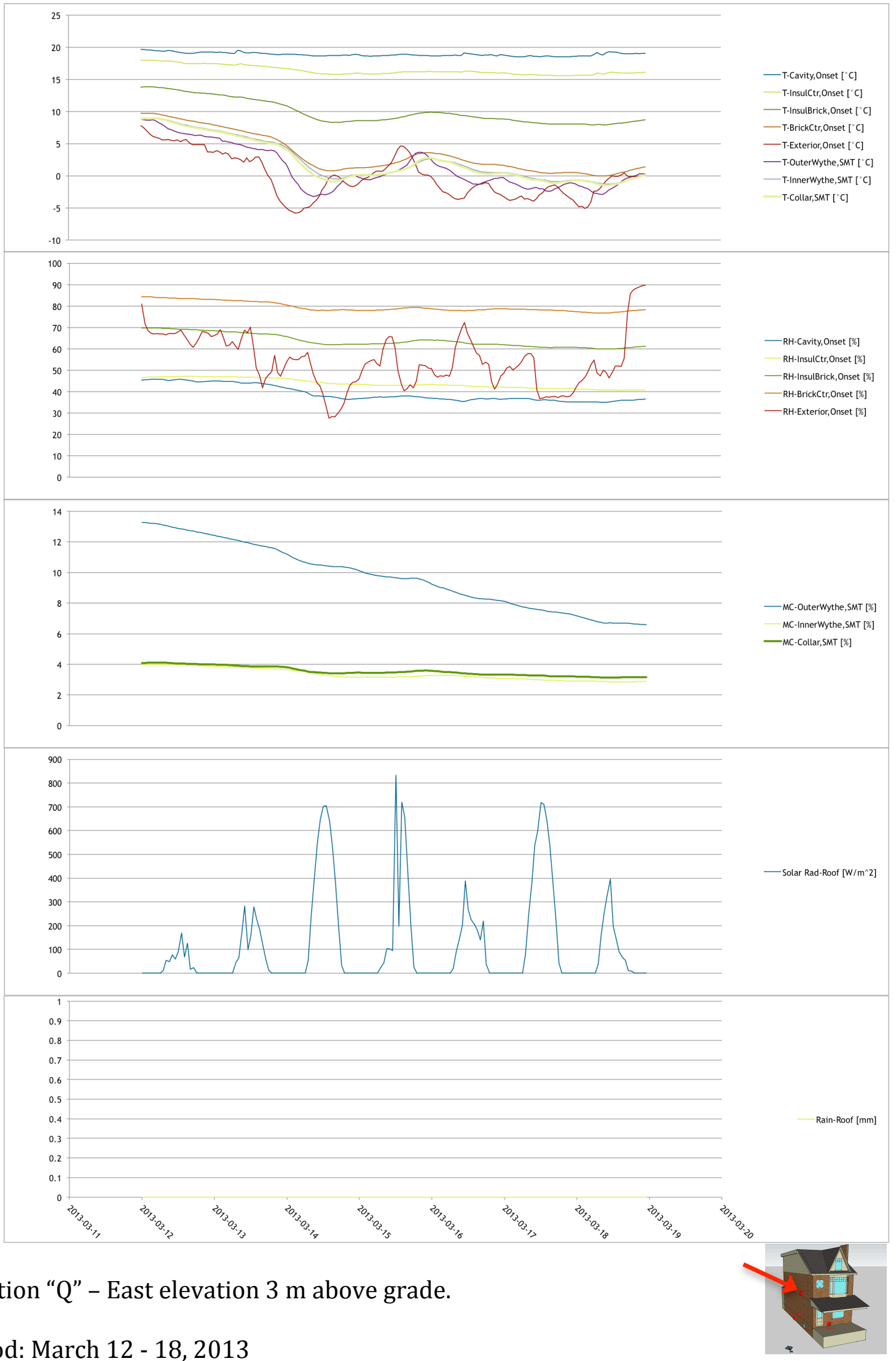

Period: March 12 - 18, 2013

Figure 55: Sensor Measurements from location "Q" - East elevation 3 m above grade. March 12 - 18, 2013. 


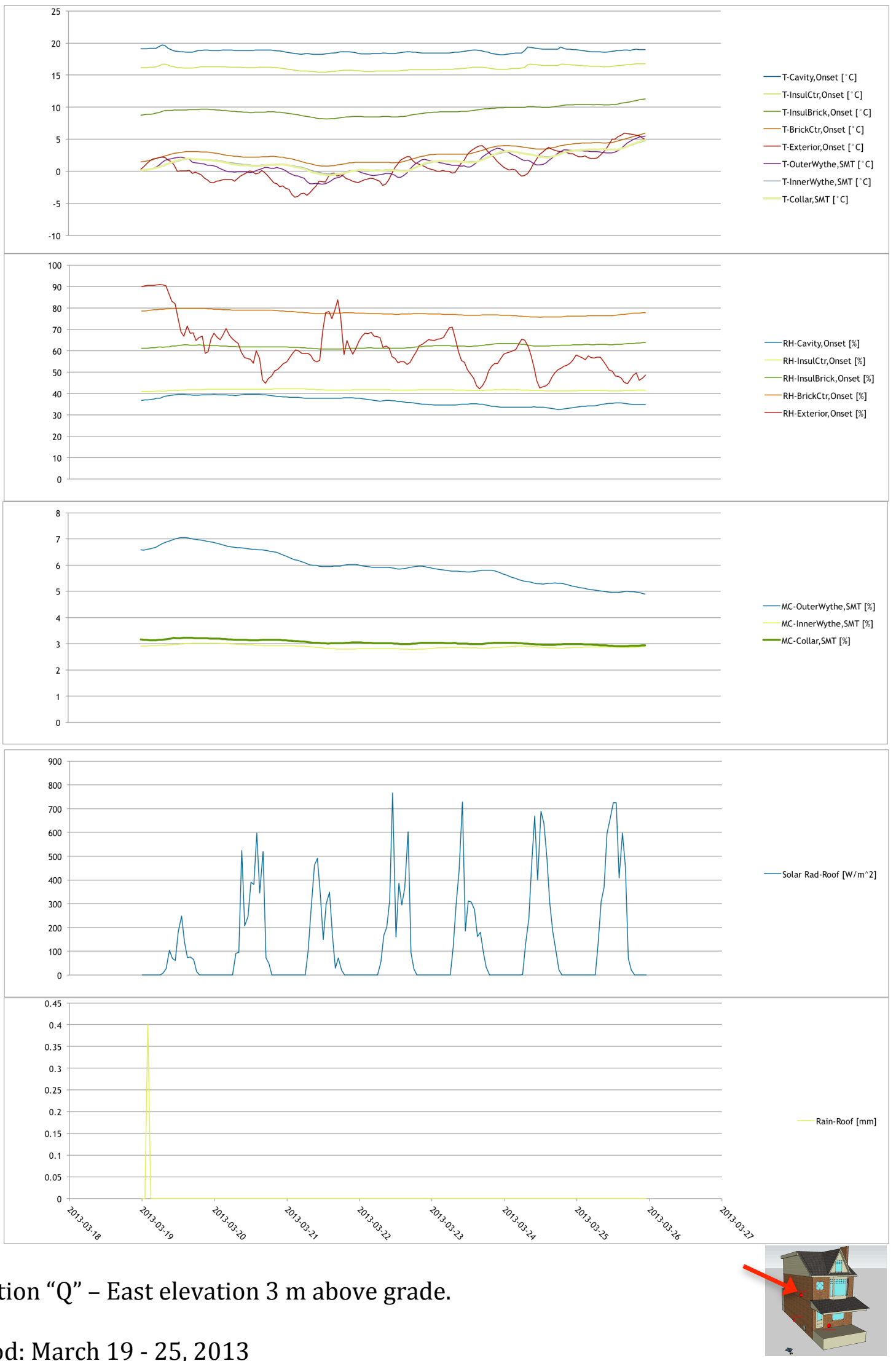

Period: March 19 - 25, 2013

Figure 56: Sensor Measurements from location "Q" - East elevation 3 m above grade. March 19 - 25, 2013. 
Locations " $\mathrm{P}$ " and " $\mathrm{Q}$ " are both installed on the east wall, but measure very different moisture characteristics in the brick (Refer to Figure 57 and Figure 58). The moisture content sensors at location "P" are installed in the clay brick just above grade, and reveal that the inner clay brick wythe has significantly greater moisture content than the outer wythe. When comparing all the sensor locations, the outer wythe of brick generally contains a higher moisture content than the inner wythe (Refer to Figure 58, Figure 59 and Figure 60). This can be seen in the plots for sensor locations " $Q$," "R," and "S." 


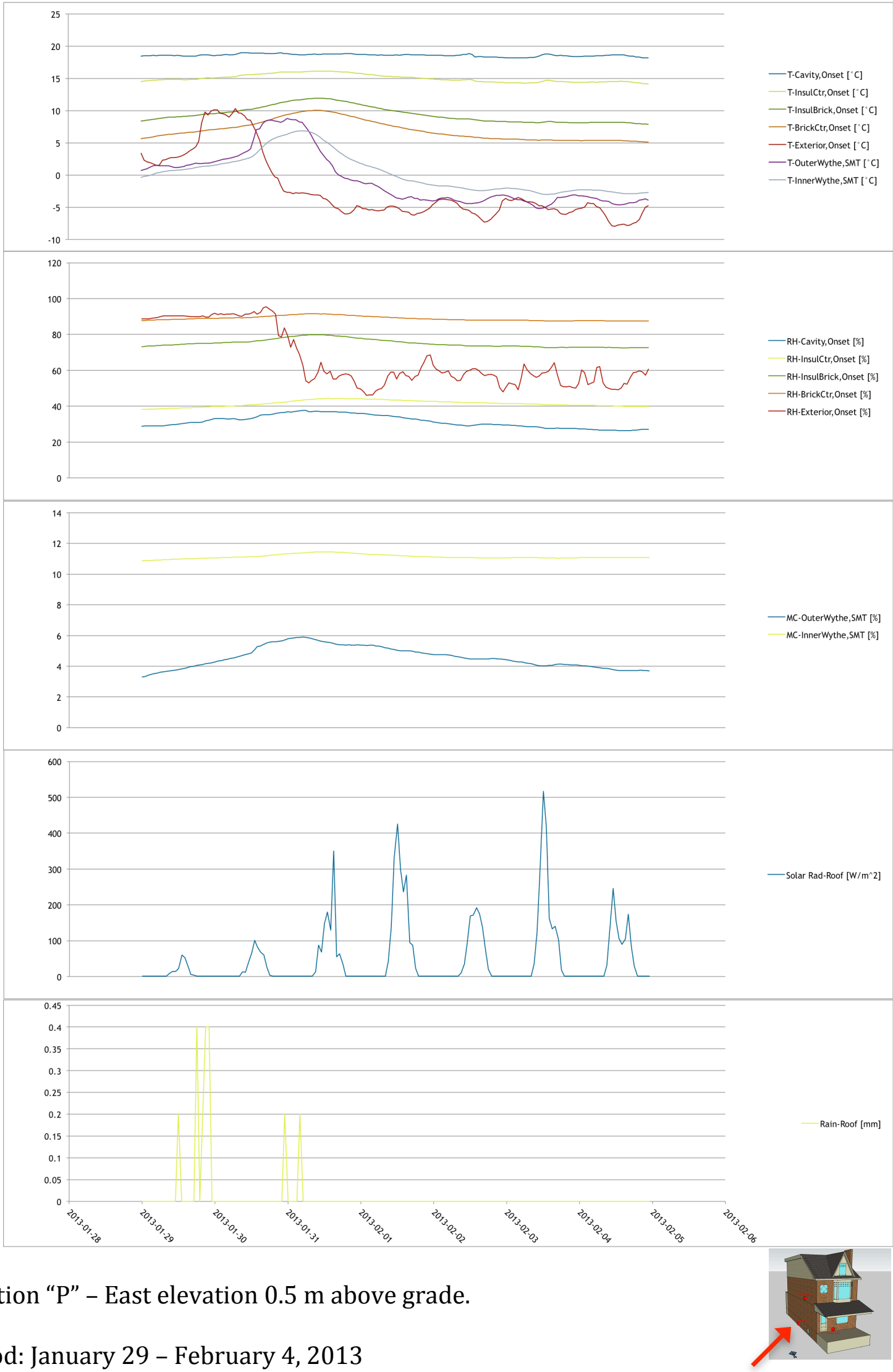

Period: January 29 - February 4, 2013

Figure 57: Sensor Measurements from location "P" - East elevation 0.5 m above grade. January 29 - February 4, 2013. 


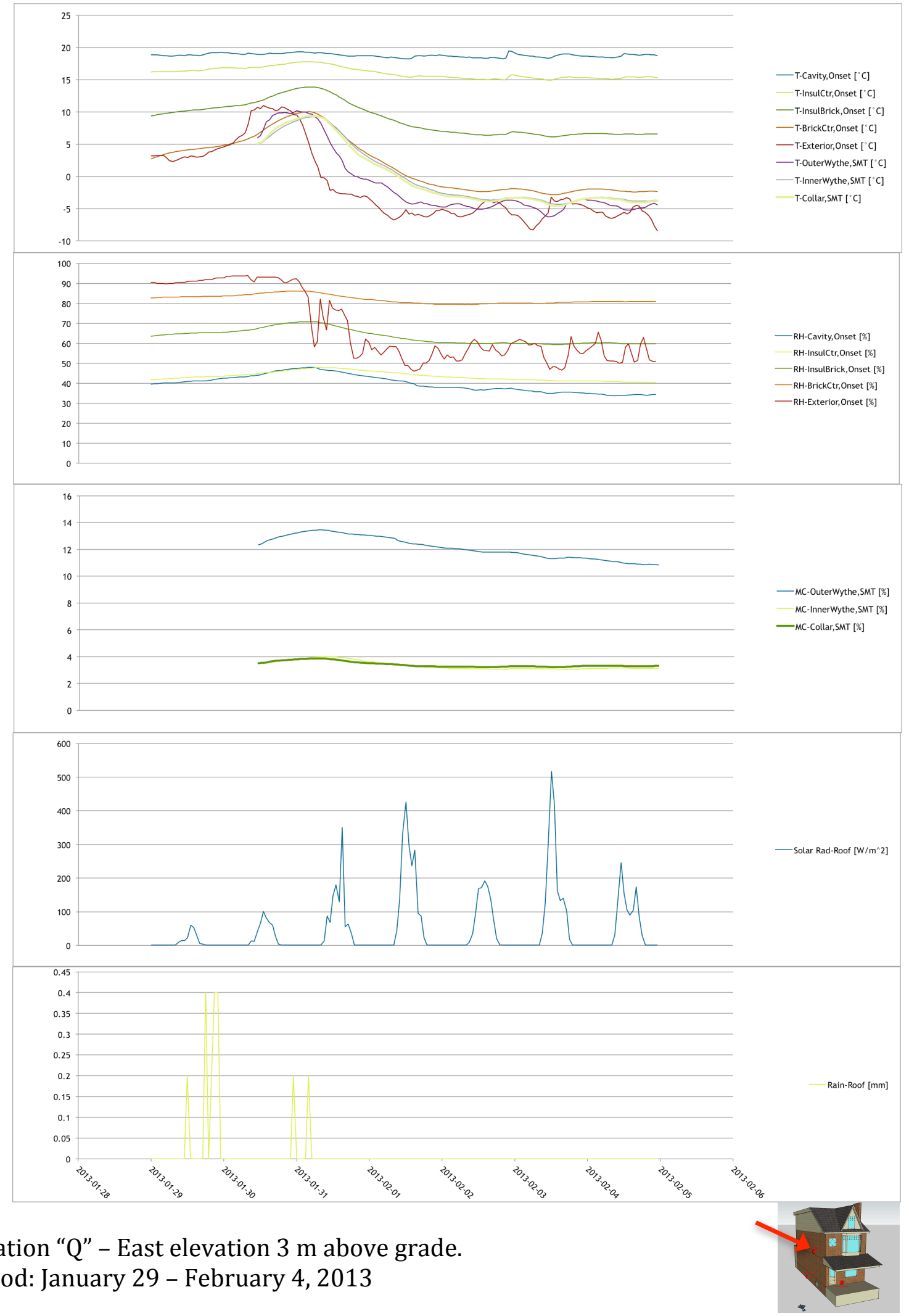

Figure 58: Sensor Measurements from location "Q" - East elevation 3 m above grade. January 29 - February 4, 2013. 


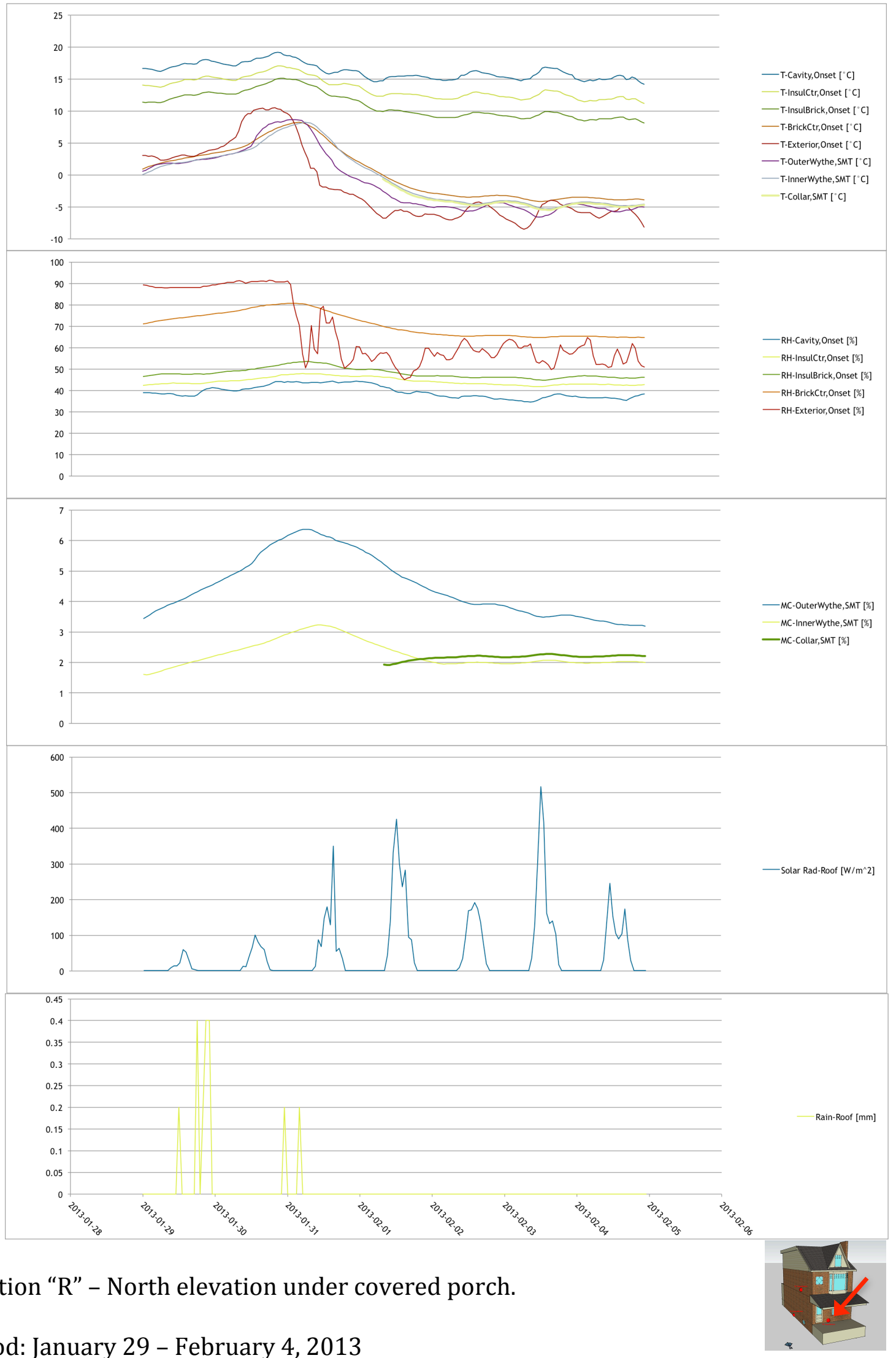

Period: January 29 - February 4, 2013

Figure 59: Sensor Measurements from location "R" - North elevation at porch. January 29 - February 4, 2013. 


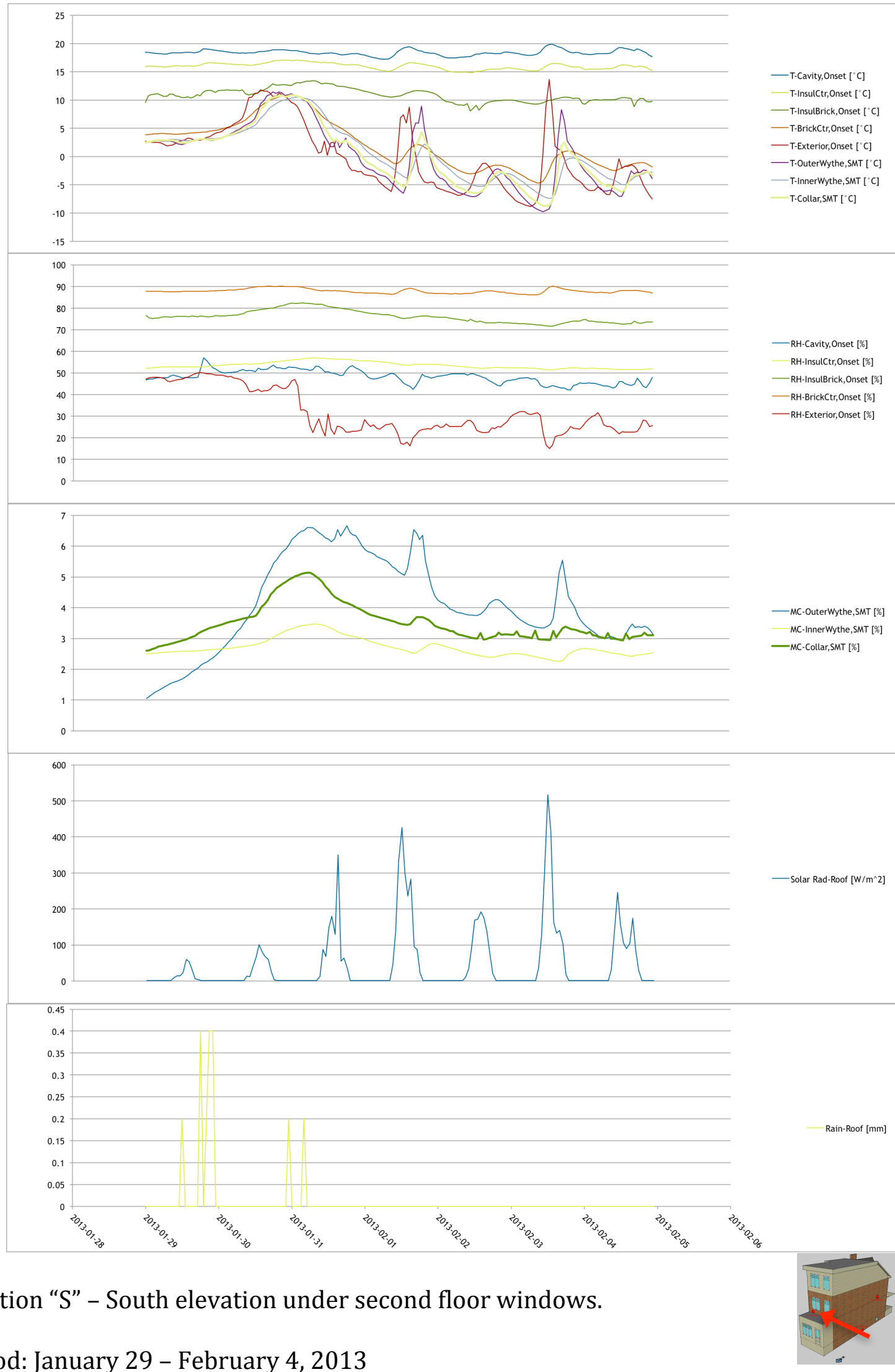

Period: January 29 - February 4, 2013

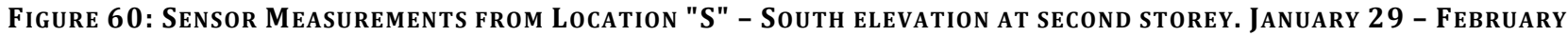
4, 2013. 
Moisture content measurements at the east wall reveal very different measurements depending on the height of the sensors (Refer to Figure 57 and Figure 58). A possible explanation for the greater moisture content measurement at the low-positioned interior wythe sensor is that ground moisture could wicking up through the foundation wall. Reviewing the gigapixel image of the east elevation (from section 6.1.1 East Elevation) shows the wall is visibly darker from moisture along its entire length. Because the outer wythe is exposed to air, it is able to dry more so than the interior wythe. The corridor on the east side of the Toronto test house has a slight negative slope toward the house; during rain events, water is promoted to flow toward the foundation wall. Given this high level of moisture in the brick masonry wall near grade, it can become a critical location when adding insulation to the interior. The amount of any insulation should be judiciously placed so not to decrease the drying potential of the clay brick masonry along the grade of the building, and also deter the brick along the grade from freezing in the winter. Alternatively, the home Owner should consider re-sloping the concrete walk way to direct water away from the brick at the wall's base.

It should be noted that not all rain events are alike. The direction of the wind was not included with the precipitation graph, but it can have a significant impact on the amount of moisture the wall is absorbs. A heavy rain event may not deposit much moisture on an exterior wall if there is little wind, however a light rain may soak a wall if the wind is coming from the right direction. Figure 61 shows this situation occurring at the Toronto test house. A heavy rain event causes a spike in the precipitation measurement, while causing the moisture content to climb to approximately 6\% M.C. before the trend plateaus. A subsequent smaller rain event 
causes the moisture content to increase significantly, likely as a result of wind load, before the trend plateaus around 15\% M.C. 


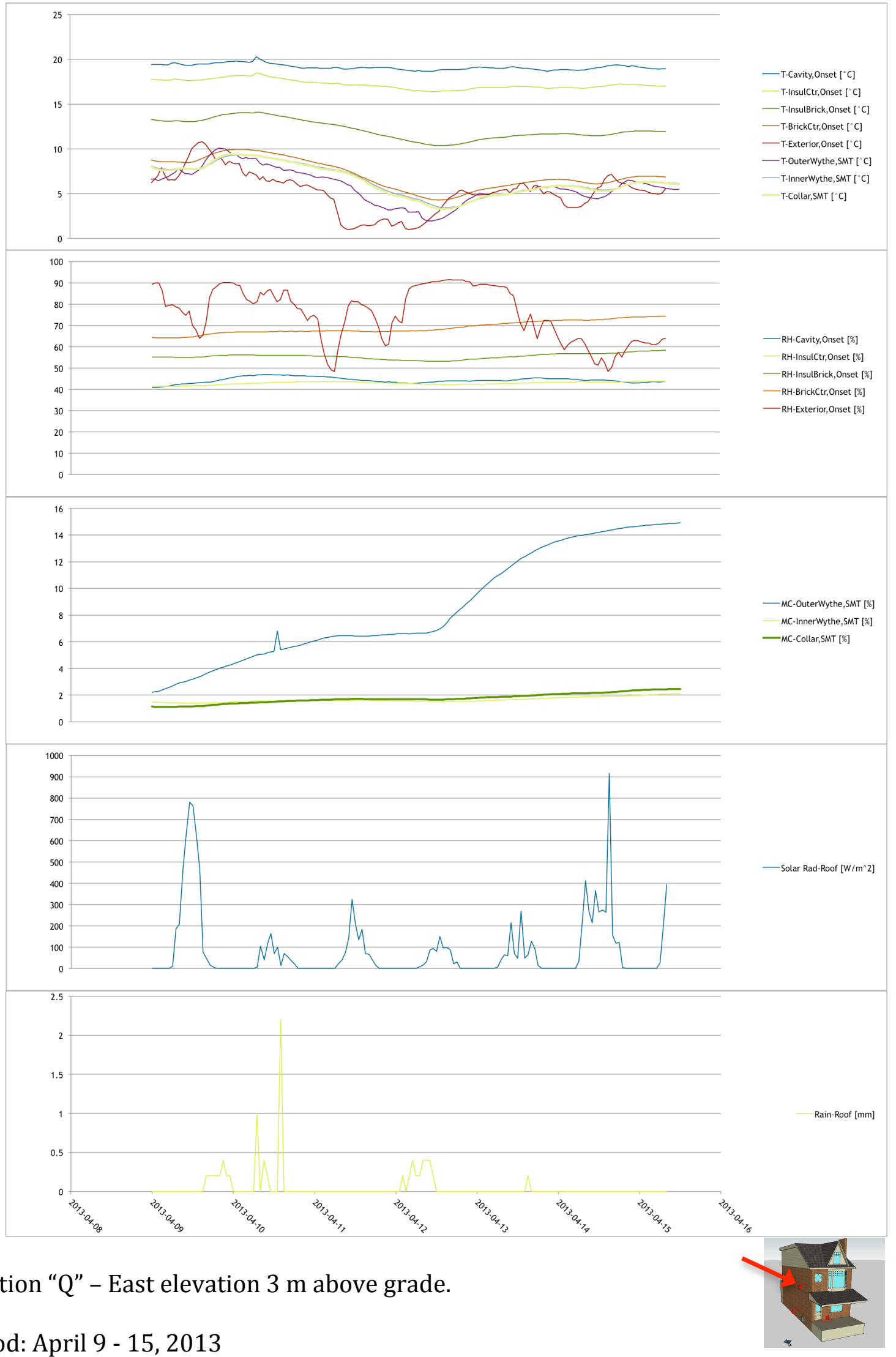

Period: April 9 - 15, 2013

Figure 61: Sensor Measurements from location "Q" - East elevation 3 m above grade. April 9 - 15, 2013. 


\section{$\underline{\text { Freeze-Thaw Cycles }}$}

Cycles of freeze-thaw were tallied from data measured by the exterior wall temperature/RH sensors, and the temperature component of the moisture content sensors installed within both wythes of brick masonry. Table 4 summarises the measurements recorded over one winter. Technical issues with the instrumentation prevented some temperature measurements at the East wall sensor location, 3 metres above grade, however the temperature conditions at the east wall are very close to those of the East wall at the 0.5 metre high sensor position, as shown in Table 4. The south elevation reveals the most number of freeze-thaw cycles by far, logging approximately 51 cycles in the exterior wythe of brick masonry between December 11 and April 15. The greatest number of freeze-thaw cycles on the south elevation is to be expected: daily solar heat gains can thaw out the wall during daylight and between passing storms and clouds. The additional cycles observed on the south elevation (compared to the east and west elevations) quantify the increase attributed to solar exposure. At night or when the sun is not heating the brick surfaces of the walls can dip below the freezing point. 
TABLE 4: FREEZE-THAW CYCLES MEASURED OVER ONE WINTER (2012/2013):

\begin{tabular}{|c|c|c|c|c|c|c|c|c|c|c|c|c|}
\hline \multicolumn{13}{|c|}{ Count of Complete Freeze-Thaw Cycles by location* } \\
\hline \multirow[b]{2}{*}{ Period } & \multicolumn{3}{|c|}{ East Wall, $0.5 \mathrm{~m}$ above grade } & \multicolumn{3}{|c|}{ East Wall, $3 \mathrm{~m}$ above grade } & \multicolumn{3}{|c|}{ North Wall, under porch roof } & \multicolumn{3}{|c|}{ South Wall, 2nd floor } \\
\hline & $\mathbf{P}_{\text {Outdoor }}$ & $\mathbf{P}_{\text {Ext. Wythe }}$ & $\mathbf{P}_{\text {Int. Wythe }}$ & $\mathbf{Q}_{\text {outdoor }}$ & $\mathbf{Q}_{\text {Ext. Wythe }}$ & $\mathbf{Q}_{\text {Int. Wythe }}$ & $\mathbf{R}_{\text {Outdoor }}$ & $\mathbf{R}_{\text {Ext. Wythe }}$ & $\mathbf{R}_{\text {Int. Wythe }}$ & $\mathbf{S}_{\text {Outdoor }}$ & $\mathbf{S}_{\text {Ext. Wythe }}$ & $\mathbf{S}_{\text {Int. Wythe }}$ \\
\hline Dec 11-17 & - & - & - & - & - & - & 1 & 1 & 0 & 2 & 3 & 0 \\
\hline Dec 18-24 & 1 & 0 & 0 & - & - & - & 2 & 1 & 0 & 2 & 2 & 0 \\
\hline Dec 25-31 & - & 1 & 1 & - & - & - & - & 1 & 1 & - & 4 & 1 \\
\hline Jan 1-7 & - & 2 & 1 & - & - & - & - & 2 & 1 & - & 5 & 4 \\
\hline Jan 8-14 & 0 & 0 & 0 & - & - & - & 0 & 0 & 0 & 0 & 1 & 0 \\
\hline $\operatorname{Jan} 15-21$ & 1 & 1 & 1 & - & - & - & 2 & 1 & 1 & 4 & 5 & 2 \\
\hline Jan 22-28 & 1 & 1 & 0 & - & - & - & 1 & 1 & 1 & 4 & 3 & 2 \\
\hline Jan 29-Feb 4 & 0 & 0 & 1 & 0 & 0 & 0 & 0 & 0 & 0 & 2 & 2 & 1 \\
\hline Feb 5-11 & 1 & 1 & 1 & 1 & 1 & 1 & 1 & 1 & 1 & 5 & 4 & 4 \\
\hline Feb 12-18 & 2 & 0 & 0 & 1 & 0 & 0 & 1 & 0 & 0 & 3 & 3 & 3 \\
\hline Feb 19-25 & 2 & 2 & 2 & 1 & 2 & 2 & 2 & 2 & 2 & 3 & 3 & 2 \\
\hline Feb 26-Mar 4 & 0 & 0 & 0 & 0 & 0 & 0 & 0 & 0 & 0 & 4 & 3 & 3 \\
\hline Mar 5-11 & 3 & 1 & 1 & 1 & 1 & 1 & 1 & 1 & 1 & 2 & 1 & 1 \\
\hline Mar 12-18 & 3 & 2 & 1 & 2 & 2 & 2 & 2 & 2 & 1 & 5 & 4 & 2 \\
\hline Mar 19-25 & 2 & 2 & 0 & 2 & 2 & 1 & 2 & 2 & 2 & 5 & 5 & 2 \\
\hline Mar 26-Apr 1 & 5 & 3 & 1 & 0 & 0 & 0 & 0 & 0 & 0 & 0 & 0 & 0 \\
\hline Apr 2-8 & 2 & 1 & 0 & 1 & 1 & 0 & 4 & 2 & 0 & 4 & 3 & 0 \\
\hline Apr 9-15 & 0 & 0 & 0 & 0 & 0 & 0 & 0 & 0 & 0 & 0 & 0 & 0 \\
\hline TOTALS: & 23 & 17 & 10 & & & & 19 & 17 & 11 & 45 & 51 & 27 \\
\hline
\end{tabular}

In the city of Toronto, north elevations are not exposed to solar radiation in the winter. There are no solar heat gains on the north elevation of the Toronto test house in the winter.

(Toronto's city survey is not aligned with true north; inspecting any map reveals the city plan is rotated almost $15^{\circ}$ counter-clockwise from true north. As a result, the "north" elevations of buildings in the city are slightly west facing, and can receive afternoon solar radiation during the height of summer.) At the east elevation where the sensors are positioned, the neighbouring house and the tunnel-like corridor also prevent much solar radiation from heating the brick masonry wall. Solar radiation only reaches the corridor for a brief period, and hits the wall at an acute angle. As a result there is very little heating of the majority of the east elevation from solar radiation. As a result, the totalled freeze-thaw cycles within the exterior wythes of brick on the north and east elevation are approximate the same at 17 cycles for each location in the winter of 2012/2013. 
Potential for freeze-thaw damage occurring at the Toronto test house is discussed further in the Frost Dilatometry results section 6.3.4 Discussion. 


\subsection{FROST DILATOMETRY RESULTS - GENERAL NOTES}

Plotted below are the results of the clay brick frost dilatometry data collected from a number of clay bricks that were extracted from the walls of the Toronto test house. Graphs are grouped by the clay brick specimens from which they were cut. Specimens were saturated to a percentage of their maximum moisture content, which was determined by a combination of vacuum saturation and boil method saturation. All clay brick specimens listed here were exposed to 9 freeze-thaw cycles and measured for expansion along two or three axes, depending on the specimen size.

The small clay brick specimens, approximately $100 \mathrm{~mm}$ x $63 \mathrm{~mm}$ x $10 \mathrm{~mm}$ were measured for dilatometry expansion along 2 dimensions. In the graphs below, the $100 \mathrm{~mm}$ dimension is labelled as "X-Axis." The $63 \mathrm{~mm}$ dimension is labelled as "Y-Axis." Expansion along the $10 \mathrm{~mm}$ thickness ("Z-Axis") of the specimen is not included in this paper, as expansion was too small to reliably measure with the equipment available.

Modern clay brick from Hanson Brick run as a comparison to the historic century clay brick, but could not be cut into specimens in the same manner because the modern clay brick units contain 3 larges cores instead of a frog. As a result, each clay brick could only yield 4 specimens to be analyzed for freeze-thaw expansion. Graphs grouped by clay brick each possessing four specimen data points do not warrant the insertion of a trend line. These graphs are included for comparison purposes only.

The larger $100 \mathrm{~mm}$ x $100 \mathrm{~mm}$ x $63 \mathrm{~mm}$ specimens were measured for frost dilatometry expansion across all three dimensions. Clay bricks were halved to yield 2 specimens. The "XAxis" measurements refer to the $100 \mathrm{~mm}$ dimension parallel to the frog (the width). The "Y- 
Axis" measurements refer to the $100 \mathrm{~mm}$ dimension perpendicular to the frog (the depth). The "Z-Axis" measurement refers to the $63 \mathrm{~mm}$ dimension of the clay brick (the height).

Below, graphs show all expansion measurement data points for bricks tested for frost dilatometry. Where data points may be within the $\mathrm{S}_{\text {crit }}$ realm (on the right side of each graph) a trend line has been added to help demonstrate the critical saturation point. The critical saturation point is close to where the trend line intercepts 0 Expansion on the Y-axis of the graph; it is an Microsoft Excel generated trend line based on the average slope of the data points in the $80 \%$ to $100 \%$ saturation region of the graphs. 


\subsubsection{PLOTTED RESULTS OF 2-DIMENSIONAL FROST DILATOMETRY}

All measured datapoints:

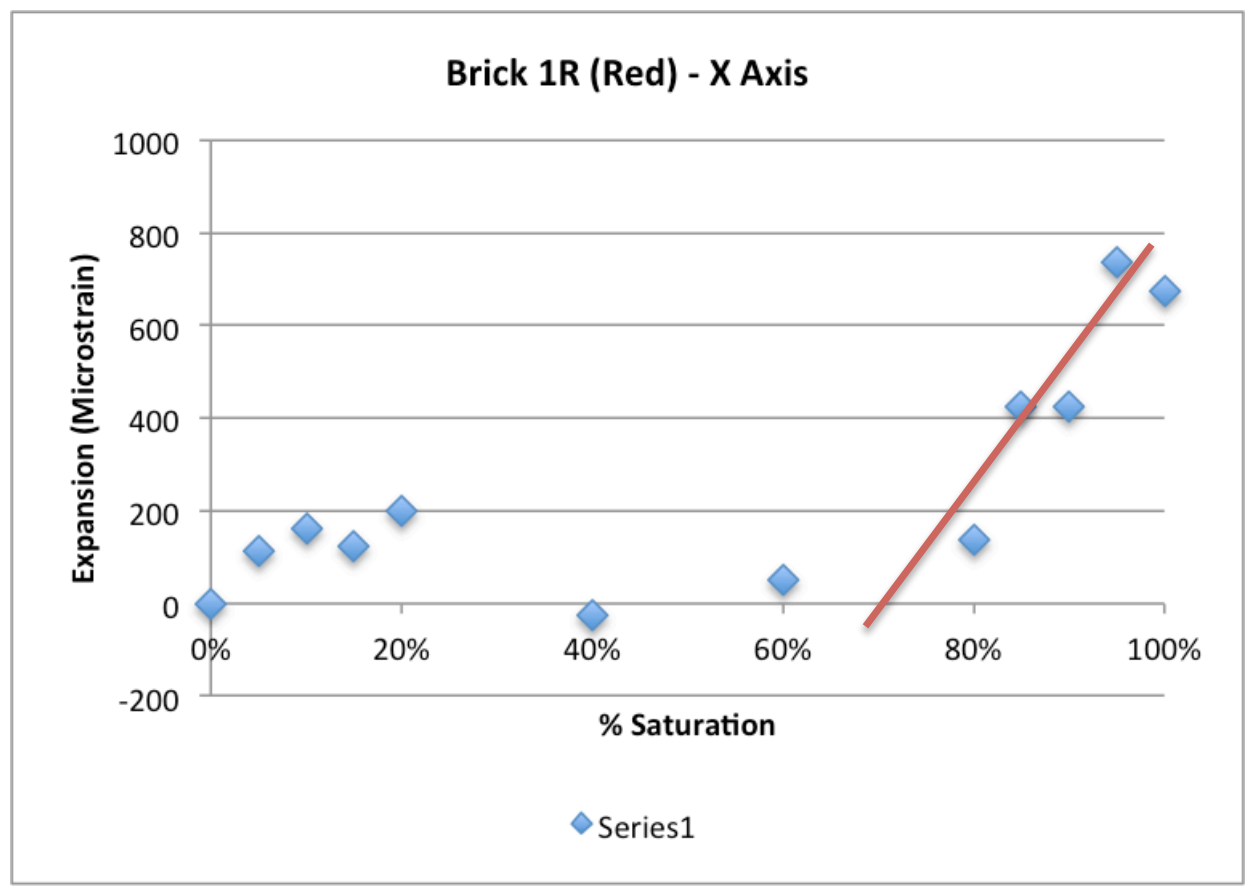

Figure 62: 2-Dimensional Frost Dilatometry results - Brick Specimen 1R - X Axis aVerage Scrit Measurements.

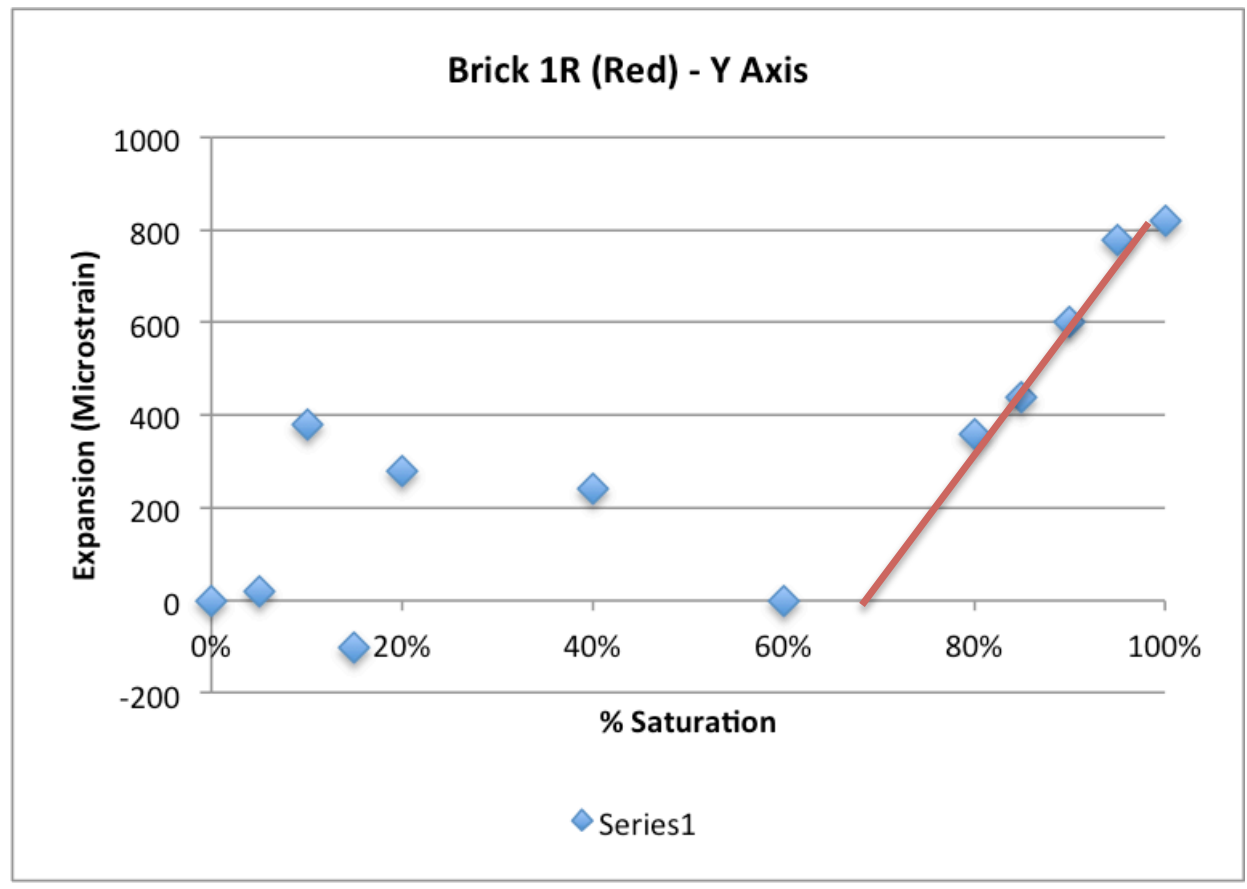

Figure 63: 2-Dimensional Frost Dilatometry results - Brick Specimen 1R - Y Axis aVerage Scrit Measurements. 
All measured datapoints:

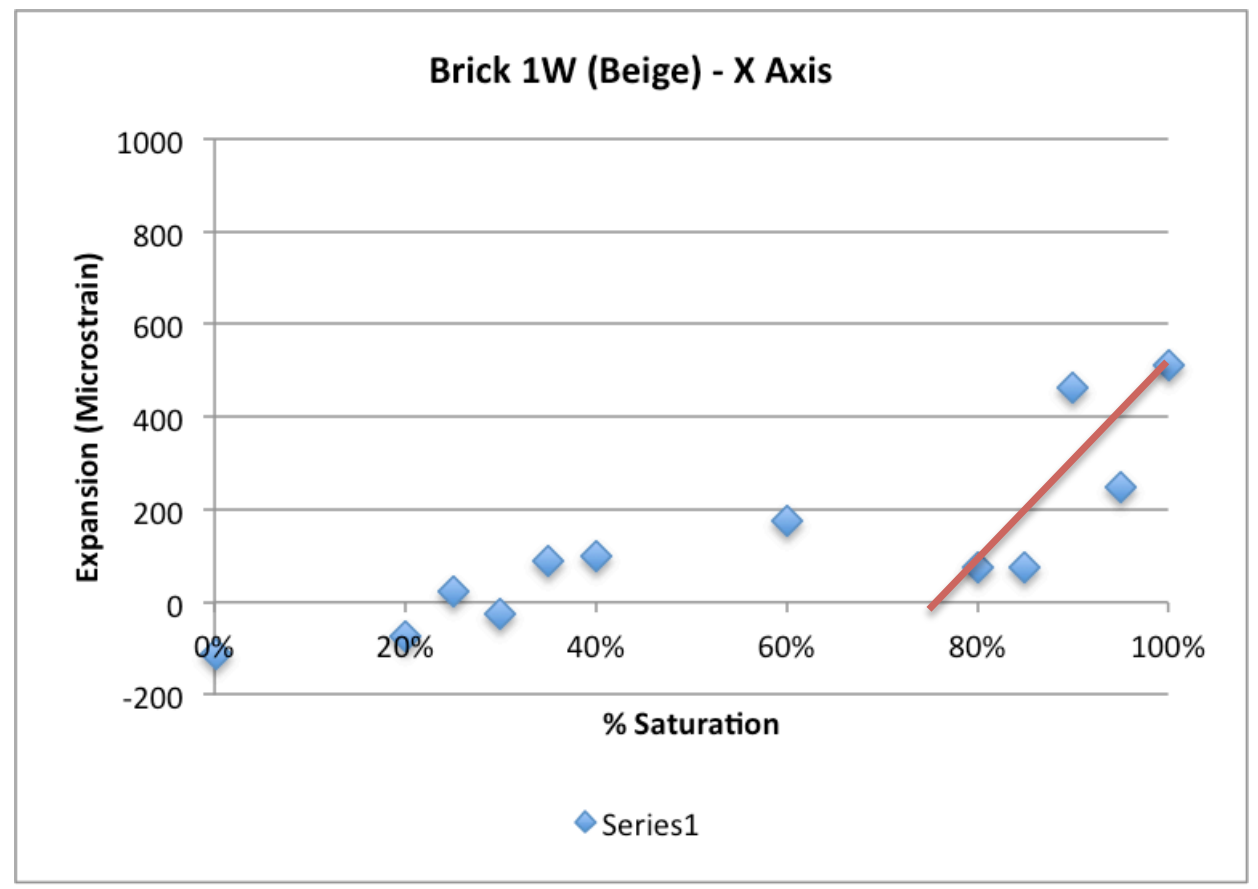

Figure 64: 2-Dimensional frost Dilatometry results - Brick Specimen 1 W - X Axis aVerage Scrit Measurements.

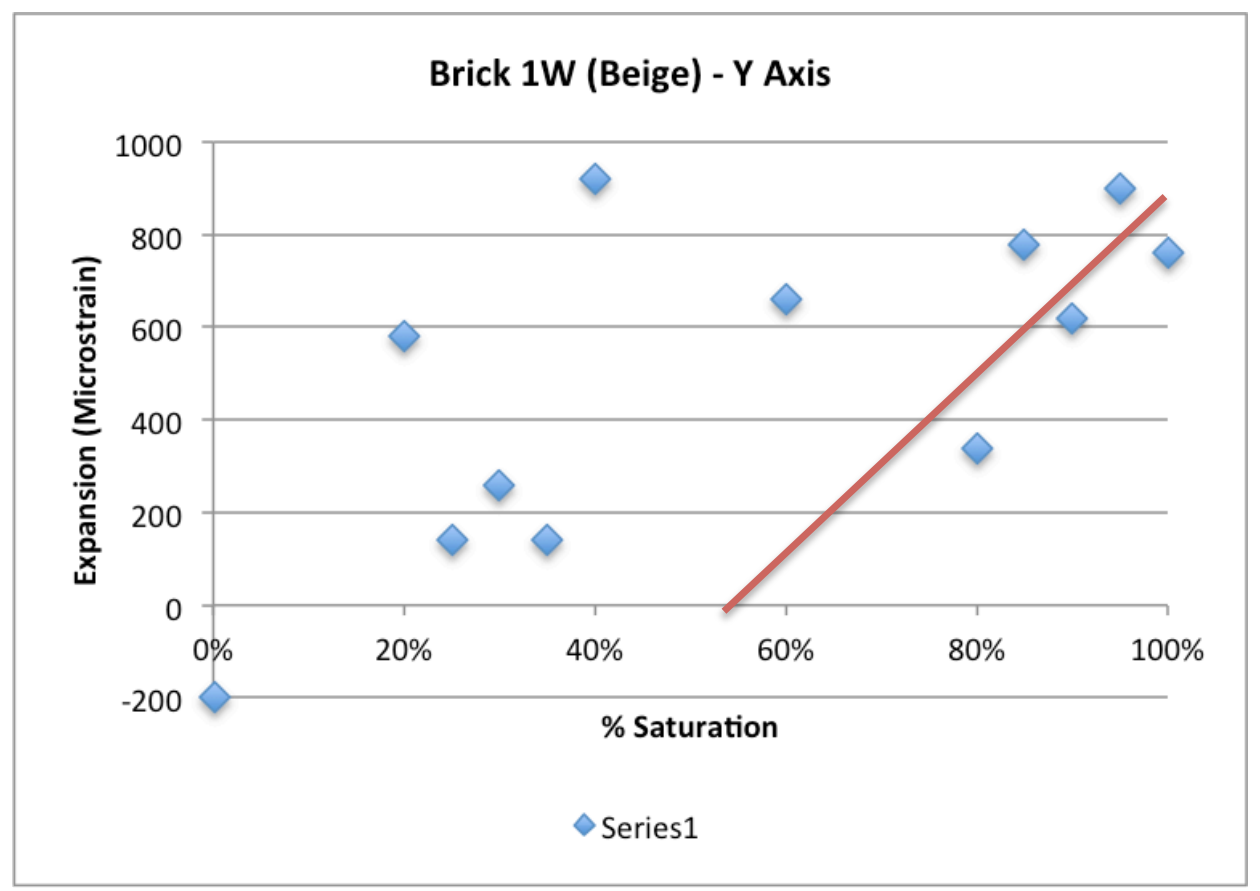

Figure 65: 2-Dimensional Frost Dilatometry results - Brick Specimen 1W - Y Axis aVerage Scrit Measurements. 
All measured datapoints:

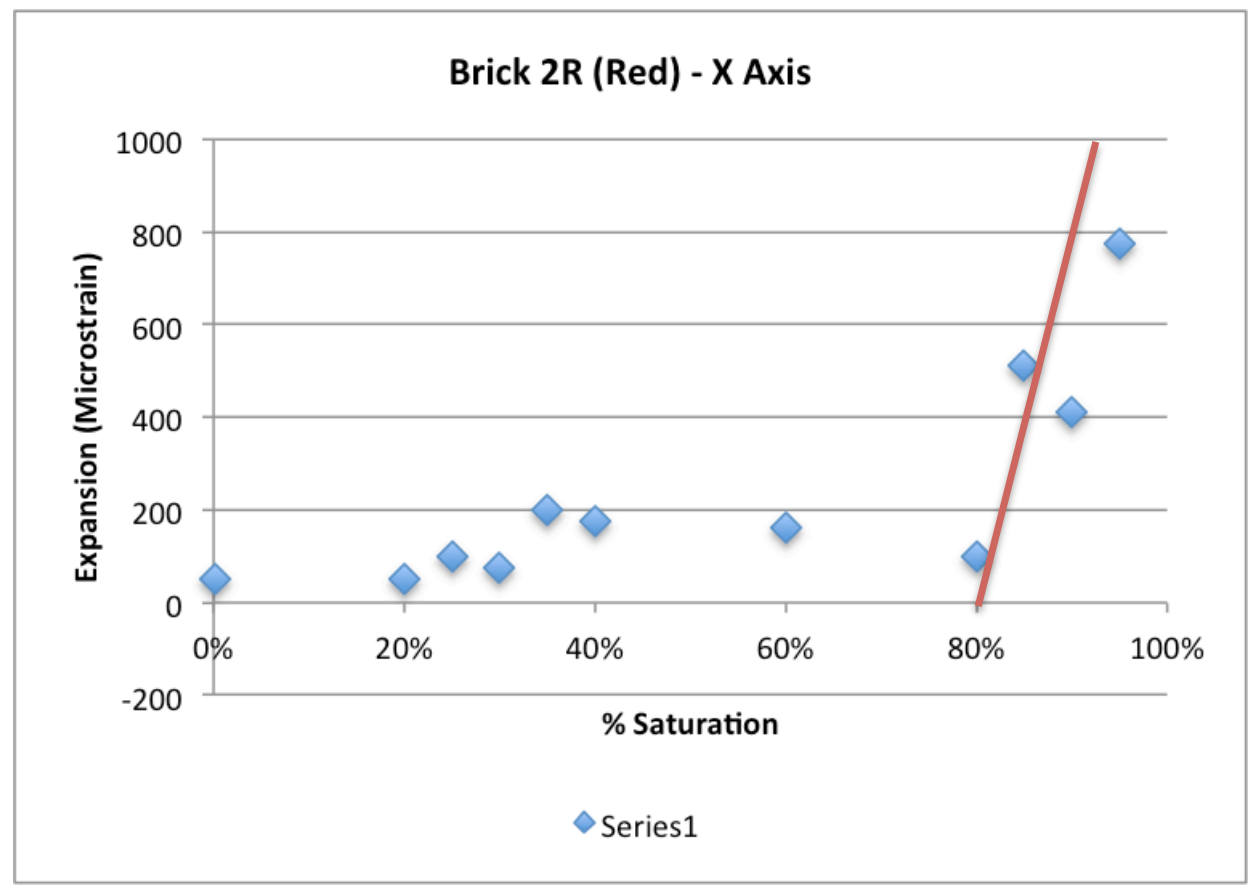

Figure 66: 2-Dimensional Frost Dilatometry results - Brick Specimen 2R - X Axis aVerage Scrit measurements.

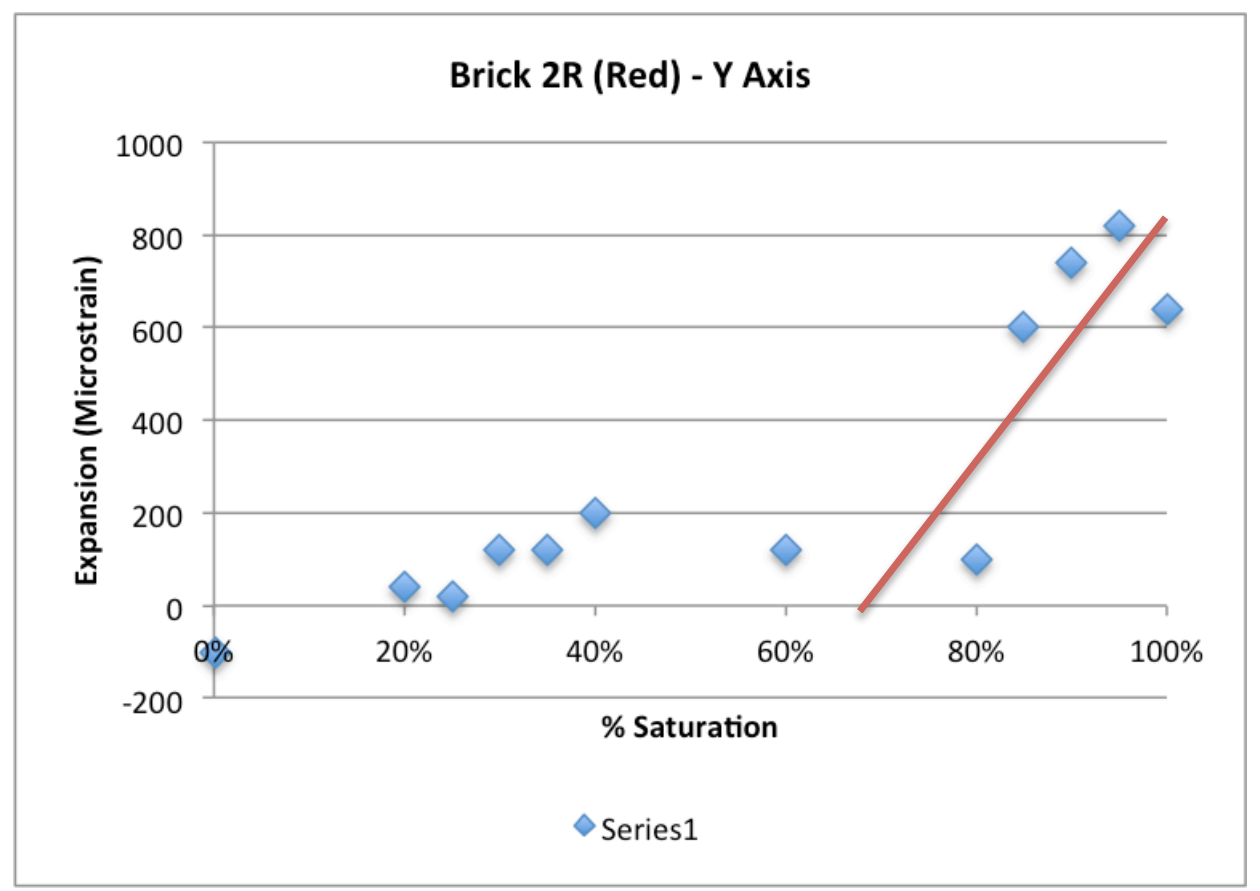

Figure 67: 2-Dimensional Frost Dilatometry Results - Brick Specimen 2R - Y Axis aVerage Scrit Measurements. 
All measured datapoints:

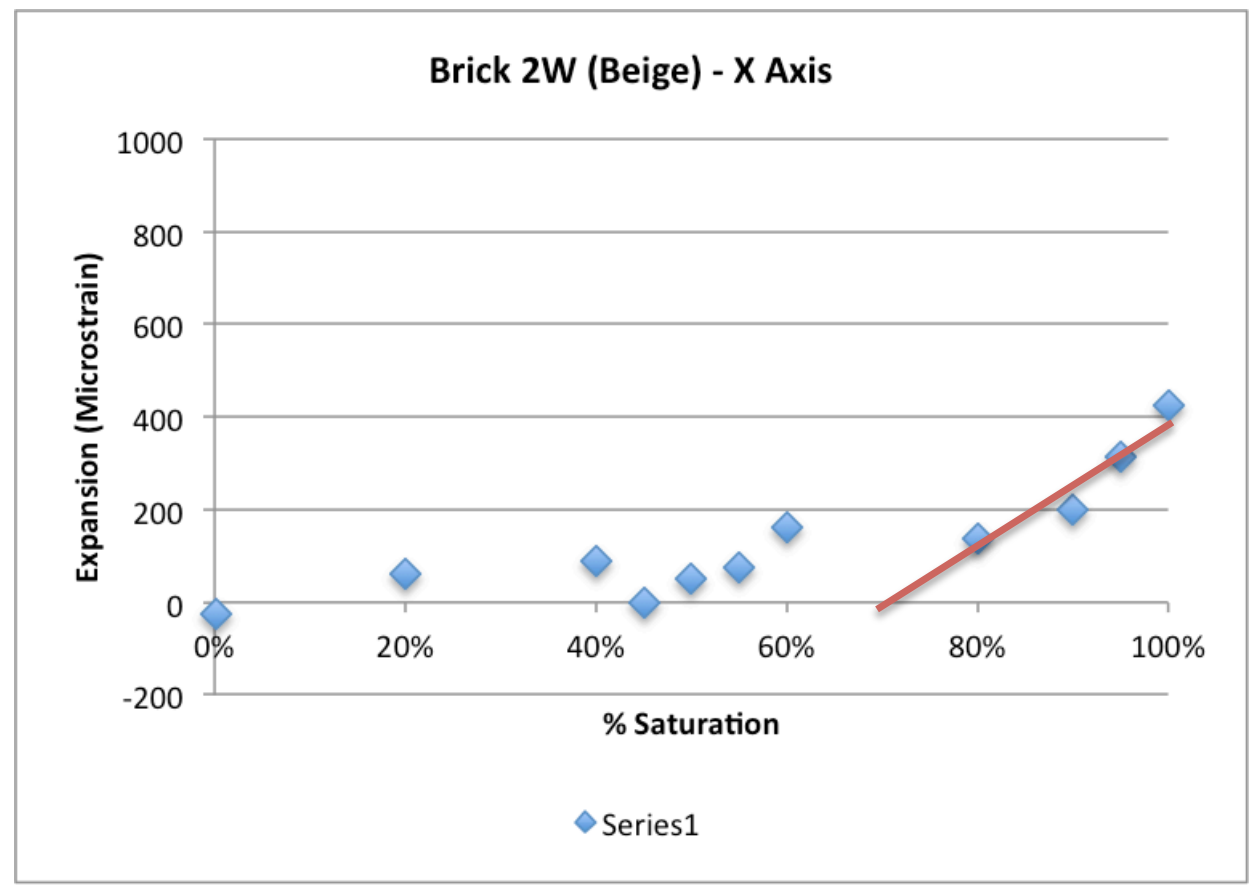

Figure 68: 2-Dimensional Frost Dilatometry results - Brick Specimen 2W - X Axis average Scrit Measurements.

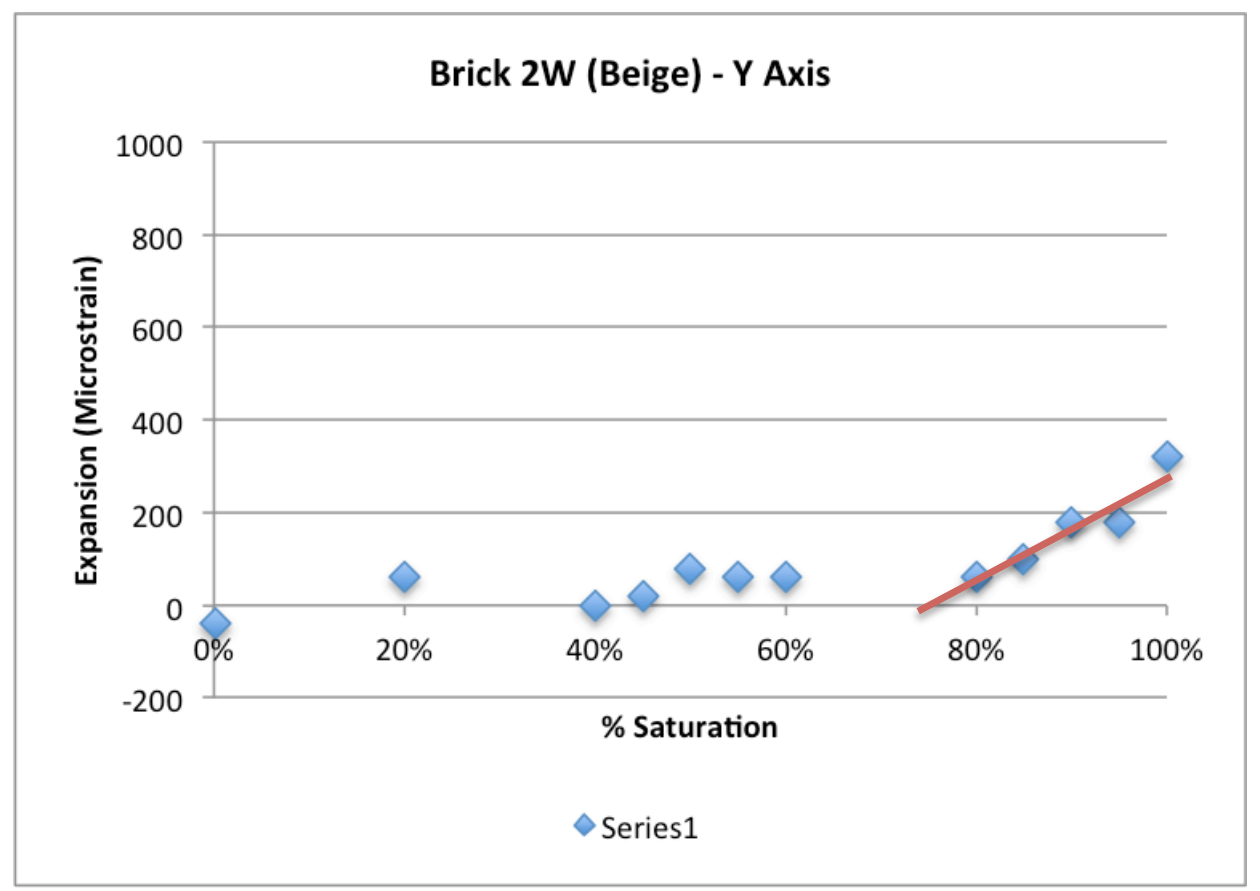

Figure 69: 2-Dimensional Frost Dilatometry results - Brick Specimen 2W - Y Axis aVerage Scrit Measurements. 
All measured datapoints:

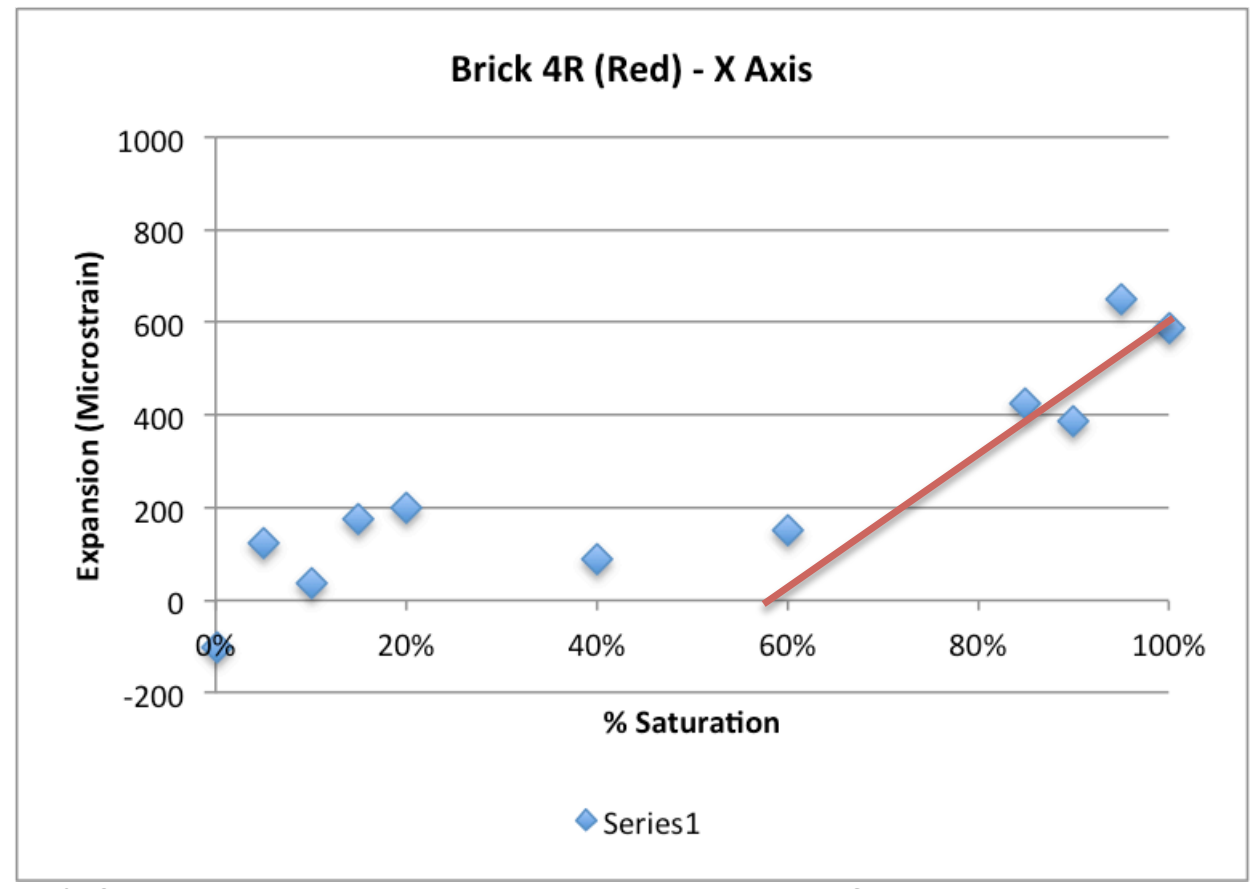

Figure 70: 2-Dimensional Frost Dilatometry results - Brick Specimen 4R - X Axis aVerage Scrit measurements.

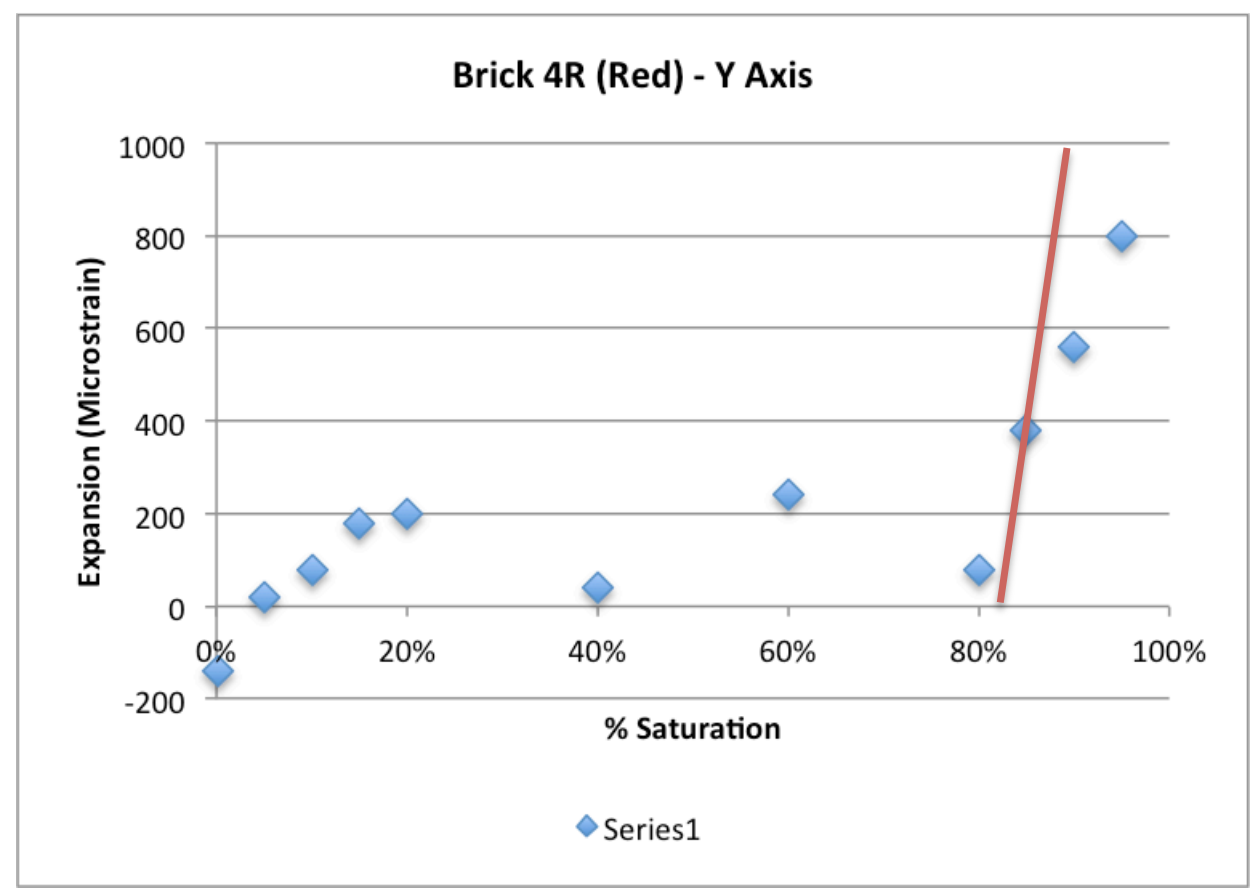

Figure 71: 2-Dimensional Frost Dilatometry Results - Brick Specimen 4R - Y Axis aVerage Scrit Measurements. 
All measured datapoints:

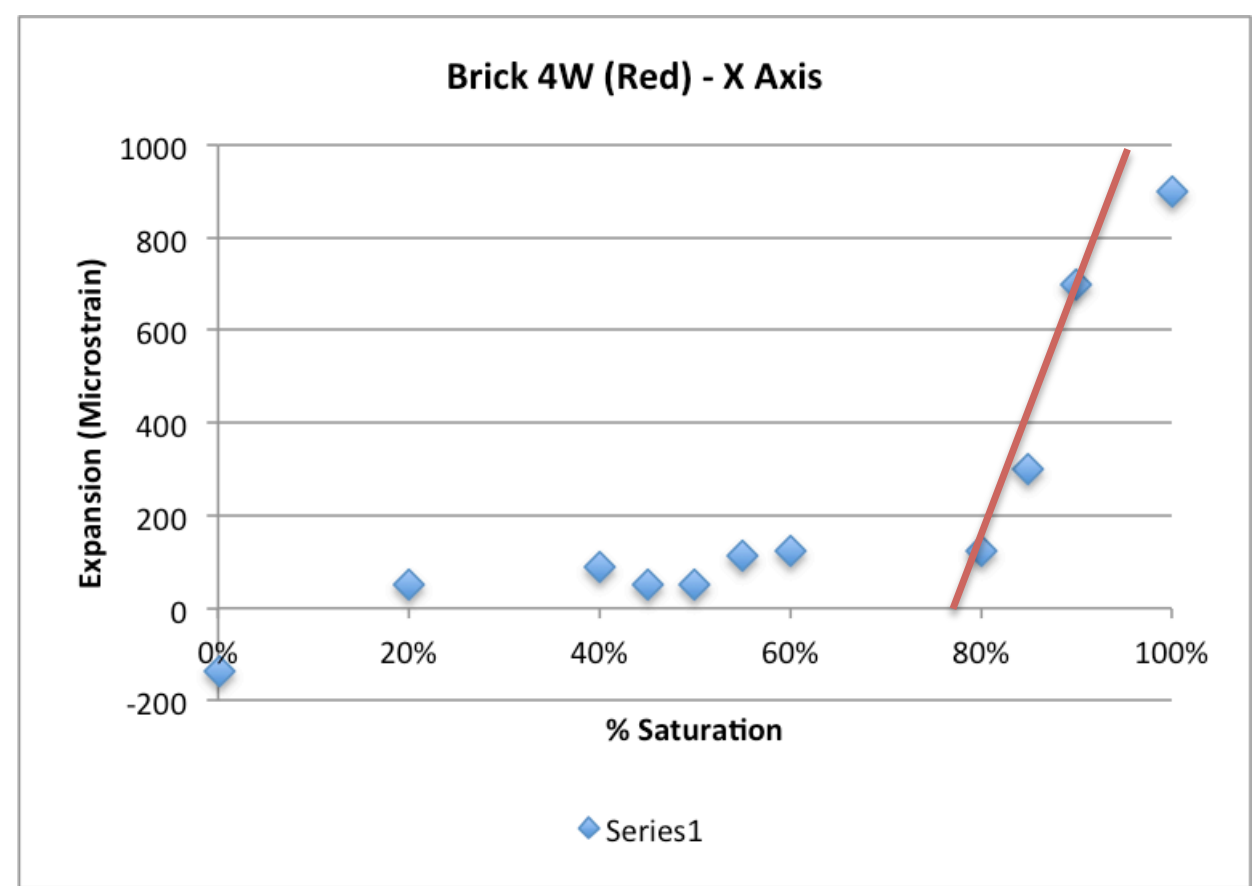

Figure 72: 2-Dimensional Frost Dilatometry results - Brick Specimen 4W - X Axis average Scrit Measurements.

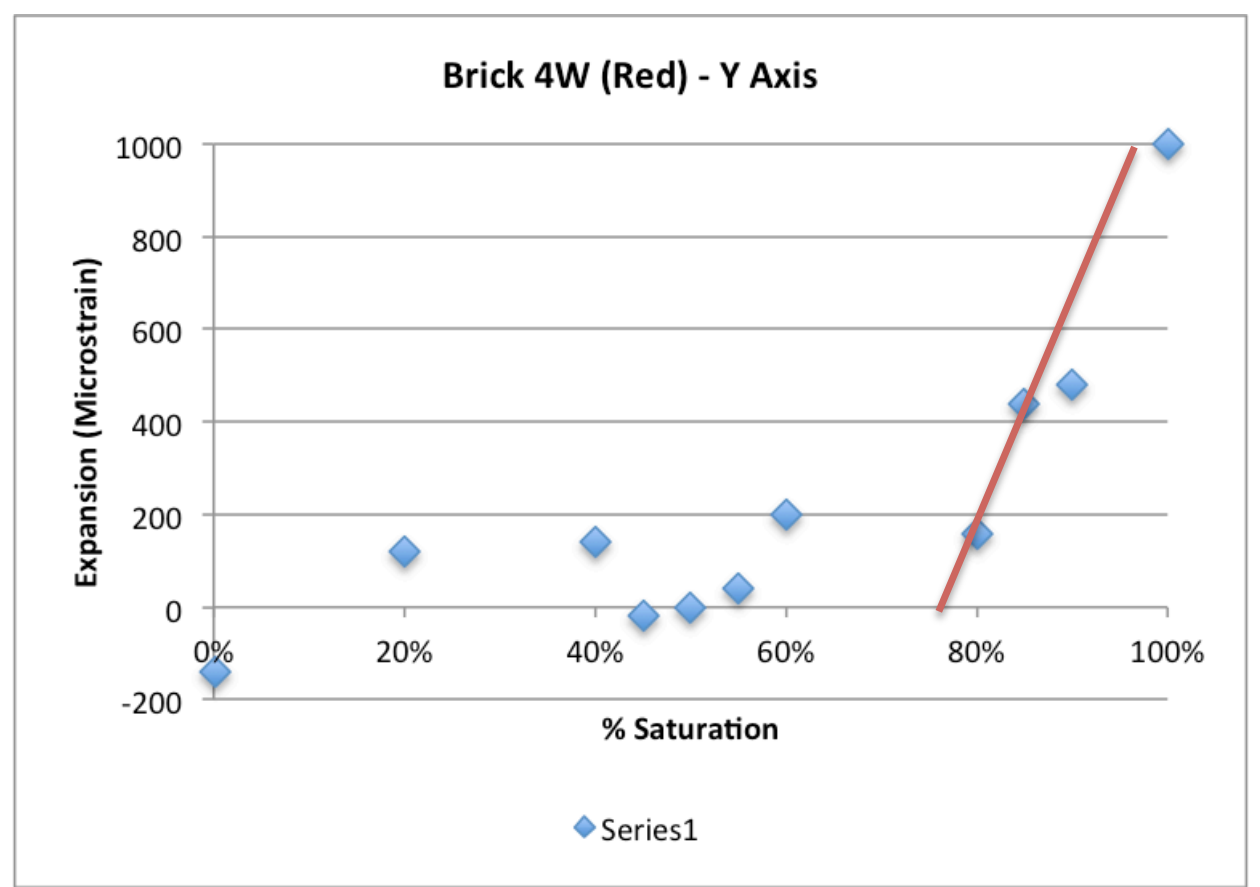

Figure 73: 2-Dimensional Frost Dilatometry results - Brick Specimen 4W - Y Axis aVerage Scrit Measurements. 
All measured datapoints:

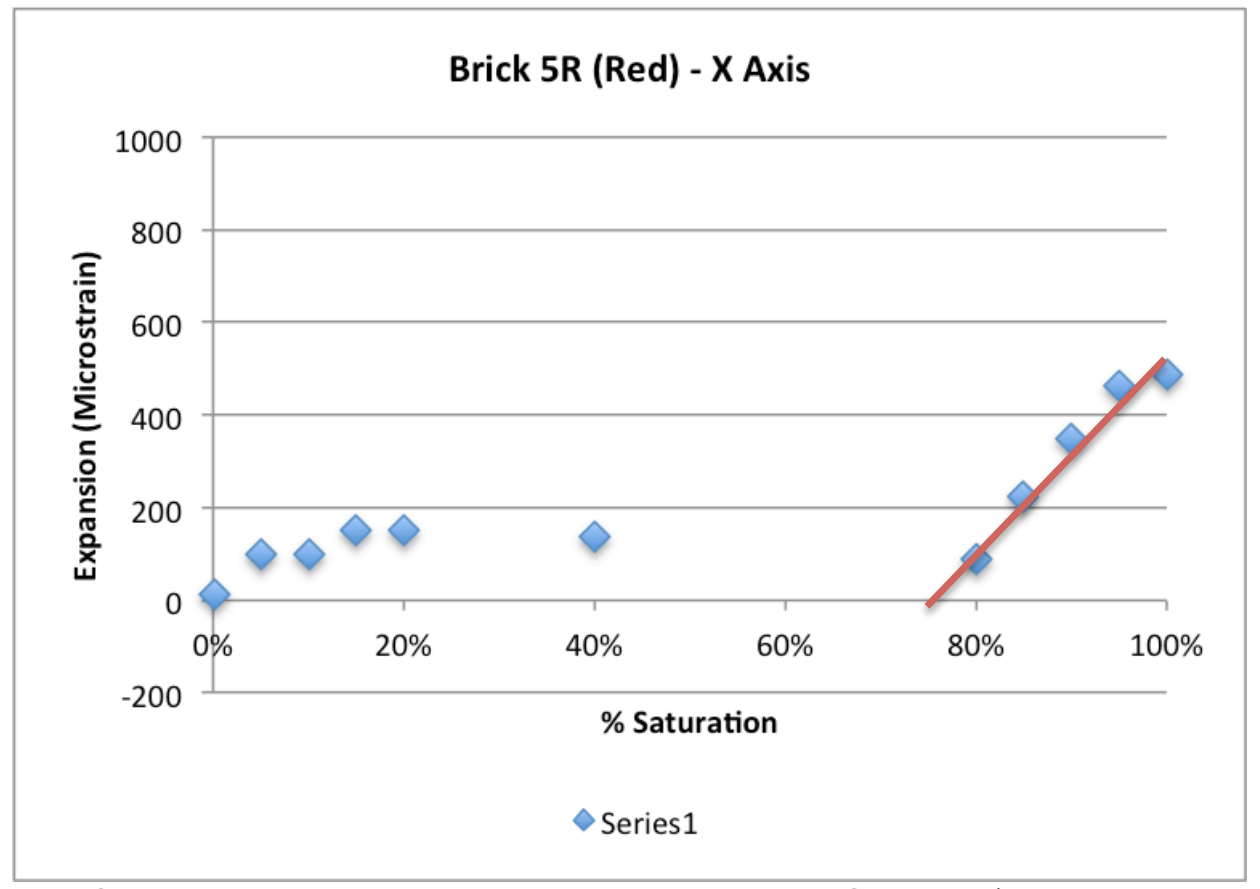

Figure 74: 2-Dimensional Frost Dilatometry results - Brick Specimen 5R - X Axis aVerage Scrit Measurements.

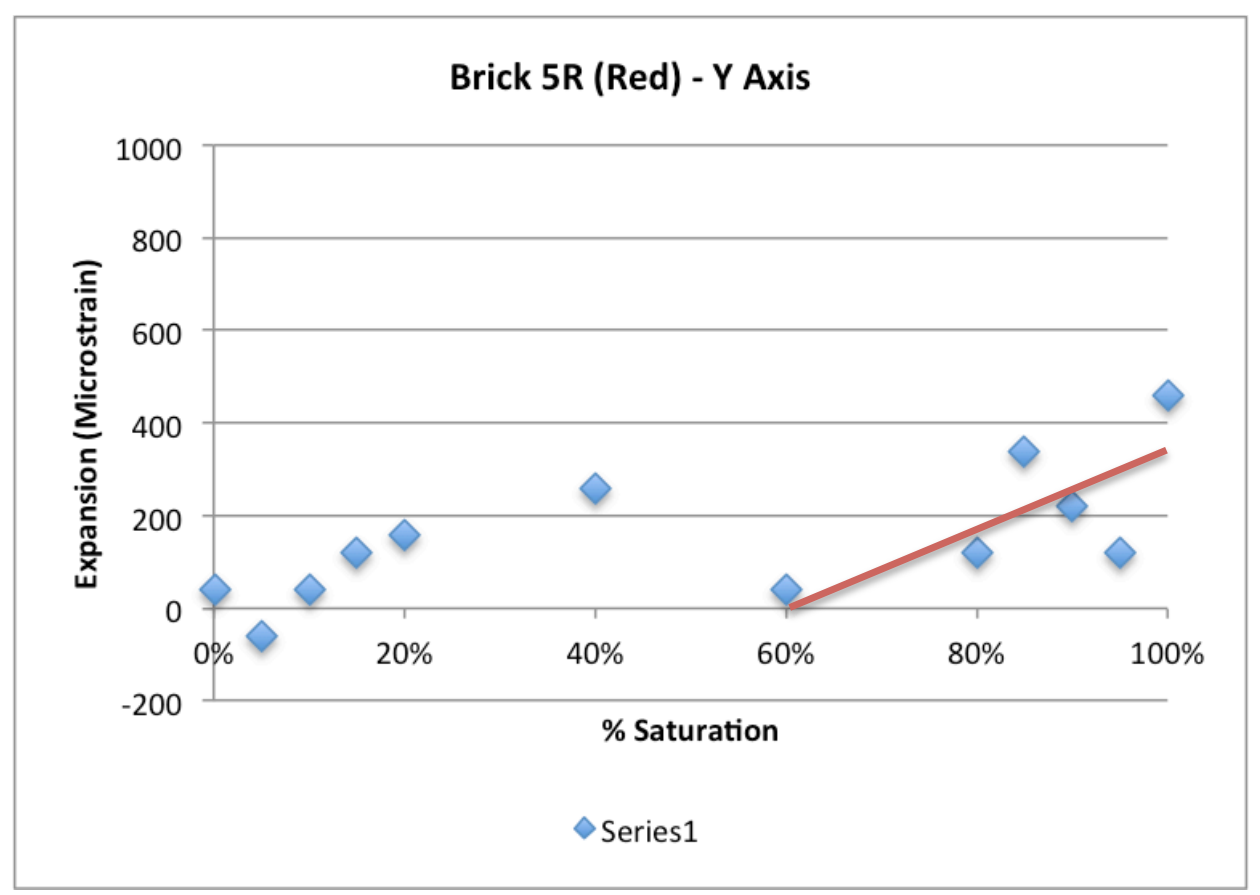

Figure 75: 2-Dimensional Frost Dilatometry Results - Brick Specimen 5R - Y Axis aVerage Scrit Measurements. 
All measured datapoints:

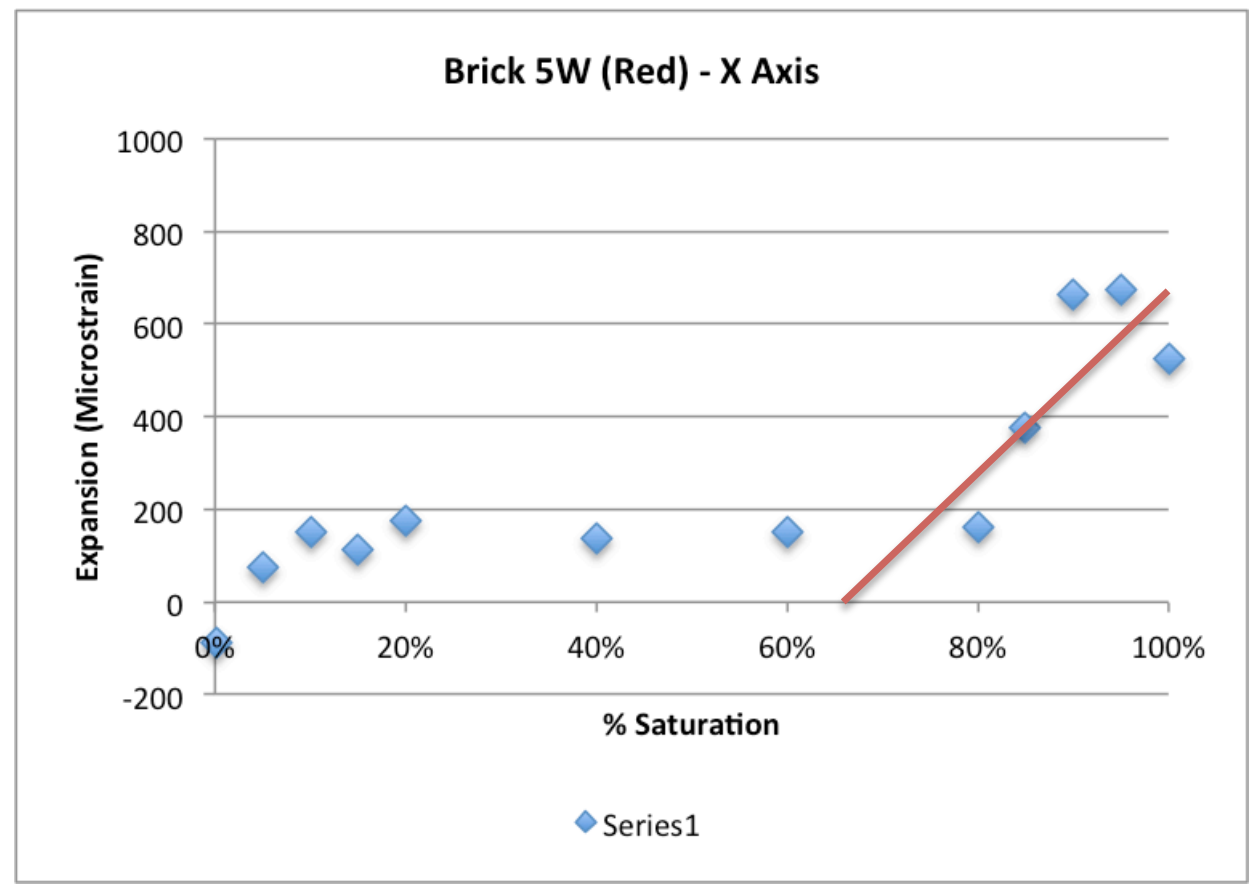

Figure 76: 2-Dimensional frost Dilatometry results - Brick Specimen 5W - X AXis aVerage Scrit Measurements.

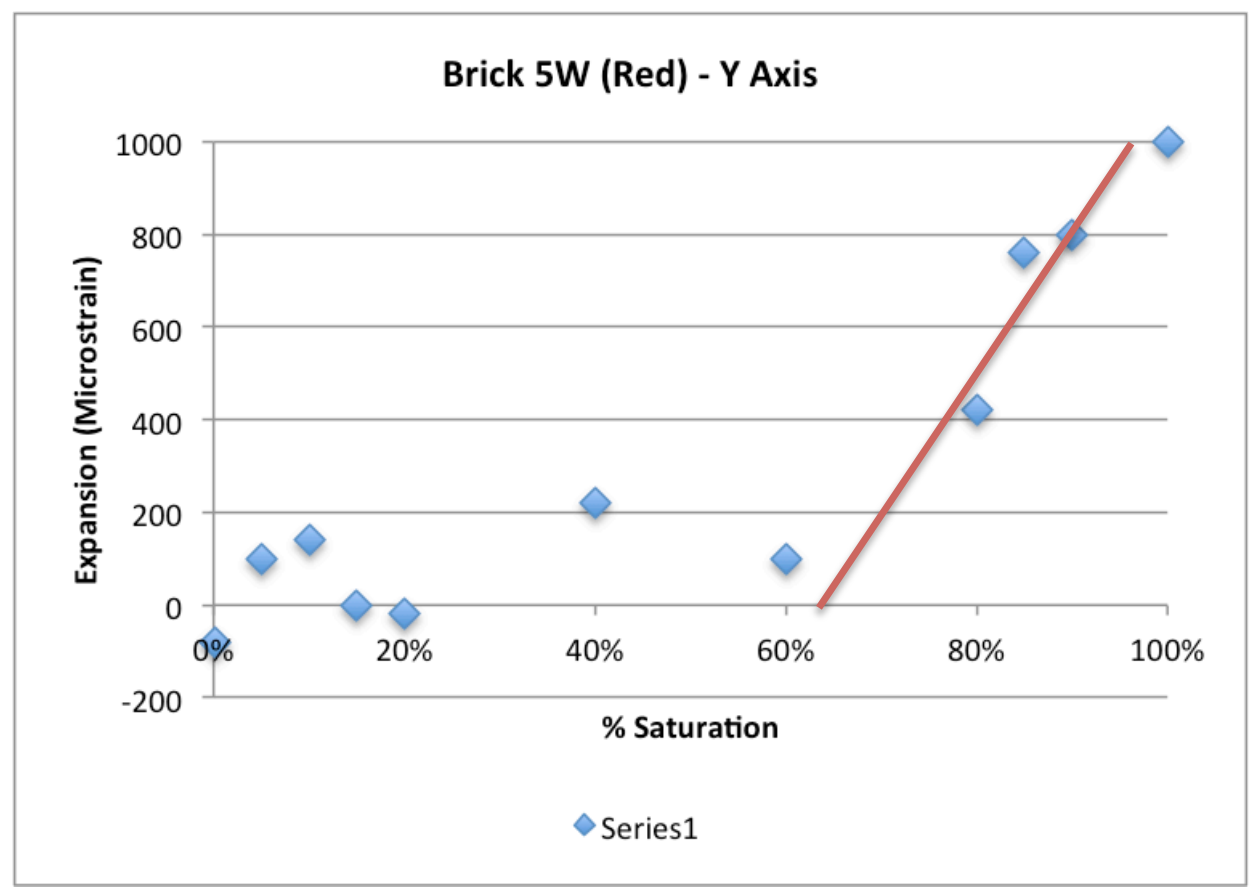

Figure 7 7: 2-Dimensional Frost Dilatometry results - Brick Specimen 5W - Y Axis aVerage Scrit Measurements. 
Results from Modern Clay brick specimens:

All measured datapoints along X-Axis direction:
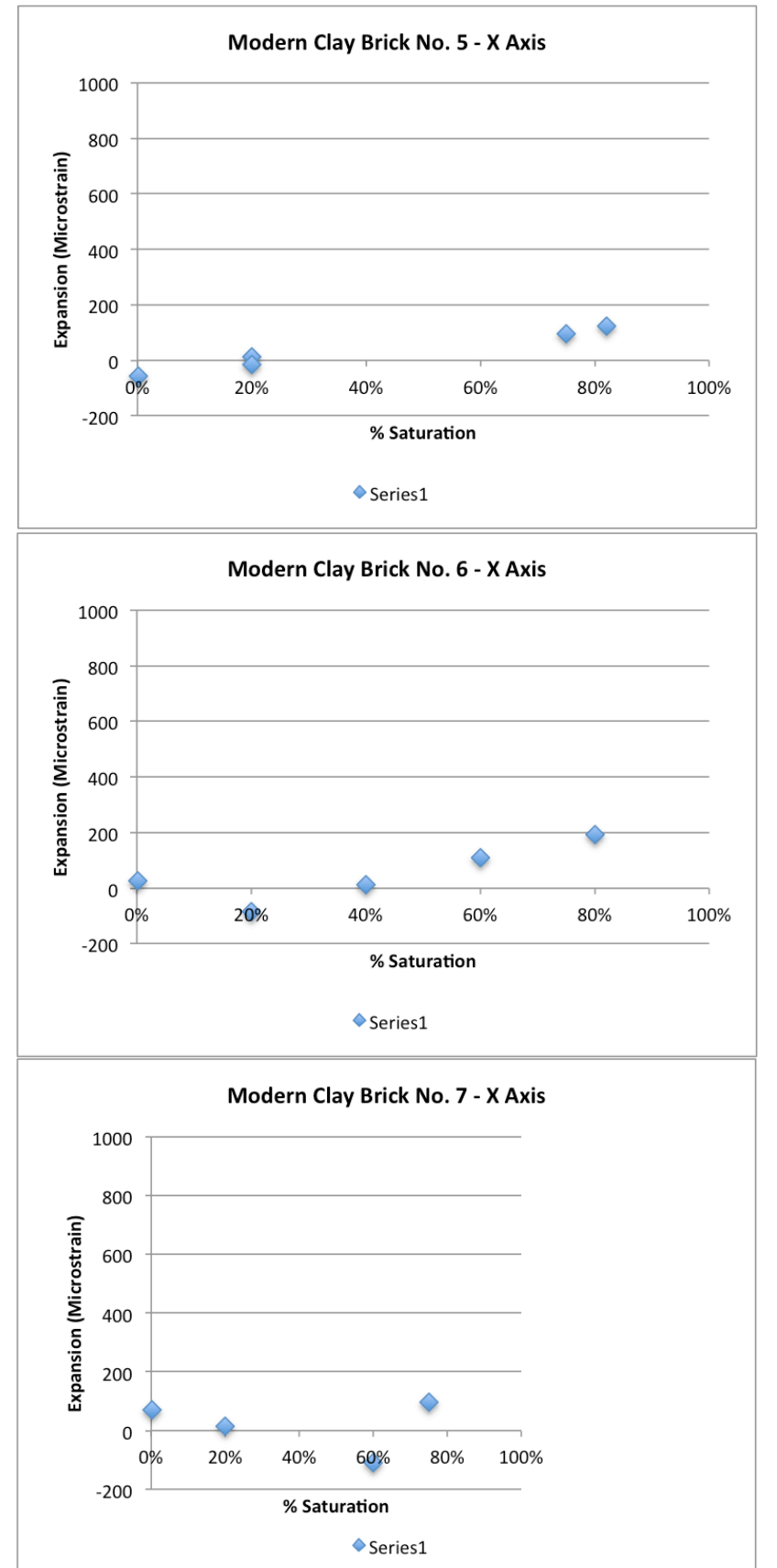

All measured datapoints along Y-Axis direction:
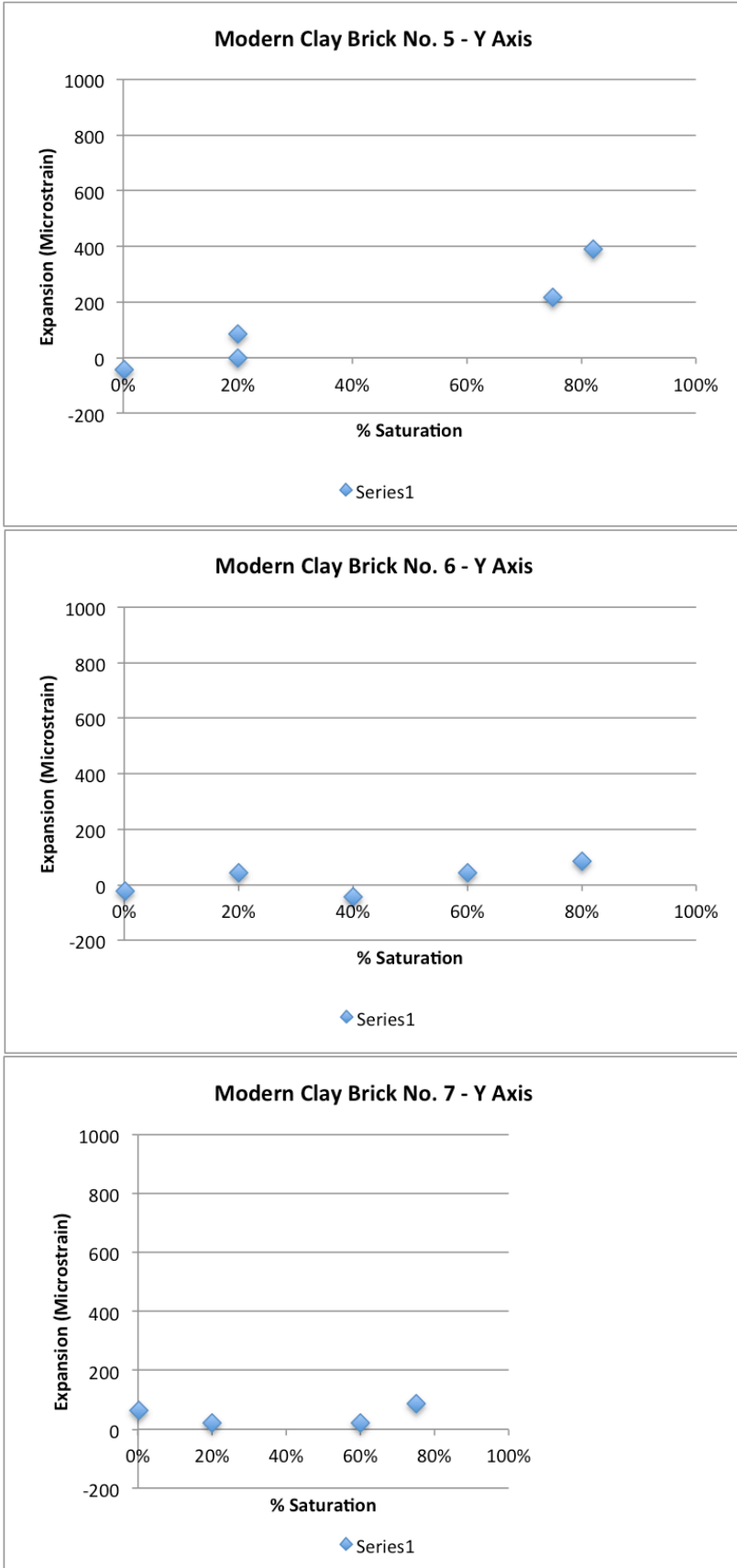

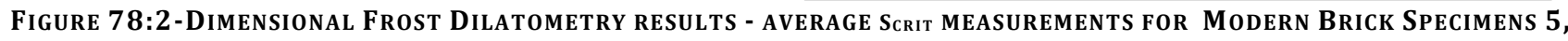
6 AND 7.

Note that $100 \%$ saturation was unable to be obtained for some samples immediately prior to frost dilatometry analysis; vacuum saturation should have been used rather than the boil method. 
Results from Modern Clay brick specimens:

\section{All measured datapoints along X-Axis} direction:

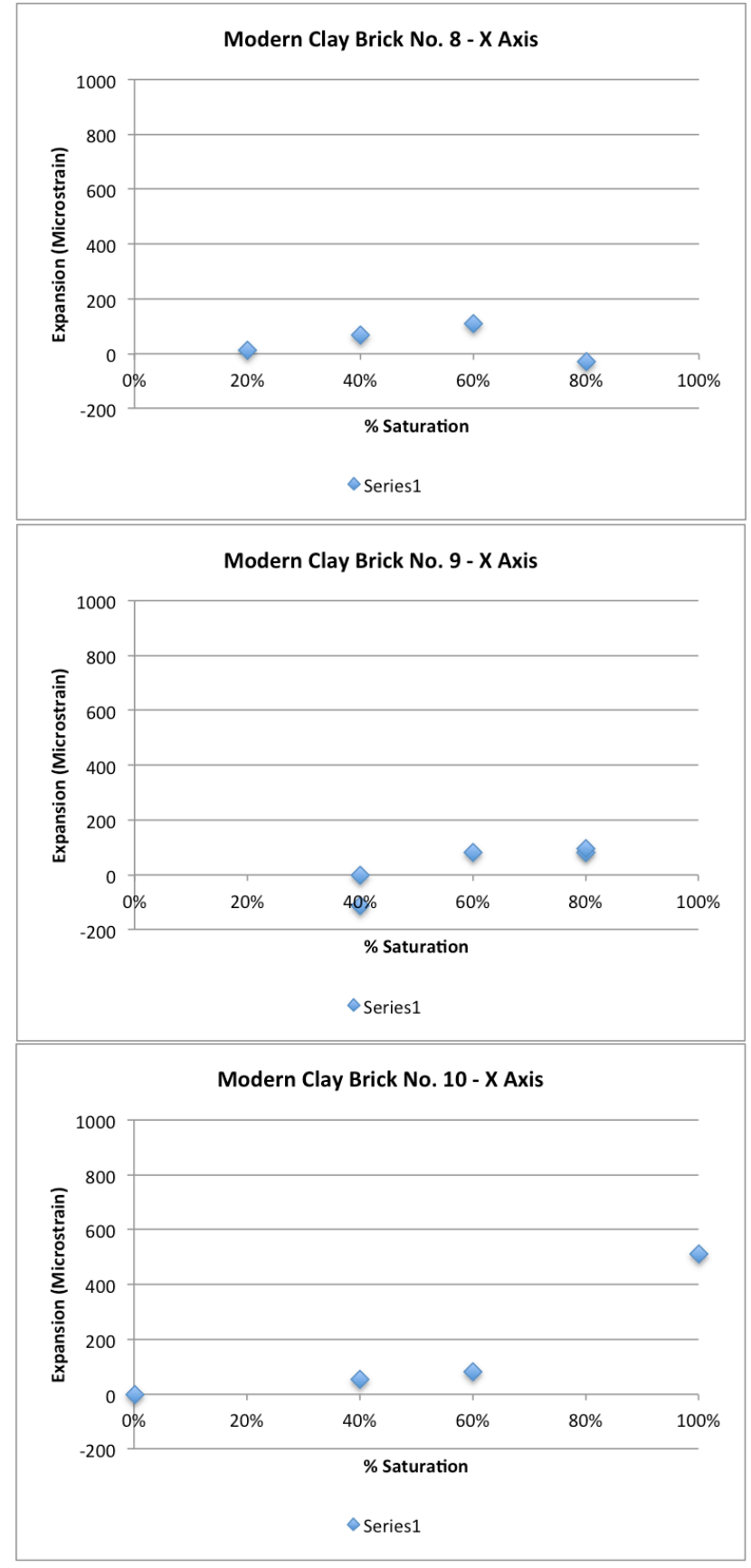

All measured datapoints along Y-Axis direction:
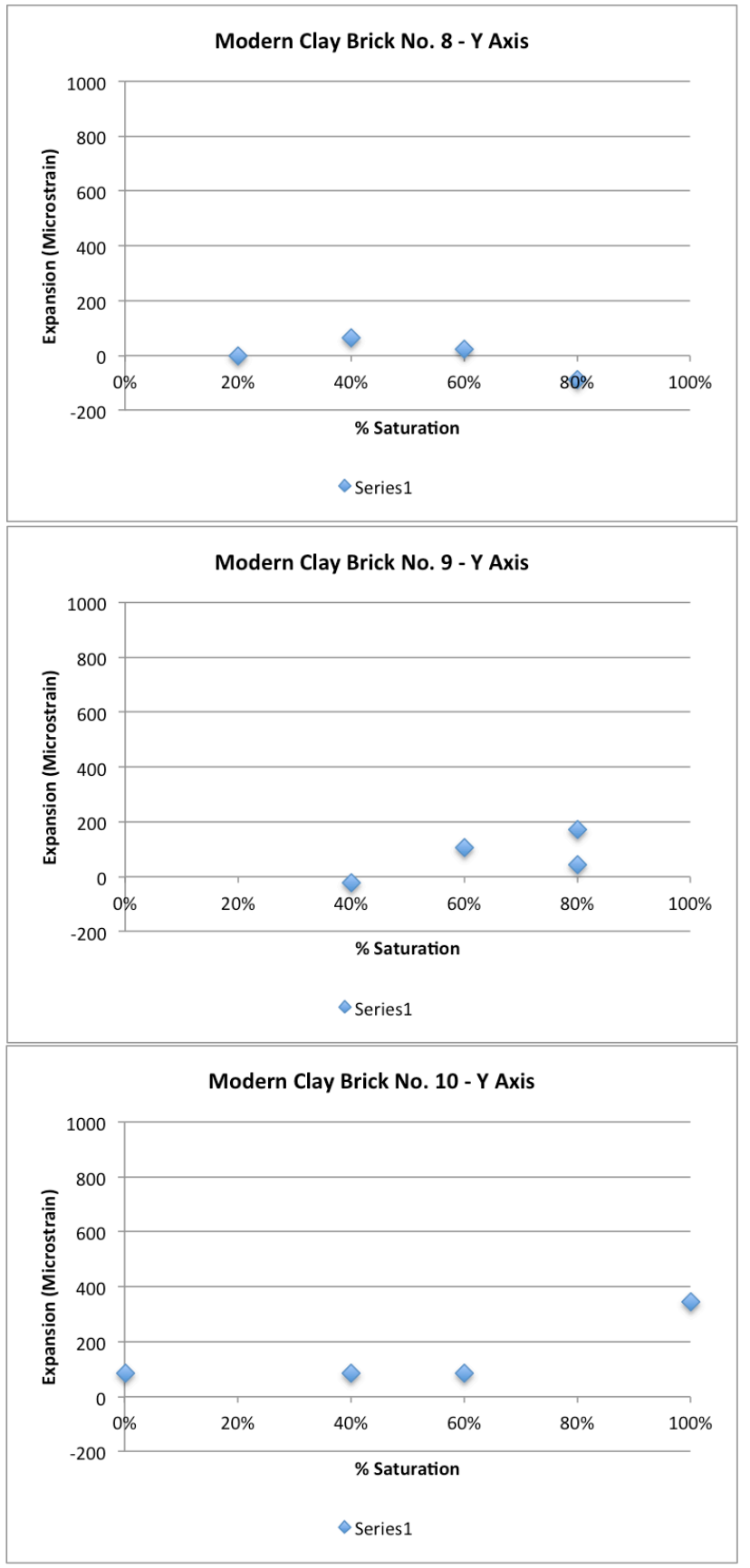

Figure 79:2-Dimensional Frost Dilatometry results - average Scrit Measurements Modern Brick Specimens 8, 9 AND 10. 
Results from Modern Clay brick specimens:

All measured datapoints along X-Axis direction:

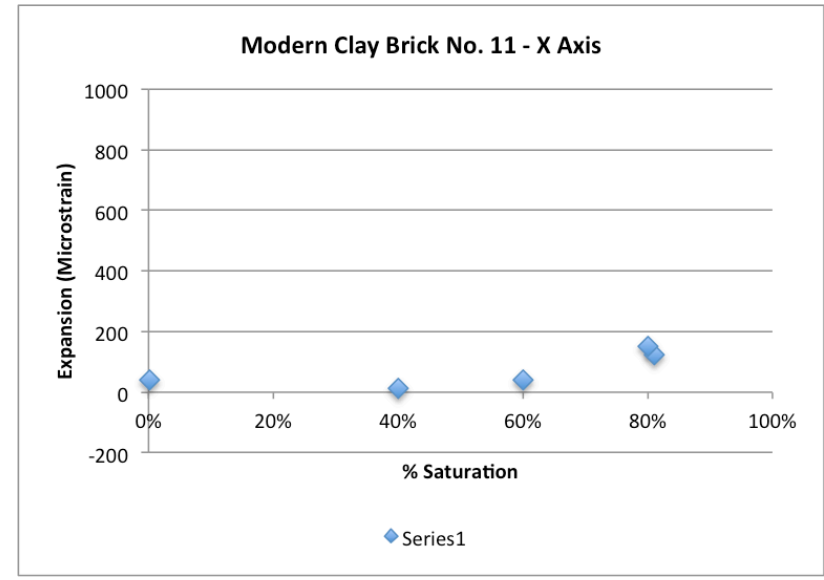

All measured datapoints along Y-Axis direction:

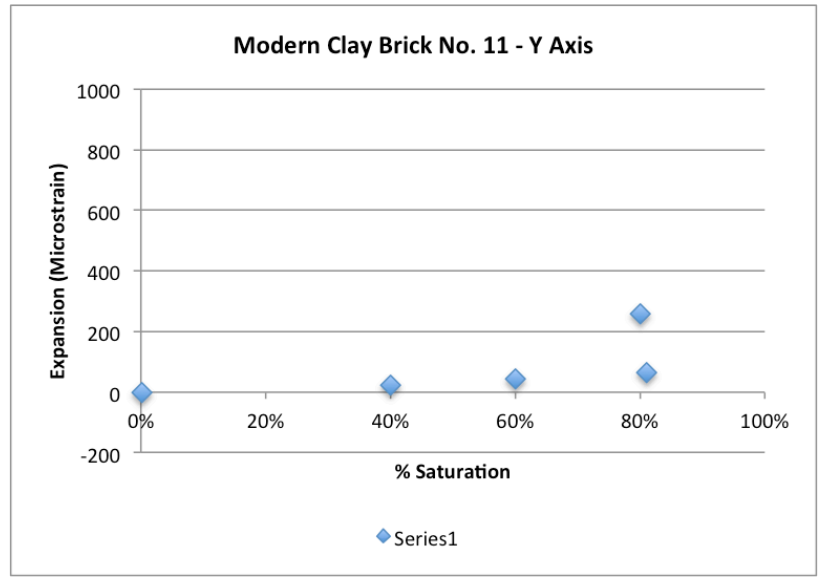

Figure 80:2-Dimensional Frost Dilatometry results - average Scrit Measurements for Modern Brick Specimen No. 11. 
3 Dimensional frost dilotometry expasion.

Each clay brick unit was halved to create 2 specimens.

Pins were inserted to allow for 2 measurements across each axis.
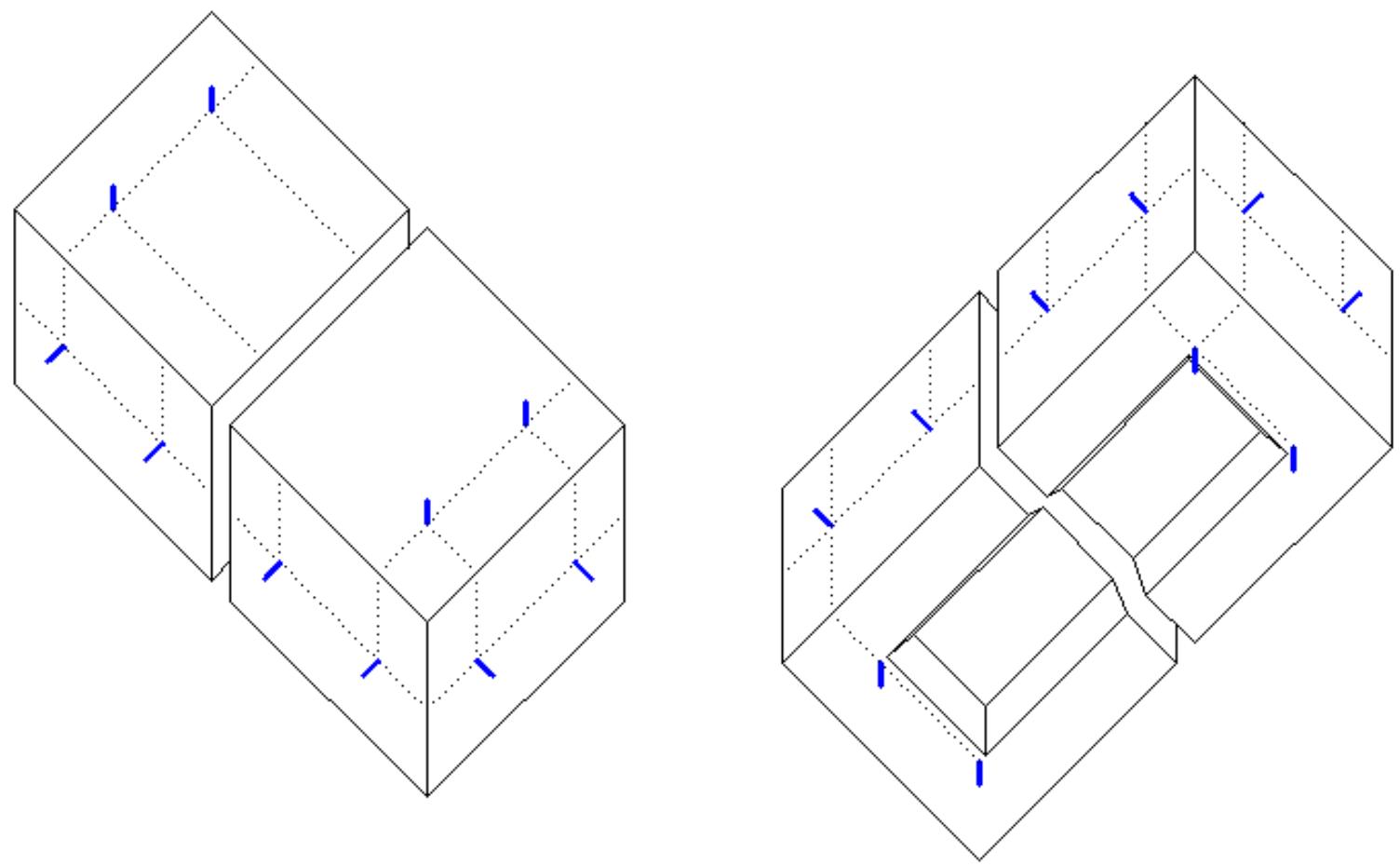

Figure 81: 3-Dimensional Frost Dilatometry - Pin Placement Diagram. 


\subsubsection{PLOTTED RESULTS OF 3-DIMENSIONAL FROST DILATOMETRY}

Specimens $6 \mathrm{n}-1$ was saturated to $73 \%$ moisture content before 9 cycles of freeze-thaw. The resulting dimension changes are shown in microstrain (unitless).

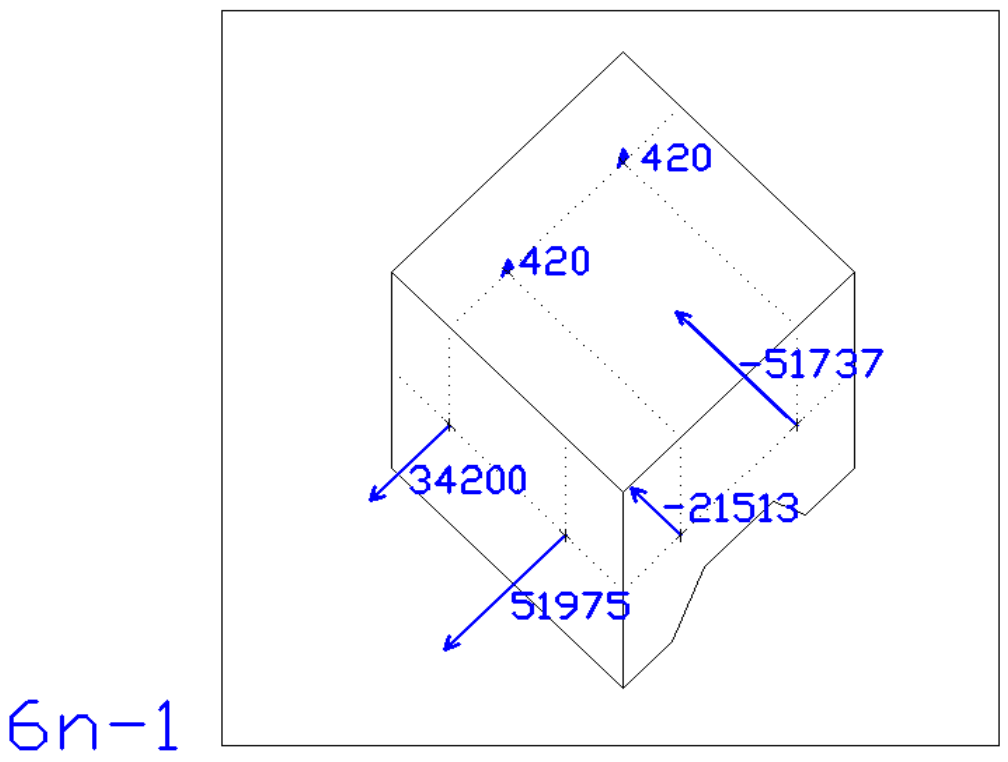

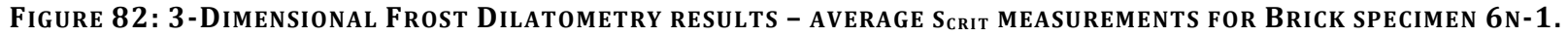

Specimens $6 \mathrm{w}-1$ was saturated to $80 \%$ moisture content before 9 cycles of freeze-thaw. The resulting dimension changes are shown in microstrain (unitless).

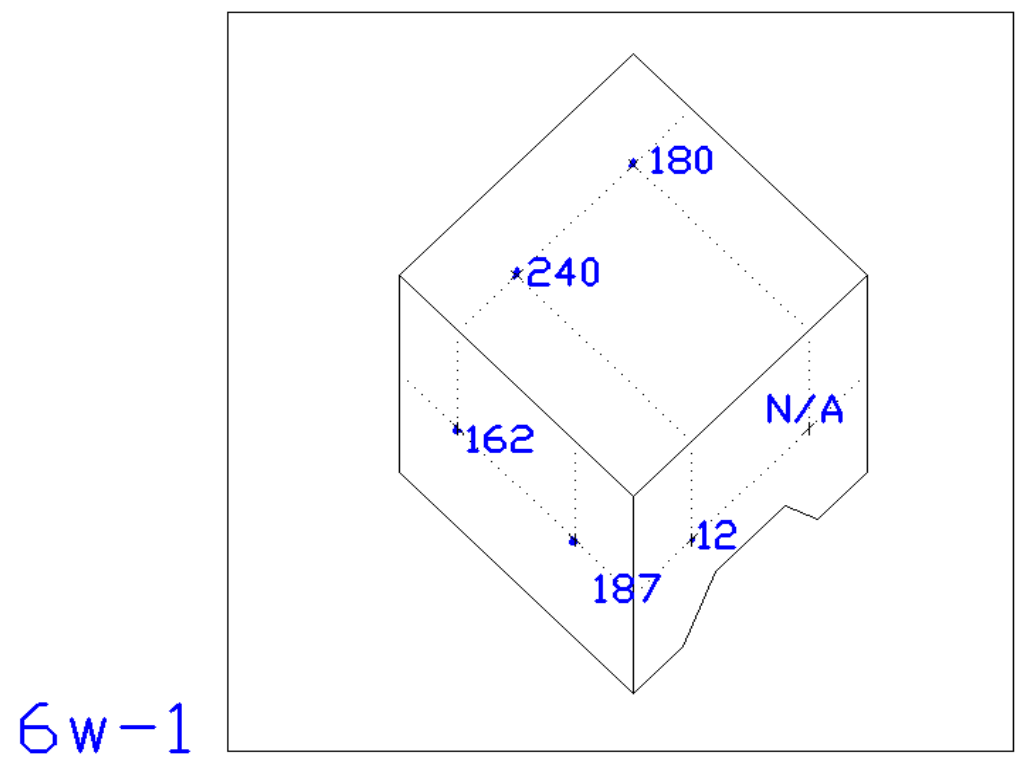

Figure 83: 3-Dimensional Frost Dilatometry Results - AVERAGE S Sit MEASUREMENTS For Brick SPECIMEN 6 W-1. 
Specimens $6 \mathrm{w}-2$ was saturated to $80 \%$ moisture content before 9 cycles of freeze-thaw. The resulting dimension changes are shown in microstrain (unitless).

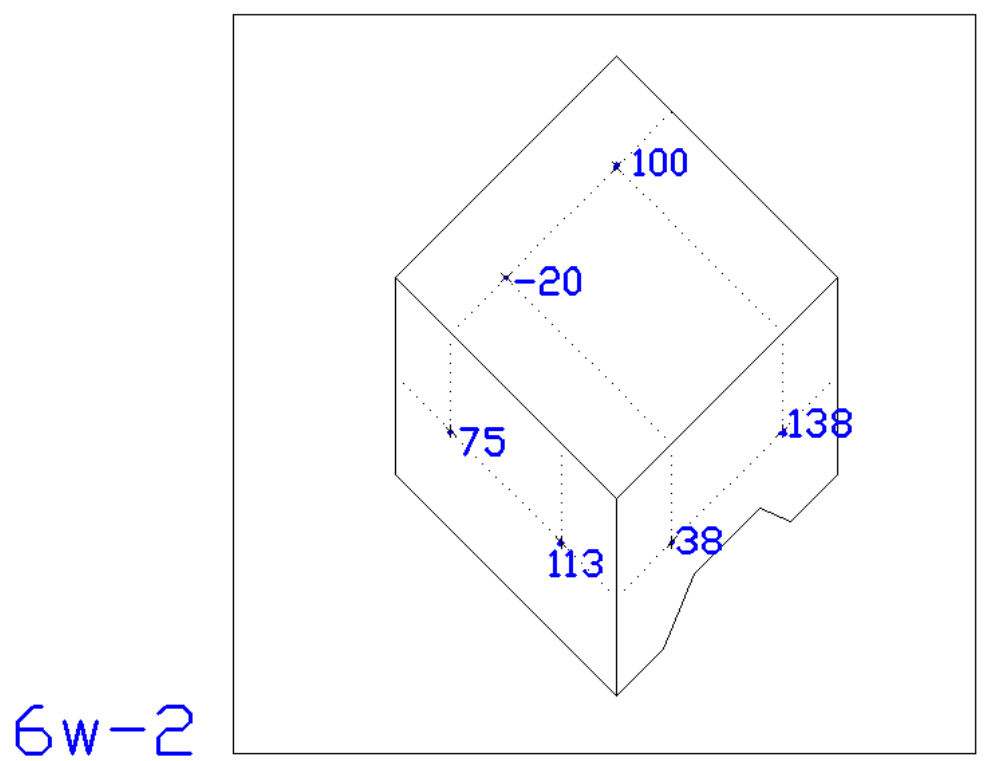

Figure 84: 3-Dimensional Frost Dilatometry ReSUlts - AVERAge S S it MEASUREMENTS for Brick SPECIMEN 6W-2.

Specimens 3r-1 was saturated to 69\% moisture content before 9 cycles of freeze-thaw. The resulting dimension changes are shown in microstrain (unitless).

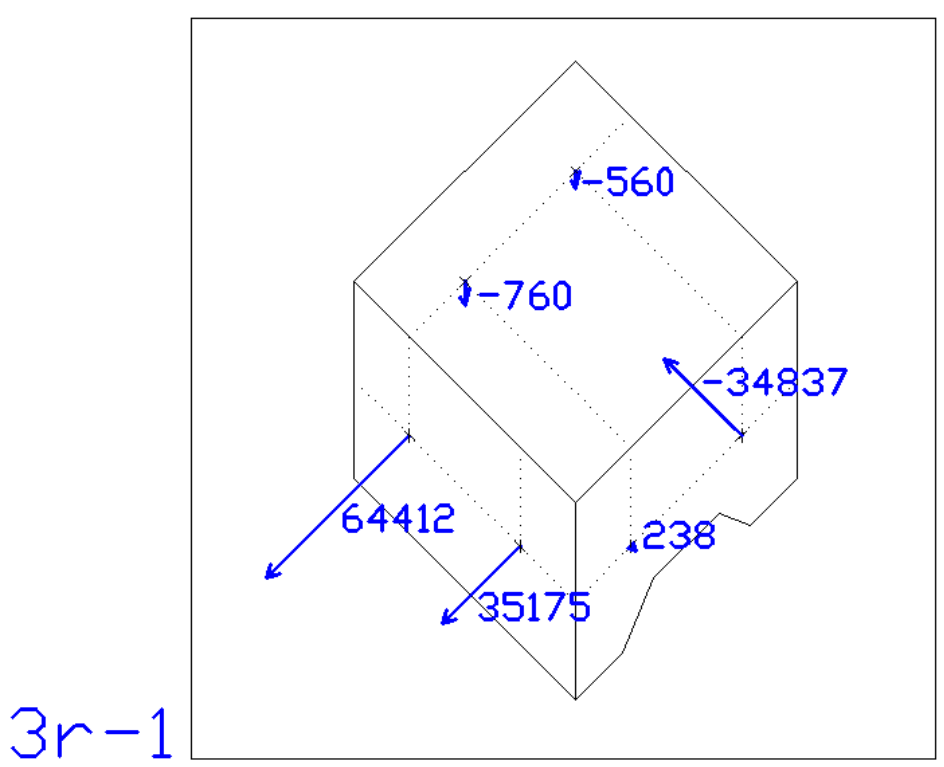

Figure 85: 3-Dimensional Frost Dilatometry results - aVerage Scrit MEasurements for Brick SPECimen 3 R-1. 
Specimens 3r-2 was saturated to $71 \%$ moisture content before 9 cycles of freeze-thaw. The resulting dimension changes are shown in microstrain (unitless).

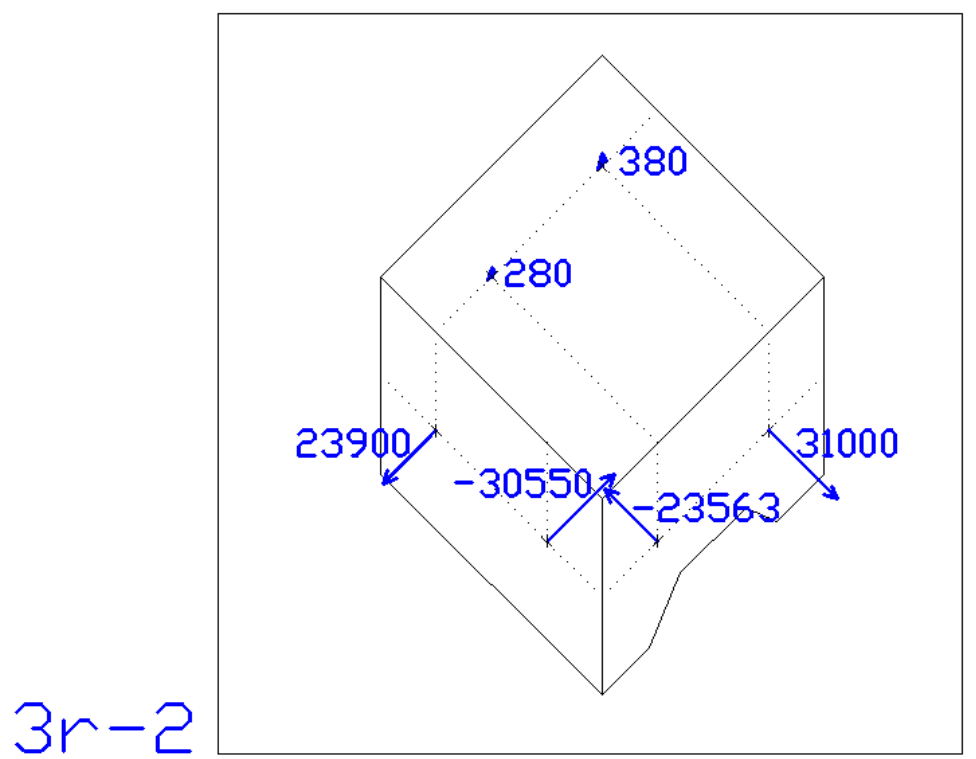

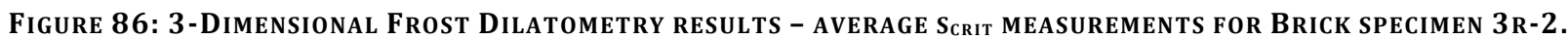

Specimens $6 r-1$ was saturated to $80 \%$ moisture content before 9 cycles of freeze-thaw. The resulting dimension changes are shown in microstrain (unitless).

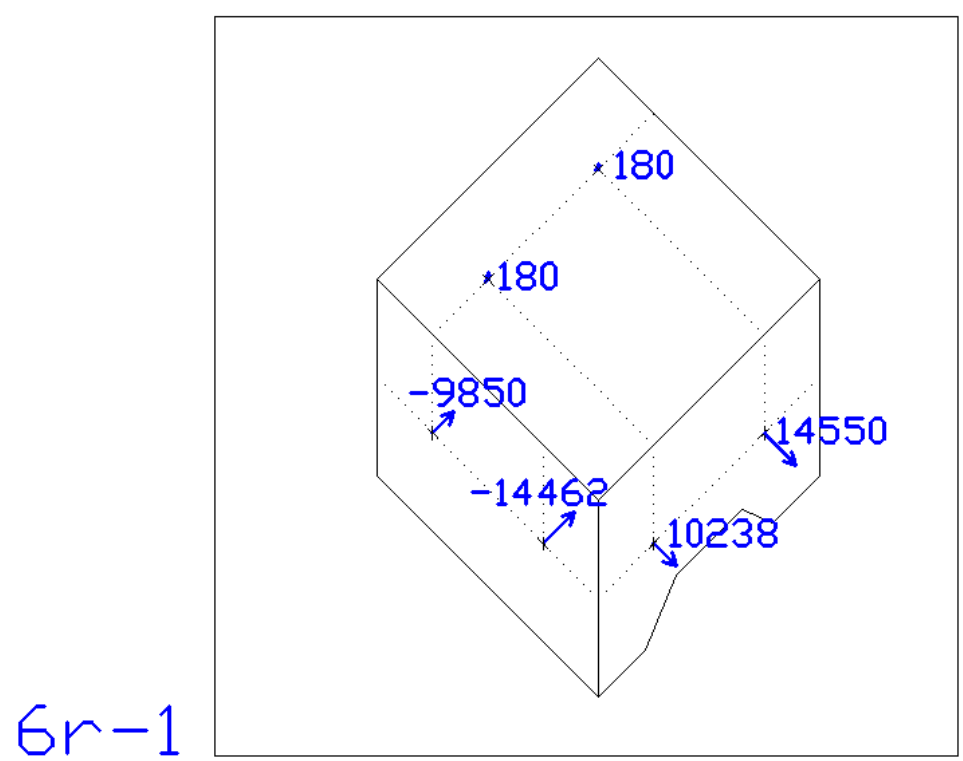

Figure 87: 3-Dimensional Frost Dilatometry Results - AVERAGe Scrit MEASUREMENTS For Brick SPECimen 6r-1. 
Specimens c1-1 was saturated to $80 \%$ moisture content before 9 cycles of freeze-thaw. The resulting dimension changes are shown in microstrain (unitless).

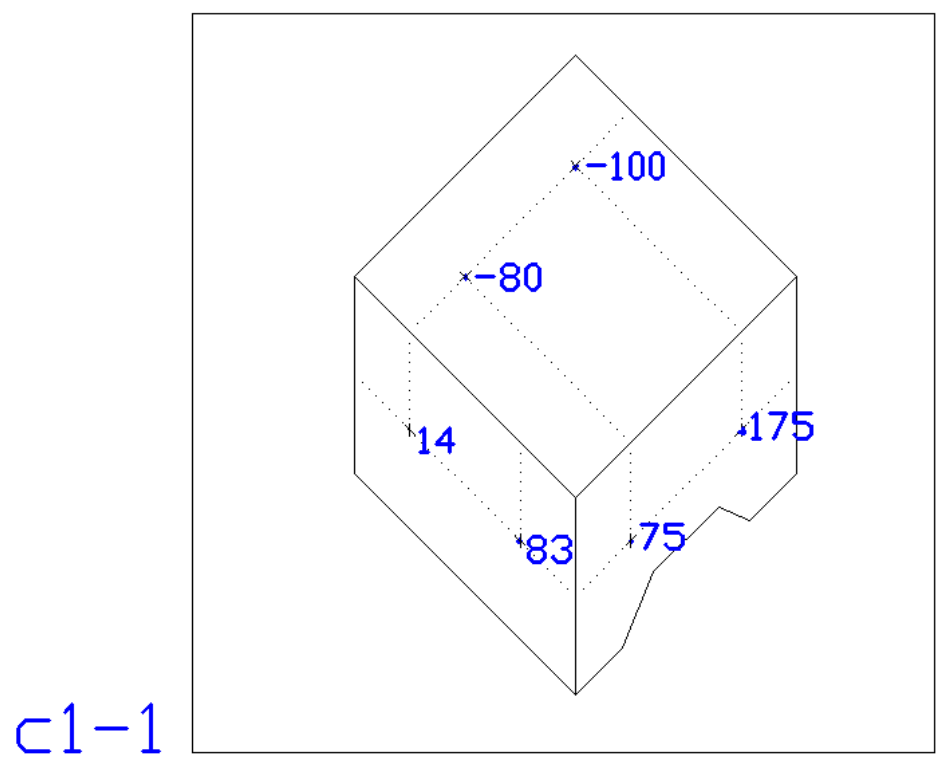

Figure 88: 3-Dimensional Frost Dilatometry Results - AVERAGE Scrit MEASUREMENTS For Brick SPECIMEN C1-1.

Specimens c1-2 was saturated to $85 \%$ moisture content before 9 cycles of freeze-thaw. The resulting dimension changes are shown in microstrain (unitless).

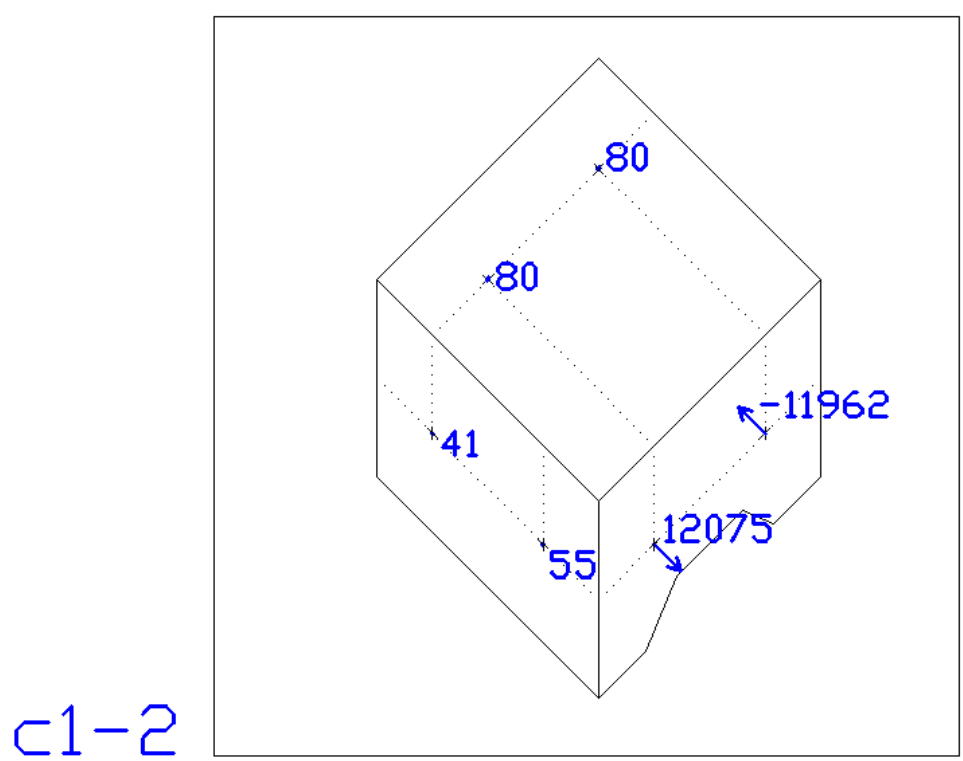

Figure 89: 3-Dimensional Frost Dilatometry Results - AVERAGe Scrit MEASUREMENTS For Brick SPECIMEN C1-2. 
Specimens c2-1 was saturated to 75\% moisture content before 9 cycles of freeze-thaw. The resulting dimension changes are shown in microstrain (unitless).

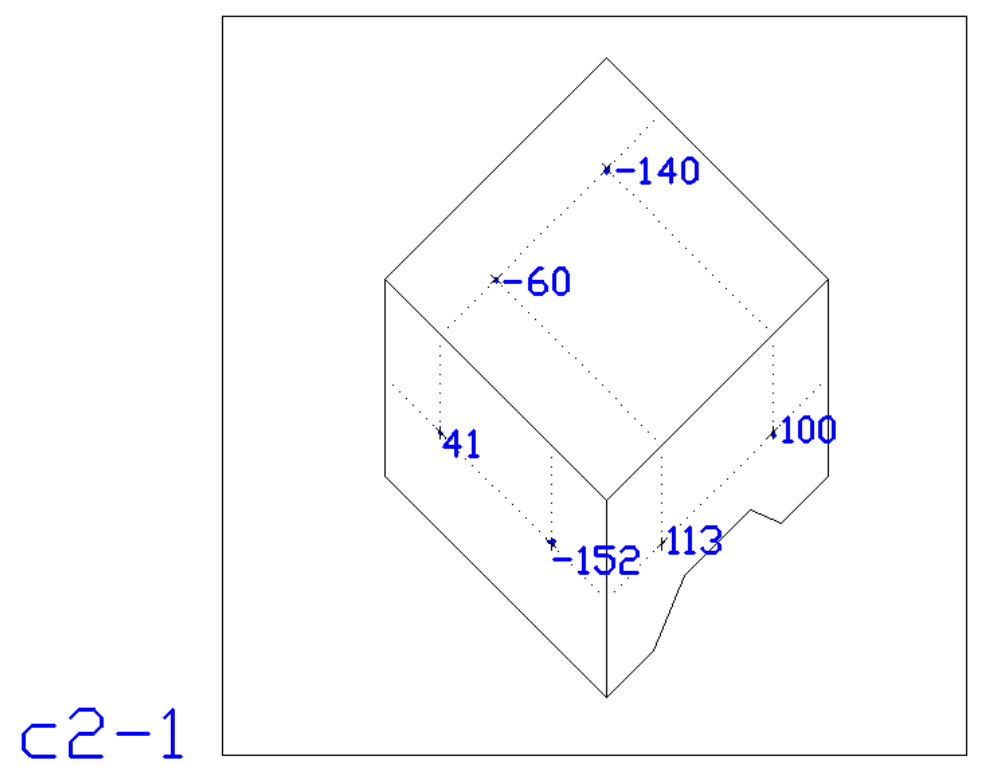

Figure 90: 3-Dimensional Frost Dilatometry Results - AVERAGE Scrit MEASUREMENTS For Brick SPECIMEN C2-1.

Specimens c2-2 was saturated to $90 \%$ moisture content before 9 cycles of freeze-thaw. The resulting dimension changes are shown in microstrain (unitless).

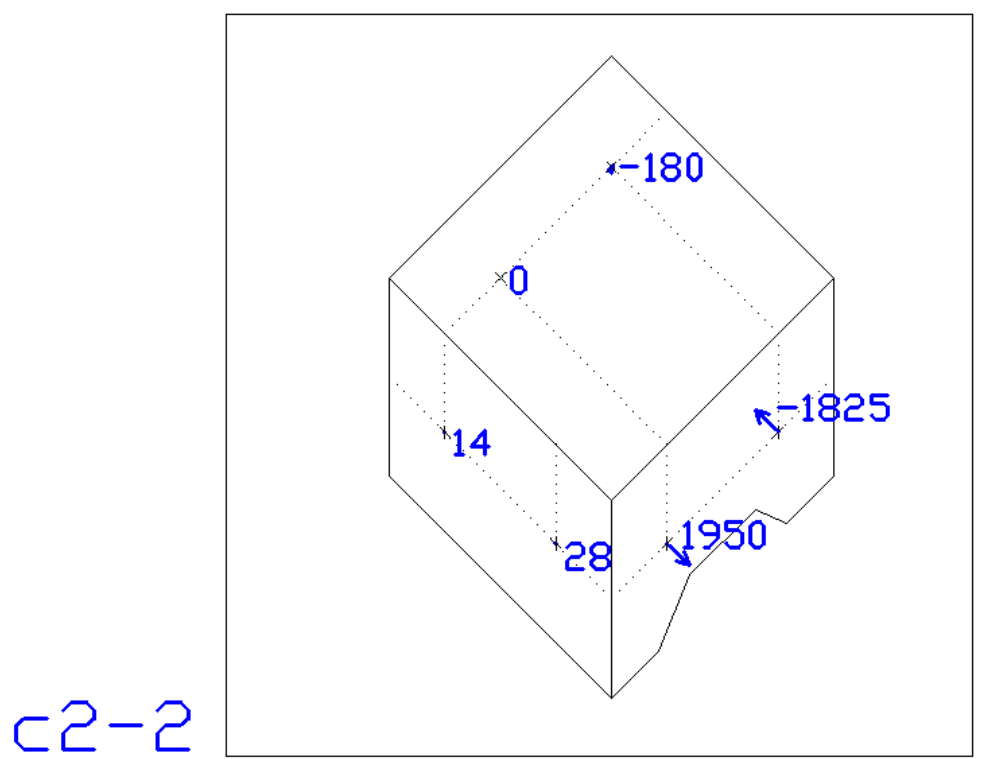

Figure 91: 3-Dimensional Frost Dilatometry Results - aVerage Scrit MEASUREMENTS for Brick SPECimen c2-2. 
Specimens c3-1 was saturated to 85\% moisture content before 9 cycles of freeze-thaw. The resulting dimension changes are shown in microstrain (unitless).

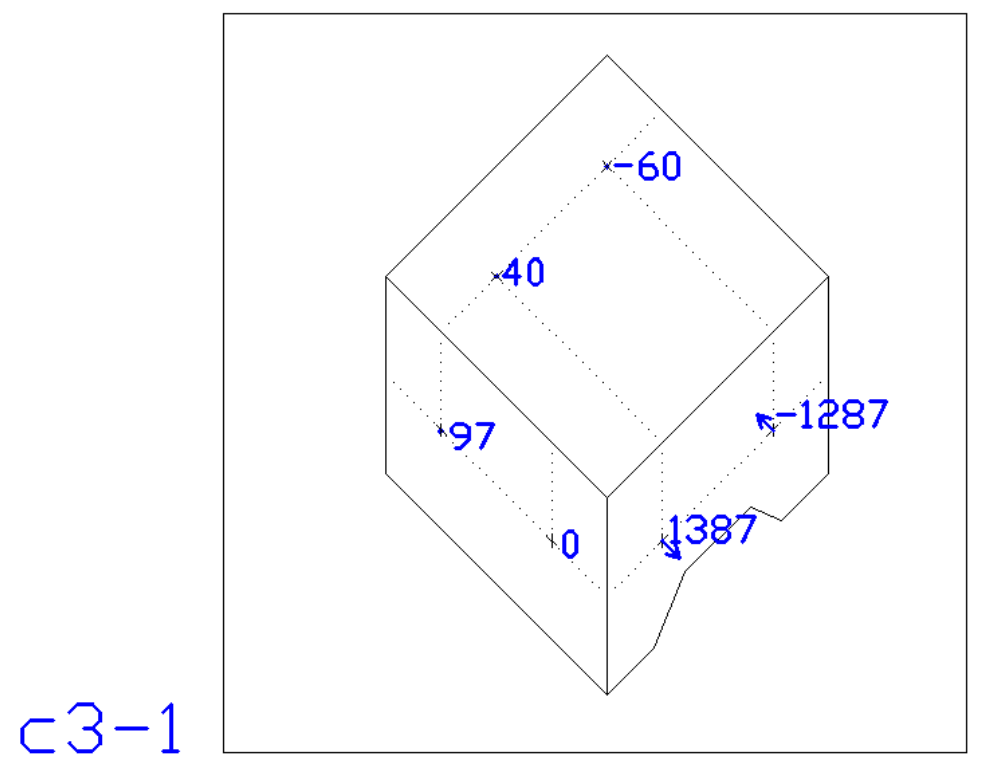

Figure 92: 3-Dimensional Frost Dilatometry Results - AVERAGE Scrit MEASUREMENTS FOR BRick SPECIMEN C3-1.

Specimens c3-2 was saturated to $90 \%$ moisture content before 9 cycles of freeze-thaw. The resulting dimension changes are shown in microstrain (unitless).

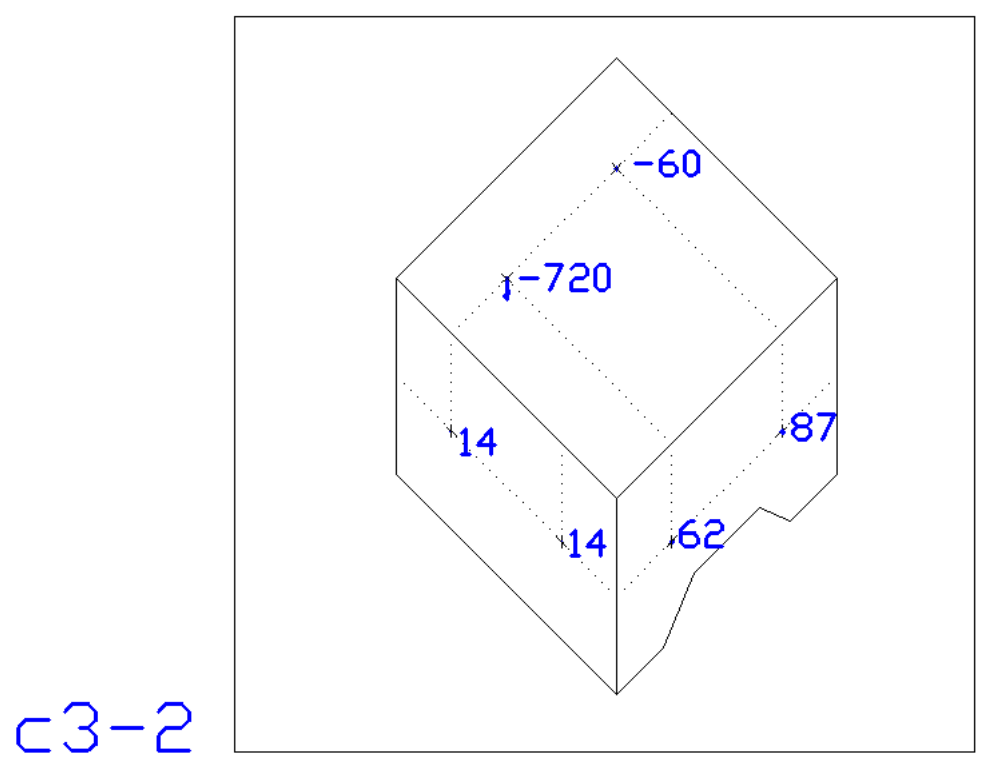

Figure 93: 3-Dimensional Frost Dilatometry Results - aVerage Scrit MEASUREMENTS for Brick SPECimen c3-2. 
Specimens c4-1 was saturated to $75 \%$ moisture content before 9 cycles of freeze-thaw. The resulting dimension changes are shown in microstrain (unitless).

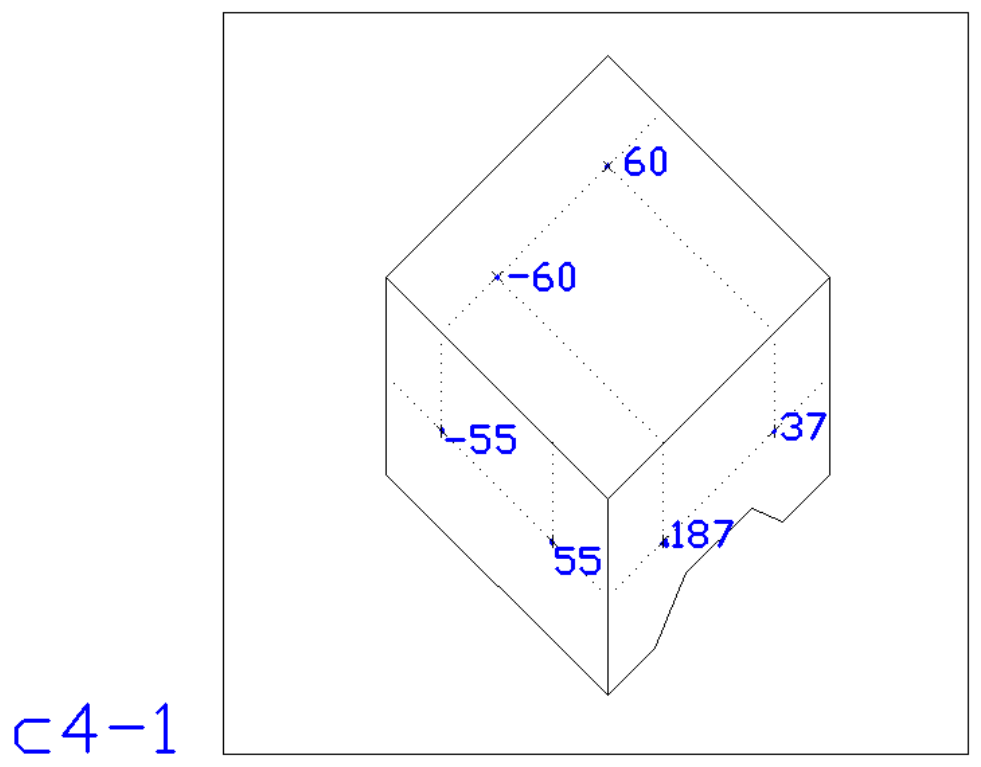

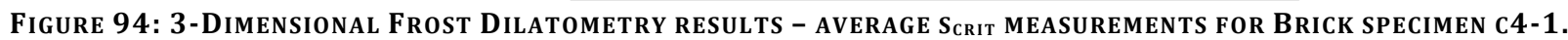

Specimens c4-2 was saturated to $80 \%$ moisture content before 9 cycles of freeze-thaw. The resulting dimension changes are shown in microstrain (unitless).

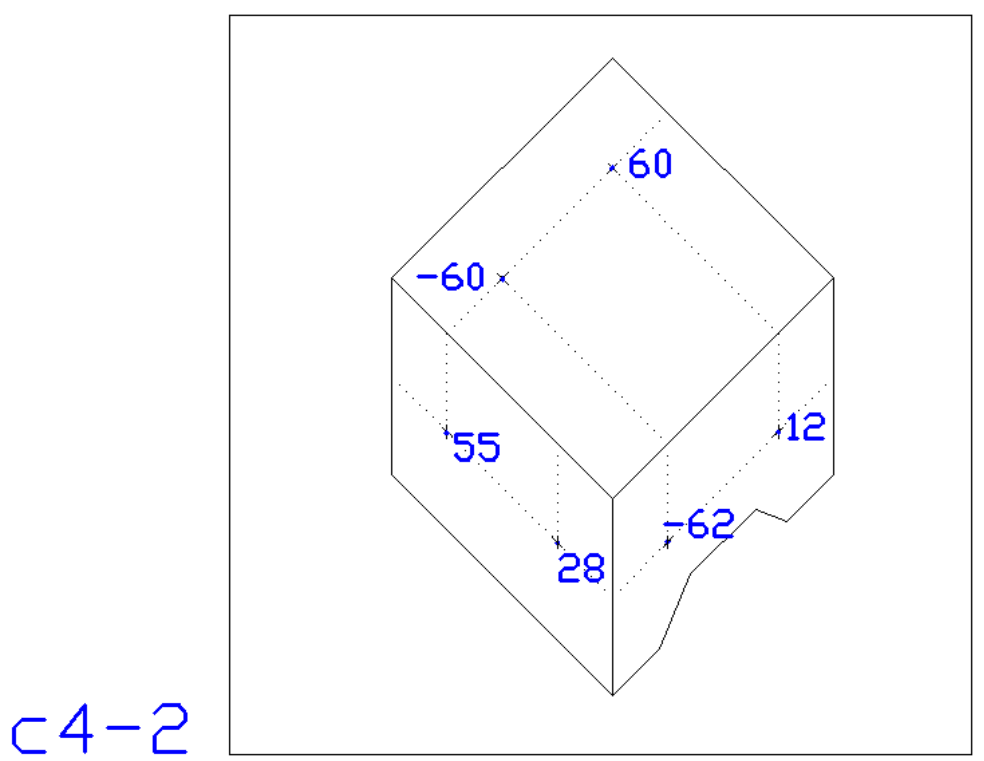

Figure 95: 3-Dimensional Frost Dilatometry results - AVERAge Scrit Measurements and Brick SPECimen c4-2. 


\subsubsection{DISCUSSION}

The majority of the critical saturation points of the 2-axes specimens fall into approximately the- $80 \%$ range. $\mathrm{S}_{\text {crit }}$ frost dilatometry results, brick porosity and brick density results are listed below (Table 5).

TABLE 5: Frost dilatometry ReSUlts.

\begin{tabular}{|c|c|c|c|c|c|c|}
\hline Brick No. & Type & $\begin{array}{c}\text { Specimen Yield } \\
\text { per Brick }\end{array}$ & $\begin{array}{c}\text { Average Porosity } \\
{\left[\mathrm{m}^{3} / \mathrm{m}^{3}\right]}\end{array}$ & $\begin{array}{c}\text { Calculated Density* } \\
{\left[\mathrm{Kg} / \mathrm{m}^{3}\right]}\end{array}$ & $\begin{array}{c}\text { Observed } \mathbf{S}_{\text {crit }} \mathbf{X} \text {-Axis** } \\
{[\%]}\end{array}$ & $\begin{array}{c}\text { Observed } \mathbf{S}_{\text {crit }} \text { Y-Axis** } \\
{[\%]}\end{array}$ \\
\hline C5 & Modern & 4 & 0.215 & 2119.5 & 75 & 60 to 70 \\
\hline C6 & Modern & 4 & 0.214 & 2174.5 & 60 & $\sim$ \\
\hline C7 & Modern & 4 & 0.197 & 2226.5 & 75 & 75 \\
\hline$C 8$ & Modern & 4 & 0.185 & 2102.2 & 60 & $\sim$ \\
\hline $\mathrm{Cg}$ & Modern & 4 & 0.199 & 2163.6 & $\sim$ & 60 \\
\hline $\mathrm{C} 10$ & Modern & 4 & 0.186 & 1934.7 & 60 to 100 & 60 to 100 \\
\hline $\mathrm{C} 11$ & Modern & 4 & 0.212 & 2117.6 & 80 & 80 \\
\hline $1 \mathrm{~N}$ & Black/Fire brick & 12 & 0.159 & 1726.4 & Not Tested & Not Tested \\
\hline $1 R$ & Red & 16 & 0.384 & 1579.6 & 70 to 80 & 70 to 80 \\
\hline $2 R$ & Red & 17 & 0.402 & 1602.9 & 80 & 80 \\
\hline $4 R$ & Red & 15 & 0.389 & 1612.8 & 70 & 80 \\
\hline $5 R$ & Red & 13 & 0.394 & 1648.9 & 75 to 80 & no clear intercept \\
\hline $1 \mathrm{~W}$ & Beige & 17 & 0.391 & 1665.3 & 80 & 70 to 80 \\
\hline $2 W$ & Beige & 17 & 0.414 & 1571.5 & 80 & 80 \\
\hline $4 \mathrm{~W}$ & Red & 17 & 0.403 & 1616.3 & 80 & 75 \\
\hline $5 W$ & Red & 15 & 0.390 & 1570.2 & 80 & 75 to 80 \\
\hline $6 \mathrm{~N}$ & Beige & 2 (1/2 Bricks) & 0.354 & 1451.8 & \multirow{5}{*}{\multicolumn{2}{|c|}{$\begin{array}{l}\text { Note: Half-brick units were used for } 3 \\
\text { dimesnsional expansion uniformity testing. } \\
\text { Results are in Section 5.3.2. }\end{array}$}} \\
\hline $3 R$ & Red & 2 (1/2 Bricks) & 0.345 & 1471.4 & & \\
\hline $6 R$ & Red & 2 (1/2 Bricks) & 0.349 & 1456.2 & & \\
\hline $3 W$ & Beige & 2 (1/2 Bricks) & 0.339 & 1444.4 & & \\
\hline $6 \mathrm{~W}$ & Red & 2 (1/2 Bricks) & 0.348 & 1415.4 & & \\
\hline \multicolumn{7}{|c|}{ 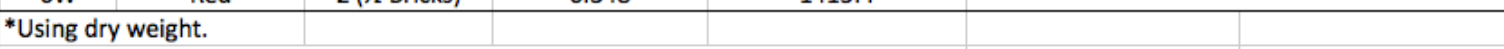 } \\
\hline \multicolumn{7}{|c|}{ **Observed from tendlines and assumes deterioration occurs at 100 Microstrain. } \\
\hline \multicolumn{4}{|c|}{ expansion less than 100 Microstrain threshold. } & & & \\
\hline
\end{tabular}

Because the 3-dimesnional ( 3 axis) measurements had to be performed on specimens thick enough to be able to measure expansion with micrometers, half-clay brick samples (100 $\mathrm{mm} \times 100 \mathrm{~mm} \times 64 \mathrm{~mm}$ ) were used. The problem this posed was by not being able to slice the clay bricks into many specimens, a very limited quantity were available to be exposed to cycles of frost dilatometry. Efforts were focuses on measuring how evenly frost dilatometry occurred in these larger specimens when they were exposed to 9 cycles of freeze-thaw while being saturated beyond the critical saturation point. These specimens 
were saturated to various levels between $70 \%$ and $85 \%$ of their maximum moisture content, just within the critical saturation region for these bricks. The results revealed that these clay brick specimens did not expand uniformly at all. Given this level of saturation, the specimens cracked and disintegrated to a degree (Figure 96, Figure 97 and Figure 98); they suffered great expansion in some direction and also shrinkage along other axes.

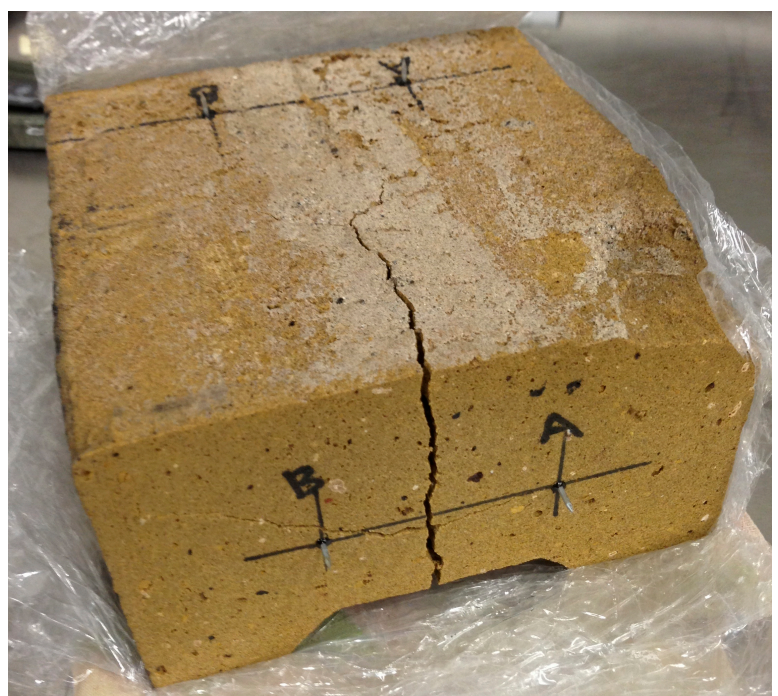

FIGURE 96: 3D FROST DILATOMETRY; UNEVEN EXPANSION.

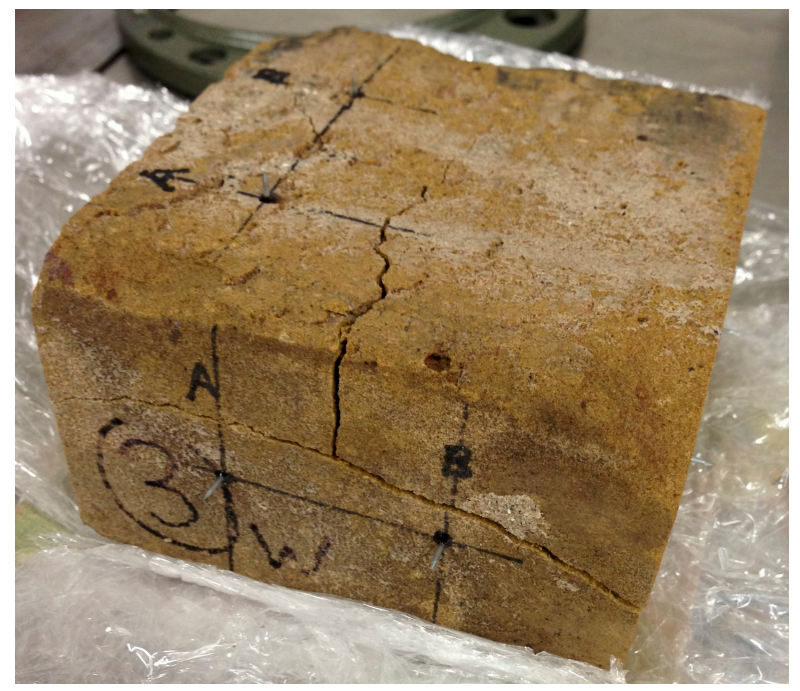

FIGURE 97: 3D FROST DILATOMETRY; UNEVEN EXPANSION.

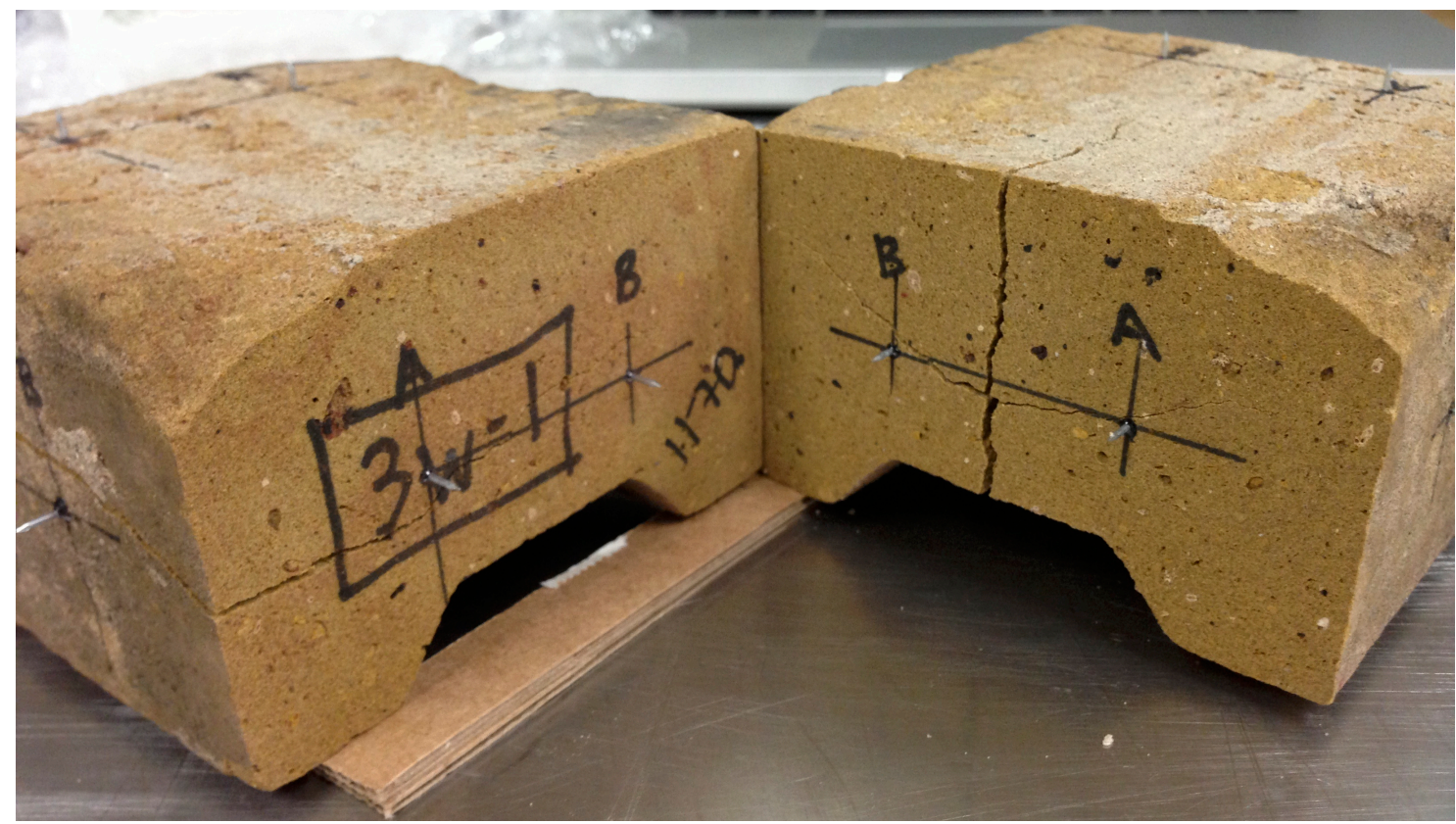

FIGURE 98: 3D FROST DILATOMETRY; CLAY BRICK EXPERIENCED DIFFERENT INTERNAL FORCES AND EXPANSION ON EITHER SIDE OF THE CUT. 
Saturation of Clay Brick

The vacuum saturation method and the boil saturation method had small differences. For the most part, the vacuum method produced a greater saturation level, on average $2 \%$ better than the boil method. There was the odd exception with specimens from four clay brick specimens, which saw a $2 \%$ better saturation using the boil method (Table 6). This may be attributed to pore characteristics in these particular specimens. Mensinga (2009) was able to produce a vacuum of $-100.2 \mathrm{KPa}(-29.6 \mathrm{inHg})$ using a superior vacuum pump; the $-94.0(-27.75 \mathrm{inHg})$ that was produced by our equipment may not have been sufficient. Mensinga (2009) used only the vacuum saturation method, so did not have boil saturation results to compare against. It should be noted that the 5-hour boil test is still an approved method for clay brick specimen saturation according to the CSA and ASTM. Any greater water saturation of the specimen achieved beyond the boil method is a bonus. For this research project, the greater of the two saturation levels was taken to be the maximum. The differential of the dry specimen weight and the saturated specimen weight is the weight of the water that the specimen can hold. This is the weight of water that can be held within the pores of a clay brick. The volume of the open pore structure within the clay brick specimen can be easily determined, given the known density of water. 
TABle 6: Boil saturation vs. vacuum Saturation. (Partial data SET.)

\begin{tabular}{|c|c|c|c|c|c|c|}
\hline Sample No. & $\begin{array}{l}\text { Wt. Dry Brick } \\
\text { Specimen }[\mathrm{g}]\end{array}$ & $\begin{array}{l}\text { Wt. 24h Natural } \\
\text { Saturation [g] }\end{array}$ & $\begin{array}{l}\text { Wt. } 5 \mathrm{~h} \mathrm{Boil} \\
\underline{\text { Saturation }[\mathrm{g}]}\end{array}$ & $\frac{\text { Wt. Vacuum }}{\text { Saturation }[\mathrm{g}]}$ & $\begin{array}{l}\text { boil vs } \\
\text { vacuum }\end{array}$ & $\frac{\text { Max. Net Water }}{[\text { gl }}$ \\
\hline $1 \mathrm{n}-1$ & 114.5 & 116.5 & 119.6 & 123.9 & $104 \%$ & 9.4 \\
\hline $1 n-7$ & 105.5 & 108.5 & 114.1 & 115.4 & $101 \%$ & 9.9 \\
\hline $1 \mathrm{n}-8$ & 106.9 & 110.8 & 116 & 117 & $101 \%$ & 10.1 \\
\hline $1 \mathrm{n}-9$ & 107.7 & 110.7 & 116 & 117.6 & $101 \%$ & 9.9 \\
\hline $1 \mathrm{n}-10$ & 105 & 108.1 & 112.6 & 114.7 & $102 \%$ & 9.7 \\
\hline $1 \mathrm{n}-11$ & 100.9 & 103.7 & 108.5 & 110.2 & $102 \%$ & 9.3 \\
\hline $1 n-12$ & 107.5 & 111 & 116.1 & 117.5 & $101 \%$ & 10.0 \\
\hline $1 r-2$ & 108.2 & 125.9 & 133.8 & 134.1 & $100 \%$ & 25.9 \\
\hline $1 \mathrm{r}-8$ & 95 & 110.7 & 117.8 & 118.1 & $101 \%$ & 23.1 \\
\hline $1 r-9$ & 98.5 & 114.8 & 122.1 & 122.7 & $103 \%$ & 24.2 \\
\hline $1 \mathrm{r}-12$ & 96.2 & 112.3 & 119.6 & 119.7 & $100 \%$ & 23.5 \\
\hline $1 \mathrm{r}-13$ & 97.7 & 114 & 121.1 & 121.5 & $102 \%$ & 23.8 \\
\hline $1 \mathrm{r}-14$ & 95.2 & 110.9 & 118.2 & 118.4 & $101 \%$ & 23.2 \\
\hline $1 \mathrm{r}-15$ & 100.6 & 117.4 & 124.8 & 125.2 & $102 \%$ & 24.6 \\
\hline $1 \mathrm{r}-16$ & 94.2 & 109.9 & 117 & 117.3 & $101 \%$ & 23.1 \\
\hline $1 w-1$ & 87.3 & 100.3 & 107 & 107.1 & $101 \%$ & 19.8 \\
\hline $1 w-7$ & 103 & 118.9 & 127.1 & 127.3 & $101 \%$ & 24.3 \\
\hline $1 w-8$ & 101.2 & 117 & 125.1 & 125.2 & $100 \%$ & 24.0 \\
\hline $1 w-9$ & 101 & 116.7 & 124.8 & 125.1 & $101 \%$ & 24.1 \\
\hline $1 w-10$ & 105.1 & 121.5 & 130 & 129.9 & $100 \%$ & 24.8 \\
\hline $1 w-11$ & 103.1 & 119.3 & 127.8 & 127.9 & $100 \%$ & 24.8 \\
\hline $1 w-12$ & 104.4 & 121.1 & 129.2 & 129.5 & $101 \%$ & 25.1 \\
\hline $1 w-13$ & 102.6 & 119.1 & 127 & 127.1 & $100 \%$ & 24.5 \\
\hline $1 w-14$ & 106.3 & 123.3 & 131.5 & 131.5 & $100 \%$ & 25.2 \\
\hline $1 w-15$ & 114.6 & 132.6 & 141.4 & 141.6 & $101 \%$ & 27.0 \\
\hline $1 w-16$ & 114.2 & 132.2 & 141.2 & 141.4 & $101 \%$ & 27.2 \\
\hline $1 w-17$ & 112 & 129.5 & 138.1 & 138.3 & $101 \%$ & 26.3 \\
\hline $2 r-1$ & 100.7 & 118.4 & 125.6 & 125.9 & $101 \%$ & 25.2 \\
\hline $2 r-7$ & 97.8 & 115 & 122.3 & 122.6 & $101 \%$ & 24.8 \\
\hline $2 r-8$ & 98.2 & 115.2 & 122.5 & 123 & $102 \%$ & 24.8 \\
\hline $2 r-9$ & 97.1 & 114.1 & 121.2 & 121.7 & $102 \%$ & 24.6 \\
\hline $2 \mathrm{r}-10$ & 98.7 & 115.9 & 123.1 & 123.5 & $102 \%$ & 24.8 \\
\hline $2 r-11$ & 99.4 & 116.3 & 123.8 & 124.3 & $102 \%$ & 24.9 \\
\hline $2 \mathrm{r}-12$ & 96.8 & 113.4 & 120.6 & 120.9 & $101 \%$ & 24.1 \\
\hline $2 \mathrm{r}-13$ & 95.7 & 111.9 & 119.1 & 119.5 & $102 \%$ & 23.8 \\
\hline $2 \mathrm{r}-14$ & 100.2 & 117.5 & 124.8 & 125.4 & $102 \%$ & 25.2 \\
\hline $2 \mathrm{r}-15$ & 105.9 & 123.8 & 131.7 & 132.3 & $102 \%$ & 26.4 \\
\hline $2 r-16$ & 104.4 & 122.2 & 130.2 & 130.5 & $101 \%$ & 26.1 \\
\hline $2 \mathrm{r}-17$ & 133 & 155.1 & 165.4 & 166.1 & $102 \%$ & 33.1 \\
\hline $2 w-1$ & 107.6 & 125.5 & 134.5 & 134.5 & $100 \%$ & 26.9 \\
\hline $2 w-2$ & 106 & 123.3 & 132.4 & 132.3 & $100 \%$ & 26.3 \\
\hline $2 w-3$ & 106.5 & 123.9 & 133.2 & 133.3 & $100 \%$ & 26.8 \\
\hline $2 w-4$ & 101.2 & 117.8 & 126.6 & 126.6 & $100 \%$ & 25.4 \\
\hline $2 w-5$ & 101.8 & 118.6 & 127.3 & 127.1 & $99 \%$ & 25.3 \\
\hline $2 w-6$ & 100.7 & 117.3 & 126 & 125.8 & $99 \%$ & 25.1 \\
\hline $2 w-7$ & 101.4 & 118.1 & 126.9 & 126.6 & $99 \%$ & 25.2 \\
\hline $2 w-8$ & 104.1 & 121.5 & 130.2 & 129.8 & $98 \%$ & 25.7 \\
\hline $2 w-14$ & 97.5 & 114.3 & 122.2 & 122.6 & $102 \%$ & 25.1 \\
\hline $2 w-15$ & 109.6 & 128.3 & 136.8 & 137.4 & $102 \%$ & 27.8 \\
\hline $2 w-16$ & 111.5 & 129.6 & 138.7 & 139.4 & $103 \%$ & 27.9 \\
\hline $2 w-17$ & 103.9 & 120.1 & 128.2 & 128.9 & $103 \%$ & 25.0 \\
\hline $4 r-1$ & 131.2 & 152.2 & 162.2 & 162.8 & $102 \%$ & 31.6 \\
\hline $4 r-8$ & 98.9 & 115.2 & 122.4 & 122.9 & $102 \%$ & 24.0 \\
\hline $4 r-10$ & 99.1 & 115.3 & 123 & 123 & $100 \%$ & 23.9 \\
\hline $4 r-11$ & 98.3 & 114.7 & 122.1 & 122.2 & $100 \%$ & 23.9 \\
\hline $4 r-12$ & 96.2 & 112.3 & 119.3 & 119.4 & $100 \%$ & 23.2 \\
\hline $4 r-13$ & 96 & 112.1 & 118.9 & 119.4 & $102 \%$ & 23.4 \\
\hline $4 r-14$ & 96.2 & 113.1 & 119.5 & 119.8 & $101 \%$ & 23.6 \\
\hline $4 r-15$ & 100.2 & 117.6 & 124.6 & 124.9 & $101 \%$ & 24.7 \\
\hline $4 w-7$ & 99.1 & 116.3 & 123.8 & 123.9 & $100 \%$ & 24.8 \\
\hline $4 w-8$ & 98.8 & 115.9 & 123.3 & 123.6 & $101 \%$ & 24.8 \\
\hline $4 w-9$ & 103.5 & 120.8 & 128.9 & 129.2 & $101 \%$ & 25.7 \\
\hline $4 w-10$ & 101.8 & 119 & 126.8 & 127.4 & $102 \%$ & 25.6 \\
\hline $4 w-11$ & 102.8 & 120.5 & 128.1 & 128.4 & $101 \%$ & 25.6 \\
\hline $4 w-12$ & 104.6 & 122.5 & 130.6 & 130.8 & $101 \%$ & 26.2 \\
\hline $4 w-13$ & 103.1 & 120.5 & 128.4 & 128.6 & $101 \%$ & 25.5 \\
\hline $4 w-14$ & 101.8 & 119.5 & 127.1 & 127.4 & $101 \%$ & 25.6 \\
\hline $4 w-15$ & 103.5 & 120.8 & 128.9 & 129.3 & $102 \%$ & 25.8 \\
\hline $4 w-16$ & 106.9 & 124.8 & 133.1 & 133.4 & $101 \%$ & 26.5 \\
\hline $4 w-17$ & 108.8 & 126.6 & 135.2 & 135.4 & $101 \%$ & 26.6 \\
\hline
\end{tabular}

Some of the higher moisture content values measured by the in-situ moisture content sensors are in the area of $15-16 \%$ M.C. for red brick. When these values are related to the moisture storage curve (refer to Figure 102 and Figure 103), the actual moisture content of the brick is revealed to be approximately $29 \%$ M.C. - less than half the value of the critical saturation point 
of the brick for the Toronto test house (which is in the area of $60 \%$ to $80 \%$ M.C. as presented in Section 6.3.1 Plotted Results of 2-Dimensional Frost Dilatometry). The moisture content of brick at the locations of the moisture content sensors is well below the critical saturation point. There is greater risk of the clay brick reaching the critical saturation point at grade, where the pooling water can saturate a brick as thoroughly as "the 24 hour natural saturation method" performed in the lab, which could saturate brick to approximately $60 \%$ of their maximum moisture content. Combined with the 17 freeze-thaw cycles experienced at the east and north elevation, or the 50 freeze-thaw cycles at the south elevation, there does exist the potential for freeze thaw damage. Even with this being the case, very little freeze-thaw damage is currently evident on any of the brick where they interface with grade. The Toronto test house is built on sandy loam, so there is very good drainage around the building. It is likely that the water around the building doesn't sit around long enough to saturate the clay brick at the base of the house into the $60 \%$ to $70 \%$ moisture content zone.

One topic that should be considered is the degree of saturation that clay brick specimens must be capable of withstanding in order to pass a frost dilatometry test. The real question that arises: is it reasonable to saturate a clay brick beyond a saturation point that naturally occurs? (I.e. saturating clay brick specimens by the vacuum method.) The benefit of such a test will lead to the determination of a critical saturation point that that can only be obtained in a laboratory. Testing for freeze/thaw expansion in clay brick by saturating beyond what it would ever likely experience in an as-built construction 
It appears the Toronto test house is safe from freeze-thaw damage, as the moisture content of the brick is well below its critical saturation point. But there is a possibility that many clay brick buildings in North American cities, including those in Toronto, may only have survived as long as they have due to their lack of insulation. As costs of energy increase, and as more people add insulation to their homes to reduce their heating costs, the effects of freeze-thaw may become more evident. If the building owners want to maintain their structure and appearance, they should not hastily rush into insulating their interior walls. Care should be taken into determining how much insulation can be added to these walls, otherwise problems could develop with moisture saturated clay brick and freeze-thaw damage occurring in severe weathering areas of North America. 


\subsection{ABSORPTION CURVE MEASUREMENTS}

Brick specimens were placed on end, and immersed approximately $3 \mathrm{~mm}$ into a shallow bath and allowed to absorb water. The bricks were quickly removed every 1-minute and weighed. Their weights were plotted the graphs below with respect to time (Refer to Figure 99, Figure 100 and Figure 101).

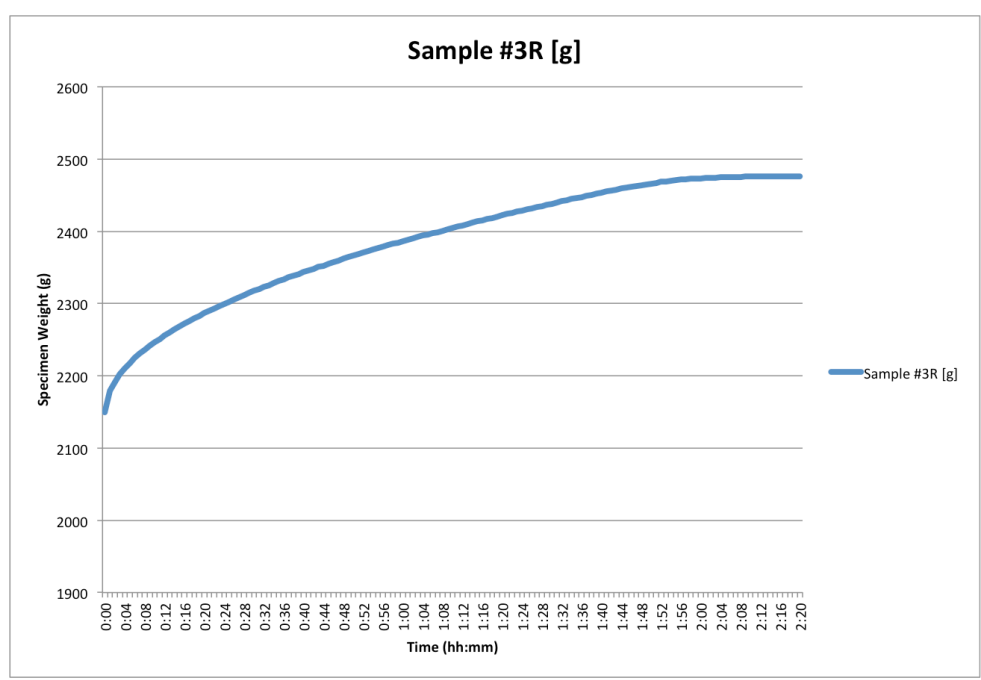

Figure 99: AbSorption CURVE For BRiCK SPECIMEN 3 R.

Specimen \#3R (Red full clay brick)

Absorption Curve, Initial A-value $=0.611 \frac{\mathrm{kg}}{\mathrm{m}^{2} \sqrt{\mathrm{s}}}$ 


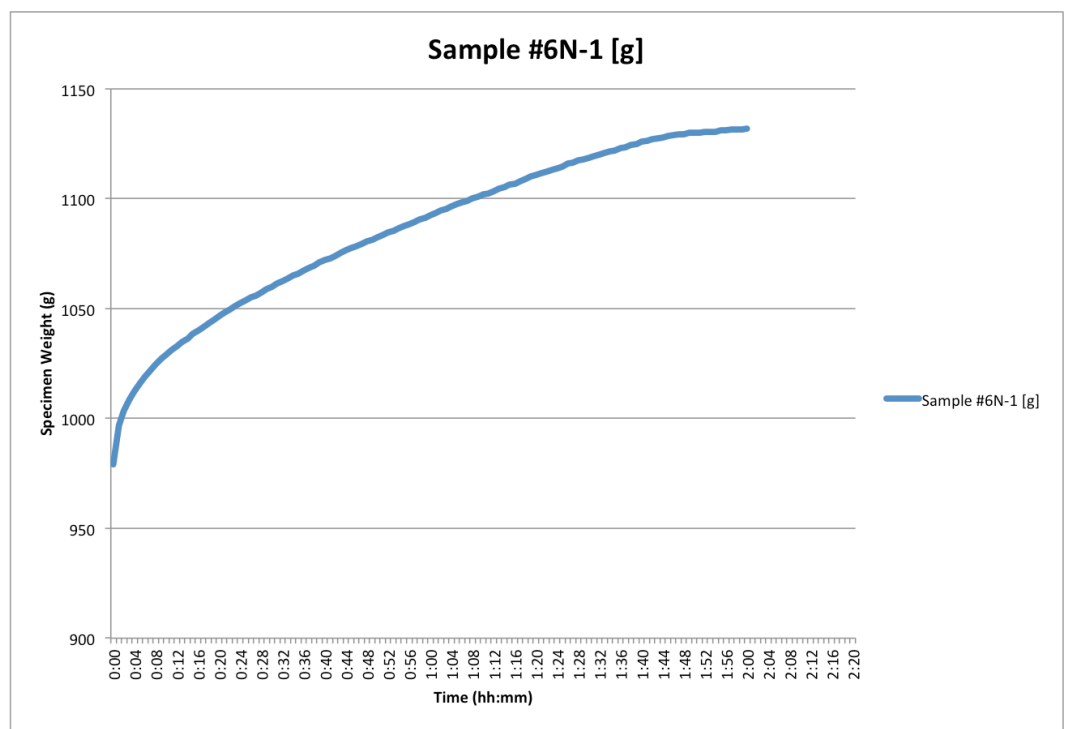

FiguRE 100: ABSORPTION CURVE FOR BRICK SPECIMEN 6N-1

Specimen \#6N-1 (beige $1 / 2$ clay brick)

Absorption Curve, Initial A-value $=0.299 \frac{\mathrm{kg}}{\mathrm{m}^{2} \sqrt{\mathrm{s}}}$

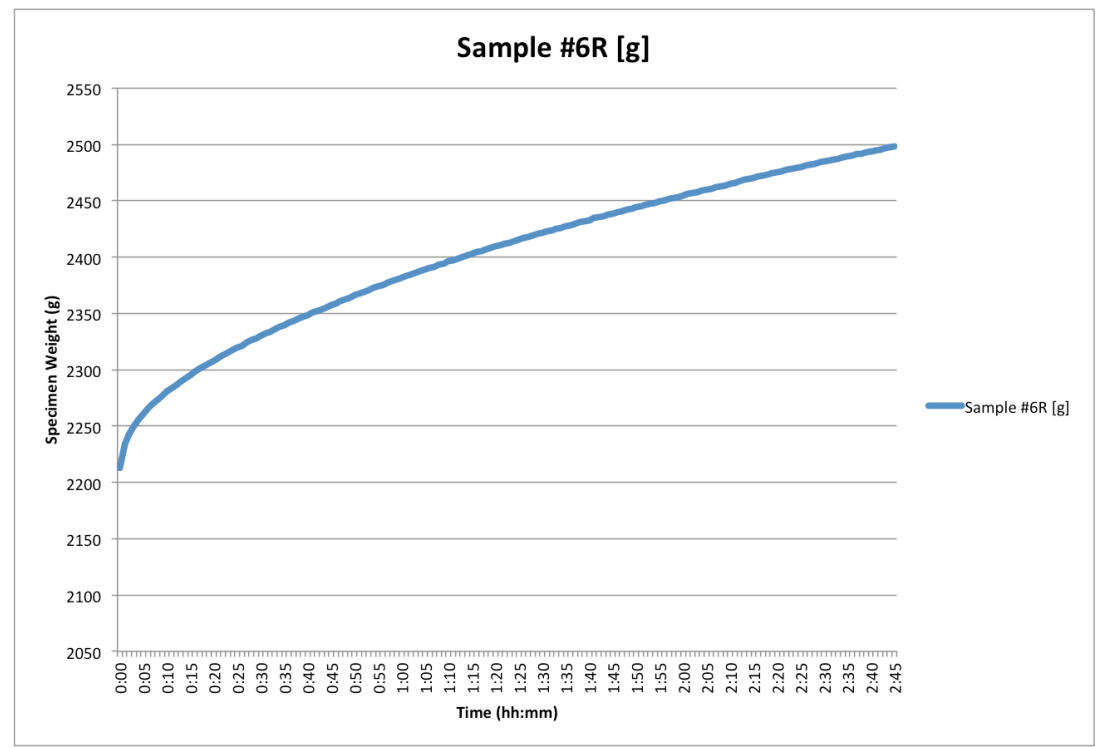

Figure 101: ABSORPtion CURVE FOR BRICK SPECIMEN 6R

Specimen \#6R (Red full Clay brick)

Absorption Curve, Initial A-value $=0.433 \frac{\mathrm{kg}}{\mathrm{m}^{2} \sqrt{\mathrm{s}}}$ 
Although the graphs in Figure 99, Figure 100 and Figure 101 represent the absorption curve for bricks standing on end, there are alternative faces on which the absorption tests may be performed. CAN/CSA-A82 calls for using the bed face of the brick for determining the absorption curve. In context of a built wall, this would be useful in determining how moisture flows vertically through a brick masonry wall assembly, from a source such as a damp foundation wall.

Another alternative method for measuring A-value would be to immerse the brick's weathering face (the face of the brick exposed to the exterior side of the building) into the bath of water. In this instance, the data obtained would be useful for determining how water flows transversely thought a brick masonry wall assembly, and would be representative moisture taken on by wind driven rain hitting an exterior wall.

For this project, the bricks were measured on their end so that moisture would have to travel the longest distance, creating the longest curve with respect to duration of measurement. 
The experiment confirmed that while the relative humidity inside the vessel reached the desired level in under 2 hours, the moisture content sensor embedded in the clay brick took approximately a week to equilibrate to the moisture level inside the vessel.

Both clay brick types were allowed to acclimatize over each salt solution (listed in Table 3 ) for over one week. After a seven-day period, the vessel was opened, and the clay brick specimens were weighed. The results are listed in Table 7.

Table 7: RH to Gravimetric Clay brick Moisture Content Relationship

\begin{tabular}{|c|c|c|c|c|c|c|c|c|c|}
\hline Brick & $\mathrm{Wt}_{\text {Dry }}[\mathrm{g}]$ & $\mathrm{Wt}_{\text {Soturated }}[\mathrm{g}]$ & $\mathrm{Wt}_{\text {Max Net Water }}[\mathrm{g}]$ & $\mathrm{Wt} @ 45 \% \mathrm{RH}$ \% Sat'n @45 & Wt @76\% RH \% Sat'n @76 & Wt @100\% RH \% Sat'n @ 100 \\
\hline $6 \mathrm{n}-2$ & 980.0 & 1221.0 & 241.0 & 983 & $1.24 \%$ & 984 & $1.66 \%$ & 994.5 & $6.02 \%$ \\
$6 \mathrm{r}-2$ & 927.5 & 1101.5 & 174.0 & 931.0 & $2.01 \%$ & 931.5 & $2.30 \%$ & 939.0 & $6.61 \%$ \\
\hline
\end{tabular}

The gravimetric clay brick moisture content results from Table 7 were imported into WUFI to create an extrapolated sorption isotherm curve for both brick types. The extrapolated values for the red brick are listed in Table 8 with the resulting sorption isotherm curve shown in Figure 102. The extrapolated sorption values for the beige brick are listed in Table 9 with the associated sorption isotherm curve shown in Figure 103. The sorption isotherm curves of the red brick and the beige brick are very similar to one another with the exception of the maximum of the curves: the beige brick has a slightly steeper slope. 
TABLE 8: WUFI EXTRAPOLATED SORPTION ISOTHERM VALUES FOR RED BRICK.

\begin{tabular}{|c|c|c|}
\hline \multicolumn{3}{|c|}{ Red Brick (6r-2) Sorption Isotherm } \\
\hline No. & RH [\%] & Moisture Content [kg/m $\left.\mathbf{m}^{3}\right]$ \\
\hline 1 & $0 \%$ & 0 \\
\hline 2 & $10 \%$ & 0.11 \\
\hline 3 & $20 \%$ & 0.24 \\
\hline 4 & $30 \%$ & 0.4 \\
\hline 5 & $40 \%$ & 0.61 \\
\hline 6 & $50 \%$ & 0.89 \\
\hline 7 & $55 \%$ & 1.07 \\
\hline 8 & $60 \%$ & 1.29 \\
\hline 9 & $65 \%$ & 1.56 \\
\hline 10 & $70 \%$ & 1.89 \\
\hline 11 & $75 \%$ & 2.32 \\
\hline 12 & $80 \%$ & 2.9 \\
\hline 13 & $85 \%$ & 3.72 \\
\hline 14 & $90 \%$ & 4.96 \\
\hline 15 & $91 \%$ & 5.29 \\
\hline 16 & $92 \%$ & 5.69 \\
\hline 17 & $93 \%$ & 6.08 \\
\hline 18 & $94 \%$ & 6.54 \\
\hline 19 & $95 \%$ & 7.08 \\
\hline 20 & $96 \%$ & 7.7 \\
\hline 21 & $97 \%$ & 8.41 \\
\hline 22 & $98 \%$ & 9.26 \\
\hline 23 & $99 \%$ & 10.27 \\
\hline 24 & $100 \%$ & 11.5 \\
\hline & & \\
\hline
\end{tabular}

TABLE 9: WUFI EXTRAPOLATED SORPTION ISOTHERM VALUES FOR BEIGE BRICK.

\begin{tabular}{|c|c|c|}
\hline \multicolumn{3}{|c|}{ Beige Brick (6n-2) Sorption Isotherm } \\
\hline No. & RH [\%] & Moisture Content $\left[\mathrm{kg} / \mathrm{m}^{3}\right.$ ] \\
\hline 1 & $0 \%$ & 0 \\
\hline 2 & $10 \%$ & 0.11 \\
\hline 3 & $20 \%$ & 0.24 \\
\hline 4 & $30 \%$ & 0.41 \\
\hline 5 & $40 \%$ & 0.62 \\
\hline 6 & $50 \%$ & 0.91 \\
\hline 7 & $55 \%$ & 1.09 \\
\hline 8 & $60 \%$ & 1.31 \\
\hline 9 & $65 \%$ & 1.58 \\
\hline 10 & $70 \%$ & 1.91 \\
\hline 11 & $75 \%$ & 2.33 \\
\hline 12 & $80 \%$ & 2.9 \\
\hline 13 & $85 \%$ & 3.69 \\
\hline 14 & $90 \%$ & 4.87 \\
\hline 15 & $91 \%$ & 5.18 \\
\hline 16 & $92 \%$ & 5.52 \\
\hline 17 & $93 \%$ & 5.91 \\
\hline 18 & $94 \%$ & 6.34 \\
\hline 19 & $95 \%$ & 6.83 \\
\hline 20 & $96 \%$ & 7.39 \\
\hline 21 & $97 \%$ & 8.03 \\
\hline 22 & $98 \%$ & 8.77 \\
\hline 23 & $99 \%$ & 9.65 \\
\hline 24 & $100 \%$ & 10.7 \\
\hline & & \\
\hline
\end{tabular}

FIGURE 102: WUFI EXTRAPOLATED SORPTION ISOTHERM CURVE FOR RED BRICK.

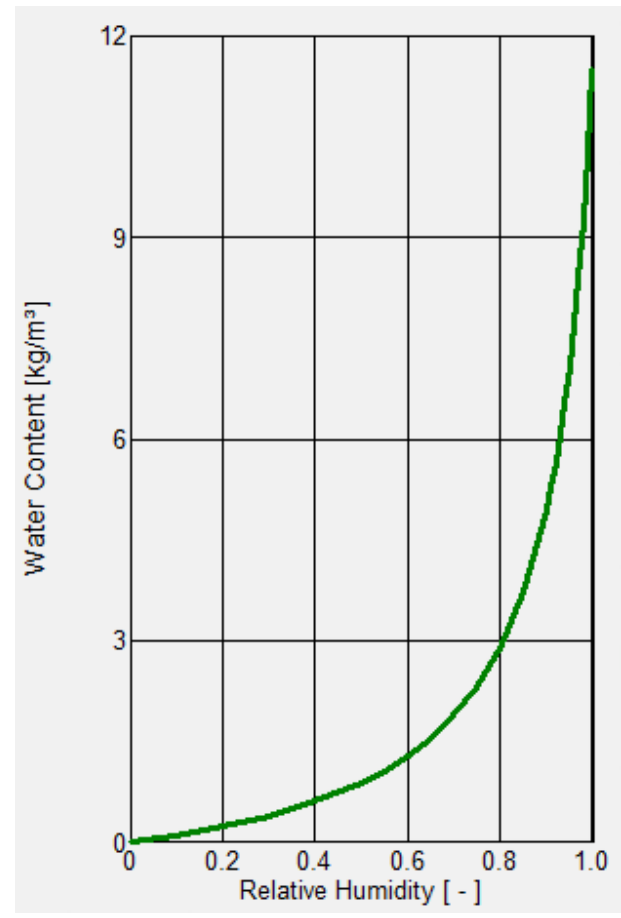

FIGURE 103: WUFI EXTRAPOLATED SORPTION ISOTHERM CURVE FOR BEIGE BRICK.

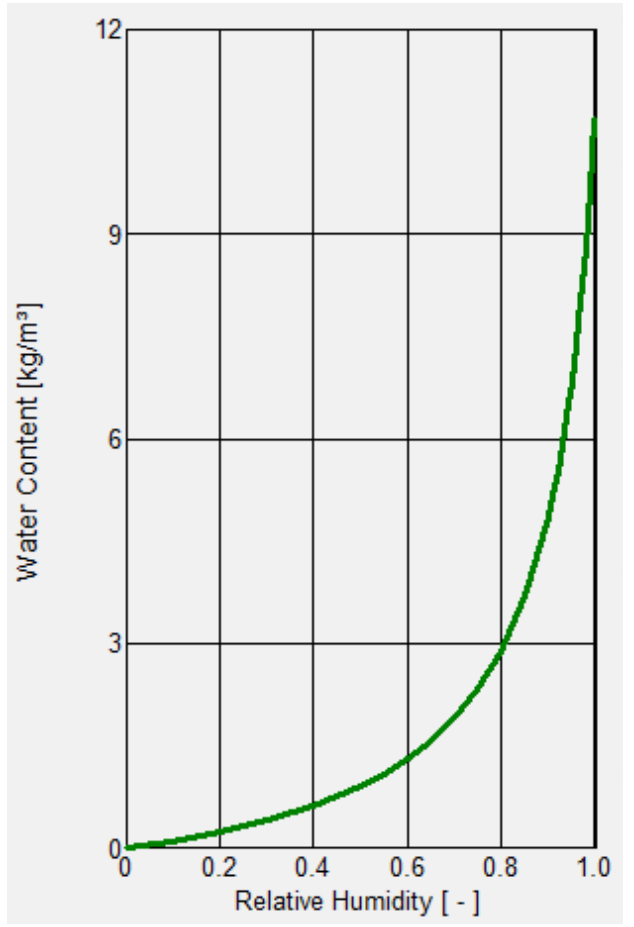


Once the gravimetric measurements were taken of both brick types at different humidities, the entire process was repeated with Moisture Content sensors installed within bricks. The bricks, and sensors within, were sealed inside a vessel with a controlled relative humidity, and allowed to acclimatize over a 1-week period. The following calibration curves were obtained by charting the gravimetric moisture content against the moisture content sensor for each type of clay brick (Refer to Figure 104 and Figure 105).

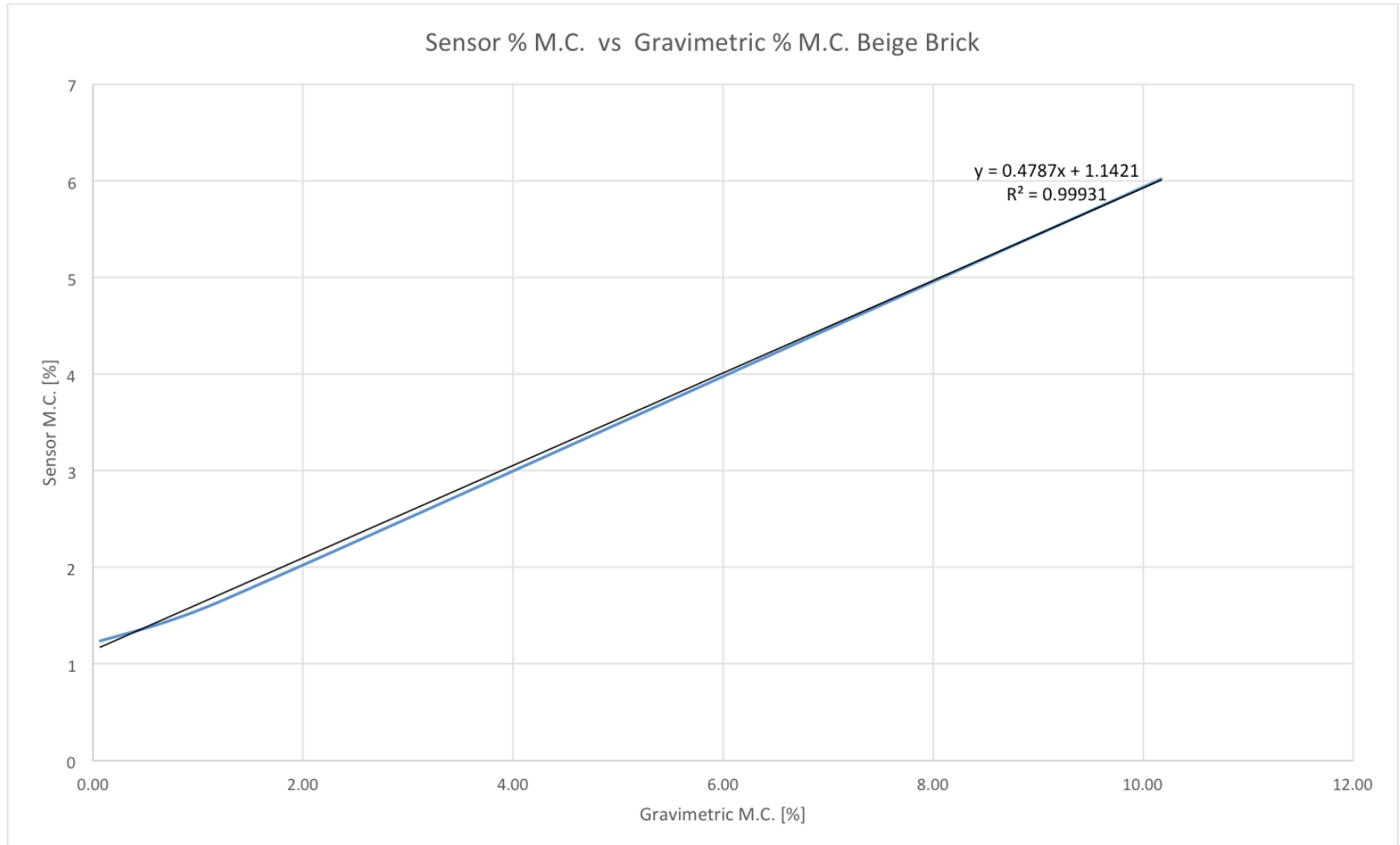

Figure 104: Moisture Content Sensor Correlation to Gravimetric Moisture Content for Beige Clay brick. 
Sensor \% M.C. vs Gravimetric \% M.C. Red Brick

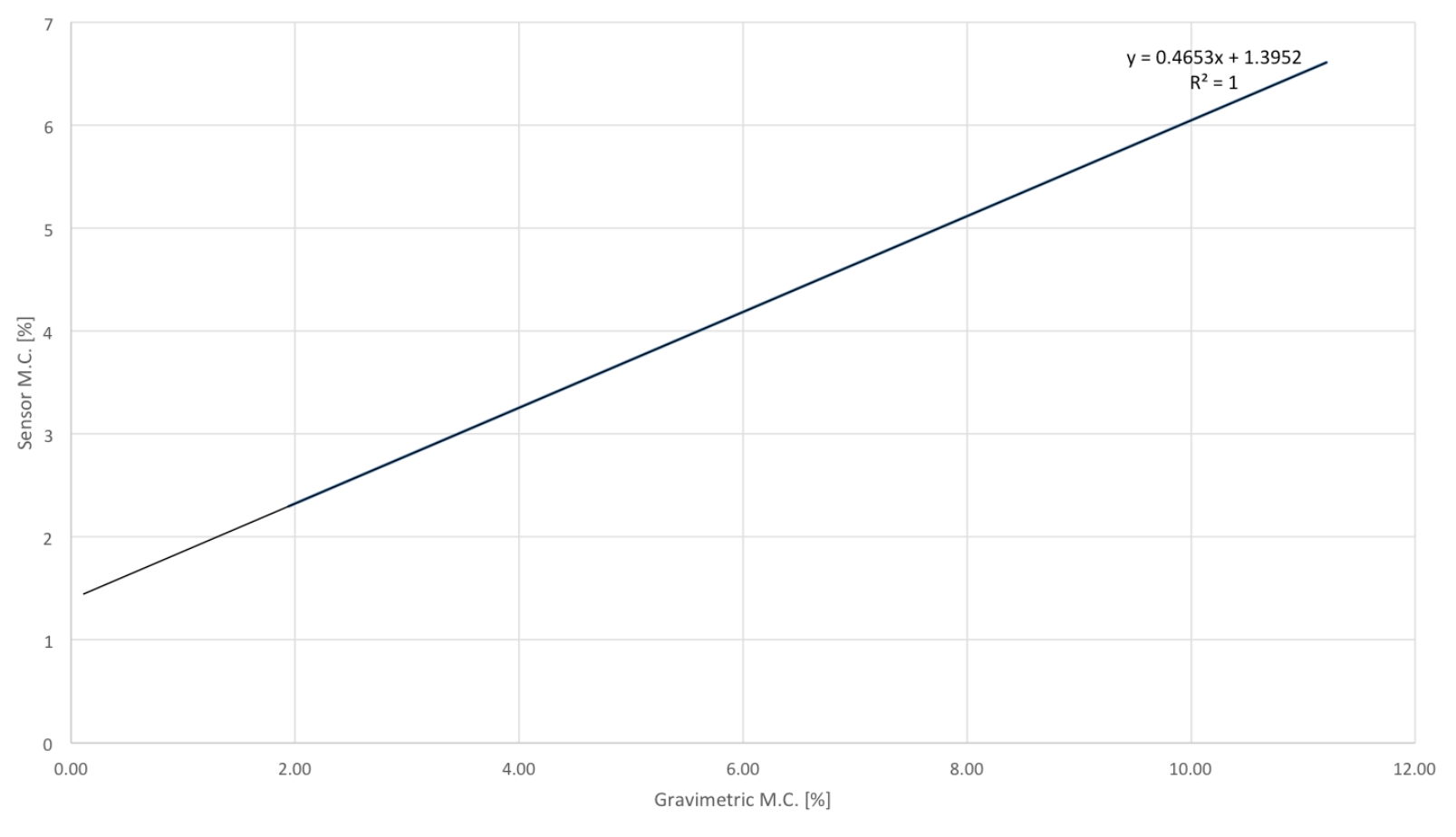

Figure 105: Moisture Content Sensor Correlation to Gravimetric Moisture Content for Red Clay brick.

A great deal of effort was taken in developing the calibration relationships between gravimetrically and sensor-measured moisture contents for the beige and red clay bricks. However, the calibration curve does not appear accurate enough to produce an actual brick moisture content prediction based on the raw moisture content values from the wooden sensors. When the conversion formulas (as indicated beside the trend lines in Figure 104 and Figure 105) were applied to the raw moisture content data recorded by the data loggers, the results did not appear to calculate expected Moisture Content values, especially around particular rain events that should have soaked the wall. Table 10 shows some "Measured" (raw) moisture content values, and "Actual Predicted" (calculated) values from the formula for red brick at sensor location "P" for three different periods in time to show different ranges of exterior temperatures. The calculated M.C. values predicted are close to the raw values, but not close enough to be accurate. When the temperature is warm and the 
brick has relatively low moisture content, the calculated M.C. values are in the negatives. Further field research is required with this method in order to develop the process to a level capable of being applied in practice.

TAble 10: Sample of MC measurements and Corrected/PRedicted MC at SEnSors location P.

\begin{tabular}{|c|c|c|}
\hline $\begin{array}{l}\text { Location P Ext. } \\
\text { Wythe Temp [C] }\end{array}$ & $\begin{array}{l}\text { Location P Ext. Wythe } \\
\text { Measured MC [\%] }\end{array}$ & $\begin{array}{l}\text { Location P Ext. Wythe } \\
\text { Actual Predicted MC [\%] }\end{array}$ \\
\hline 5.49 & 4.00 & 5.97 \\
\hline 5.35 & 3.72 & 5.38 \\
\hline 5.17 & 3.68 & 5.30 \\
\hline 4.89 & 3.64 & 5.21 \\
\hline 4.64 & 3.60 & 5.13 \\
\hline-1.96 & 3.05 & 3.98 \\
\hline-2.10 & 3.04 & 3.97 \\
\hline-3.24 & 2.94 & 3.75 \\
\hline-3.13 & 2.95 & 3.77 \\
\hline-2.71 & 2.99 & 3.86 \\
\hline-2.34 & 3.02 & 3.92 \\
\hline-2.00 & 3.04 & 3.97 \\
\hline-1.60 & 3.07 & 4.03 \\
\hline-1.33 & 3.08 & 4.05 \\
\hline-1.17 & 3.08 & 4.06 \\
\hline 15.02 & 0.49 & -1.35 \\
\hline 15.19 & 0.52 & -1.30 \\
\hline 15.59 & 0.56 & -1.21 \\
\hline 16.29 & 0.63 & -1.08 \\
\hline 16.81 & 0.66 & -1.00 \\
\hline 18.30 & 0.76 & -0.79 \\
\hline 18.54 & 0.75 & -0.83 \\
\hline 18.92 & 0.74 & -0.84 \\
\hline 19.12 & 0.71 & -0.91 \\
\hline 19.33 & 0.67 & -0.98 \\
\hline 19.34 & 0.63 & -1.07 \\
\hline 19.45 & 0.59 & -1.16 \\
\hline 19.35 & 0.53 & -1.29 \\
\hline 18.98 & 0.45 & -1.45 \\
\hline 18.61 & 0.39 & -1.58 \\
\hline
\end{tabular}

The accuracy in these moisture content correction formulas remain in question, so the safer choice for presenting the results of this thesis is to leave the moisture content sensor measurements as tuned by the supplier, in moisture content of the hemlock wood dowel from which they are made.

When using measured data from the Onset equipment, a comparison can be made between the measured $\mathrm{RH}$ and the measured moisture content readings at a particular moment in time. The corresponding measurements in Figure 106 have been chosen to compare 
measurements between the RH instrumentation and the moisture content measuring equipment; a red vertical line indicates the point of comparison (at "2013/2/10"). The line is positioned near the end of a plateau where the exterior $\mathrm{RH}$ is relatively stable, and the exterior wythe moisture content measurement is also flat. At this point in time the Relative humidity is measured to be $85 \% \mathrm{RH}$, and the moisture content is measured to be $3.2 \%$ (raw). These measurements can be cross-referenced with the isotherm curve in Figure 102: at $85 \% \mathrm{RH}$, the moisture content of the brick should be approximately $4 \mathrm{~kg} / \mathrm{m}^{3}$ which is an unrealistically low value, given that the red brick is capable of holding roughly 382 $\mathrm{kg} / \mathrm{m}^{3}$ during vacuum saturation.

There are several possible reasons for the apparent error identified above. It could be the result of the limited number of clay bricks used to build the calibration curves. If this work was to be repeated, calibration curves should be developed for 5 or 10 clay bricks, and averaged. A single moisture content sensor is not adequate for performing this task, especially given the visibly varying degree of homogeneousness between sliced brick specimens. In order to efficiently benchmark calibration curves to relative humidity, multiple dedicated moisture content sensors, as well as instrumentation, would be required. This is recommended for future work and is beyond the scope of this thesis. 


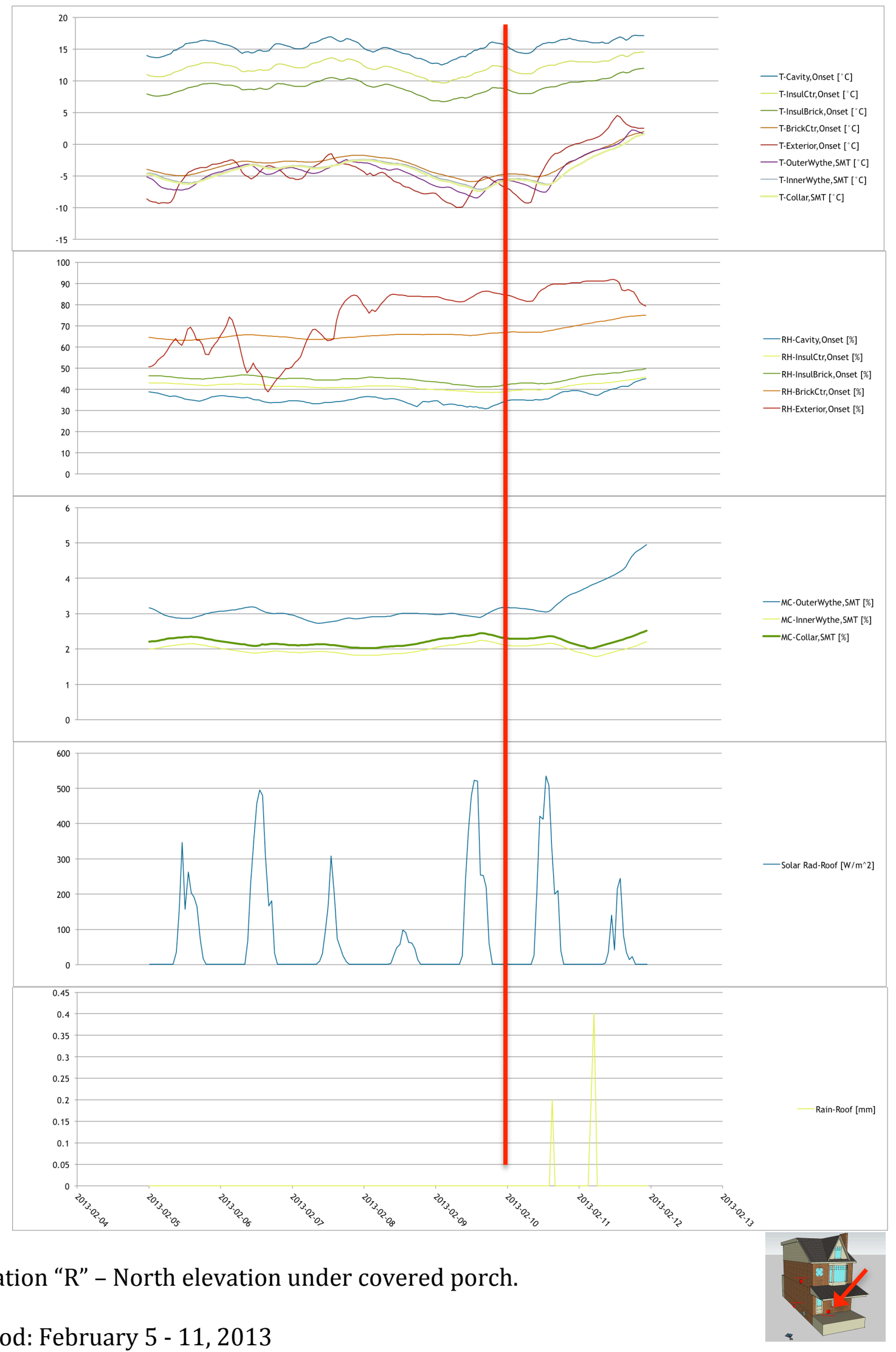

Period: February 5 - 11, 2013

Figure 106 Sensor Measurements from location "R" - North elevation under porch. Jan 22-28, 2013. 


\section{CONCLUSIONS}

The first objective of this study was to determine if a simple reference tool could be created for the future visual review of the exterior wall assemblies. Using panoramic photostitching software, constructing large composites of existing-condition building elevations is possible, but it is tedious and time consuming. The software used for this project is very powerful, however was not designed for this particular application. As a result, many hours were spent coaxing the program to stitch the photos in a representative manner. Therefore, other methods should be explored such as mapping individual images to a CAD elevation drawing key map. In the future, improvements in technology - both of the photo-stitching computer software, and of the camera itself, may make it easier to assemble gigapixel images automatically.

The second research question addressed whether or not the heavily insulated walls allow the exterior side of the building envelope to cool and stay frozen in the winter. The exterior brick masonry walls of the Toronto test house walls do closely follow the exterior temperature, particularly on the north and east elevations. However, the climate in Toronto typically does not steadily stay below the freezing point over the winter months, so even on elevations sheltered from solar radiation, the temperature of the exterior brick masonry walls cycle above and below the freezing point. Where walls are protected from solar radiation, less than 20 freeze-thaw cycles were experienced by the brick masonry. Where exposed to solar radiation, approximately 50 freeze-thaw cycles were experience by the brick masonry on the south elevation. Solar heat gains are a major factor in increasing the number of freeze-thaw cycles experience in a winter. 
Furthermore, in terms of frost dilatometry, this study examined if the expansion of clay brick is greater along one particular axis, or if brick expands uniformly in all directions. As can be seen from the 3-dimensional frost dilatometry expansion graphs, the bricks analysed here do not expand in a uniform manner; they expand in very inconsistent patterns. Adjacent specimens cut from the same brick expand and crack in different directions; this is likely caused by different patterns of moisture storage within a single brick.

Finally, this research explored if it is possible to use sensors embedded in the brick wall insitu to monitor if the moisture content of brick units approach the critical saturation point during winter months. Wood surrogate moisture content sensors are very capable of measuring moisture within a brick, however their speed and accuracy are in question. Issues experienced with precisely calibrating the moisture content sensors were not aided by the few specimens analysed to build the RH calibration curve. Moisture content measurements of brick at the Toronto test house from the in-situ moisture content sensors reveal that the moisture content is half that of the critical saturation point. This demonstrates that it is possible to use wood surrogate moisture content sensors in brick to determine how closely the moisture content is to the critical saturation point. However, determining the critical saturation point requires some initial destructive testing. The brick at the Toronto test house should continue to age well, even with the recently installed polyurethane foam insulation on the interior. 


\section{FURTHER RESEARCH AND FUTURE WORK}

WUFI

The next step for future work would be to take the clay brick critical saturation point data, the A-value data and the porosity data and develop an accurate WUFI computer model for long-term projection of the clay brick walls at the Toronto test house.

\section{Areas of improvement}

A problem that became evident during the frost dilatometry measurement process was how delicate the wear-pins were. The slightest bump while handling the clay brick specimens was enough to move or blunt the pin tips, which could cause error in the measurement. Also, the pins used were of mild carbon steel; extensive use in the lab around water would cause them to rust, and their fine tips could corrode away further adding error to the measurements. When future work is being performed, hardened stainless wear pins should be used as the measurement points for the micrometers. Although the scale used in for the majority of this work had a precision of $0.1 \mathrm{~g}$, the use of a highly precise scale with a resolution of $.01 \mathrm{~g}$ would have been beneficial, and likely would have helped eliminate error with regards to saturating the specimens to the desired moisture content.

The size of the sample set was an issue with this project, especially when it came to building the calibration curve for the moisture content sensors. A limited number of clay bricks (just over a dozen) were extracted from the exterior wythe of the Toronto test 
house, and distributed amongst the different research areas of this paper. More brick specimens should be analysed during future work. Additional clay brick specimens could have also been extracted from the inner wythe, to help build much larger data set.

The moisture content sensors provided a slow response time, as shown in the graphs. If a much smaller sensor could be developed, response time may improve. Also improvements to the installation process could provide improved measurement accuracy and speed. Developing a technique to compress the wood dowel before insertion into the brick could provide a much better contact to the pore structure of the brick without the need for brickdust as an intermediate capillary transport mechanism between the brick and the dowel.

Further work studying the 3-dimensional freeze-thaw dilatometry of brick specimens could be investigated. Due to a limited number of specimens, the scope of the 3-D work in this project was limited the analysis to within the critical saturation region, however it would be beneficial to determine if different critical saturation points exist along different axes. 
APPENDIX A - PROCEDURES 


\section{PROCEDURE \#1: FROST DILATOMETRY PROCEDURE}

Procedure as outlined in "Assessing the Freeze-Thaw Resistance of Clay Brick for Interior Insulation Retrofit Projects" (Straube et al., 2010), "ASTM C67-11 - Standard Test Method for Sampling and Testing Brick and Structural Clay Tile" (American Society for Testing and Materials, 2011a) and “The critical degree of saturation method of assessing the freeze/thaw resistance of concrete" (Fagerlund, 1977).

Equipment list:

- Diamond bladed masonry saw

- Laboratory drying oven $\left(105^{\circ} \mathrm{C}\right)$

- Digital scale (0.5 g sensitivity)

- Permanent marker

- $\quad$ Epoxy

- Distilled Water

- Hard stainless pins

- Large Micrometer 100mm (4") Ratchet-type accurate to $\pm 0.001 \mathrm{~mm}( \pm 0.00004 ")$

- Boiling apparatus
- Container $(<13 \mathrm{~mm} \times 300 \mathrm{sq}$ in $)$

- Sprint level

- Supports for Clay brick

- Small recirc. Water pump

- Constant-Temperature room $\left(21 \pm 1.4^{\circ} \mathrm{C}\right)$

- $\quad$ Timing device (seconds)

- Programmable Automatic Freezer/Thaw Chamber (<$\left.15^{\circ} \mathrm{C}\right)$

- Aluminum foil

- Plastic kitchen wrap 
Procedure:

1) Slice clay brick into $10 \mathrm{~mm}$ wide pieces, like a loaf of bread. Slice as many as possible; a minimum of 12 pieces is required. Pieces must be full width and cannot be broken.

2) Number each of the specimens.

3) Dry the samples in a $105^{\circ} \mathrm{C}$ lab oven (Hall \& Hoff, 2012). Measure the mass of the samples periodically during the drying process. When the change in mass is reduced to less than $0.05 \%$ after a 2 -hour duration in the oven, the specimen is considered to be dry. Record the dry mass of each specimen.

4) Determine the saturated mass of each of the samples as outlined in ASTMC67-11, 5.1:

a. Submerge the specimens into clean room temperature water (15.5 to $30^{\circ} \mathrm{C}$ ). Ensure water can circulate all sides of the samples.

b. Heat the water to a boil, and maintain the boil for 5 hours.

c. Remove the heat, and allow the water to cool to 15.5 to $30^{\circ} \mathrm{C}$.

d. Remove each of the cooled specimens from the bath, wipe off the excess water with a damp cloth, and record each of their saturated weights.

5) Determine the absorption coefficient as outlined in ASTM C67-11, 10.3:

a. Begin with dried samples (as outlined above).

b. Measure and record the dimensions of the flat surface and calculate the area of each sample.

c. Position the container so the bottom is flat and level. 
d. Place the reference sample on top of the supports in the container. Add water until $3.18 \mathrm{~mm} \pm 0.25 \mathrm{~mm}$ above the supports.

e. Remove the reference sample, and place the specimens on the supports with the largest face in contact with the water.

f. Time the immersion of sample: the specimen should be in contact with the water for 1 minute $( \pm 1 \mathrm{~s})$.

g. Quickly remove the specimen from the supports, wipe off the excess water with a damp cloth, weigh and record the mass.

h. Quickly re-immerse the bottom of the specimen in the bath on top of the supports for another minute, and repeat.

i. Perform this measurement until the specimen is completely saturated. The "1-minute" immersion period may need to be adjusted depending on the porosity of the specimen (eg. Adjust to 5-minute intervals.)

j. For each specimen, plot the change in mass against the square root of the time of immersion.

6) Prepare samples for length measurements:

a. In the centre of the end face that terminates the length of the specimen, drill a shallow hole into the sample, large enough to accommodate a mechanical pin.

b. Insert the pin into the hole; its length should be shallow in the hole. The pin themselves should be a stainless hard metal material.

c. Once fitted, use a two-part epoxy to bond the pin into the dry clay brick specimens. 
d. Allow the epoxy to harden as recommended by the manufacturer.

7) Measure Dimensions of the specimens:

a. Calibrate the micrometer on a gauge block before each use.

b. Take a micrometer measurement of the outer dimensions of the rounded pins inserted into the samples in the previous steps. Tighten the ratchet on the micrometer until it clicks. Mark this orientation on the specimen. Pins must be aligned with the very centre of the calliper anvils to produce the most consistent and accurate measurement.

c. Rotate the sample $180^{\circ}$ and take a second measurement, and note the orientation of the specimen.

d. Use the average of the two values at the measured value.

8) Determine the first round of $s_{c r i t}$ to the nearest $20 \%$ degree:

a. Start with five specimens.

b. Add water to $.2, .4, .6, .8$ and 1.0 of the saturated moisture content for reach respective specimen:

i. For lower moisture contents simply add measured water to the surface of the sample.

ii. For greater moisture contents, specimens may require drying a saturated specimen down to the desired mass.

c. Wrap each of the specimens in aluminum foil, then in plastic wrap, eliminating as much airspace as possible while sealing the plastic tightly. 
d. Let the specimens sit for 24 hours to allow moisture to evenly distribute. (If specimens have an A-value below $0.005 \mathrm{~kg} /\left(\mathrm{m}^{2} \cdot \mathrm{s}^{1 / 2}\right)$ then more time should be allotted to allow the water to distribute evenly, up to 72 hours.

e. Subject the specimens to 6 complete freeze-thaw cycles. $\left(-18^{\circ} \mathrm{C}\right.$ of a conventional freezer is fine.)

f. Unwrap the specimens and weigh them to confirm they have not lost significant moisture during the freeze/thaw process.

g. Measure the lengths of the specimens as in step 7 above.

h. Calculate the amount of expansion experienced by each of the samples using the formula:

$\mu \varepsilon=\frac{l_{6}-l_{0}}{l_{0}} \times 10^{6}$

where:

$\mu \varepsilon=$ expansion [micro strain]

$l_{0}=$ initial specimen length $[\mathrm{mm}]$

$l_{6}=$ specimen length after six freeze thaw cycles $[\mathrm{mm}]$

i. The specimen that shows the most dramatic increase in micro stain is considered to be the one showing frost damage. Note the moisture content of these samples. The second round of analysis will more precisely focus on this range of moisture content below this range. 
(eg.: If the 0.8 moisture content specimen showed the most expansion, then the next round will analyze specimens between 0.6 to 0.8 of saturated moisture content.)

j. Samples that underwent freeze/thaw not showing frost dilation can be reused in subsequent tests; samples showing frost dilation damage should be excluded.

9) Determine the second round of $s_{\text {crit }}$ to the nearest $5 \%$ degree:

a. If frost dilation occurred in the 0.8 moisture content sample then specimens having moisture contents of $0.65,0.7$ and 0.75 should now be prepared and analyzed as outlined in Step 8 above.

b. Samples that underwent freeze/thaw not frost showing dilation can be reused in subsequent tests; samples showing frost dilation damage should be excluded.

10)Determine the third round of $s_{\text {crit }}$ to the nearest $1 \%$ degree:

a. If frost dilation occurred in the 0.8 moisture content sample then specimens having moisture contents of $0.75,0.76,0.77,0.78$ and 0.79 should now be prepared and analyzed as outlined in Step 8 above, and performed on as many samples as possible.

b. Note the $s_{\text {crit }}$ of these final specimens. The average of the $s_{c r i t}$ for the $1 \%$ degree of saturation specimens should be taken as the final value. 


\section{PROCEDURE \#2: MAKING WOOD SURROGATE RH SENSORS}

Prior to investigating and purchasing wood surrogate moisture content sensors from SMT Research, this procedure was researched and assembled. It was included in the thesis to illustrate how these sensors are made. Do-it-yourself moisture content sensors are outlined in:

"Standard Test method for Determining Relative Humidity in Concrete Floor Slabs Using in situ Probes" (American Society for Testing and Materials, 2011b)

"Standard Test Methods for Direct Moisture Content Measurement of Wood and Wood-Base Materials" (American Society for Testing and Materials, 2007)

"Methodology and Design of Field Experiments for Monitoring the Frame Enclosures" (Straube et al., 2002)

Equipment list:

- Hammer drill

- $12.7 \mathrm{~mm}\left(1 / 2^{\prime \prime}\right)$ diameter percussionary drill bit

- Douglas Fir wood dowel, $6 \mathrm{~mm}$ dia., clear

- Pico PT-400 Resistance Data Logger
- Insulated pins/stainless steel nails/stainless steel screws

- Insulated copper lead wire

- Solder

- Soldering Iron

- Fine saw

- Utility knife 
- Linesman pliers

- Sewing Pins, all metal.

- Multimeter (accurate within the range of $1 \Omega-4 \mathrm{M} \Omega$ )
- Dremel rotary tool/fine drill

- Precision drill bit set

- Polyurethane Caulking

Procedure:

1) Cut the wood dowel into a $40 \mathrm{~mm}$ length. The dowel piece should be clear (free of knots, unusual grain, blemish, etc.)

2) Drill a small pilot hole into the centre of each end of the dowel about $5 \mathrm{~mm}$ deep. Use a bit slightly smaller than the diameter of the pins to be used, and only be large enough to prevent the dowel from splitting when the pins are inserted.

3) Prepare the pins by soldering lead-wires to one end of the pin. Ensure a "hot" solder joint. Test that the resistance of this assemble is less that $1 \Omega$ from end to end.

4) Thread/insert the pin into the pilot hole to a depth of $7.5 \mathrm{~mm}$. When finished the distance between the tips of the pins inside the wood should be $25 \mathrm{~mm}$.

5) Seal the ends of the dowel with a moisture impermeable coating, such as epoxy or polyurethane. 
6) Create the circuit designed by J. Straube, D. Onysko, and C. Schumacher (Straube et al., 2002) for each sensor. Connect the wood dowel "resistors" as $\mathrm{R}_{\mathrm{w}}$ in this circuit. Use a multi-meter or Datalogger to measure the resistance across $\mathrm{R}_{\text {s. }}$

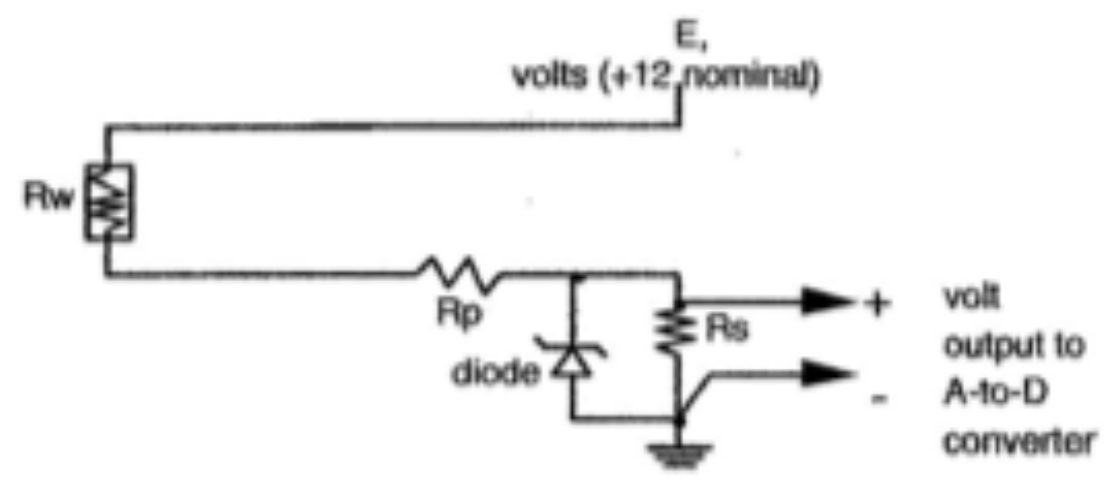

Figure 107: Voltage divider circuit (Straube et al., 2002).

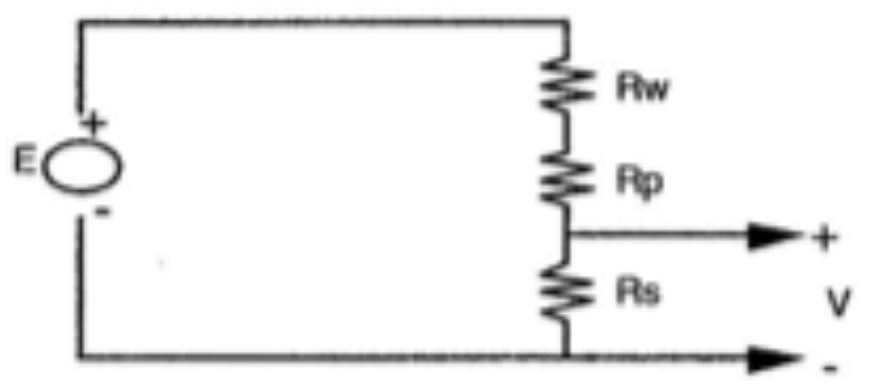

Figure 108: Voltage divider Circuit (Straube et al., 2002).

$\mathrm{R}_{\mathrm{p}}=\mathrm{R}_{\mathrm{s}}=100 \mathrm{k} \Omega$

$\mathrm{D}=5.6 \mathrm{~V}$ (or $12 \mathrm{~V}$ ) Zener diode (for instrumentation protection)

7) The following formula (provided by the US Forest Products Lab) can be used to determine the moisture content of Douglas Fir: 


$$
\log _{10}\left(M C_{u}\right)=2.99-2.113\left(\log _{10}\left(\log _{10}\left(R_{w}\right)\right)\right)
$$

where:

$\mathrm{MC}_{\mathrm{u}}=$ Moisture content of Douglas Fir (\% Mass)

$\mathrm{R}_{\mathrm{w}}=$ The measured resistance across the wood sample $(\Omega)$

8) Once constructed, these Moisture Content measuring circuits will have to be tested and possibly fine-tuned using regression analysis.

9) Drill holes in the clay brick at desired test locations, near the currently monitored locations of the Toronto test house. (Locations: P, Q, R, S.)

10)Insert the sensors into the clay brick, and seal them in place with a polyurethane caulking to prevent liquid water entry. 


\section{PROCEDURE \# 3: INSTALLATION OF TEMPERATURE/RH SENSORS}

Holes must be drilled at various depths into the envelope of the test building for this procedure. Sensors are to be installed in clusters: each measurement position on a particular wall will have a cluster of four sensor holes drilled from the inside. These holes must be close enough together that they measure the same area of wall, but they should also be far enough apart so to not effect one another. For the sake of convenience and to minimize disruption of the interior aesthetic, sensors were positioned about $30 \mathrm{~mm}$ away from each other.

Equipment list:

- Onset HOBO MicroStation (x4)

- Onset Temp/RH Smart Sensors (x16)

- Onset U10 Temp/RH Sensors $(\mathrm{x} 4)$

- Onset USB Data Shuttle

- AA Batteries (x16)

- Onset HOBOware software
- Hammer drill

- $20 \mathrm{~mm}\left(3 / 4^{\prime \prime}\right)$ dia. drill bit

- Narrow ruler (or other depth gauge)

- Great Stuff Polyurethane Foam

- Permanent marker

- Computer 
Procedure:

1) Using the $20 \mathrm{~mm}$ drill bit, carefully drill four adjacent holes through the drywall layer without drilling into the insulation. the holes should be at least $30 \mathrm{~mm}(1-1 / 4 ")$ away from one another.

2) Hole \#1 will be used for the cavity space Temp/RH sensor; no further drilling will be required for this hole.

3) Use the ruler to determine the mid-point depth of the cavity space. This will be the installation location for Temp/RH Smart Sensor \#1.

4) In hole \#3, drill completely through the insulation layer and stop when the drill bit hits clay brick. This will be the installation depth of Temp/RH Smart Sensor \#3.

5) Use the ruler to determine the midpoint of the insulation layer. The total thickness of SPF will range between $130 \mathrm{~mm}(5 ")$ and $180 \mathrm{~mm}$ (7"). This SPFmidpoint depth will be the drill depth for hole \#2.

6) In hole \#2, drill the insulation midpoint depth determined in step 5, above. This will be the sensor installation depth of Temp/RH Smart Sensor \#2.

7) In hole \#4, drill through the insulation layer until the hits clay brick. Make a mark on the drillbit with the permanent marker: the hole needs to be drilled $105 \mathrm{~mm}(4-1 / 4 ")$ beyond the insulation-brick interface. This will place the sensor just beyond the first wythe of clay brick in the collar joint in the centre of the structural clay brick wall.

8) Commission the Onset HOBO Microstation for each location using the HOBOware software: 
a. Connect four sensors to each Microstation.

b. Assign each sensor a unique identifiable name/number.

c. Physically label each sensor with its corresponding name.

d. Set the measurement duration to a reasonable time. (15-minute increments.)

e. Launch the Microstation

f. Install the cover on the Microstation enclosure.

9) Insert each sensor to the desired depth within the wall: centre of cavity, centre of insulation, insulation-brick interface and centre of clay brick wall.

10)Carefully seal each sensor in place with Great Stuff polyurethane foam. Care must be taken to prevent the SPF from reaching the front face of the Temp/RH sensors. (Otherwise, the sensor would inaccurately measure relative humidity.)

11)Use the HOBOware software to commission and launch the portable Onset U10 Temp/RH data loggers.

12)Install a portable Onset U10 Temp/RH data logger on the exterior side of the wall at each of the sensor cluster locations. In areas that are in direct exposure to rain, the U10s should be loosely covered with a tent of Tyvek or SBPO membrane.

13)Use the Onset USB Shuttle to offload the data from each of the data loggers on a regular basis. 


\section{PROCEDURE \#4: CLAY BRICK SPECIMEN EXTRACTION \& REINSTALLATION}

Some clay brick masonry units will be required for destructive tests. Also sensors must be installed into the clay brick masonry units in both wythes of the wall. Clay bricks will have to be removed from the walls for both of these tasks to be completed.

Equipment list:

- Angle grinder

- Tuck-point blade, 127 mm (5")

- Hammer drill

- Carbide-tipped masonry drill bits, $3.127 \mathrm{~mm}, 4.763 \mathrm{~mm}, 6.35$ mm. (1/8", 3/16", 1/4")

- Shop Vacuum

- Prybar

- Cold chisel

- Hammer

- Safety glasses
- Safety gear

- Dust mask

- Permanent Marker

- Clean Sand

- Type-N mortar

- Clean water

- Bucket

- Brick Trowel

- Mortar Hawk

- Jointing Tool

Removal Procedure: 
1) Determine which clay bricks to remove from the wall. Avoid removing clay bricks from damaged areas and from locations with high structural load. (Near windows, corners, etc.)

2) Use the point-tuck blade on the angle grinder to quickly remove as much of the mortar joint as possible. This is a very dusty process. Use a dust mask or respirator, safety glasses, and other appropriate safety gear.

3) The point tuck blade will only remove a depth of approximately $40 \mathrm{~mm}$ (1$1 / 2$ ") from the mortar. A hammer drill will be used for the remaining depth.

4) Choose an appropriate diameter bit for the mortar joint. Some of the joints are very tight and require a smaller bit.

5) Begin chiselling away at the mortar joint with the hammer drill. Start at one end of the mortar joint and drill squarely into it. Drill to a depth of about 115 $m m(4-1 / 2 ")$.

6) Next drill a hole directly beside the first hole, slightly overlapping. Continue until the entire mortar joint has been removed from around all sides of the clay brick.

7) The clay brick should fall on its own once enough mortar has been removed. If it does not, use the pry bar and tap lightly with the hammer. Gently pry the clay brick until the collar joint separates at the back.

8) Label each clay brick: wall and location. 
Reinstallation Procedure:

1) Determine that the replacement clay bricks are an appropriate size for the opening.

2) Clean and vacuum out the openings in the wall in preparation for the new mortar. The openings should be free of debris, dust and should be dry.

3) Mix the mortar:

a. Mix one part mortar to three parts clean sand in the bucket.

b. Add water in small amounts and mix the mortar until wet and well stirred. The mix should not be watery or soupy.

4) All clay brick surfaces should be dry prior to applying the mortar. Use the trowel to place a layer of mortar in the opening.

5) Use the trowel to put a layer of mortar on the side of the opening.

6) Use the trowel to "butter" mortar onto the sides of the replacement clay brick.

7) Put the new clay brick in place, and tap it into position. The brick masonry unit should be plumb and line up with the other clay bricks when in final position.

8) Repeat until the opening is closed up.

9) To point the last (top) mortar joint, make a $5 \mathrm{~mm}$ thick layer of mortar on the Hawk and slide it into the gap with the trowel. Make sure mortar is pushed all the way to the back of the joint. Pack the joints full of mortar.

10)Use the Jointing Tool in a sliding back-and-forth motion to press the mortar into place, and to create a concavity in the face of the mortar joint. 
11)Clean all tools before the mortar sets and bonds to them.

\title{
PROCEDURE \#5: INSTALLATION OF MOISTURE CONTENT SENSORS IN CLAY BRICK
}

\author{
The wood surrogate sensors must be installed directly into the clay brick in order to \\ measure their moisture content. Clay bricks should be extracted, the sensors \\ installed, and then the clay bricks should be placed back into their original positions \\ in the exterior walls. Refer to Procedure \#4: Clay brick Extraction and \\ Reinstallation.
}

Sensors will be installed from the exterior side of the envelope, and cables routed to a central location where the data loggers are mounted on the interior. All cables neatly routed along the exterior of the building will be less intrusive than installing the sensors from the interior. 
Equipment list:

- SMT Embedded Moisture

Sensors (x15)

- $\quad$ SMT A3 Data logger (x4)

- AA Batteries (x12)

- Carbide-tipped masonry drill bits: $3.127 \mathrm{~mm}, 4.763 \mathrm{~mm}, 6.35$ mm, 12.7 mm (1/8", 3/16", $1 / 4 ", 1 / 2 ")$

- 25 mm (1") long spade drill bit

- Drill press

- Hammer Drill
- Drill Press

- Epoxy

- Tape

- Great Stuff Polyurethane Foam

- Surface mount double-gang electrical box $(\mathrm{x} 4)$

- Wire mounting hardware

- 25 mm (1") Tapcon screws

- Cable Ties

- Paper, newspaper 
Procedure:

1) Locate the areas on the exterior wall that are in close proximity to the Temp/RH sensors already installed. (See Procedure 3: Temp RH Sensor Installation.)

2) Carefully remove an exterior clay brick. (See Procedure 4: Clay brick Extraction \& Replacement.)

3) Label the backside of the clay brick with its location information.

4) Use a drill press to drill a hole close to the outside face of the clay brick:

a. Lay down a sheet of paper to capture the dust from the drilling process. This clay brick dust will be reused later.

b. Secure the clay brick to the drilling platform so it does not wobble. Any movement of the old brittle clay brick while drilling close to the face could cause the face to pop off.

c. Position the centre point of the hole $13 \mathrm{~mm}$ from the face of the clay brick. Start with a small bit and create a pilot hole. Increase the size of the bit and slowly widen the hole. The final size should be a $12.7 \mathrm{~mm}(1 / 2$ ") diameter by $50 \mathrm{~mm}(2 ")$ deep hole. Drilling a hole with a large bit very close to the face without a pilot hole could cause the face to pop off.

d. Collect and save the clay brick dust for each clay brick.

5) Use a hammer drill to make a hole in the exposed face of the inside wythe clay brick. This can easily be done through the opening from the removed clay brick. If drilling toward the middle of the clay brick, pilot holes are not necessary.

6) Place 0.5 cc of clay brick dust from the drilling procedure back into the hole of the respective clay brick. 
7) Insert the SMT Wood Surrogate sensors into the holes of each clay brick. The sensors should bottom out inside the hole and be countersunk approximately $6 \mathrm{~mm}$ $\left(1 / 4^{\prime \prime}\right)$ from the surface.

8) Place more clay brick dust on the top of the sensor. Tap the clay brick with a hammer, and use a piece of paper to coax the dust down between the sensor body and the wall of the hole. The process is slower with the horizontally inserted sensor.

9) Cover the hole with a two-part, five-minute epoxy. Tape may be required to keep the epoxy from running out of the face-installed sensor. Allow the epoxy to set.

10)Place a third sensor between the interior and exterior clay brick wythes before reinstalling the exterior clay brick.

11)Note and record each sensor number, and its location within the wall.

12)Make sure the three sensor cables at each installation point are grouped together, and exit the mortar joint in downward manner. (Otherwise rainwater will run along the cable into the wall.)

13)Mortar the exterior clay brick back in place. (See Procedure \#4: Clay brick Extraction and Replacement.)

14)Once all the sensors are installed at all the locations, bundle the cables with cable ties, and run them down the side of the house to the instrumentation location.

15)Route the cables inside through a series of holes. Seal the holes with Great Stuff polyurethane foam when complete.

16)Install the double gang electrical boxes in the instrumentation area.

17) Route the appropriate cables to the electrical box. 4 cables per box.

18)Connect the sensor cables to the SMT A3 data logger instrumentations as outline in the instrumentation manual, and mount them each in an electrical box. 19)Commission the A3 data loggers and set measurement intervals to once per hour. 
PROCEDURE \#6: PHOTO-JOURNALING AN ELEVATION FOR AUTOPANO GIGA

A component of this project is to create a catalogue of photos of existing conditions at the test building. High resolutions photos are to be taken and stitched into a large composite picture.

Equipment list:

- Elevation drawings

- Digital Camera

- Tripod

- Unipod
3-Storey Scaffolding

- AutoPano Giga Software

- Extension Ladder

- Avery Labels

Procedure:

1) Chose a digital camera with minimal lens distortion for up-close photography

2) Print reference markers on Avery labels. Number the labels sequentially, and apply a sticker at every 1-meter in a Cartesian coordinate system along the side of the building. These references will later be used for the photo-stitching portion on a computer.

3) Take photos in a linear fashion starting at one end of the building, keeping the camera level and at a consistent height from the ground. Snap a series of photos so that each overlaps the previous by about $20 \%$.

4) Note the starting photo file number and the final file number of the series. Note these on the elevation drawing for future reference. 
5) Repeat with a new linear series of photos the next row up. The vertical overlap should also be about $20 \%$.

6) Set up scaffold as required for reaching the higher areas.

7) Use the camera on a unipod to photograph areas beyond the reach of the scaffold. The timer and sequential photograph functions on the camera allow for taking photos while the camera is out of reach.

8) Stitch the photos together using AutoPano Giga software as per the software manufacturers instructions. 


\section{PROCEDURE \# 7: DETERMINING THE WATER ABSORPTION COEFFICIENT (A-VALUE) FOR CLAY BRICK WATER UPTAKE.}

The speed at which a clay brick absorbs water is one of the characteristics used by software such as WUFI when analysing the wetting and dry capabilities of a wall envelope.

Equipment list:

- Clay brick specimens, (full clay brick units),

- Extra Clay brick for set up of the basin

- Large shallow basin (such as a storage tote, approximately $1 \mathrm{~m} \mathrm{x}$ $.5 \mathrm{~m} \times .15 \mathrm{~m})$

- Dowels or rods to support clay bricks
- Stop watch

- Scale, .5 g resolution

- Distilled water

- Damp cloth, wrung dry

- Drying Oven 


\section{Procedure:}

1) Place Clay brick specimens in the drying oven at $105^{\circ} \mathrm{C}$ until they no longer decrease in weight from water drying. (Approximately 2 days, if they are wet.)

2) Place the plastic tote basin on a workbench, or in an area at a convenient height for working.

3) Place the 2 support rods parallel to one another in the bottom of the basin.

4) The clay brick will be stood on end on top of the support rods. Precisely measure the area of each clay brick end (i.e. the face of the clay brick that is approximately 65 $\mathrm{mm} \times 100 \mathrm{~mm})$.

5) Record the dry weight of each specimen.

6) To set up the water level, place the extra clay brick on top of the rods, so that it is standing on end. The clay brick should be plumb once in place.

7) Carefully add distilled water to the basin until the water reaches the bottom of the clay brick. Water should cover the support rods by $3 \mathrm{~mm} \pm .25 \mathrm{~mm}$.

8) Remove the set up clay brick from the support rods.

9) Take an initial weight of the first specimen.

10)Stand the specimen on the support rods, just as the set up clay brick had been positioned.

11)Immediately start the timer.

12)At the 1-minute mark, quickly but carefully remove the clay brick from the basin, immediately wipe the bottom with the damp cloth, weigh the specimen, then replace in upon the support rods.

13) Repeat this every minute until the entire clay brick has visibly absorbed water. 
14)Note: clay bricks with a slow absorption rate may not require 1-minute measurement intervals. Measurements for such clay bricks could be taken at 5minute intervals.

15)The absorption coefficient is stated by the formula:

Equation 2: Water Absorption Coefficient

$$
A \text { Value }=\frac{\Delta w t}{a \times \sqrt{t}}
$$

where,

$$
\begin{aligned}
& \text { A-Value = the Water Absorption Coefficient, as used by WUFI }\left[\mathrm{kg} / \mathrm{m}^{2} \mathrm{~s}^{1 / 2}\right] \\
& \mathrm{wt}=\text { Mass of water, }[\mathrm{kg}] \\
& \mathrm{a}=\text { area of clay brick face in the water, }\left[\mathrm{m}^{2}\right] \\
& \mathrm{t}=\text { time }[\mathrm{s}]
\end{aligned}
$$


APPENDIX B - SENSORS MEASUREMENTS 


\section{LOCATION “P” - EAST ELEVATION, LOWER WALL}

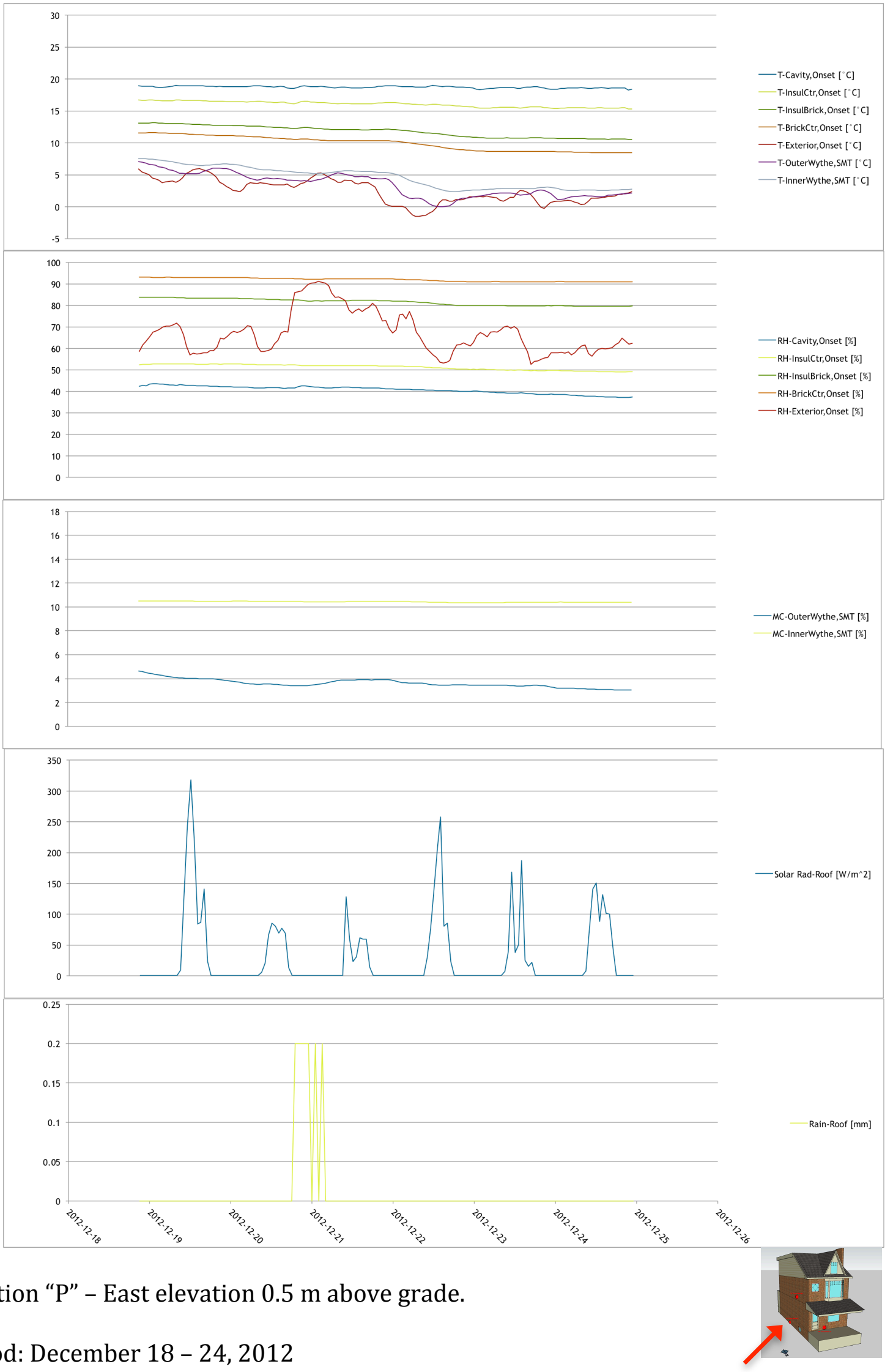

Period: December 18 - 24, 2012

Figure 109: Sensor Measurements from location "P" - East elevation 0.5 m above grade. December 18 - 24, 2012. 


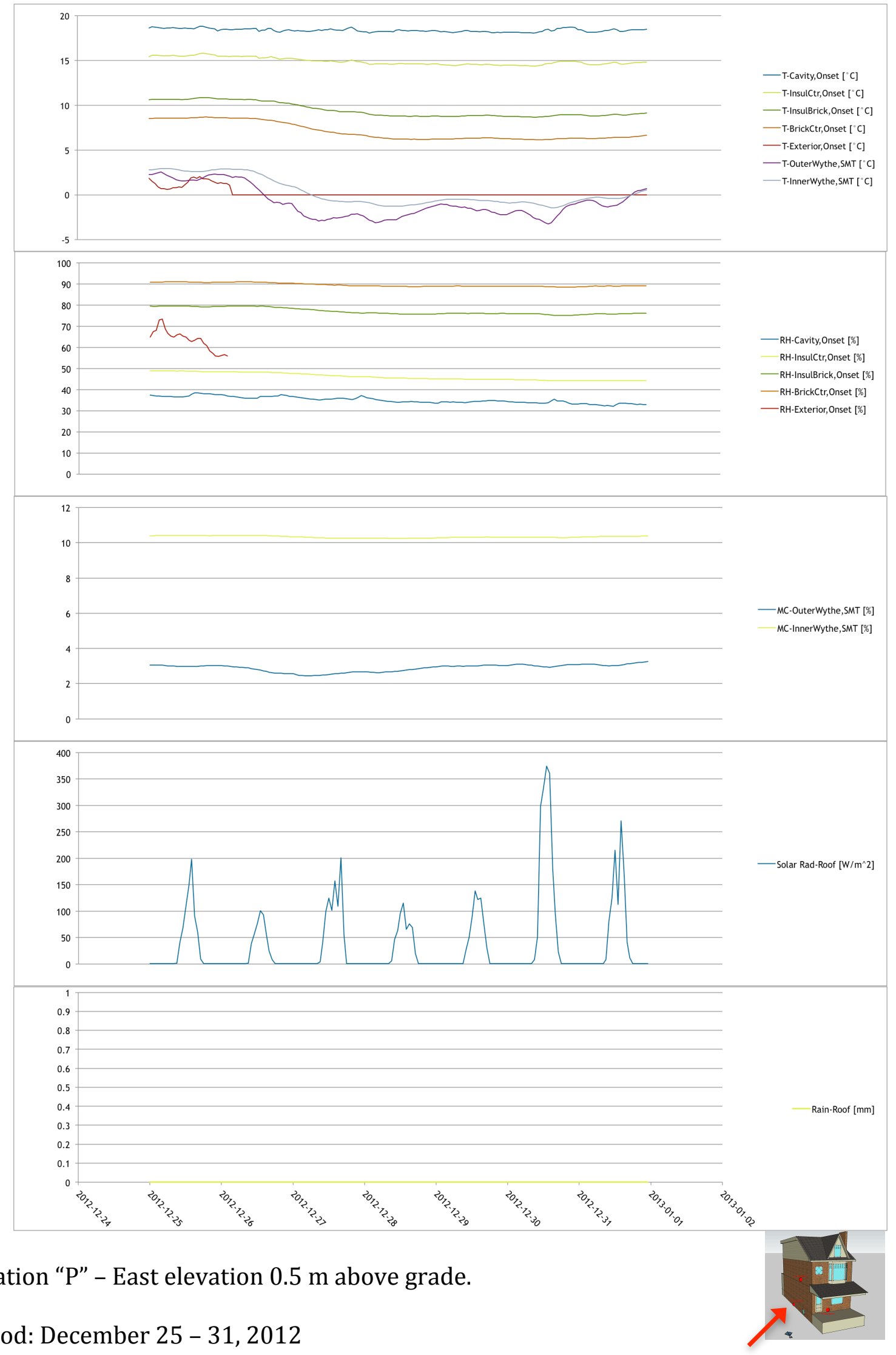

Figure 110: Sensor Measurements from location "P" - East elevation 0.5 m above grade. December 25 - 31 , 2012. 

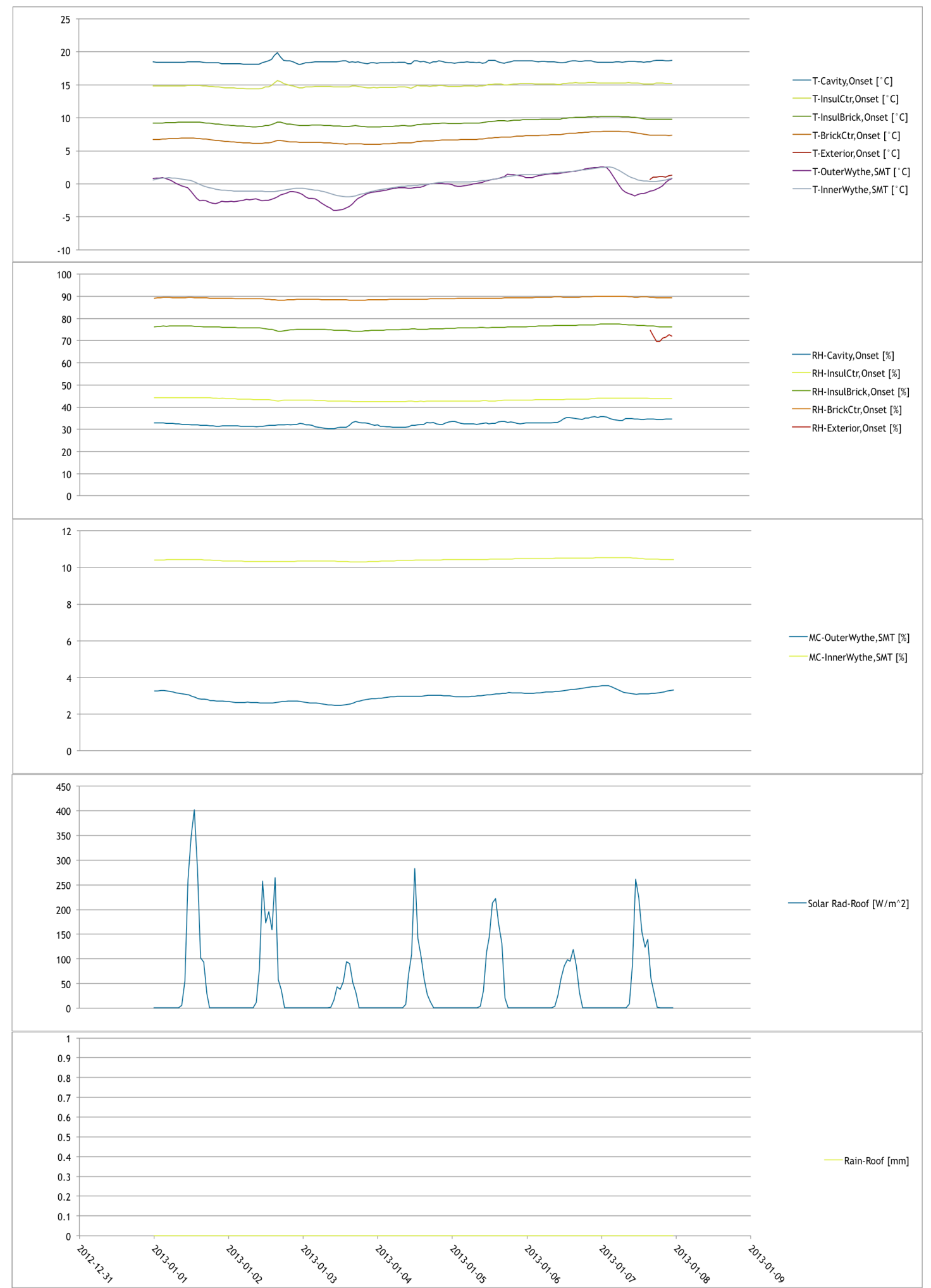

Location "P" - East elevation $0.5 \mathrm{~m}$ above grade.

Period: January 1 - 7, 2013

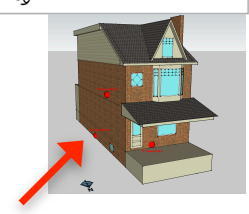

Figure 111: Sensor Measurements from Location "P" - East elevation 0.5 M above grade. January 1 - 7, 2013. 


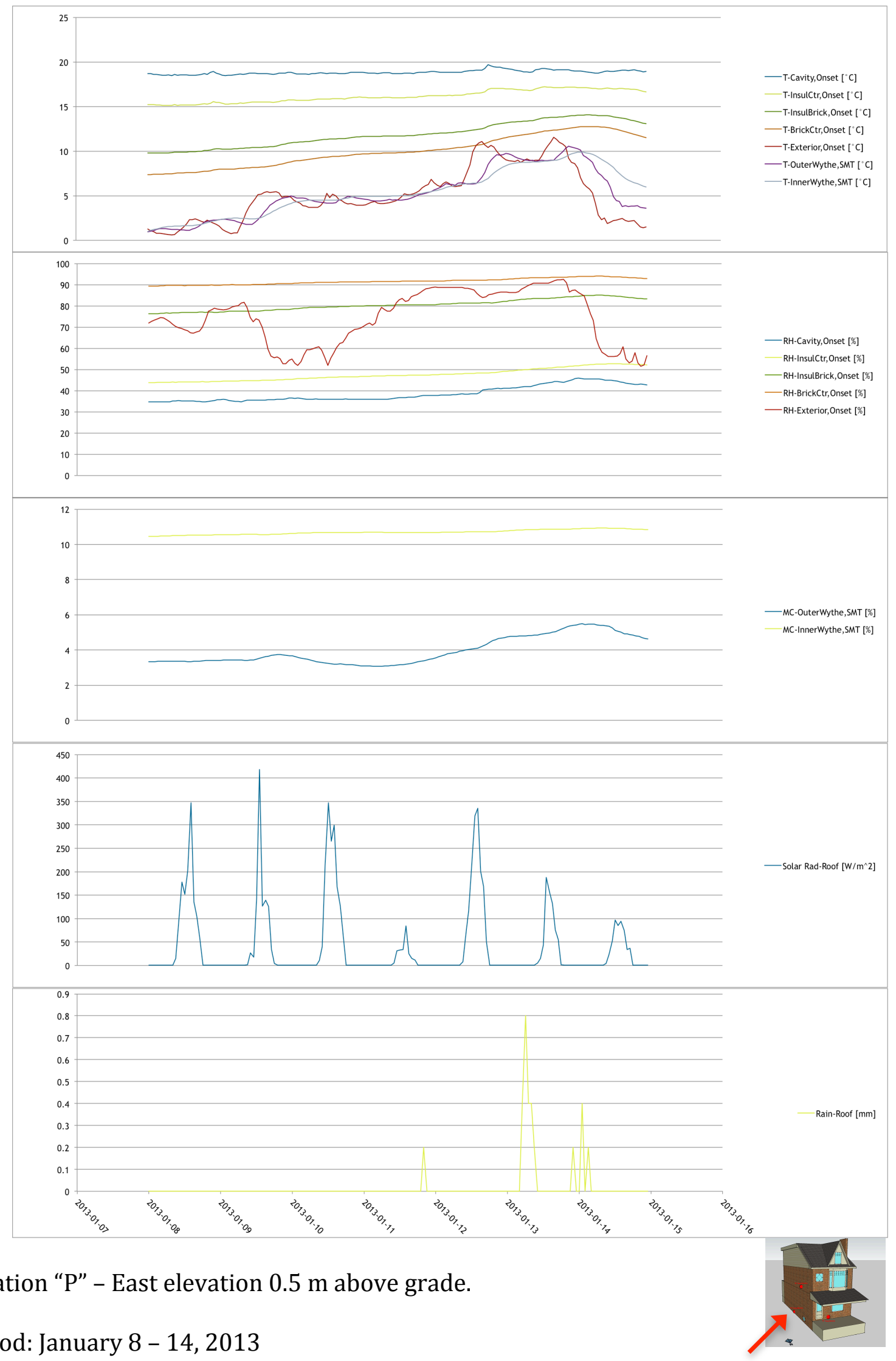

Figure 112: Sensor Measurements from location "P" - East elevation 0.5 m above grade. January 8 - 14, 2013. 


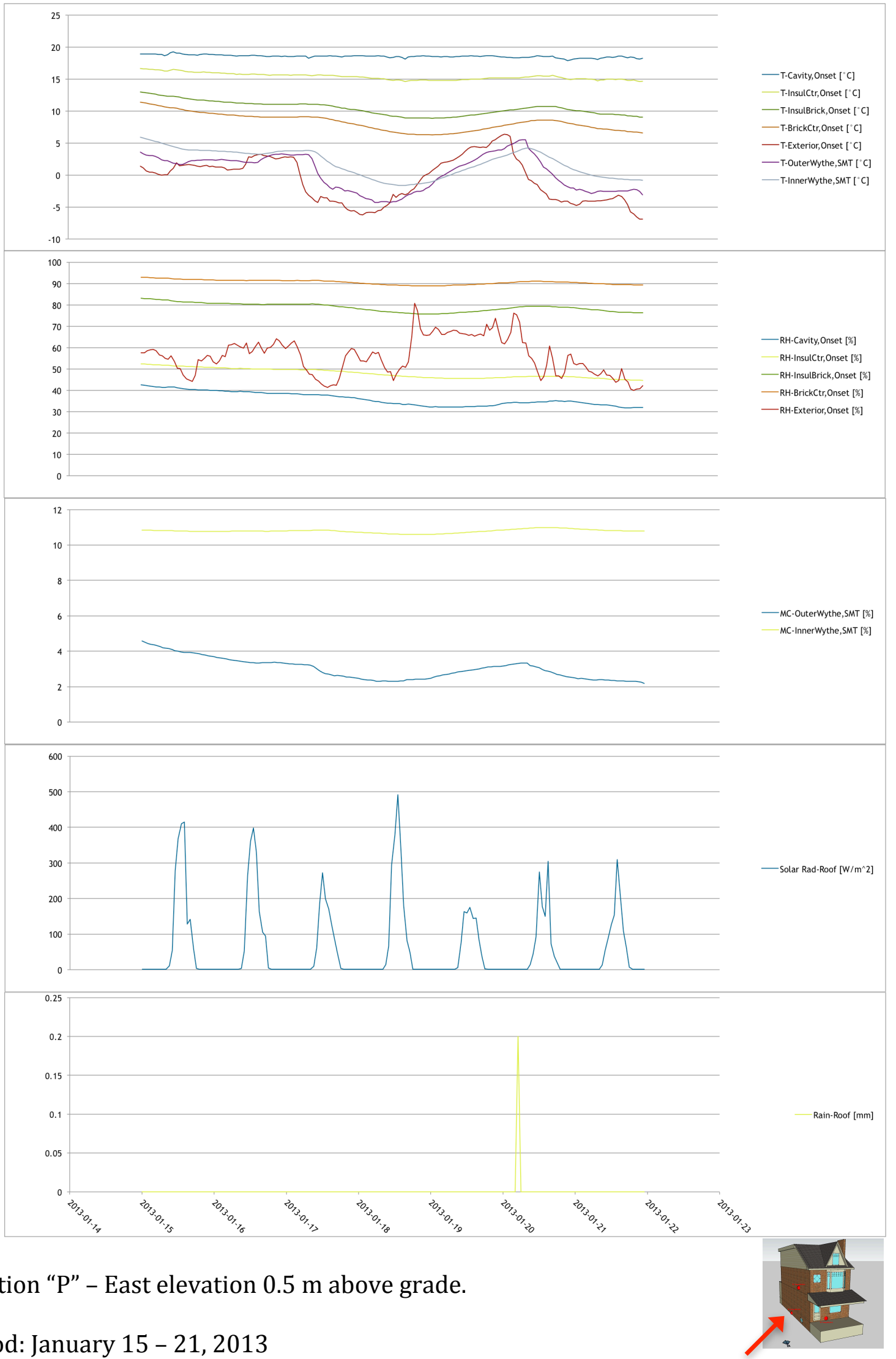

Period: January 15 - 21, 2013

Figure 113: SEnsor Measurements from Location "P" - East elevation 0.5 m above grade. January 15 - 21 , 2013. 


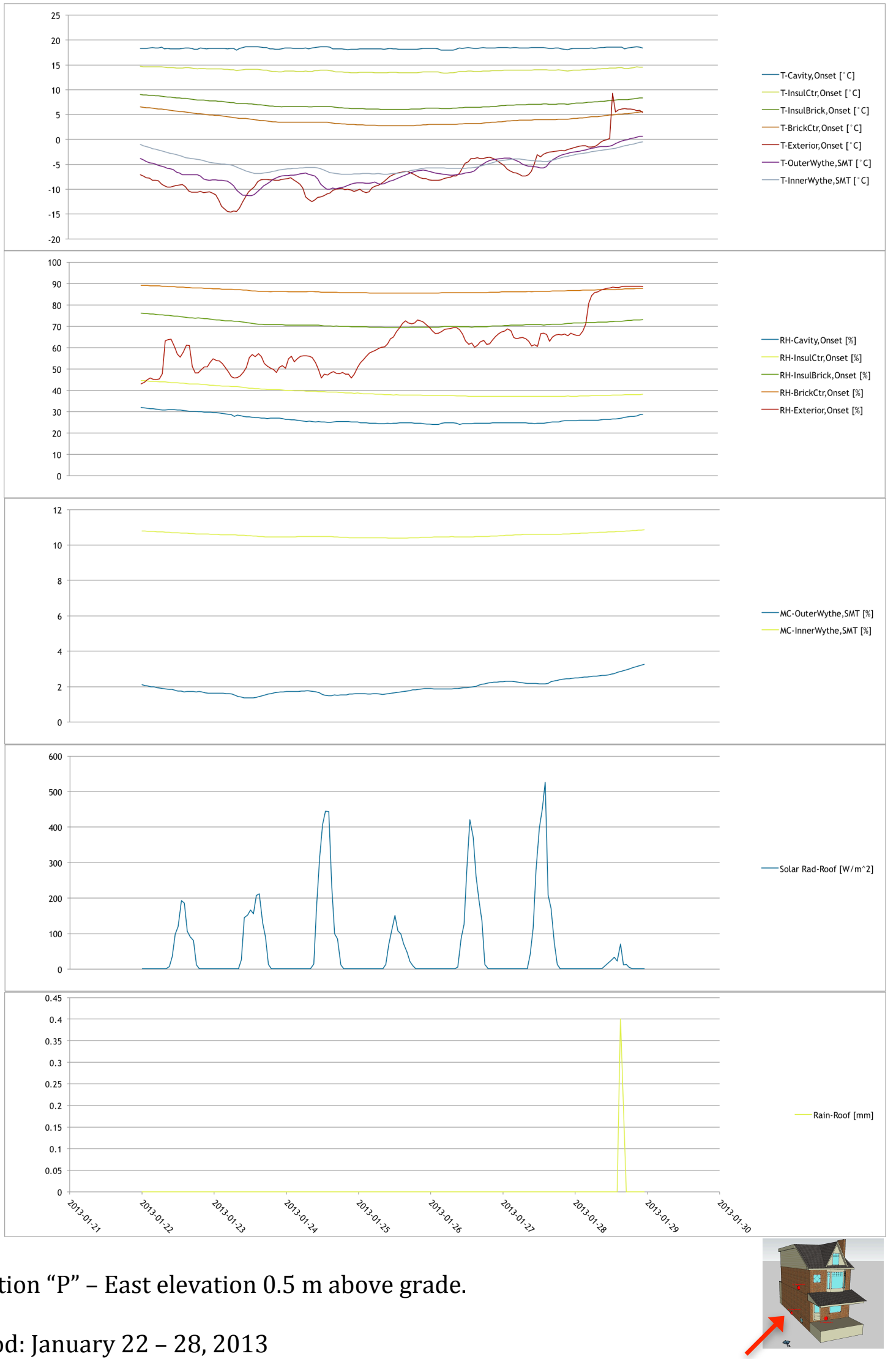

Period: January 22 - 28, 2013

Figure 114: SEnsor Measurements from Location "P" - East elevation 0.5 m above grade. January 22 - 28 , 2013. 


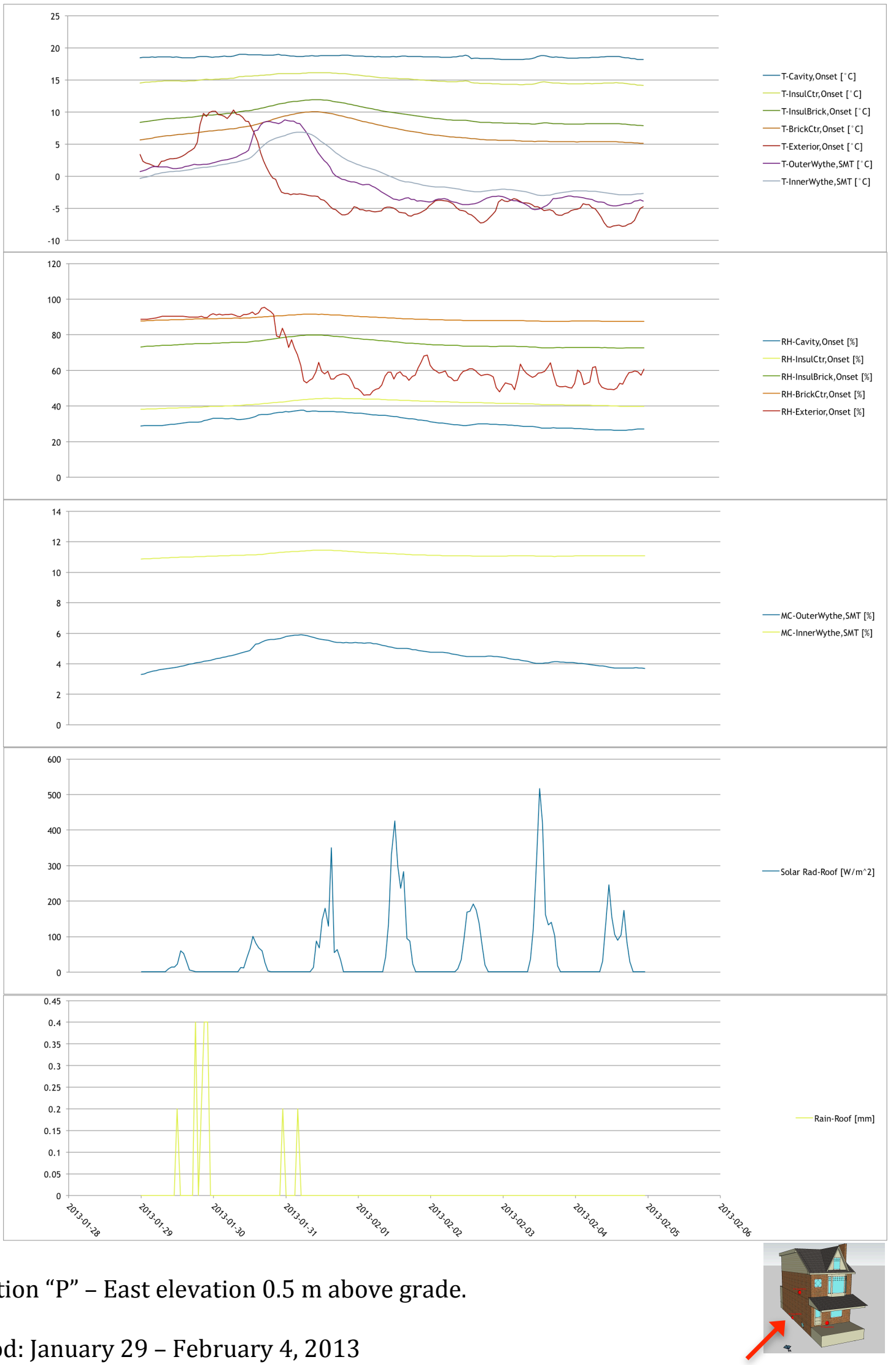

Period: January 29 - February 4, 2013

Figure 115: Sensor Measurements from location "P" - East elevation 0.5 m above grade. January 29 FEBRUARY 4, 2013. 


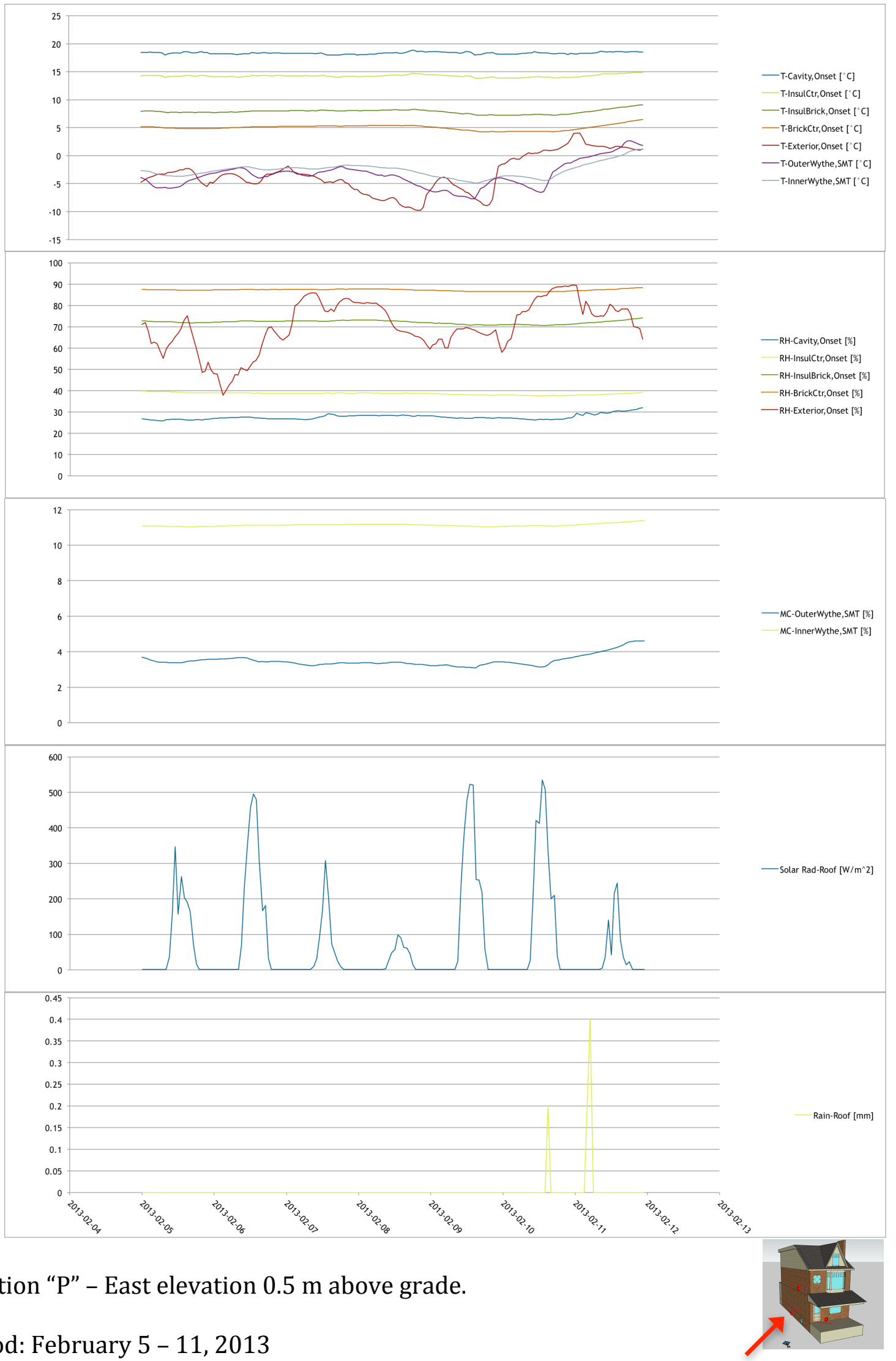

Period: February 5 - 11, 2013

Figure 116: Sensor Measurements from location "P" - East eleVation 0.5 M above grade. February 5 - 11, 2013. 


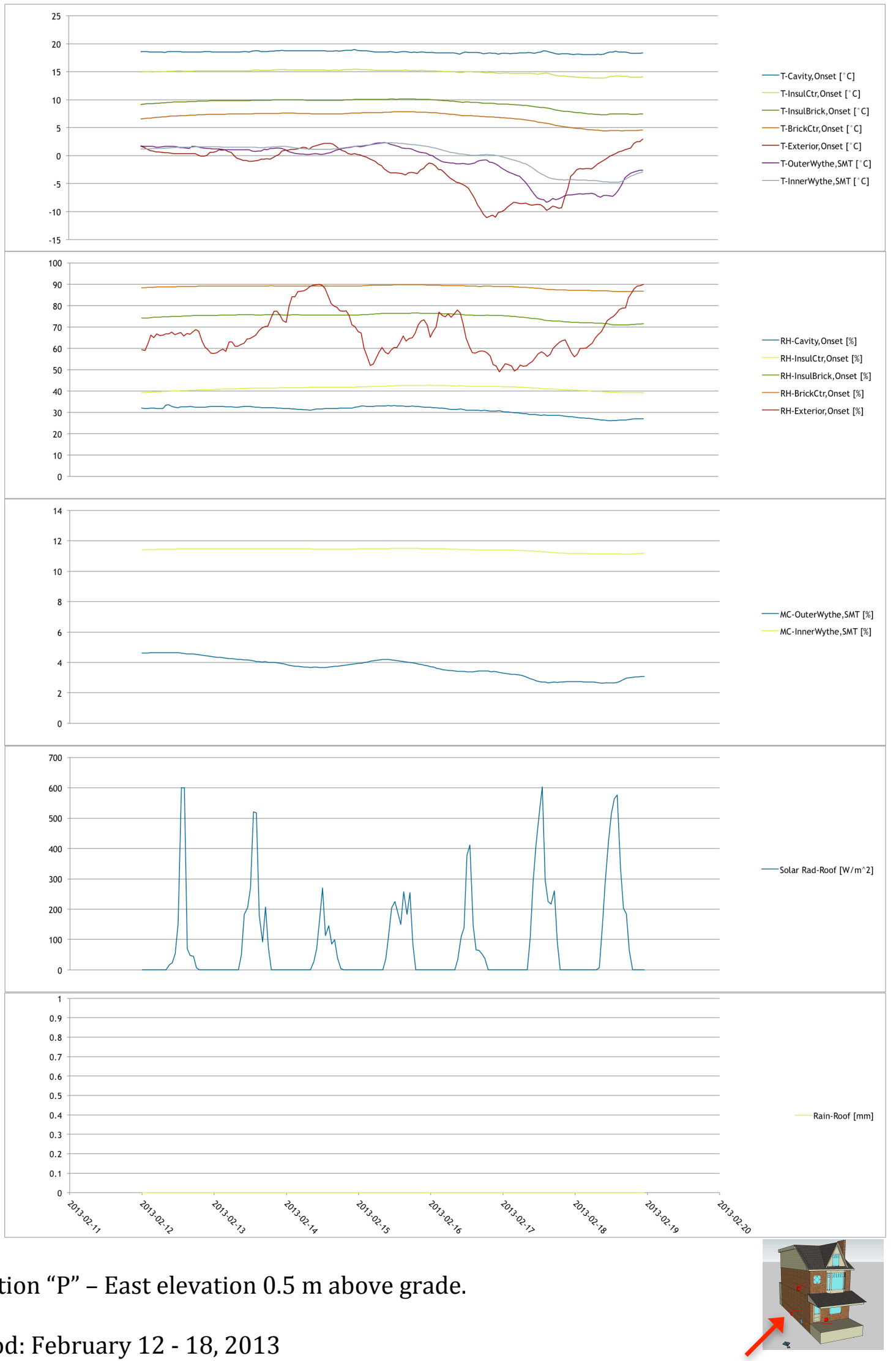

Period: February 12 - 18, 2013

Figure 117: Sensor Measurements from Location "P" - East elevation 0.5 m above grade. February 12 - 18, 2013. 


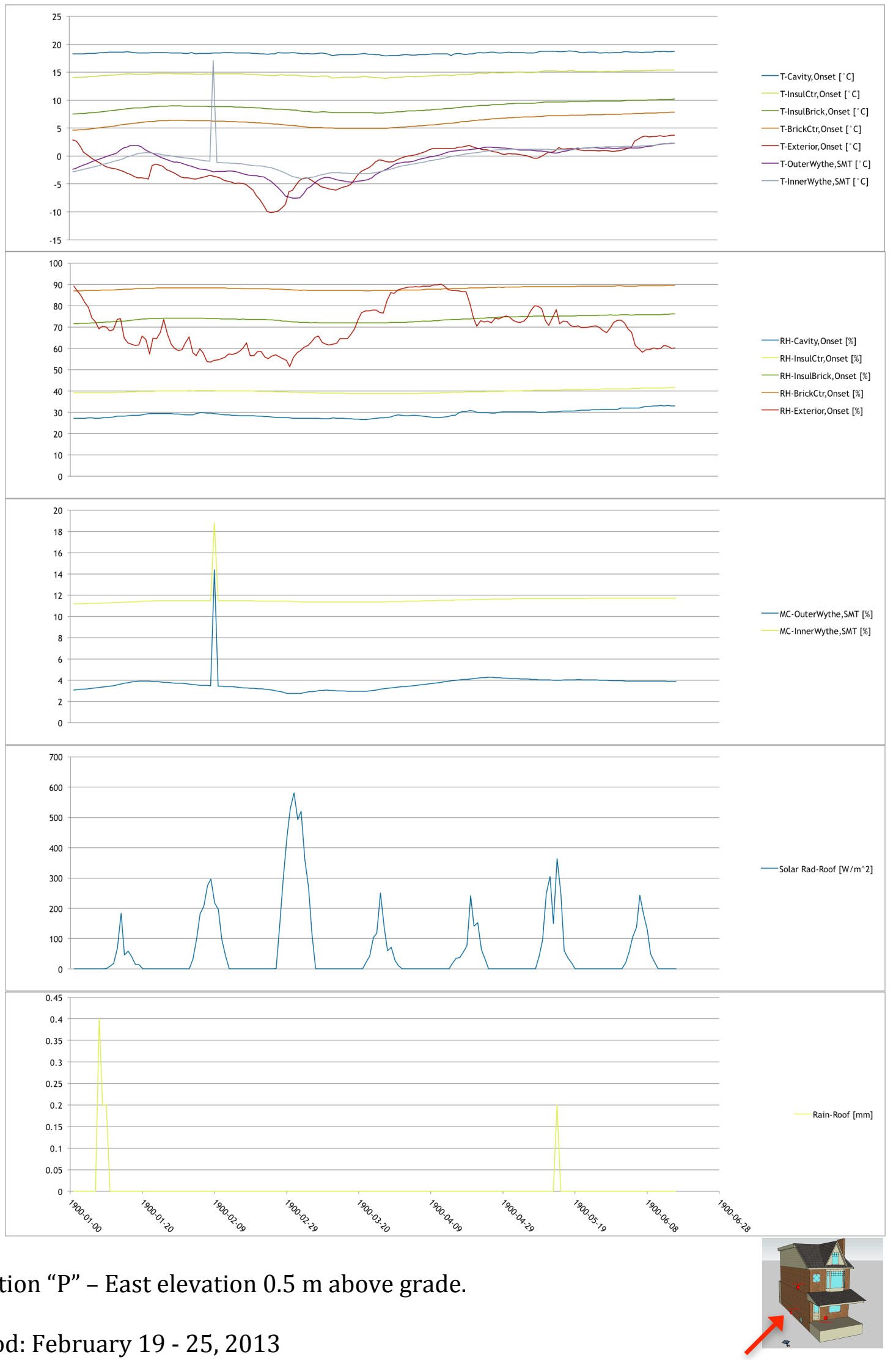

Period: February 19 - 25, 2013

Figure 118: Sensor Measurements from location "P" - East elevation 0.5 m above grade. February 19 - 25 , 2013. 


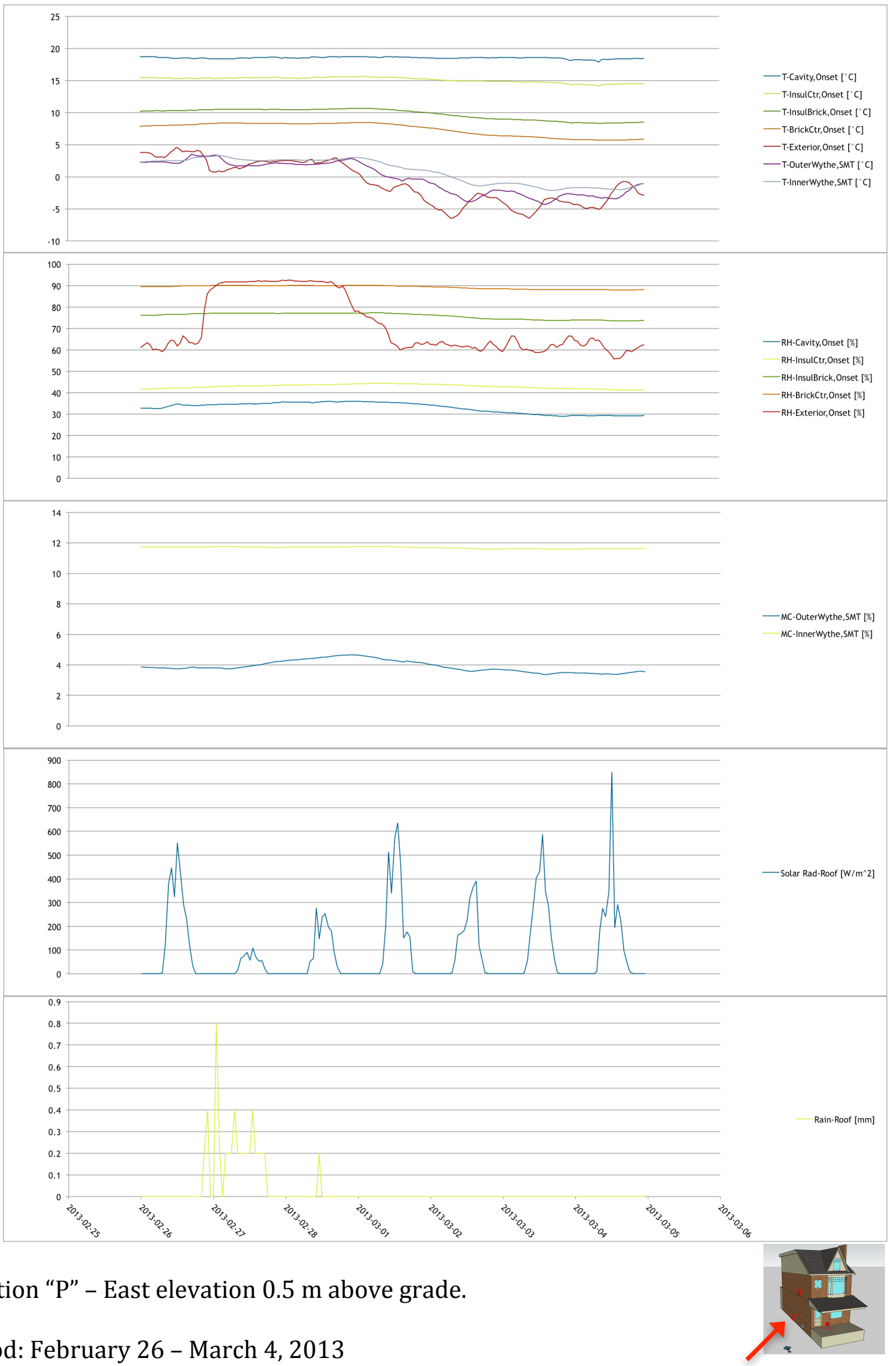

Period: February 26 - March 4, 2013

Figure 119: Sensor Measurements from location "P" - East eleVation 0.5 m above grade. February 26 MARCH 4, 2013. 


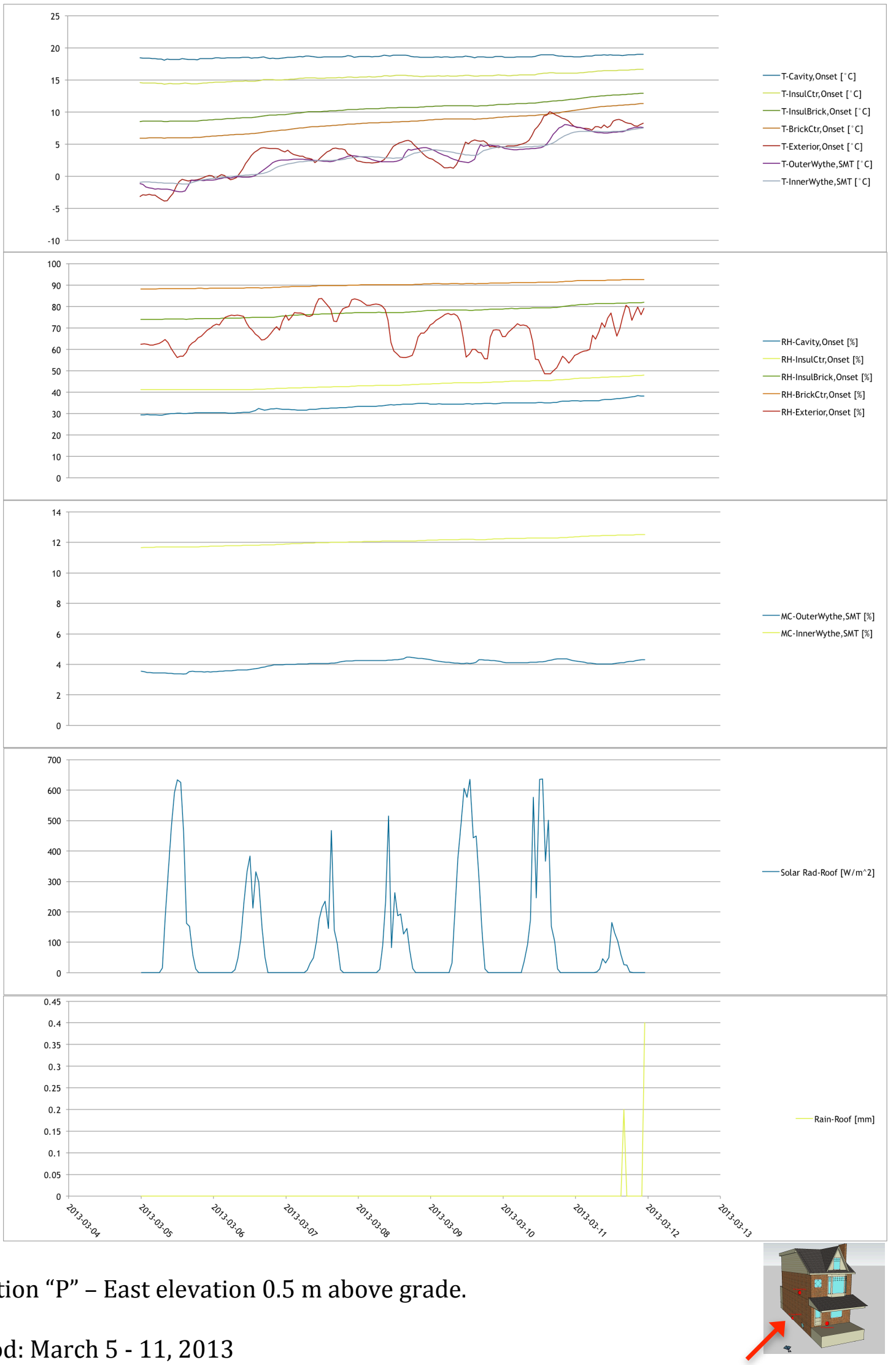

Period: March 5 - 11, 2013

Figure 120: Sensor Measurements from location "P" - East elevation 0.5 m above grade. March 5 - 11, 2013. 


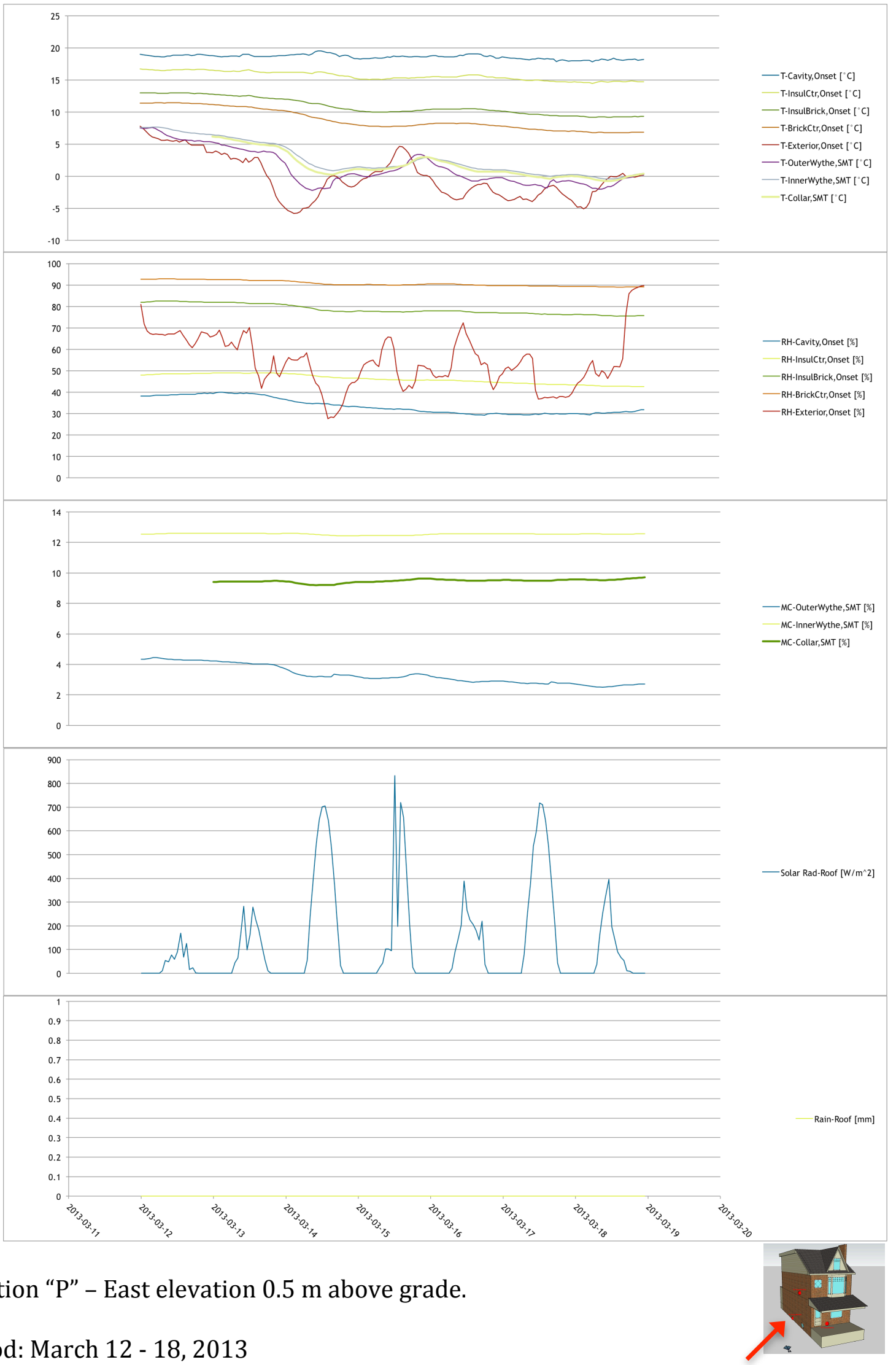

Period: March 12 - 18, 2013

Figure 121: Sensor Measurements from location "P" - East elevation 0.5 m above grade. March 12 - 18, 2013. 


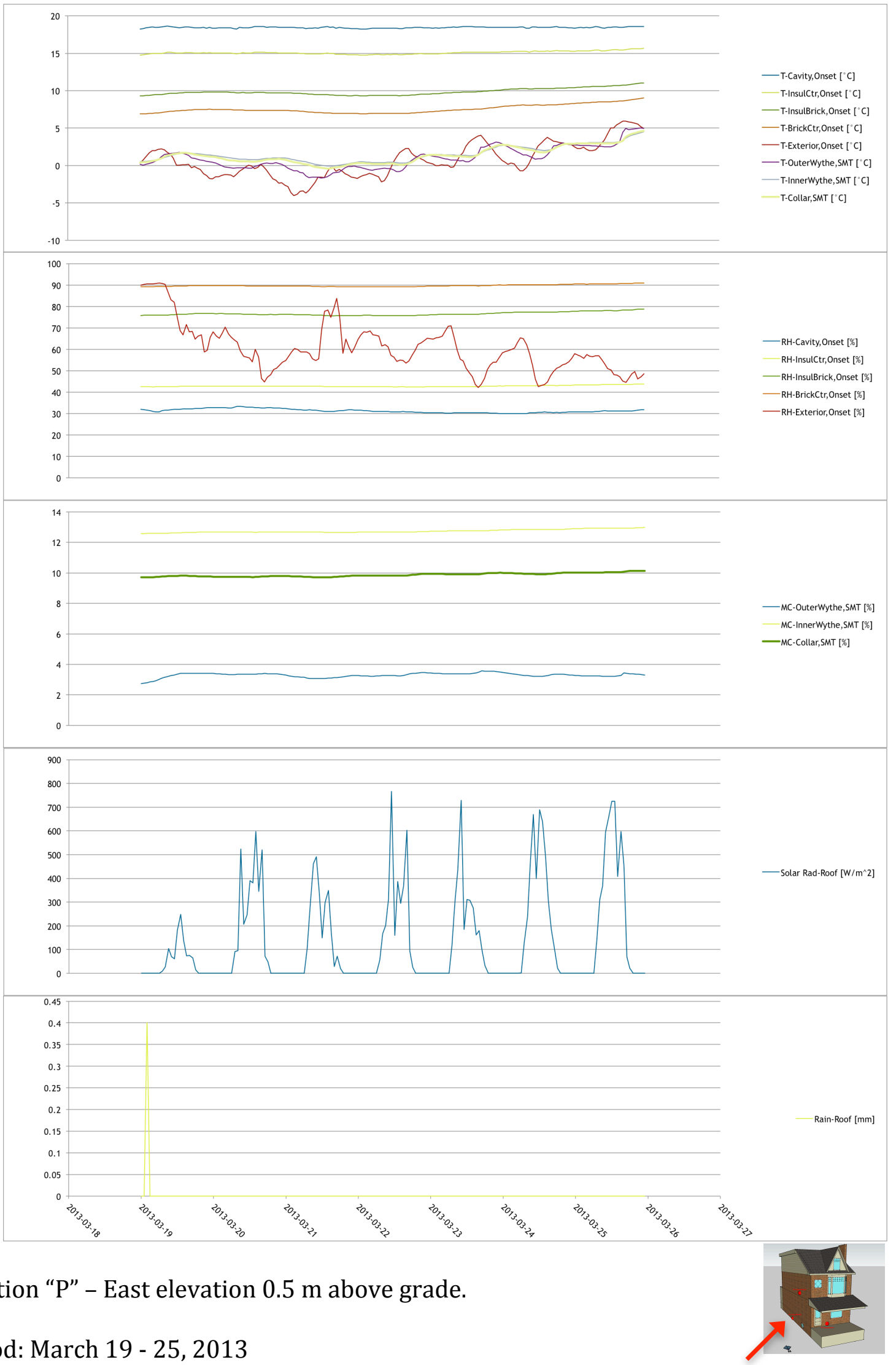

Period: March 19 - 25, 2013

Figure 122: Sensor Measurements from location "P" - East elevation 0.5 m above grade. March 19 - 25 , 2013. 


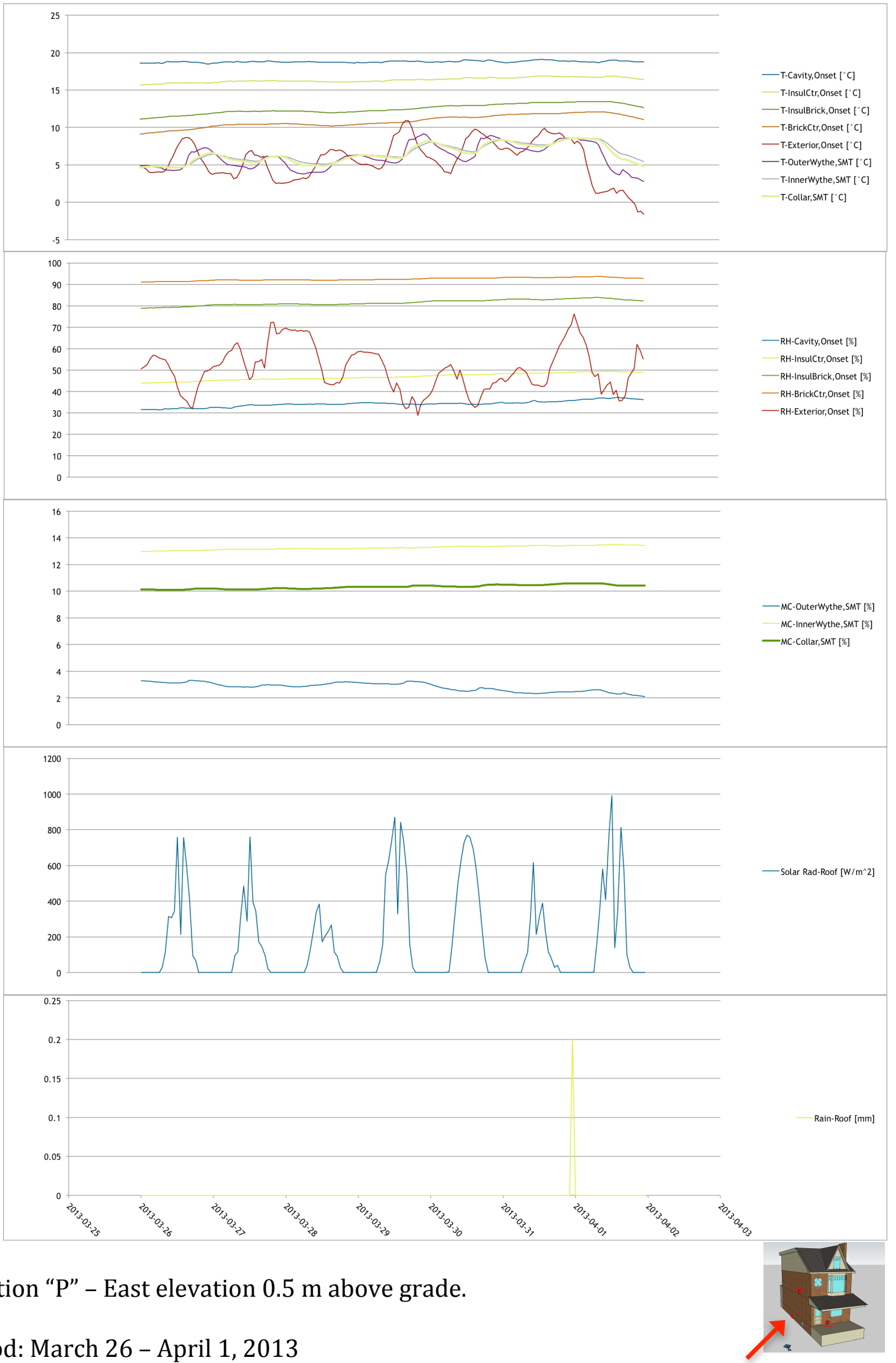

Period: March 26 - April 1, 2013

- East elevation 0.5 m above grade. March 26 - April 1, 2013. 


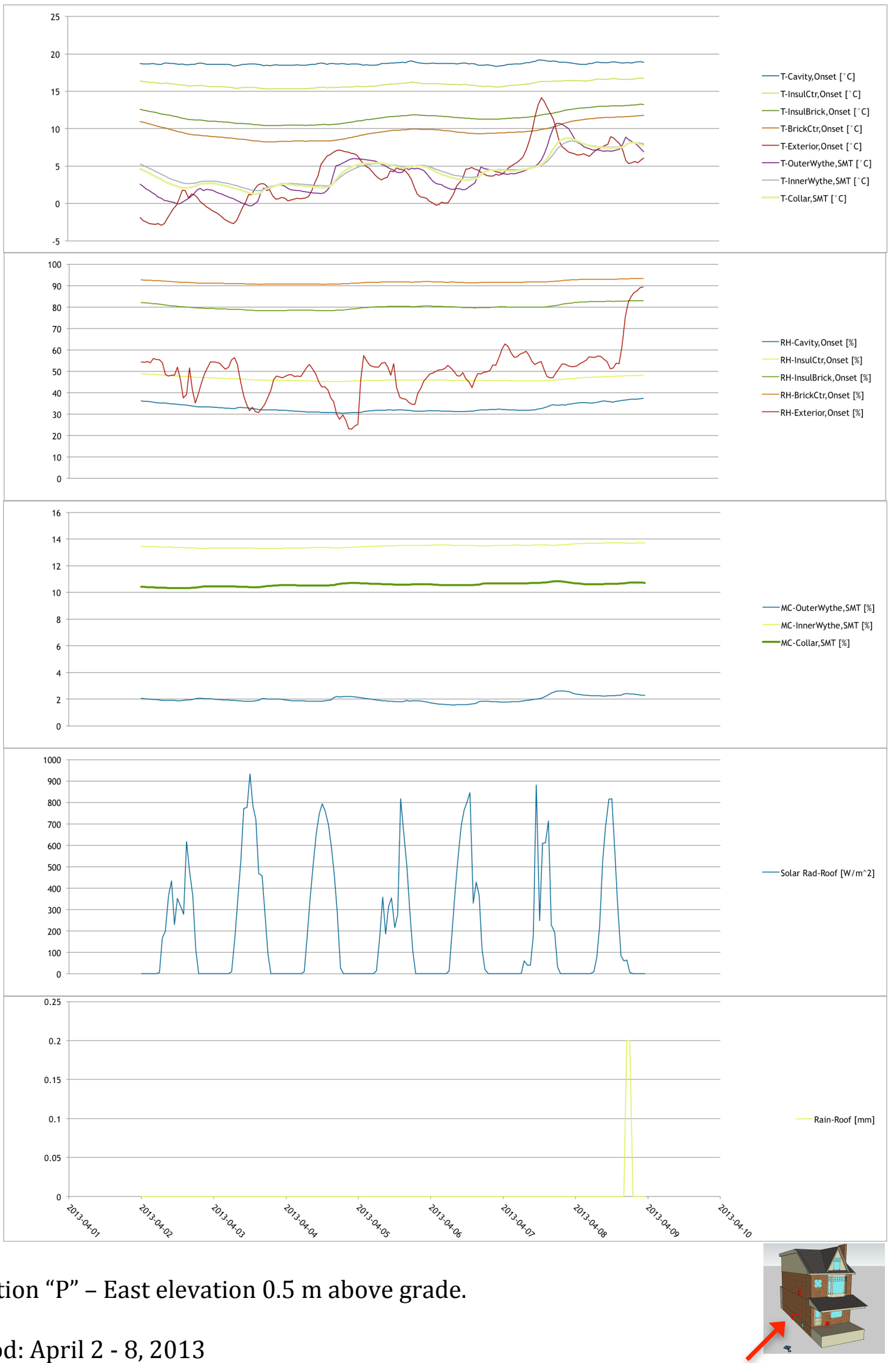

Period: April 2 - 8, 2013

- East elevation 0.5 m above grade. April 2 - 8, 2013. 


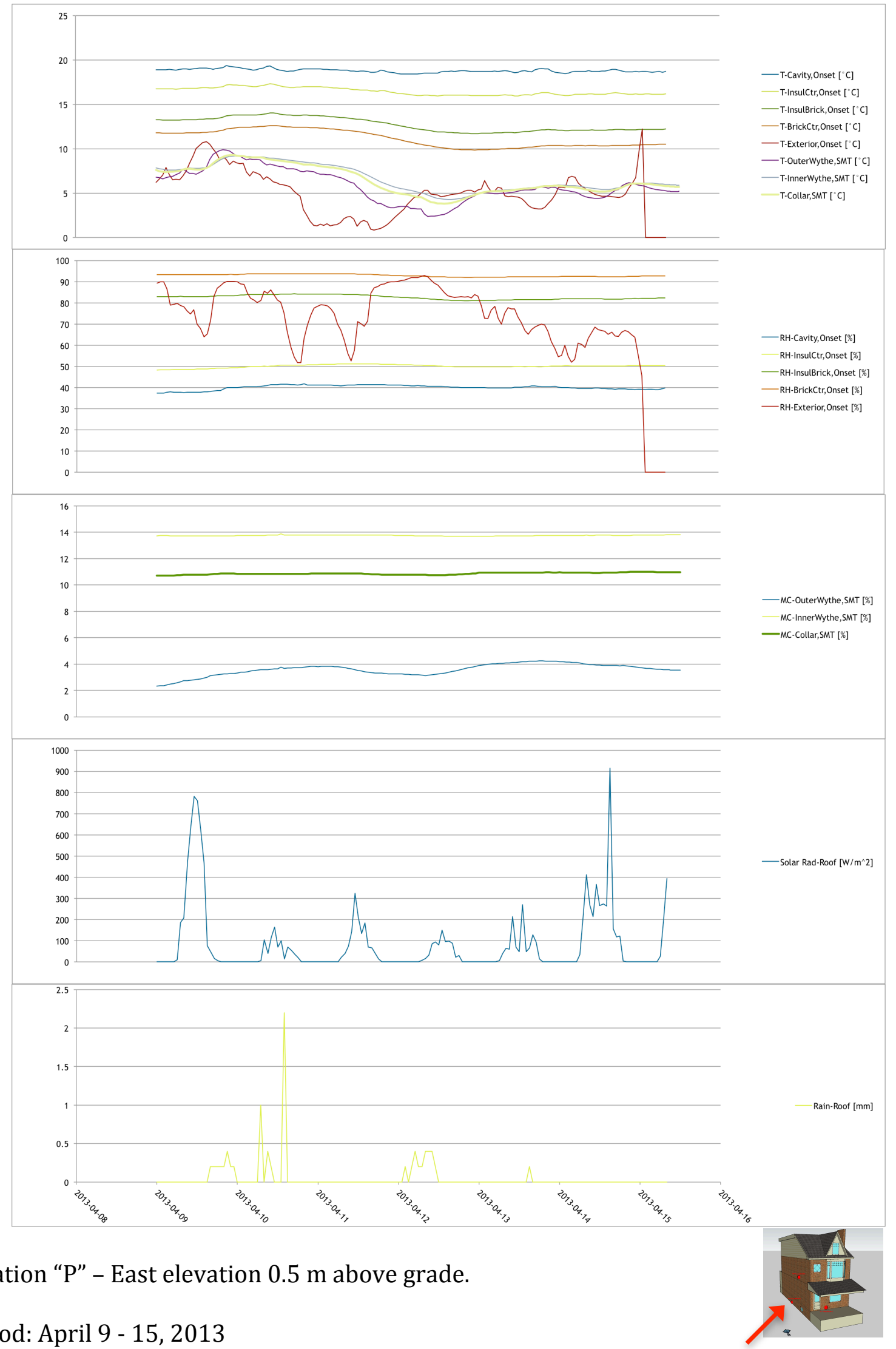

Period: April 9 - 15, 2013

- East elevation 0.5 m above grade. April 9 - 15, 2013. 


\section{LOCATION “Q” - EAST ELEVATION, UPPER WALL}

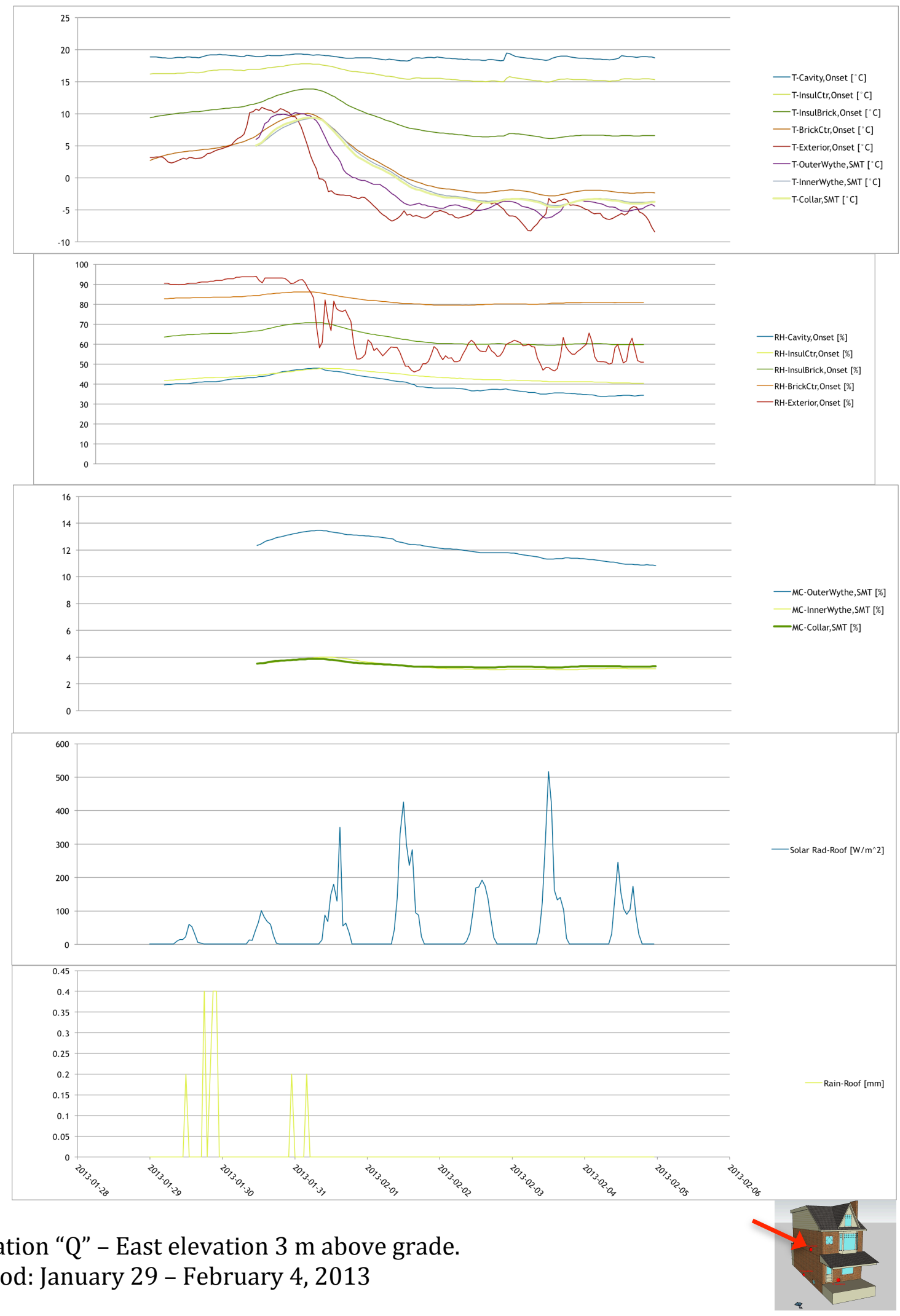

Figure 126: Sensor Measurements from Location "Q" - East eleVation 3 m above grade. January 29 FEBRUARY 4, 2013. 


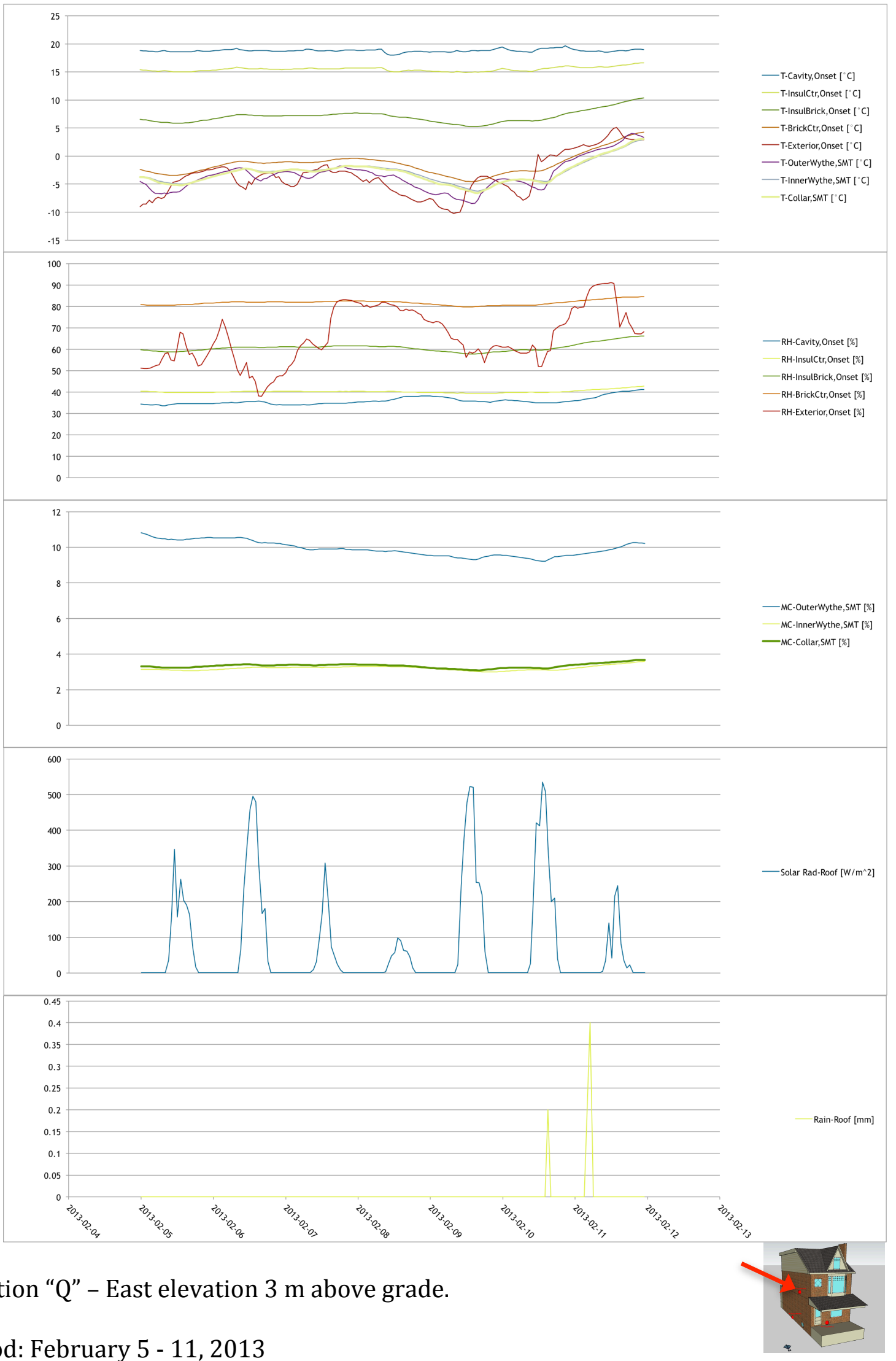

Period: February 5 - 11, 2013

Figure 127: Sensor Measurements from location "Q" - East elevation 3 m above grade. February 5 - 11, 2013. 


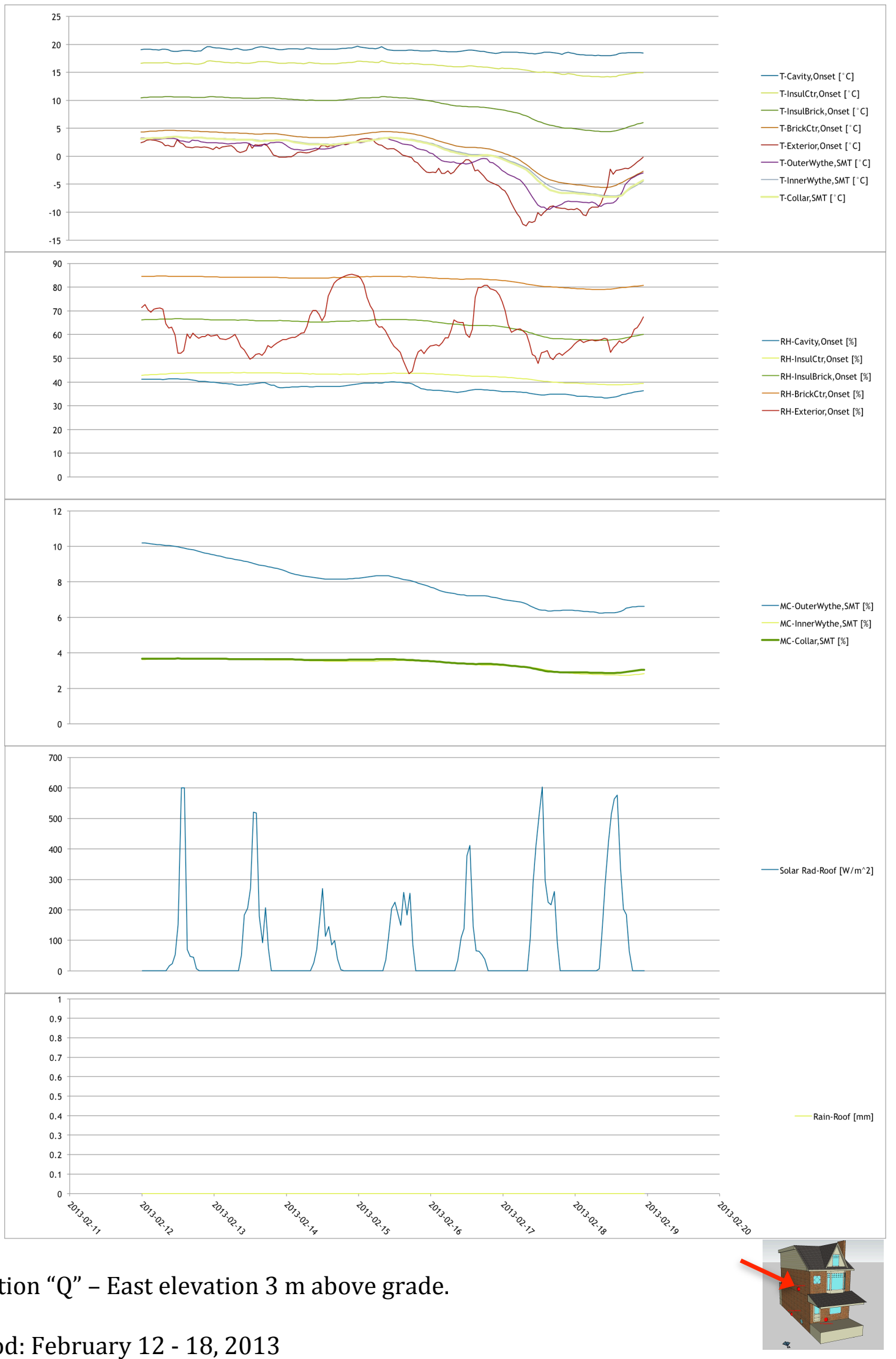

Period: February 12 - 18, 2013

Figure 128: Sensor Measurements from location "Q" - East elevation 3 m above grade. February 12 - 18, 2013. 


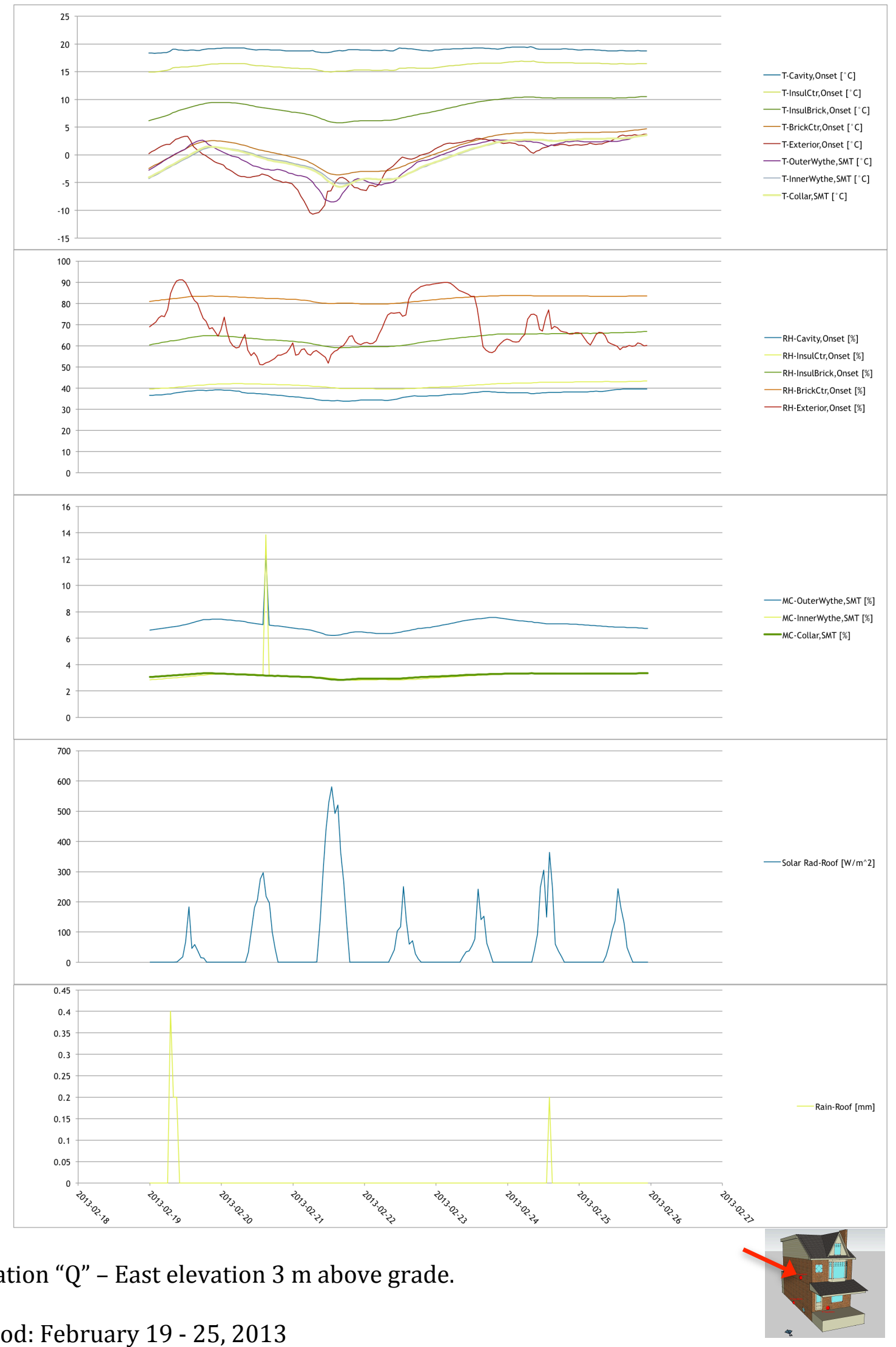

Period: February 19 - 25, 2013

Figure 129: Sensor Measurements from location "Q" - East elevation 3 m above grade. February 19 - 25 , 2013. 


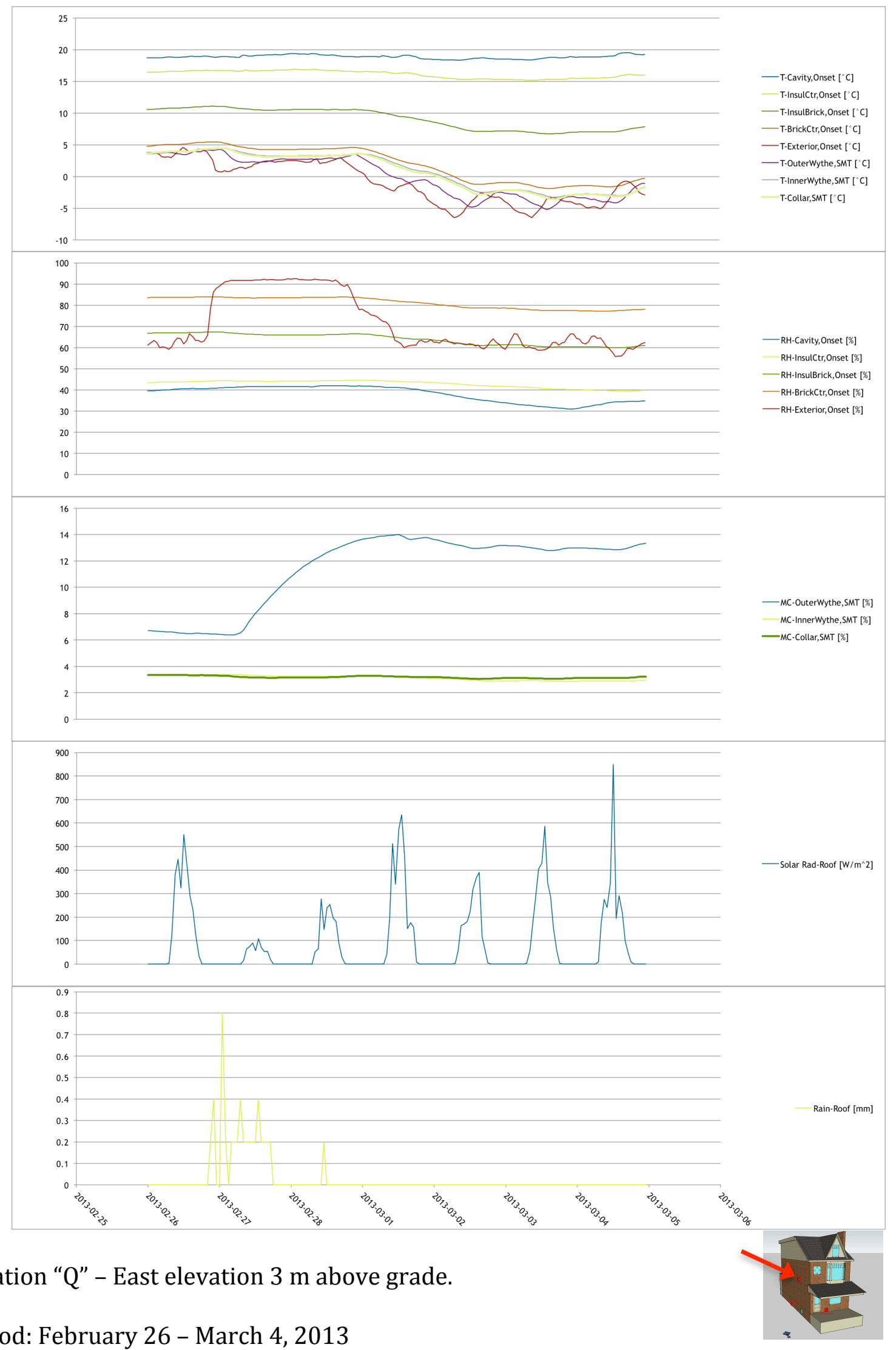

Period: February 26 - March 4, 2013

Figure 130: Sensor Measurements from location "Q" - East elevation 3 m above grade. February 26 - March 4, 2013. 


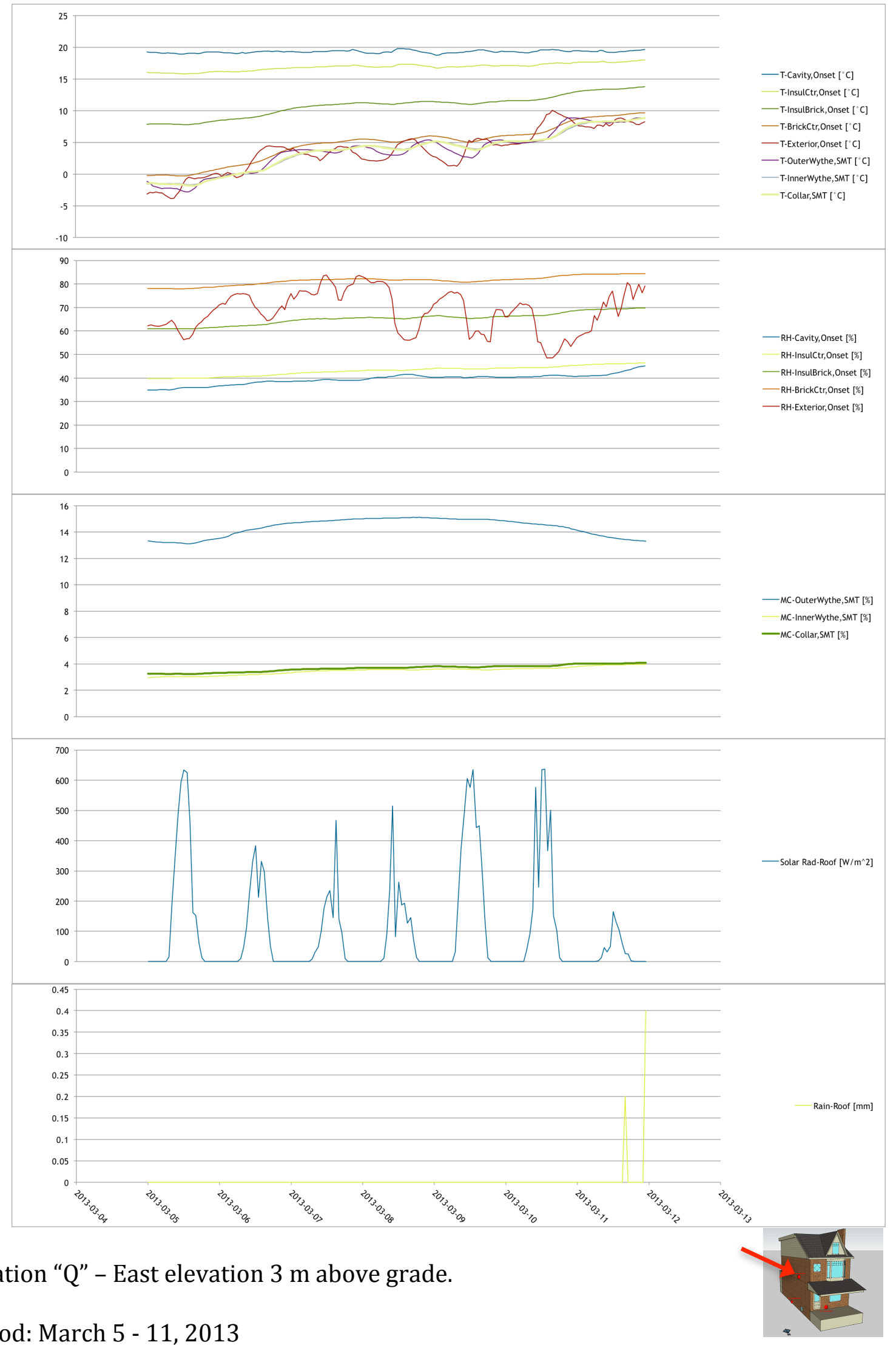

Period: March 5 - 11, 2013

Figure 131: Sensor Measurements from location "Q" - East elevation 3 m above grade. March 5 - 11, 2013. 


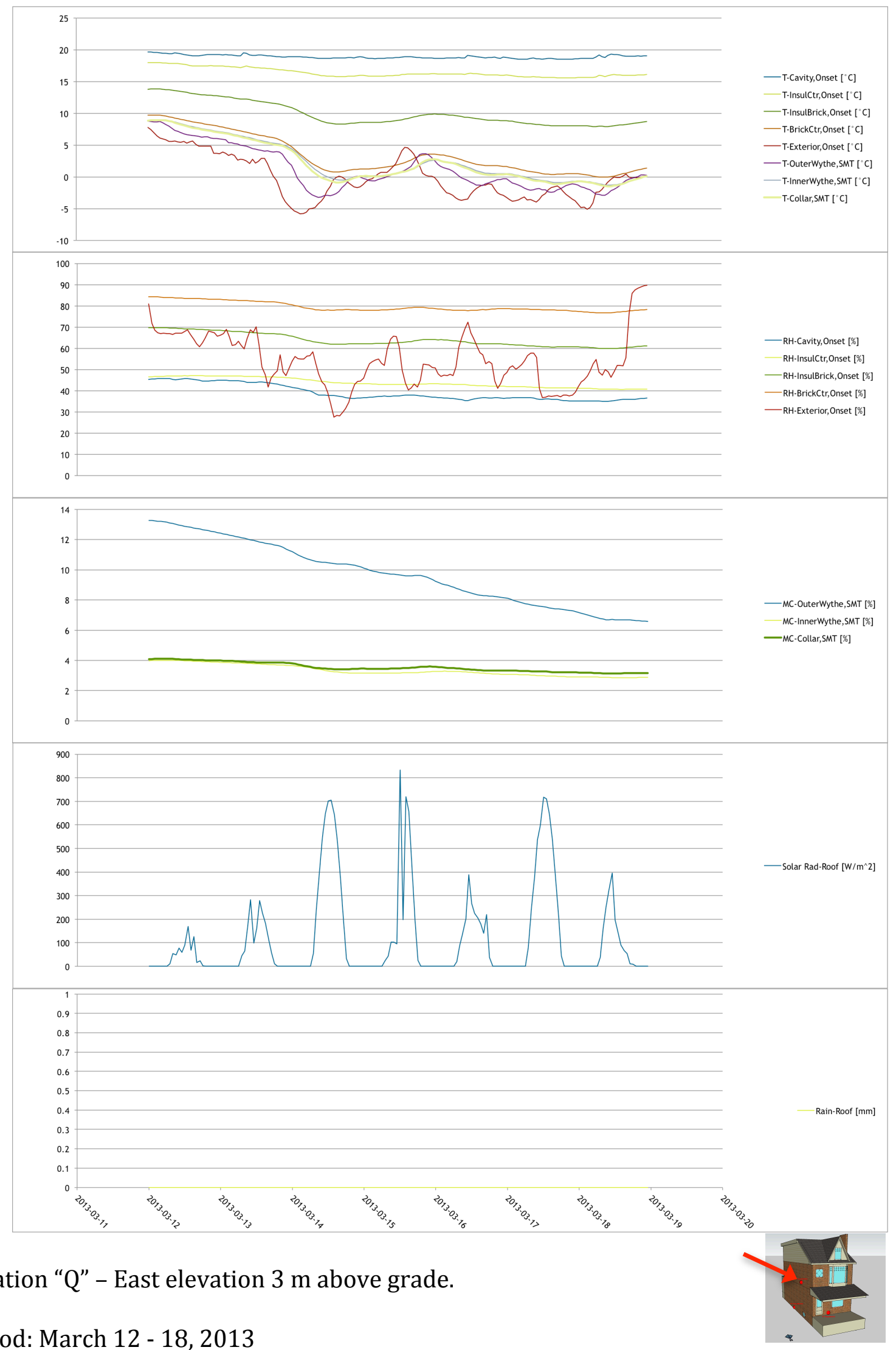

Period: March 12 - 18, 2013

Figure 132: Sensor Measurements from location "Q" - East elevation 3 m above grade. March 12 - 18, 2013. 


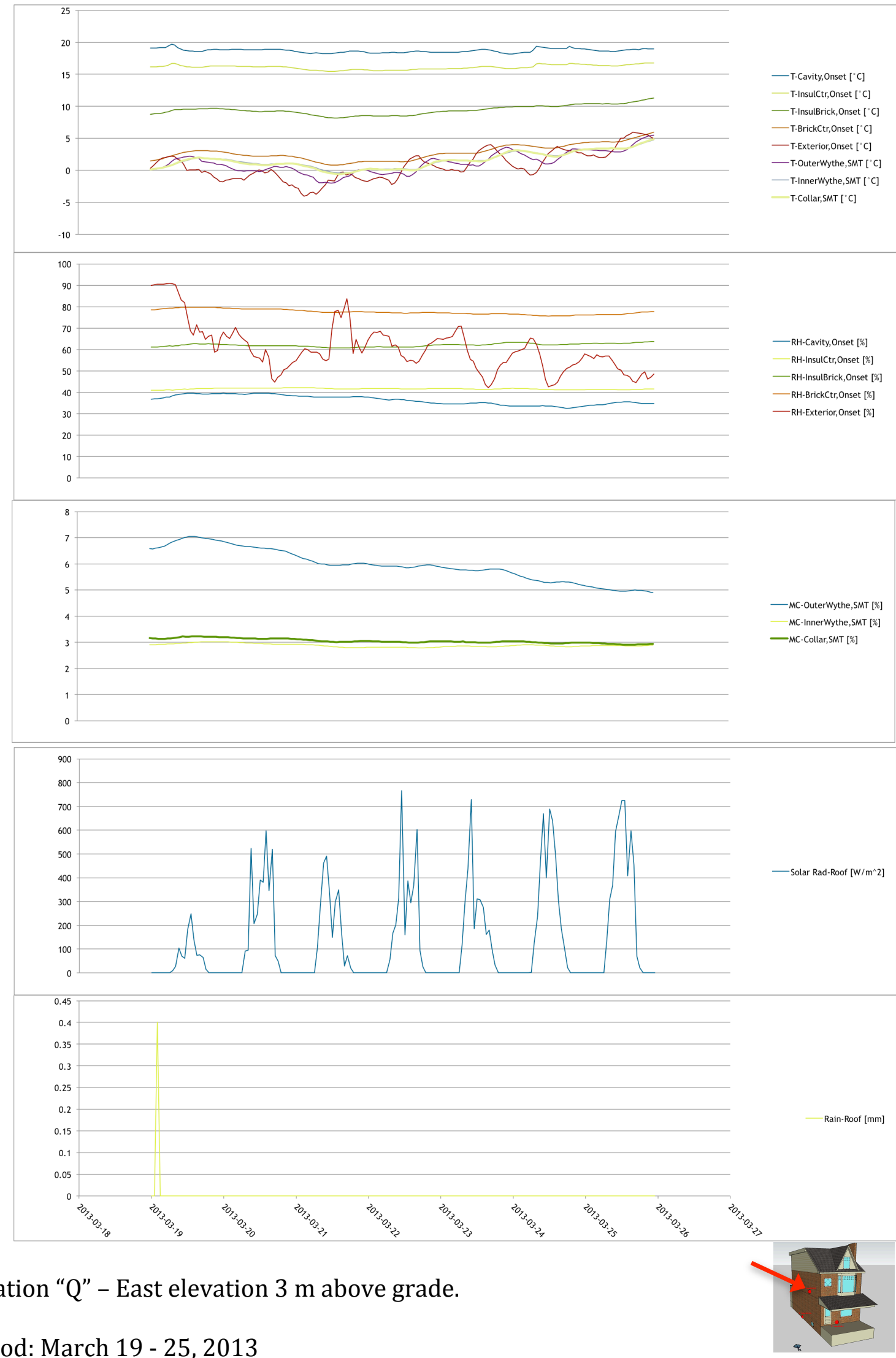

Period: March 19 - 25, 2013

Figure 133: Sensor Measurements from location "Q" - East elevation 3 m above grade. March 19 - 25 , 2013. 


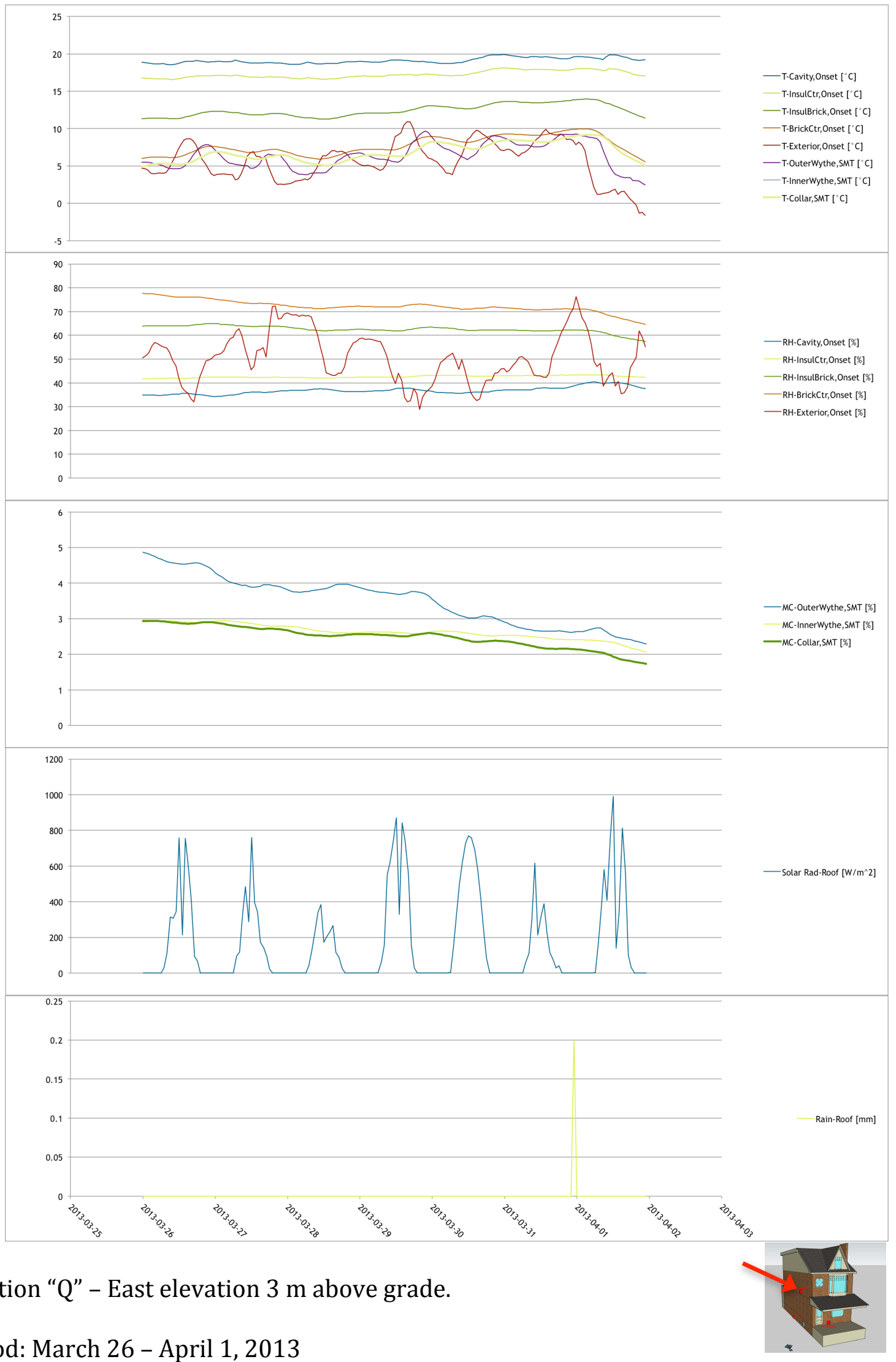

Period: March 26 - April 1, 2013

Figure 134: Sensor Measurements from location "Q" - East elevation 3 m above grade. March 26 - April 1, 2013. 


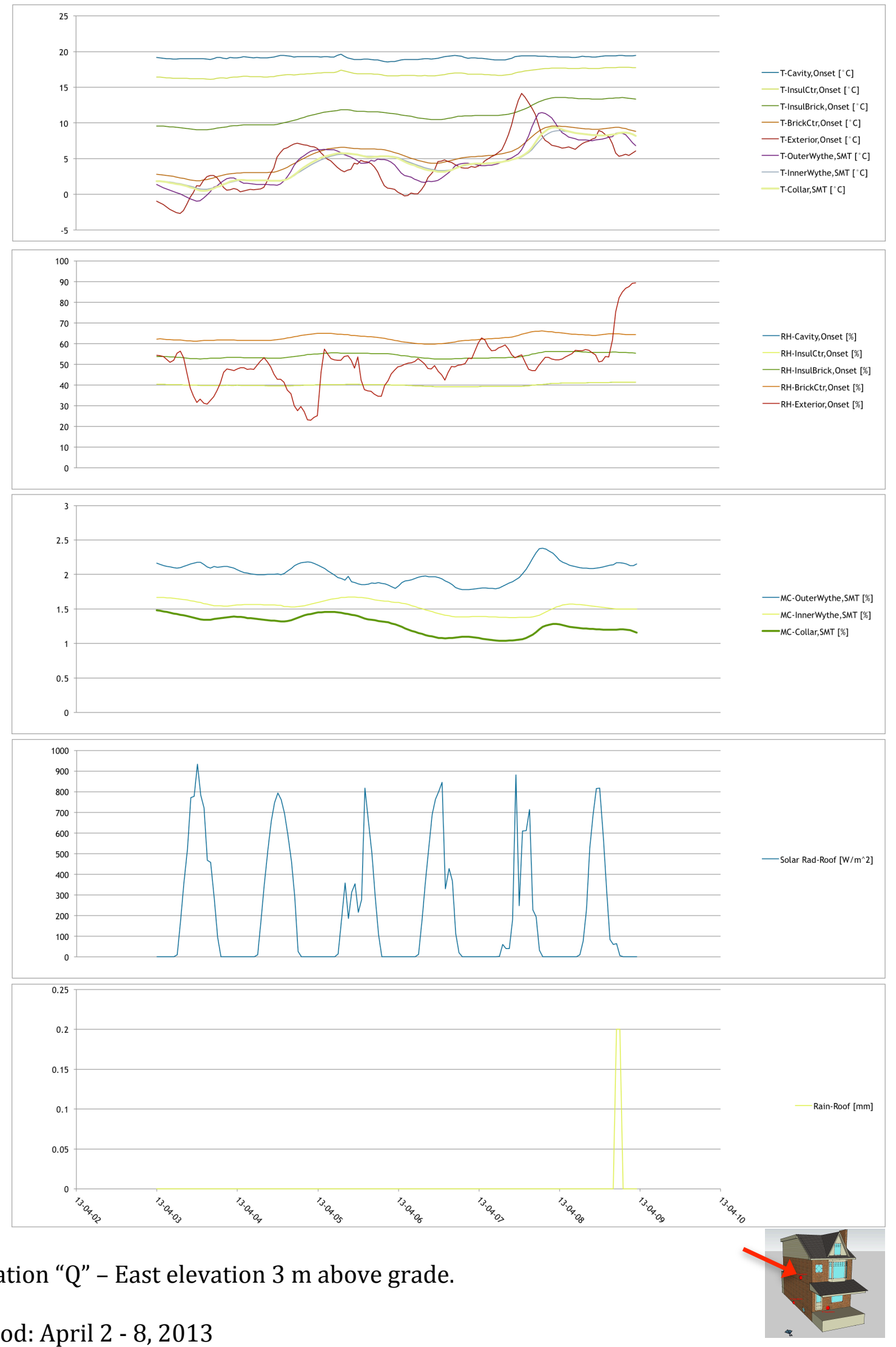

Period: April 2 - 8, 2013

Figure 135: Sensor Measurements from location "Q" - East elevation 3 m above grade. April 2 - 8, 2013. 


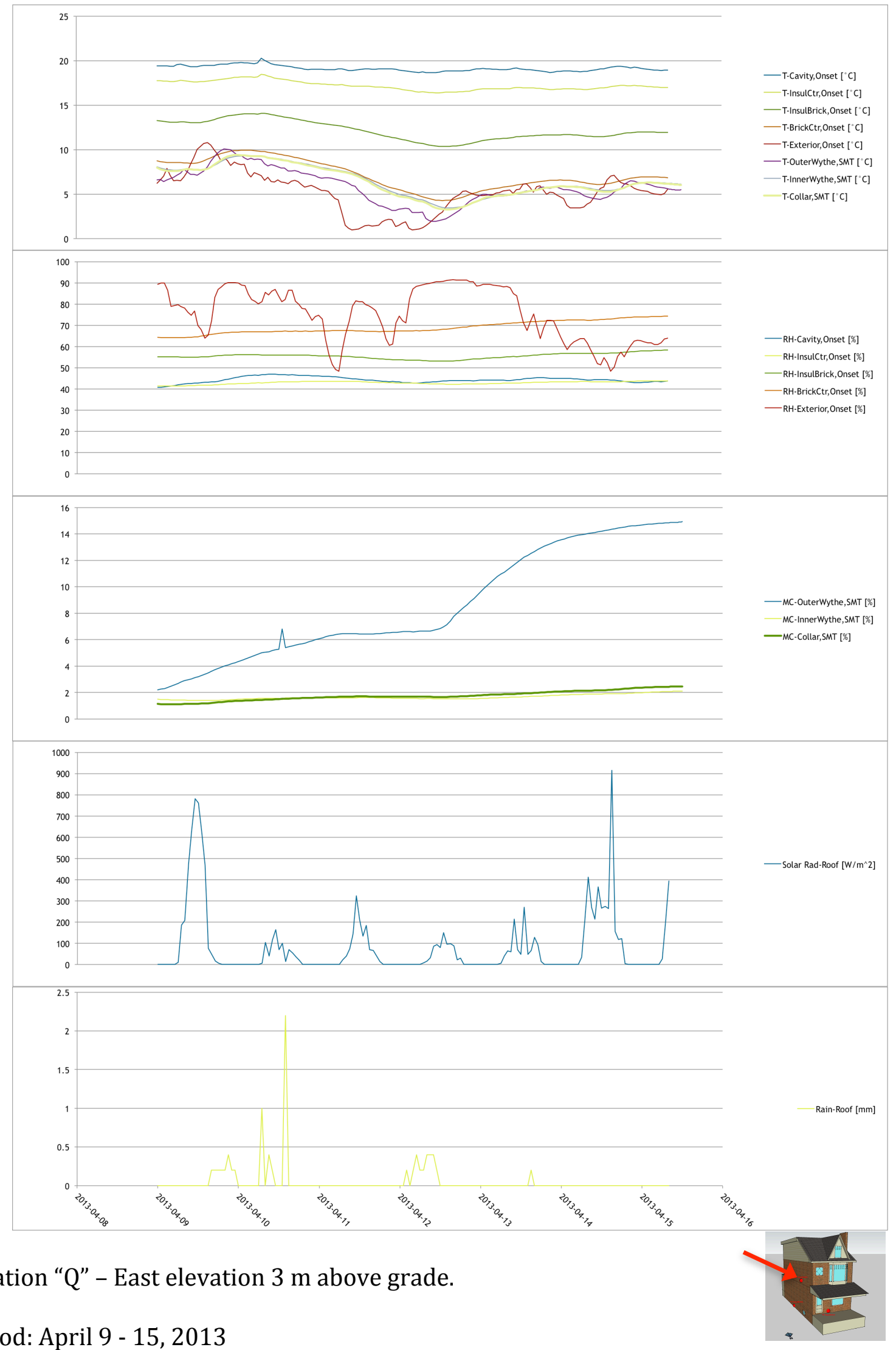

Period: April 9 - 15, 2013

Figure 136: Sensor Measurements from location "Q" - East elevation 3 m above grade. April 9 - $15,2013$. 


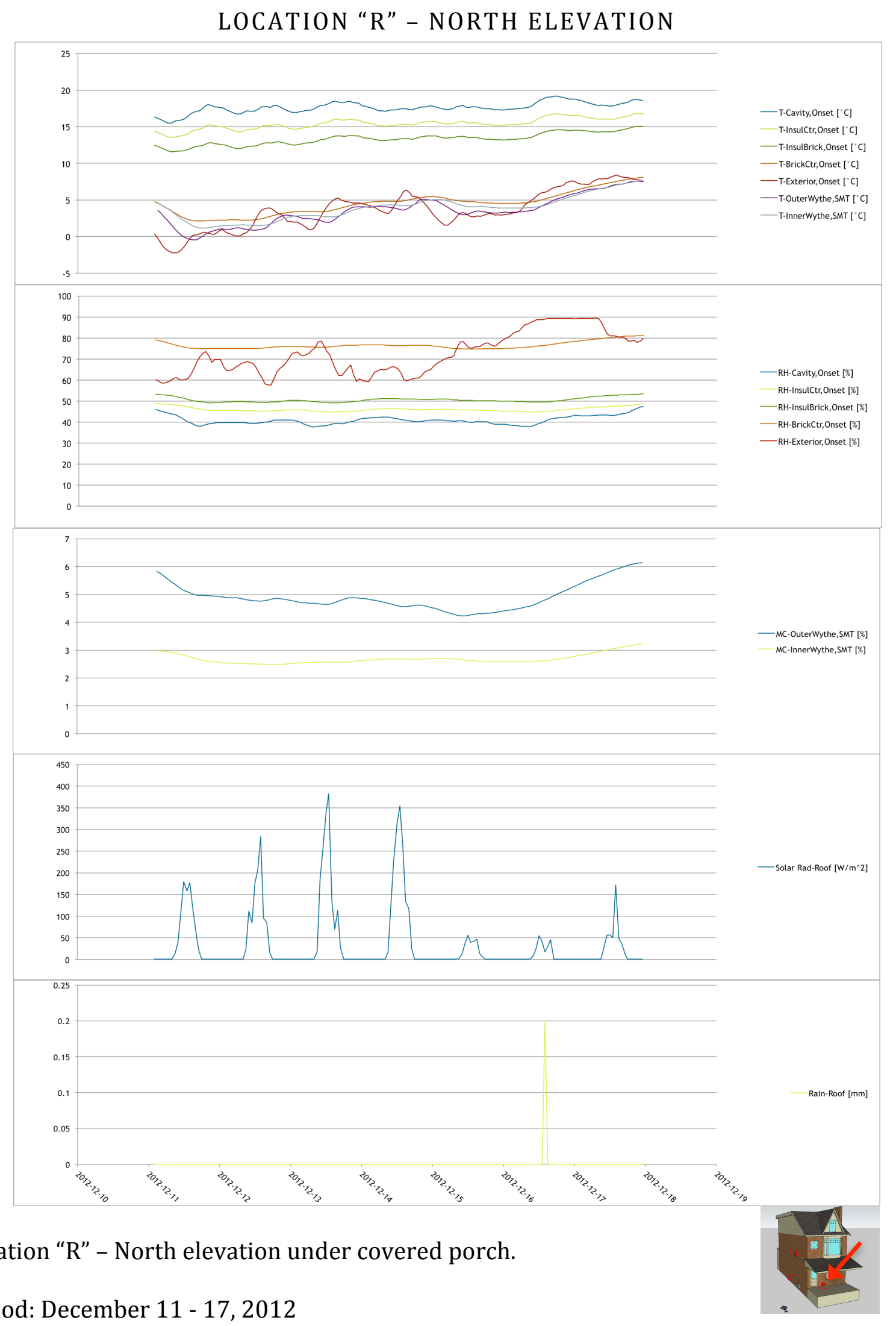

Period: December 11 - 17, 2012

Figure 137: Sensor Measurements from location "R" - North eleVation Under Covered Porch. December 11 $17,2012$. 


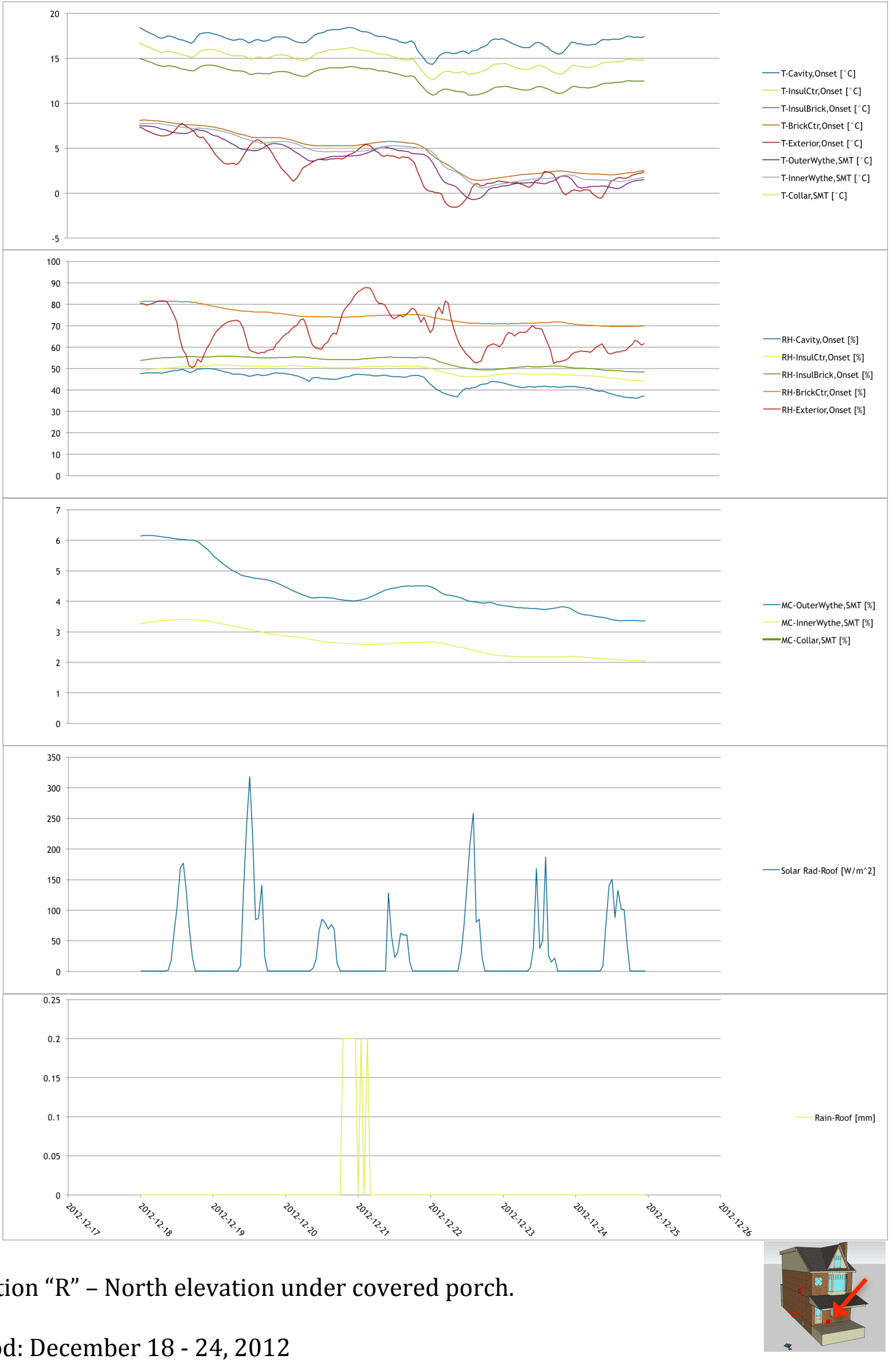

Period: December 18 - 24, 2012

Figure 138: Sensor Measurements from location "R" - North eleVation Under Covered Porch. December 18 $24,2012$. 


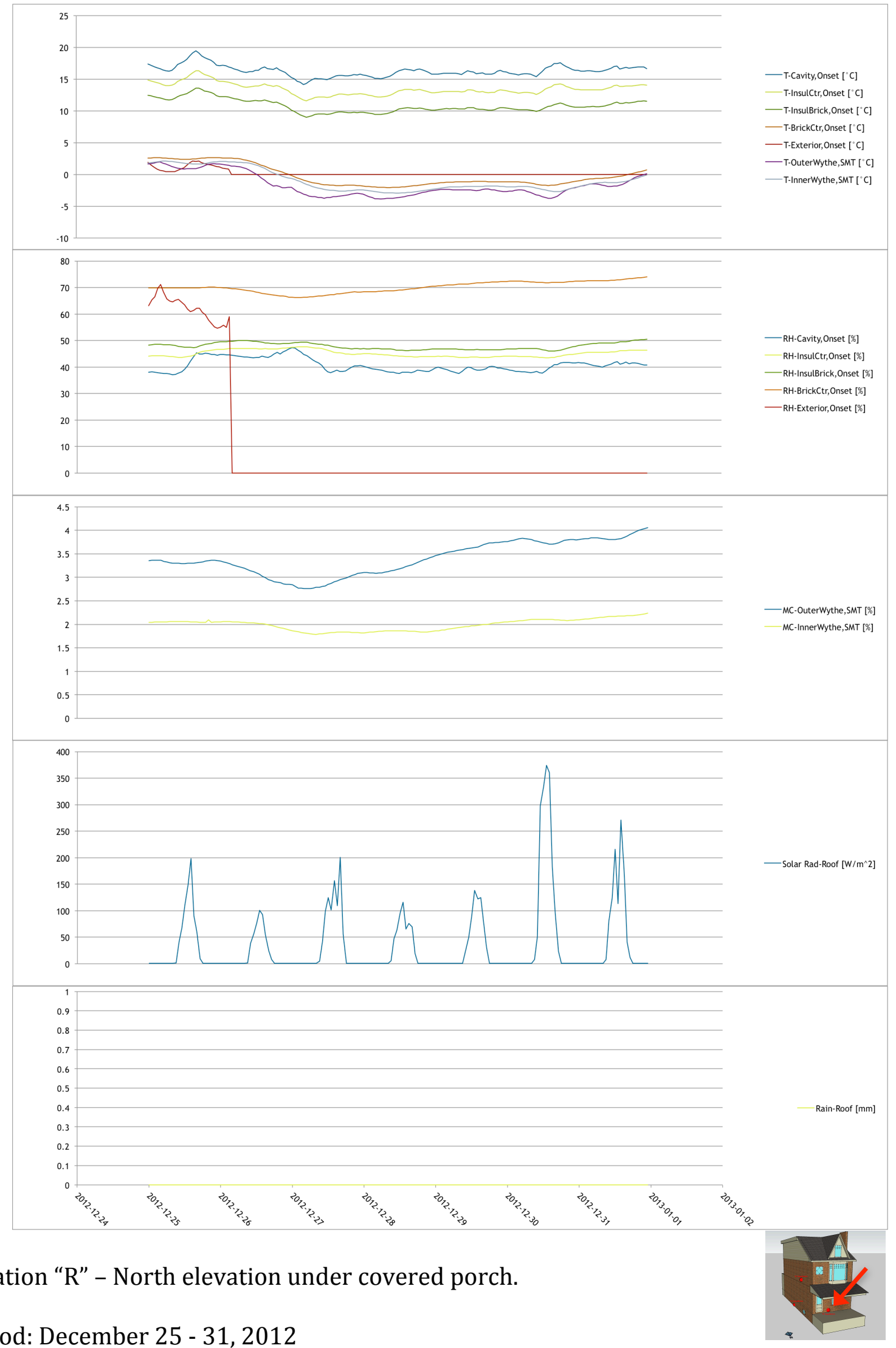

Period: December 25 - 31, 2012

Figure 139: Sensor Measurements from Location "R" - North EleVation Under Covered PORCh. DeCEMbER 25 $31,2012$. 


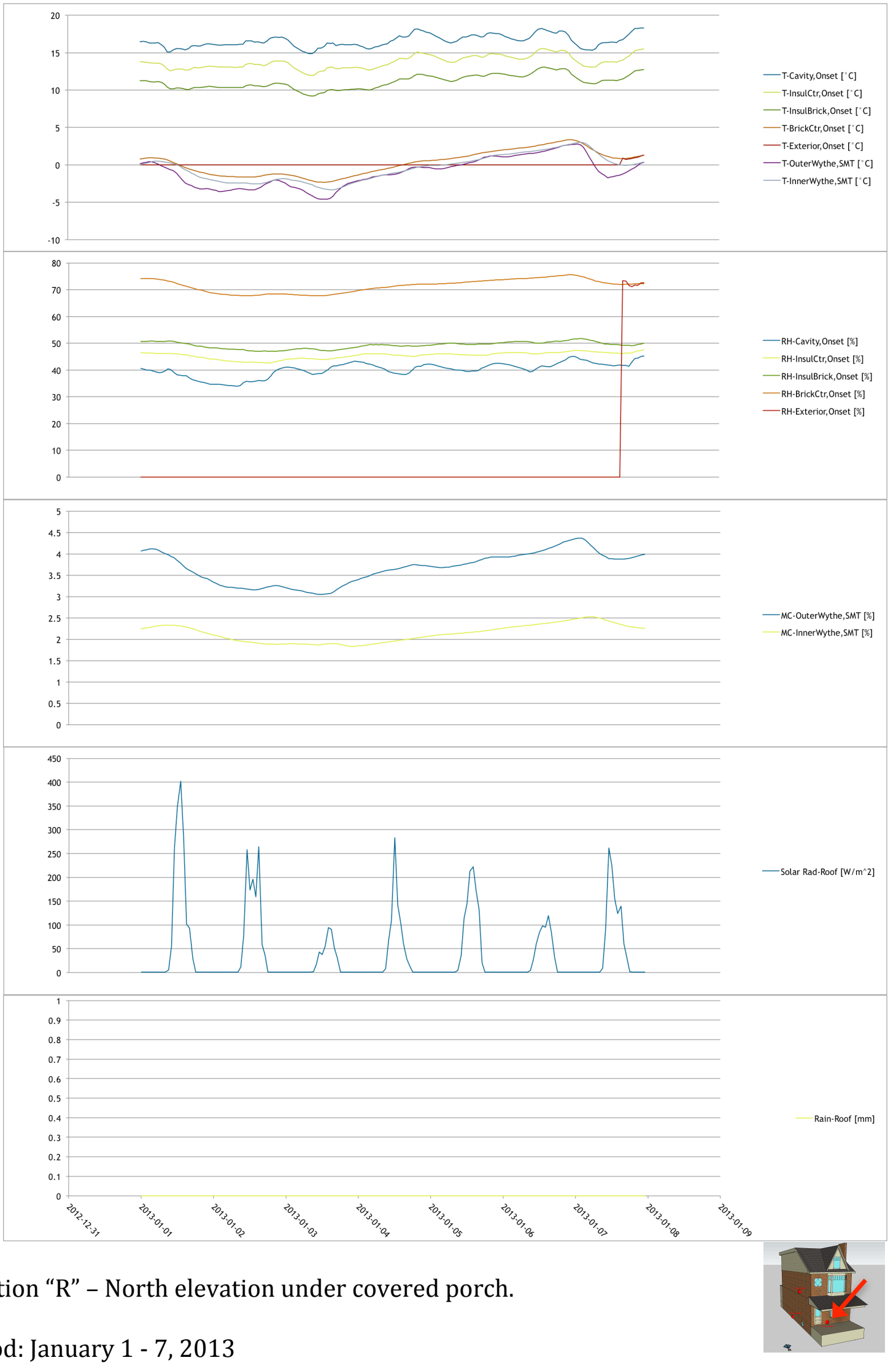

Period: January 1 - 7, 2013

Figure 140: Sensor Measurements from Location "R" - North eleVation Under Covered porch. January 1 - 7 , 2013. 


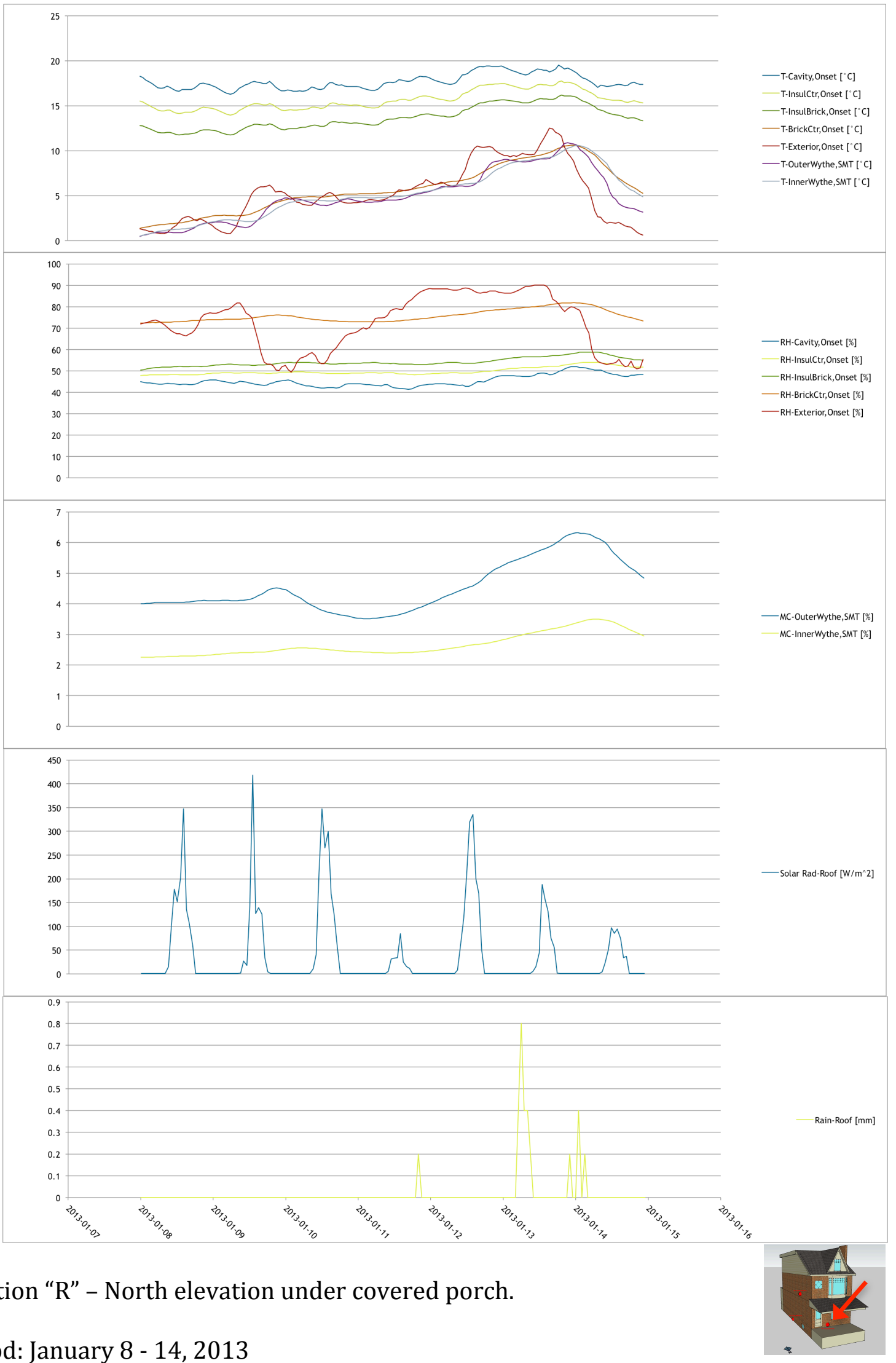

Period: January 8 - 14, 2013

Figure 141: Sensor Measurements from location "R" - North elevation under Covered Porch. January 8 - 14, 2013. 

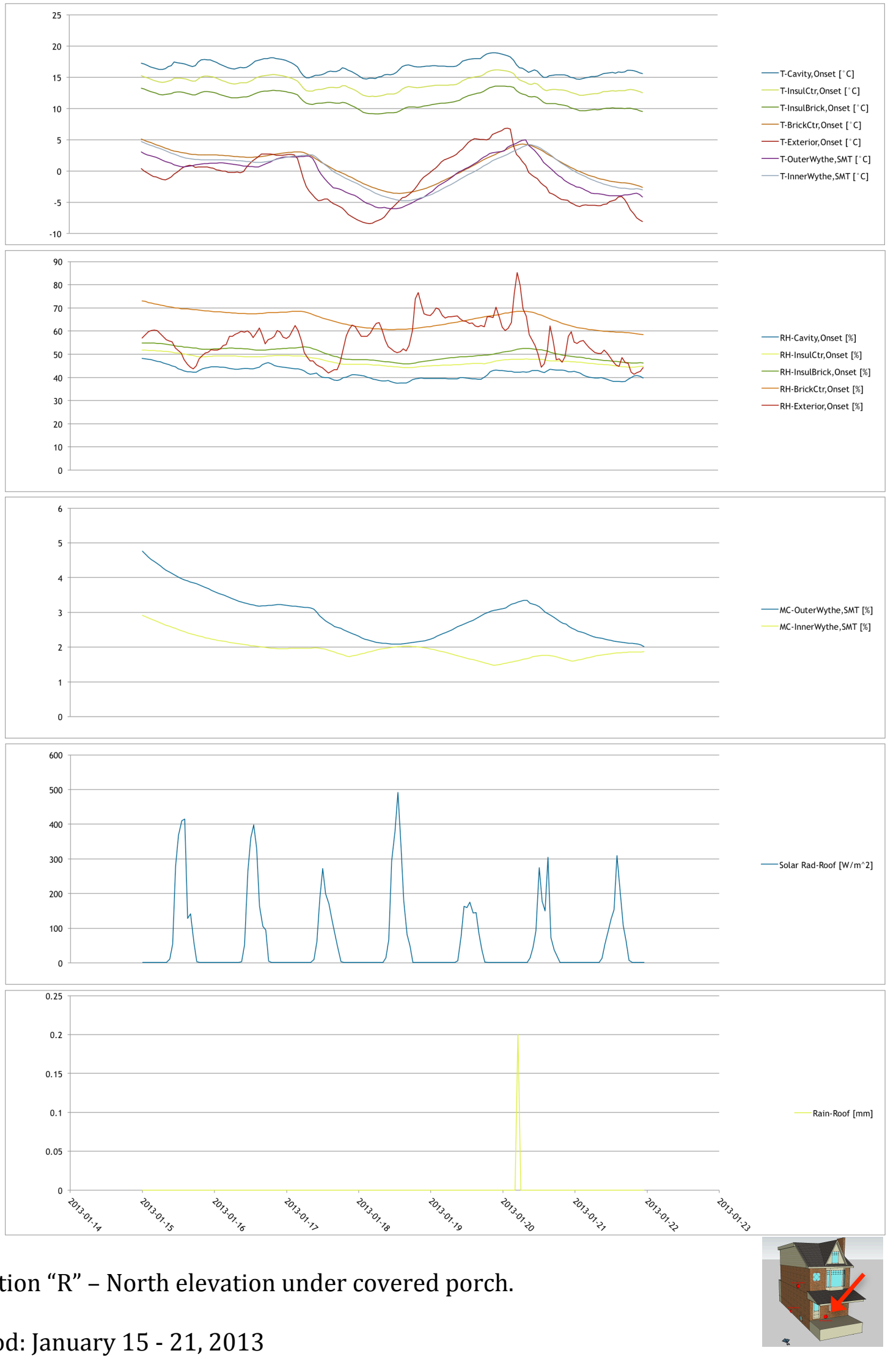

Period: January 15 - 21, 2013

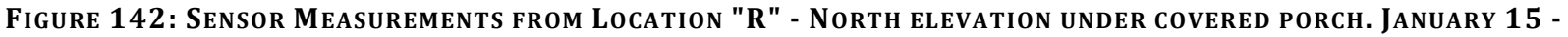
$21,2013$. 


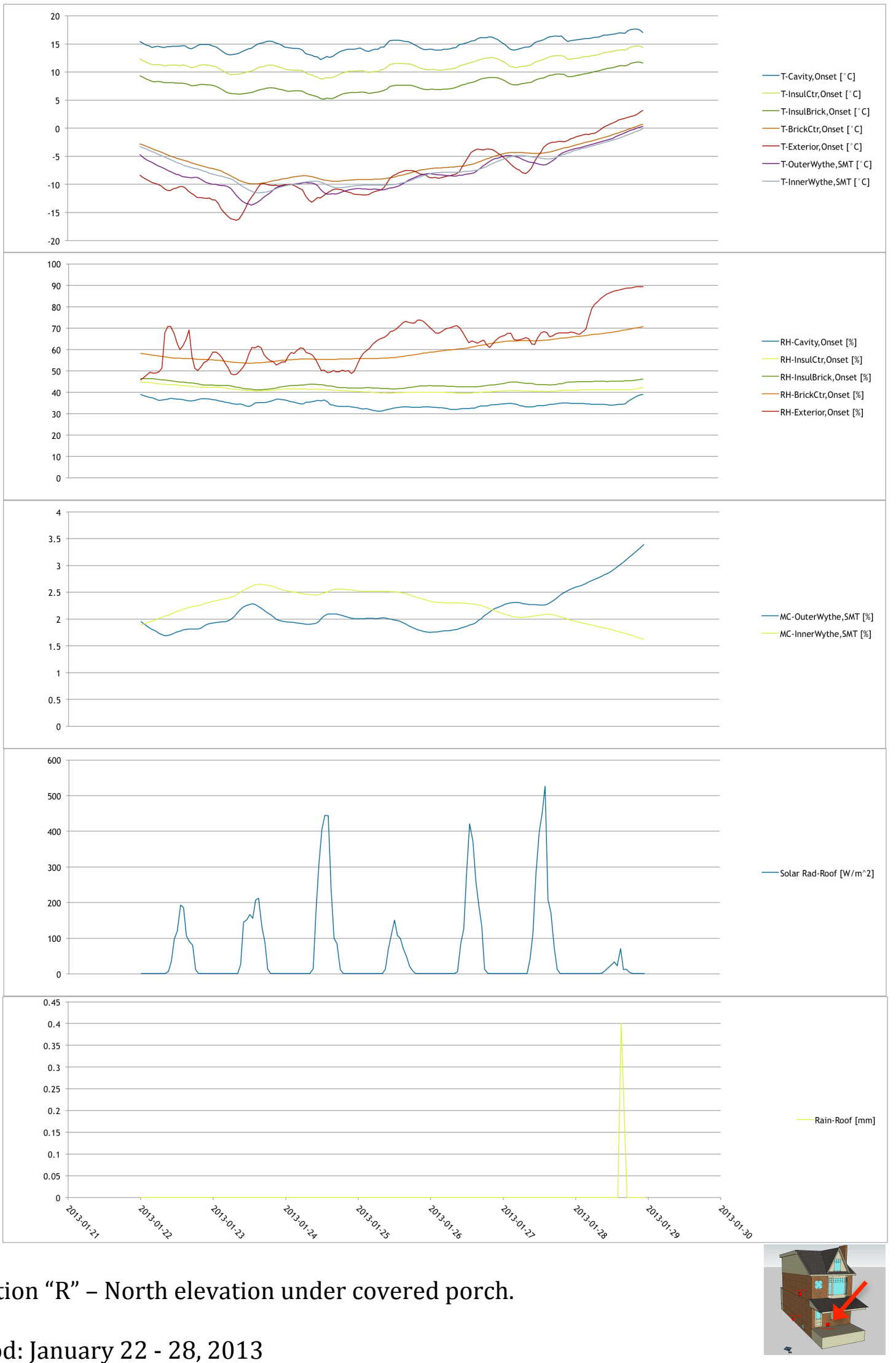

Period: January 22 - 28, 2013

Figure 143: SEnSOR MEASUREMENTS From Location "R" - NORTh ElEVATION UNDER COVERED PORCH. JANUARY 22 $28,2013$. 

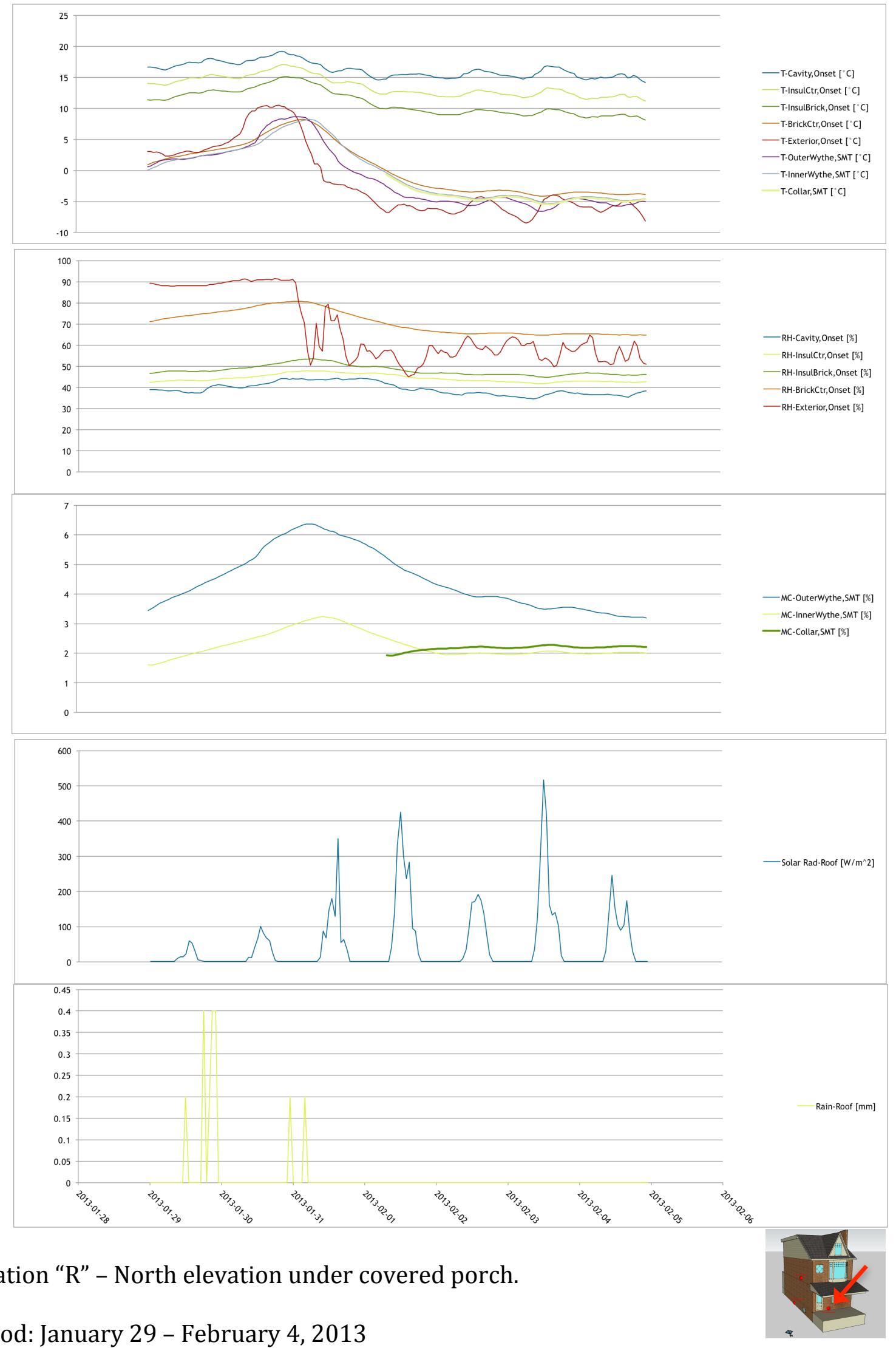

Period: January 29 - February 4, 2013

Figure 144: SEnSor Measurements from Location "R" - North EleVATION Under COVERED PORCh. JANUARY 29 FEBRUARY 4, 2013. 


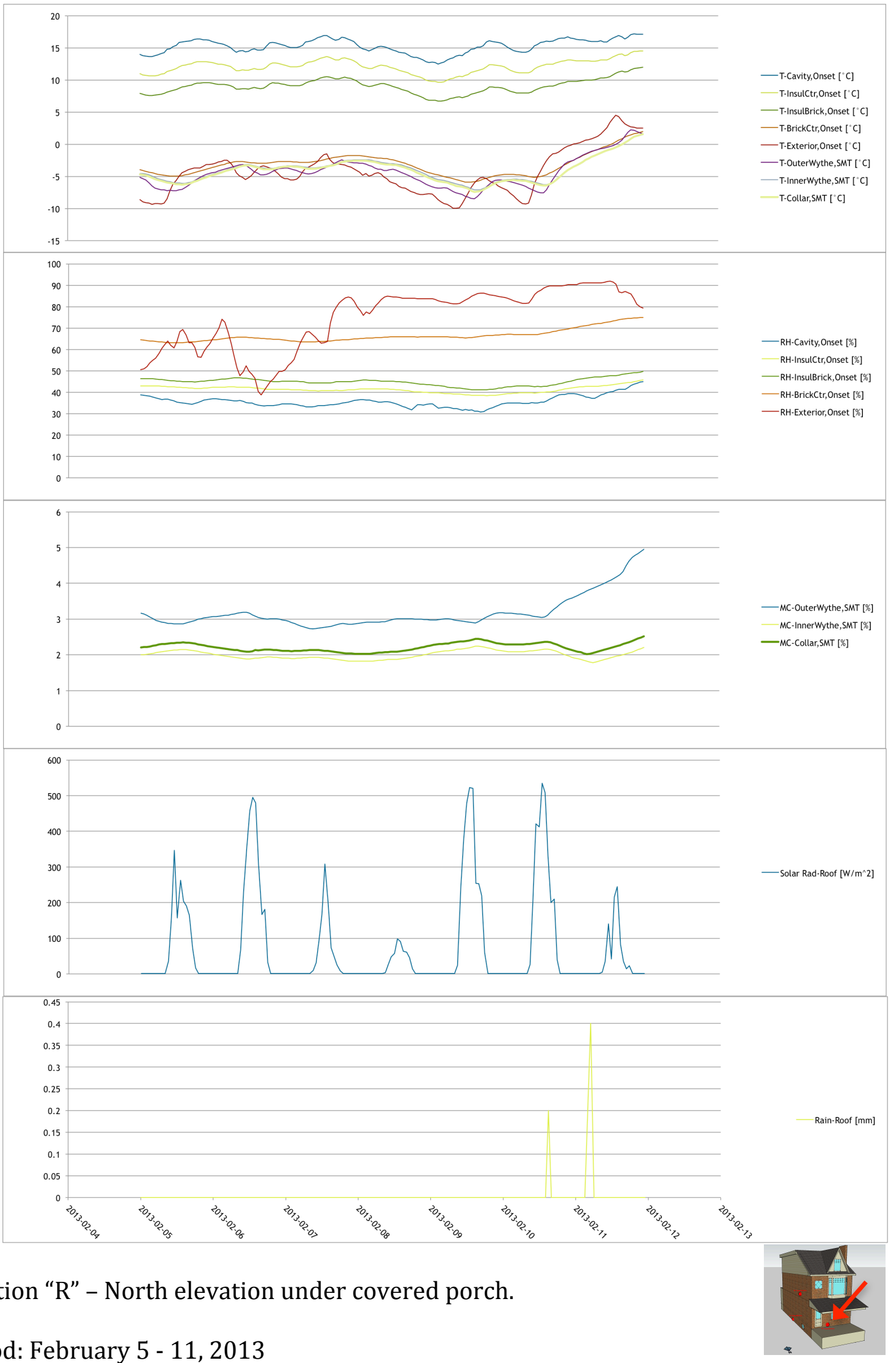

Period: February 5 - 11, 2013

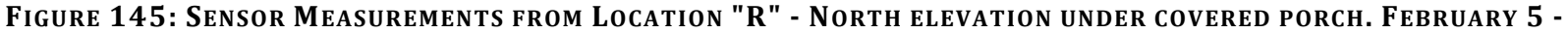
11, 2013. 

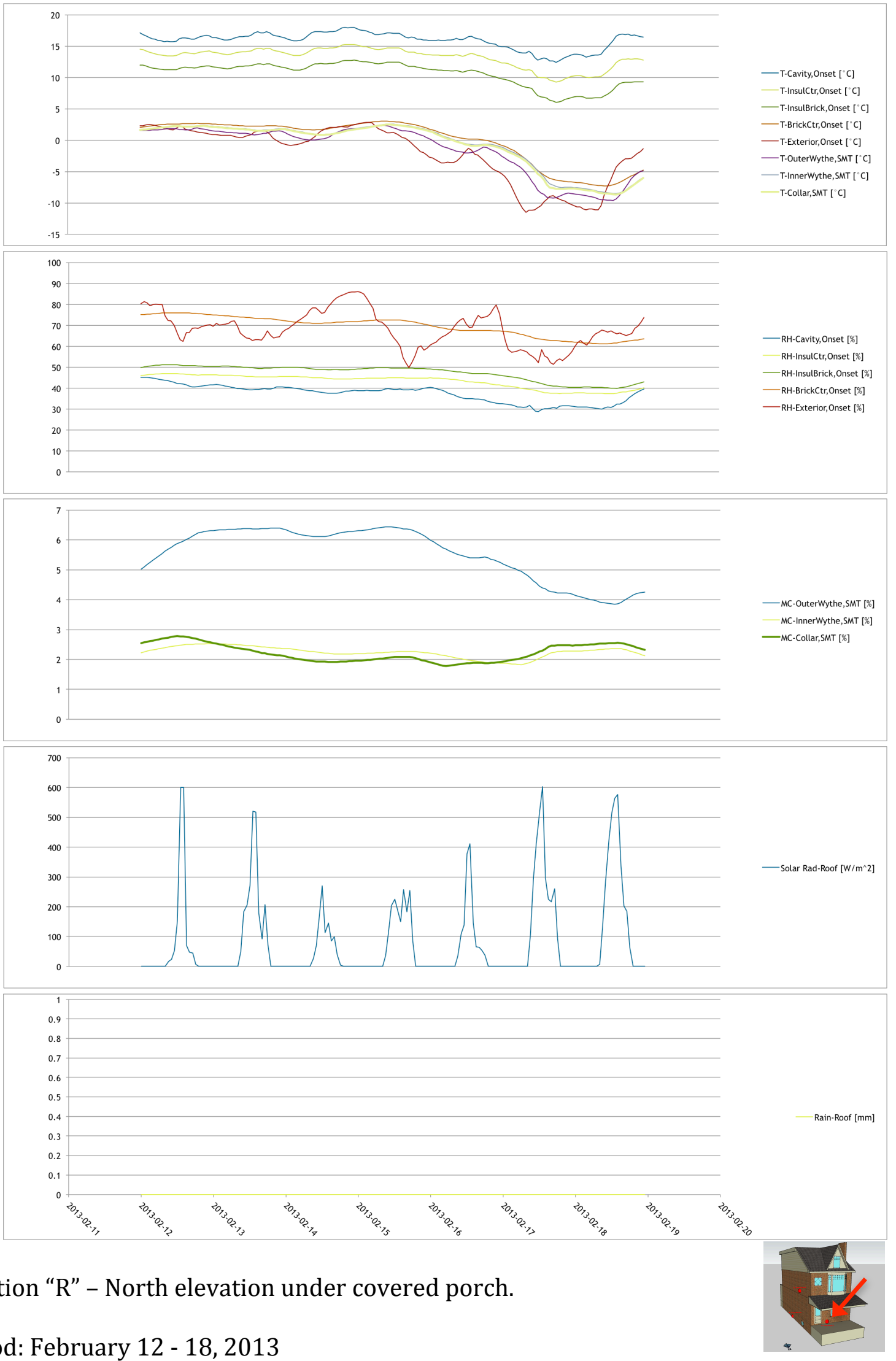

Period: February 12 - 18, 2013

Figure 146: Sensor Measurements from location "R" - North eleVation Under Covered PORCh. FEBRUARY 12 18, 2013. 


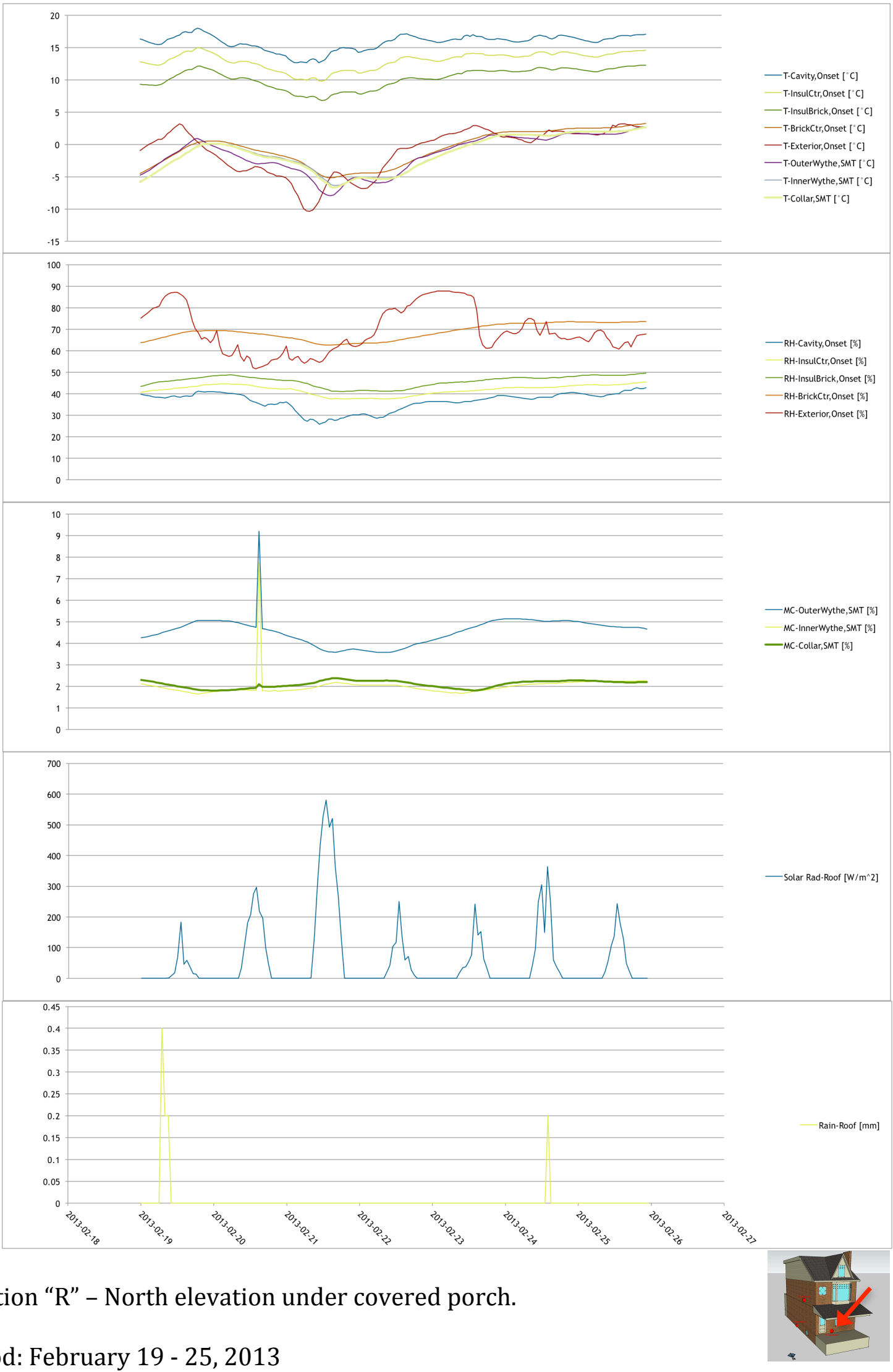

Period: February 19 - 25, 2013

Figure 147: SEnSor Measurements from Location "R" - North ElEVATION UNDER COVERED PORCH. FEBRUARY 19. $25,2013$. 


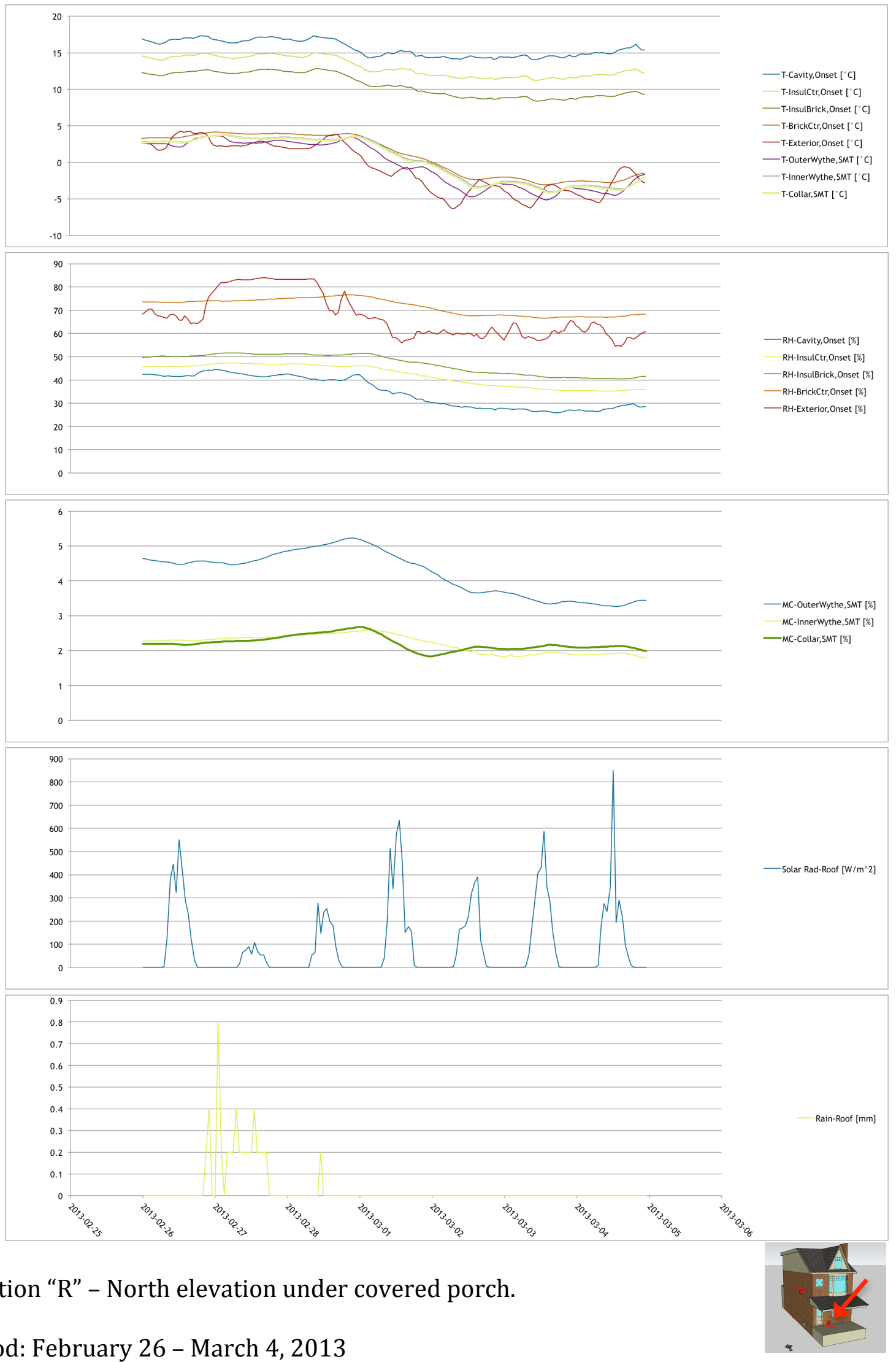

Period: February 26 - March 4, 2013

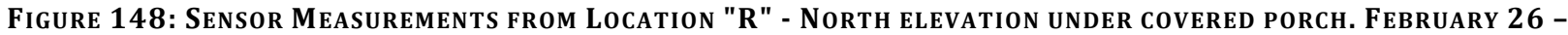
MARCH 4, 2013. 


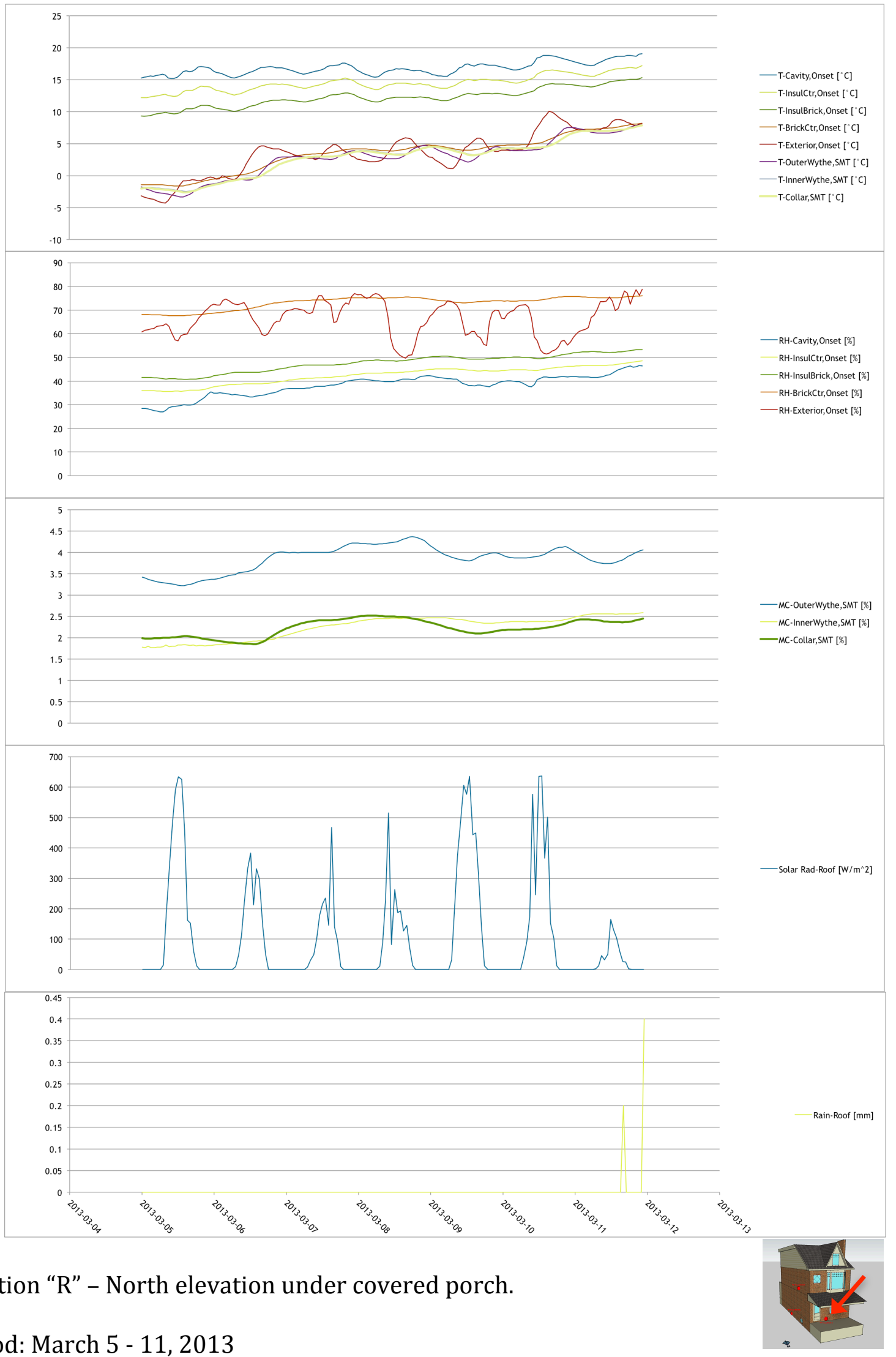

Period: March 5 - 11, 2013

Figure 149: SEnsor Measurements from Location "R" - North EleVATION UNDER COVERED PORCh. MARCh 5 - 11, 2013. 


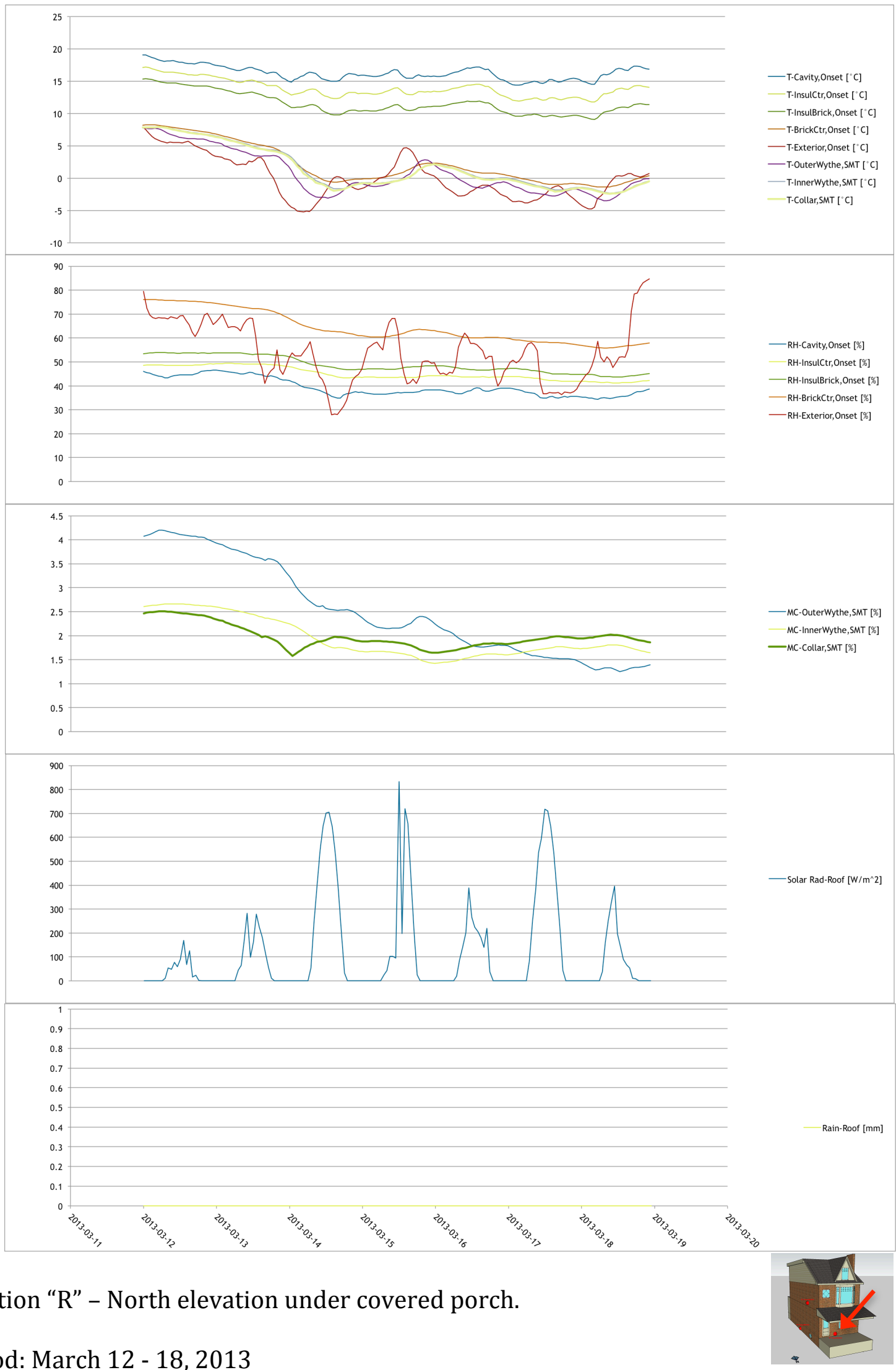

Period: March 12 - 18, 2013

Figure 150: Sensor Measurements from Location "R" - North eleVation under Covered porch. March 12 - 18, 2013. 


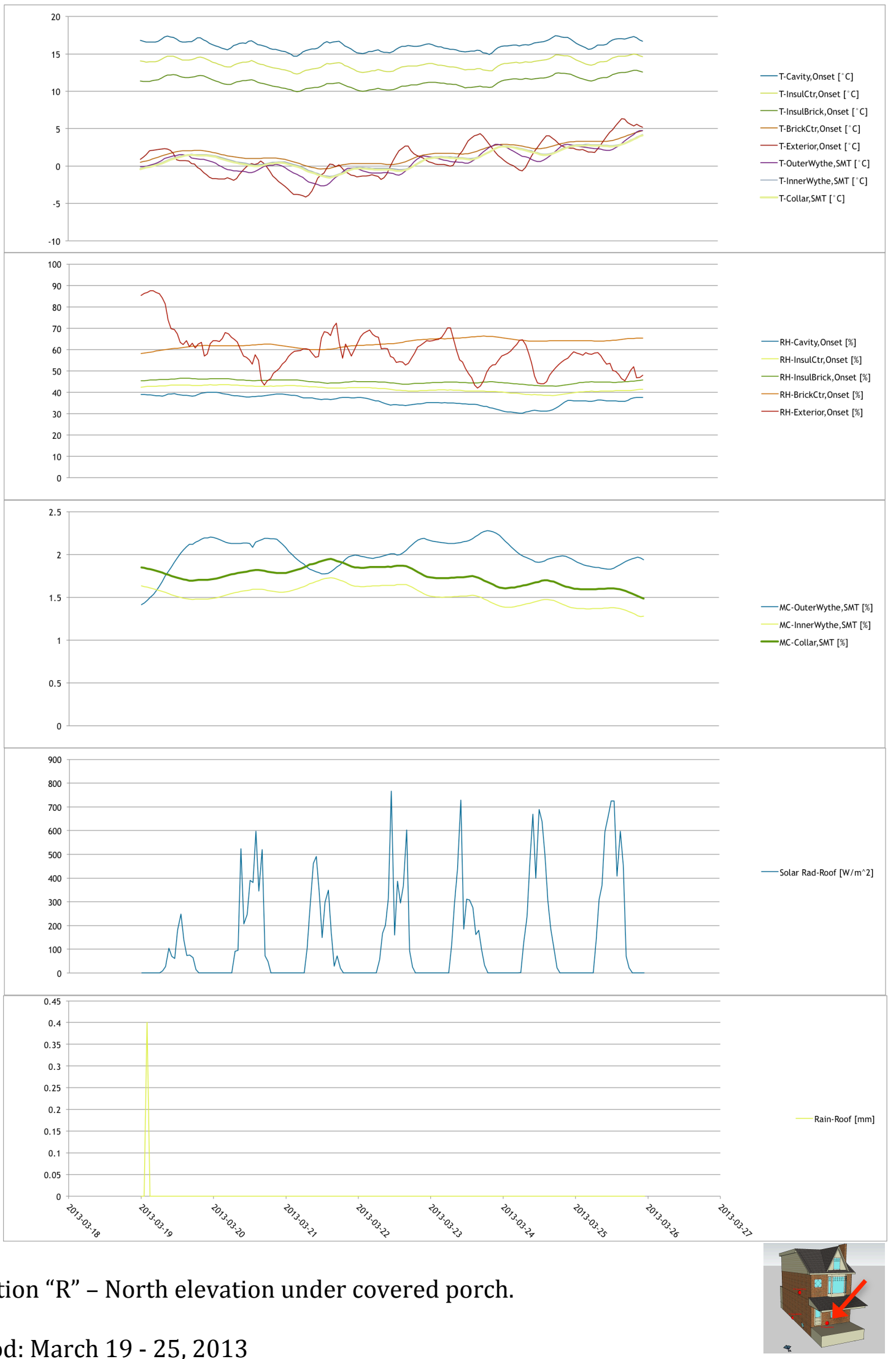

Period: March 19 - 25, 2013

Figure 151: Sensor Measurements from location "R" - North elevation under covered porch. March 19 - 25 , 2013. 


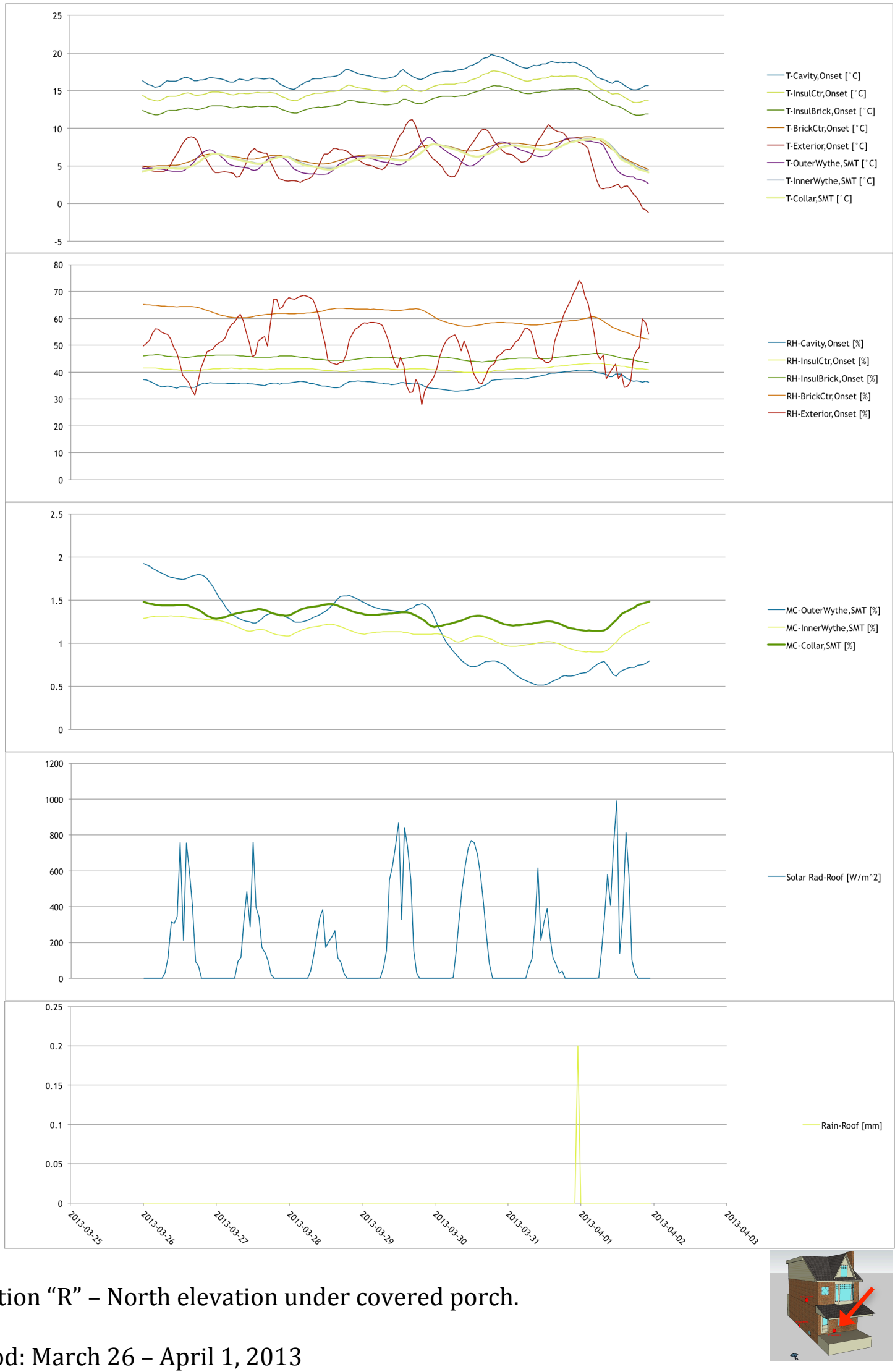

Period: March 26 - April 1, 2013

Figure 152: Sensor Measurements from location "R" - North elevation under Covered Porch. March 26 April 1, 2013. 


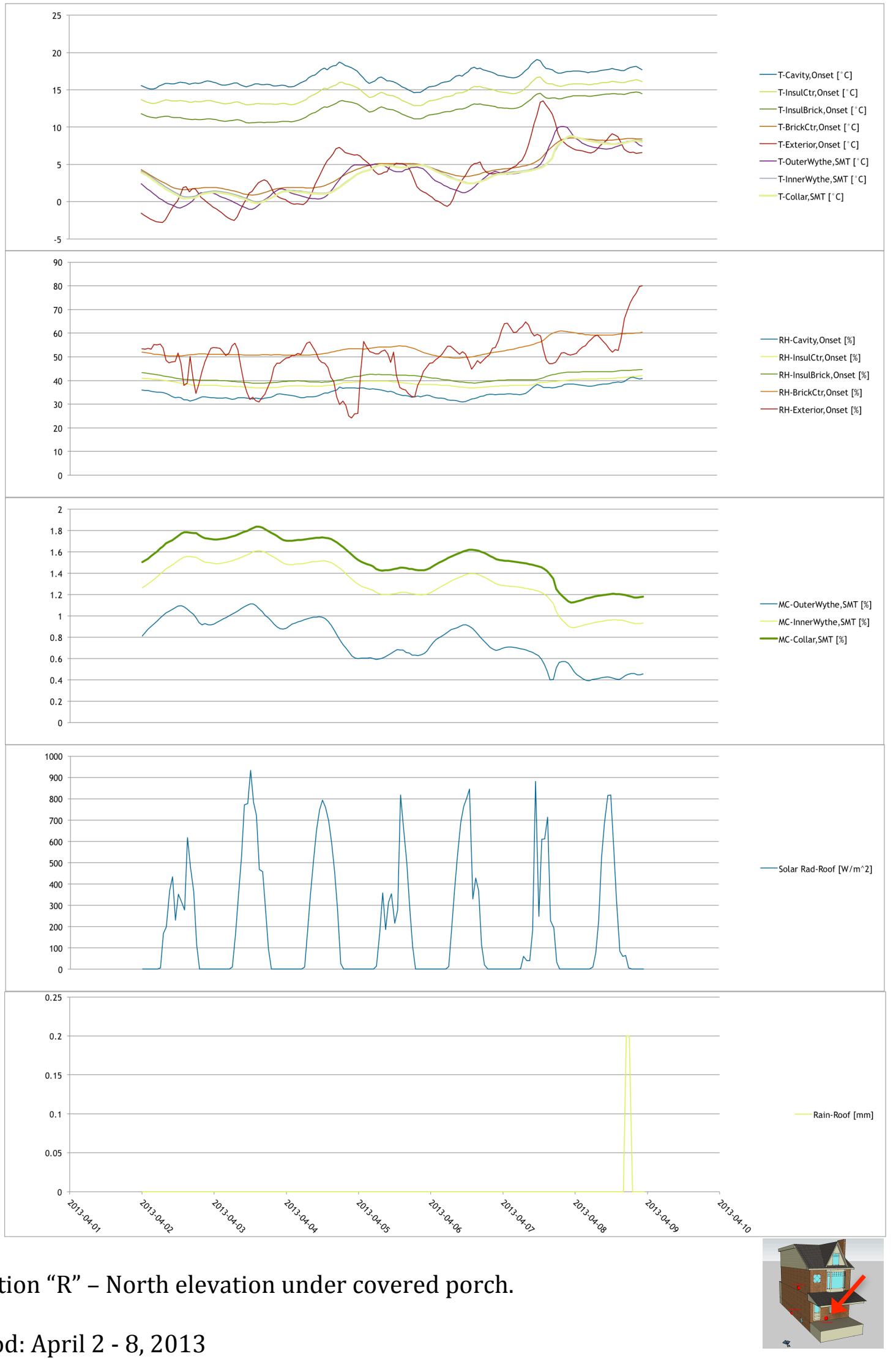

Period: April 2 - 8, 2013

Figure 153: Sensor Measurements from location "R" - North elevation Under Covered Porch. April 2 - 8, 2013. 


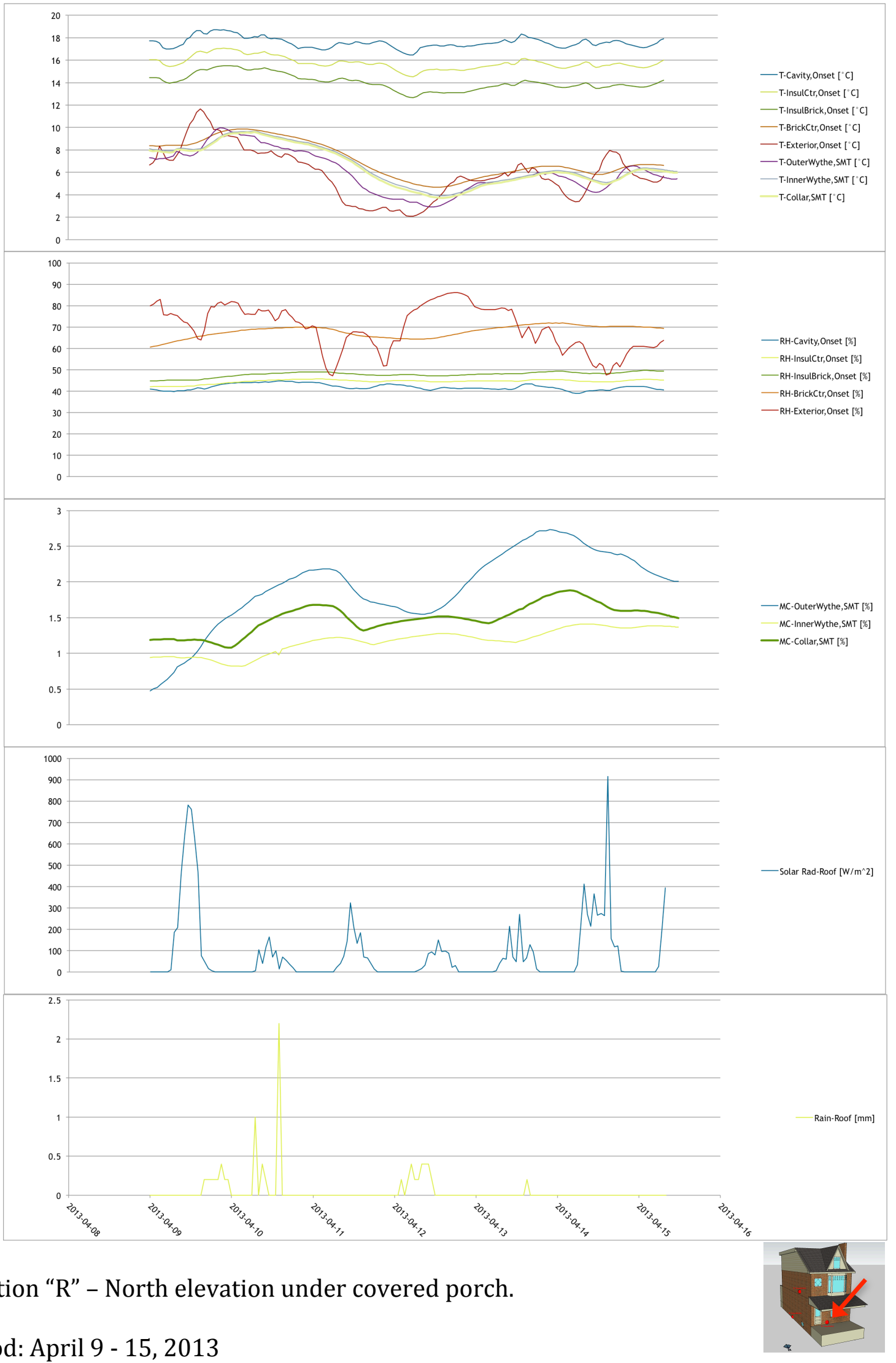

Period: April 9 - 15, 2013

Figure 154: Sensor Measurements from location "R" - North eleVation under covered porch. April 9 - 15, 2013. 


\section{LOCATION "S" - SOUTH ELEVATION}

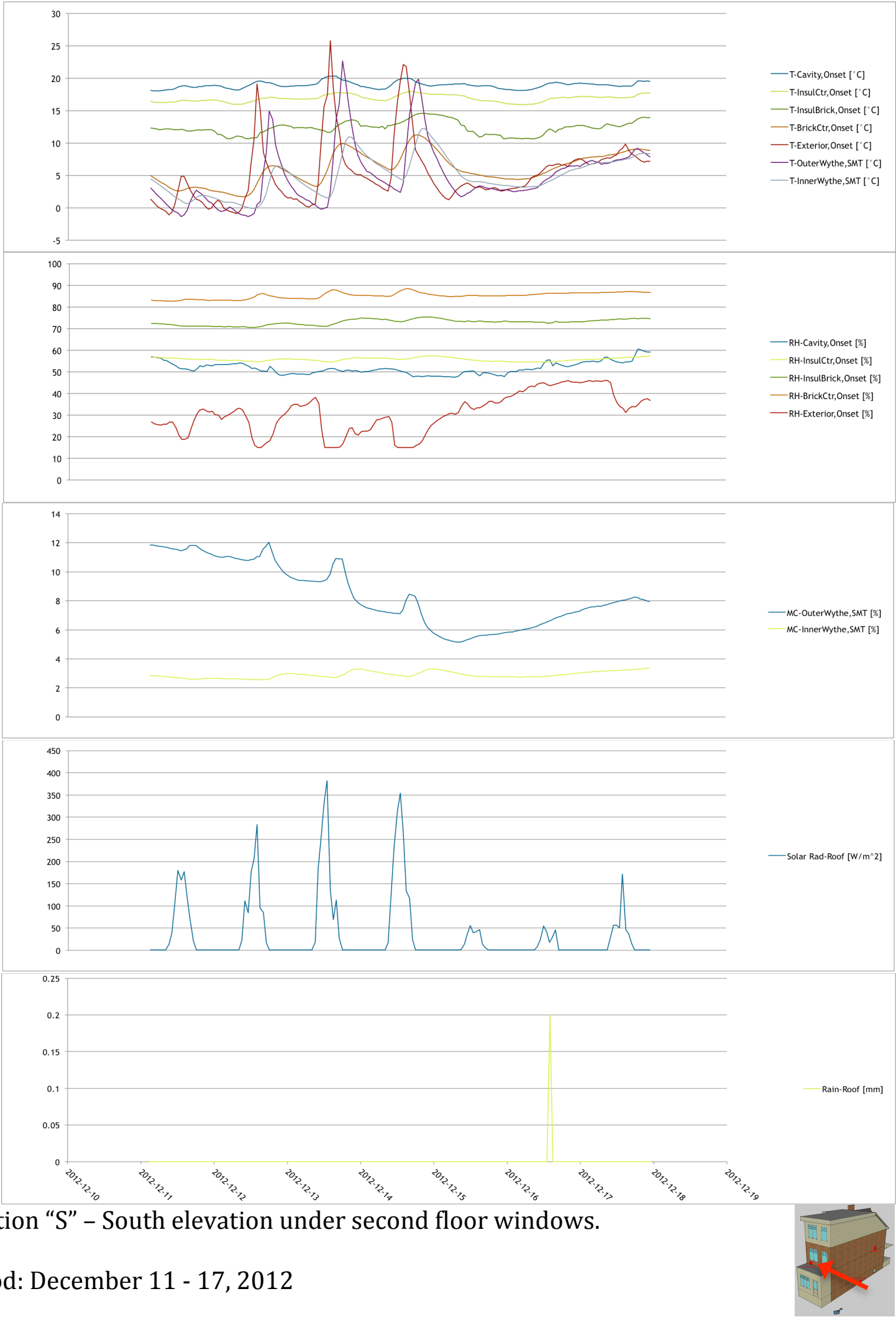

Figure 155: Sensor Measurements from location "S" - South Elevation Under SECond floor Windows. DeCEMBER 11 - 17, 2012. 


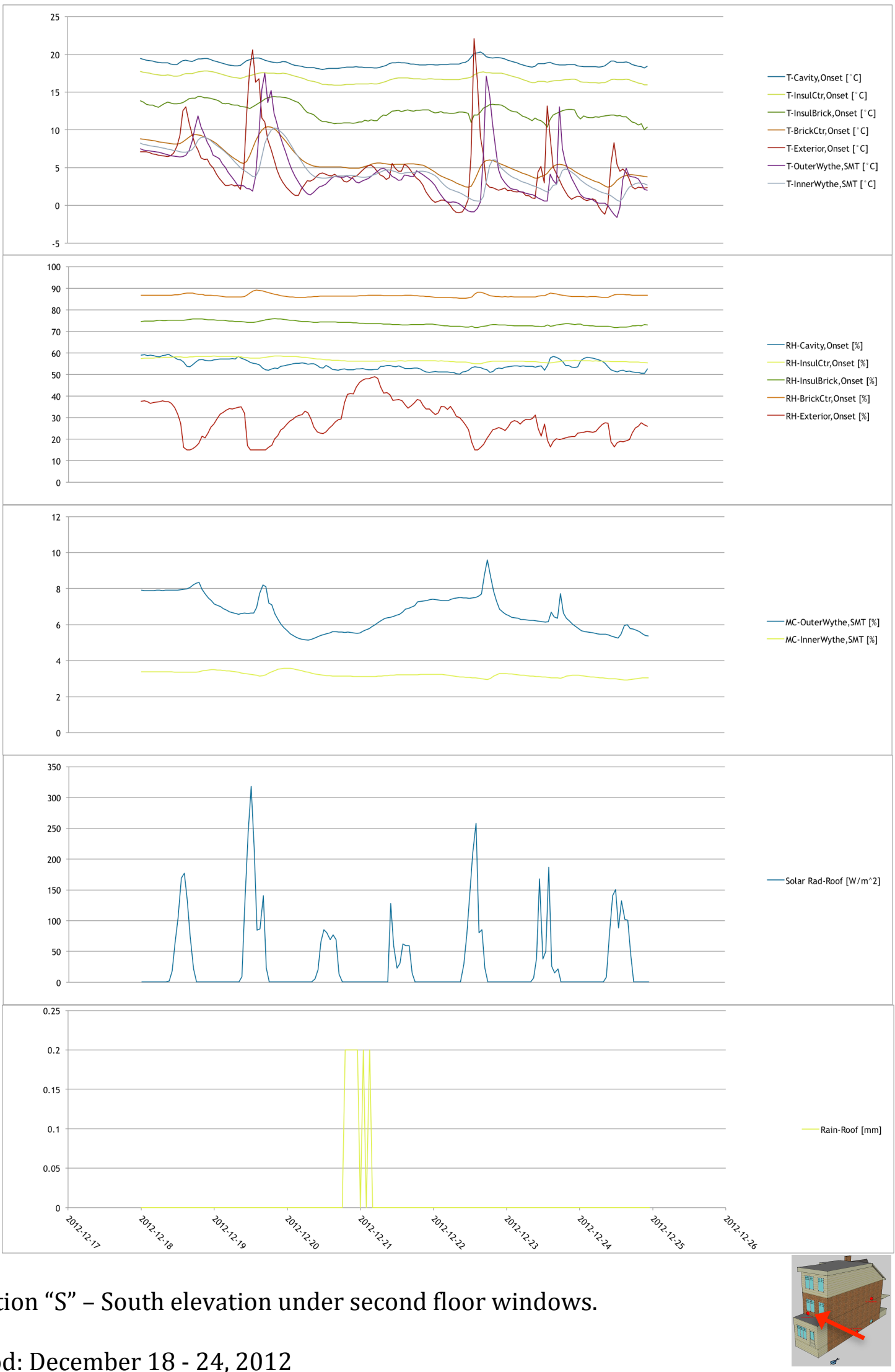

Period: December 18 - 24, 2012

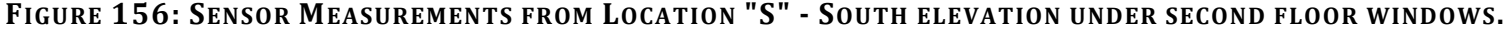
DECEMBER 18 - 24, 2012. 


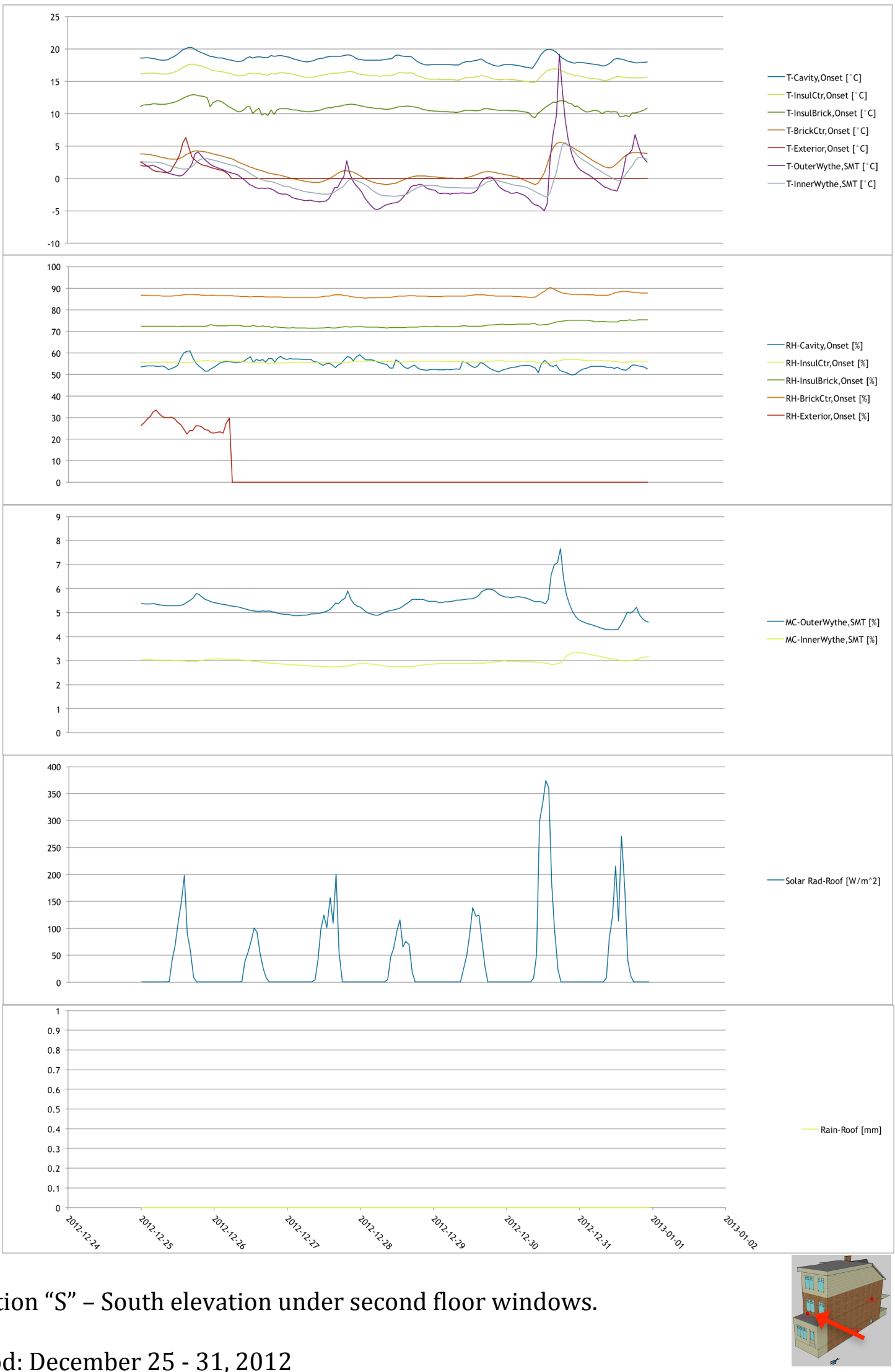

Period: December 25 - 31, 2012

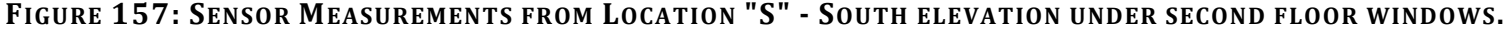
DECEMBER 25 - 31, 2012. 


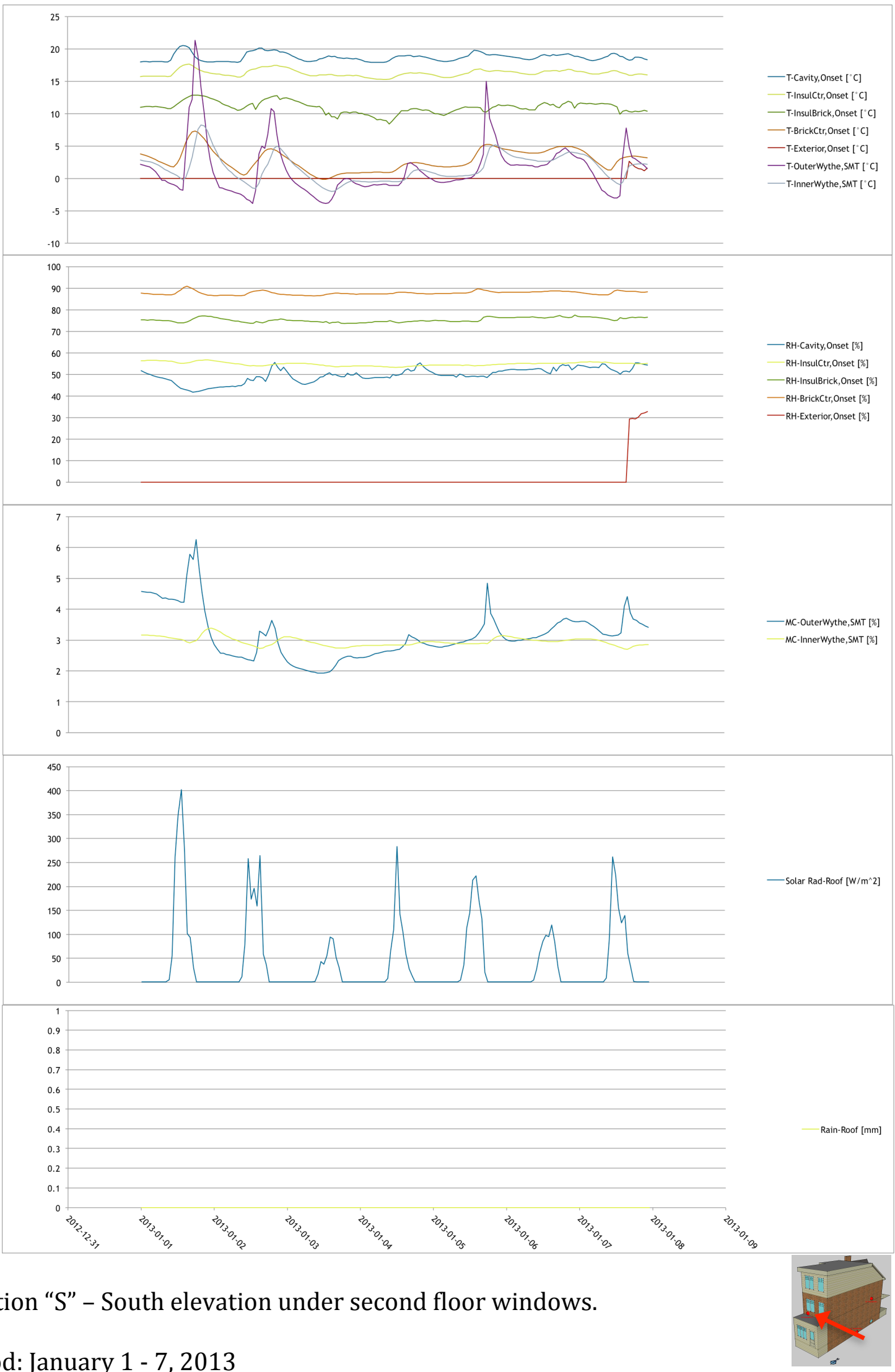

Period: January $1-7,2013$

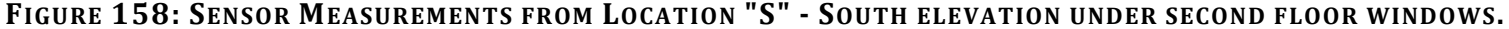
JANUARY 1 - 7, 2013. 


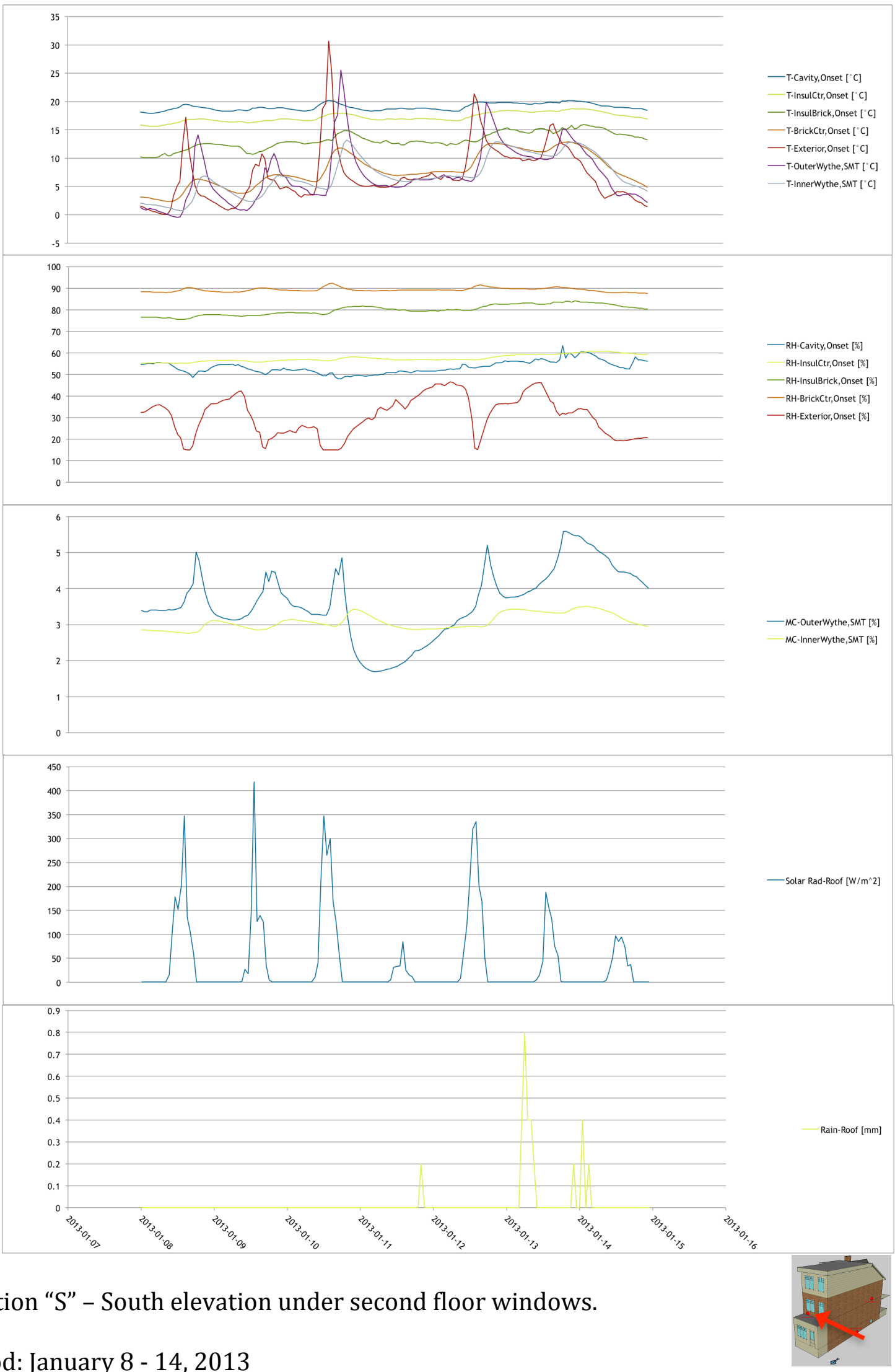

Period: January 8 - 14, 2013

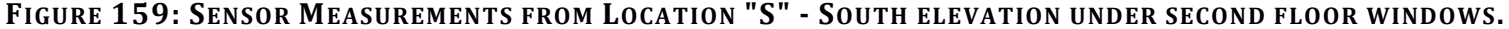
JANUARY 8 - 14, 2013. 


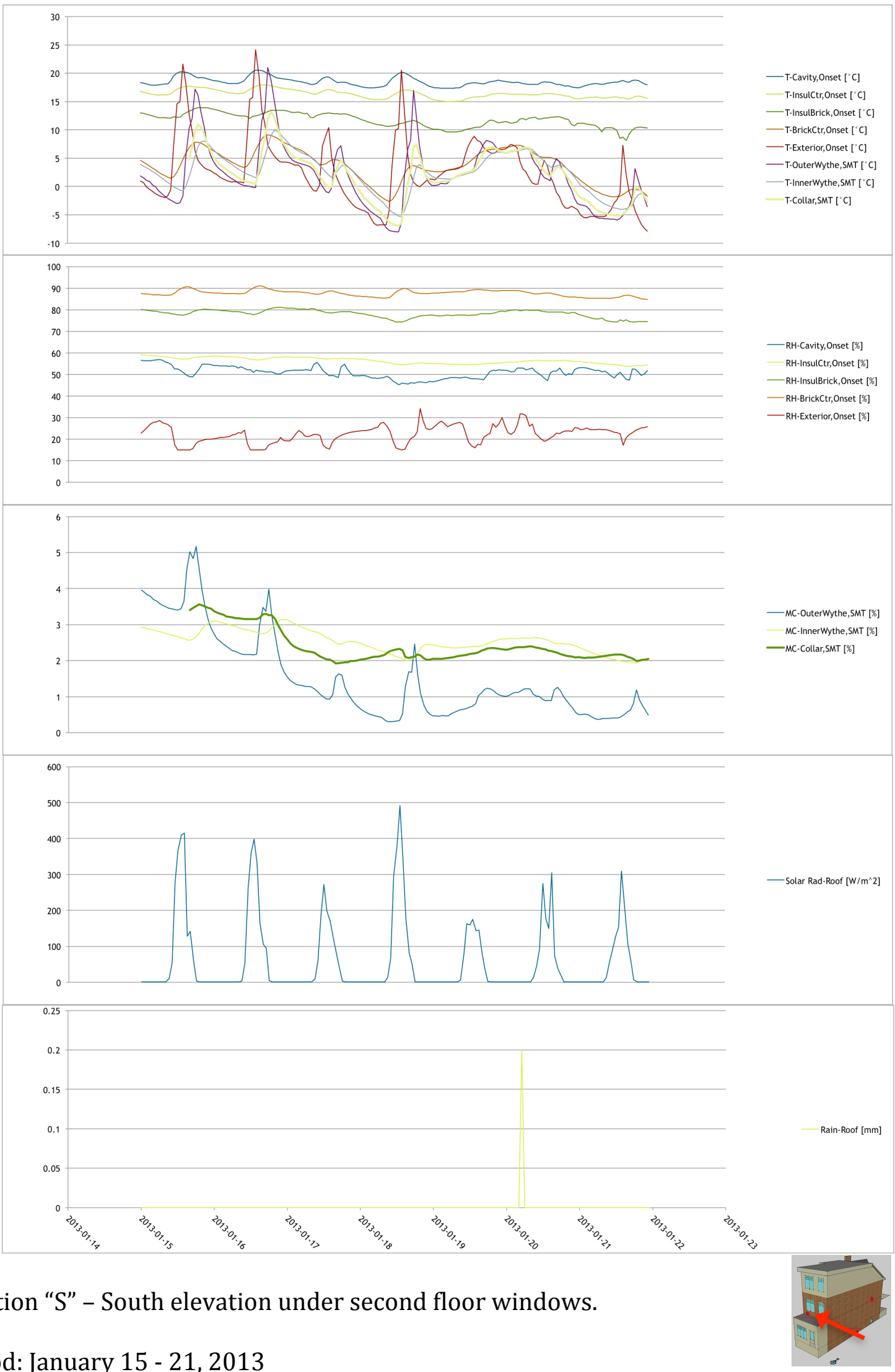

Period: January 15 - 21, 2013

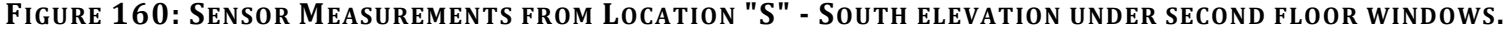
JANUARY 15 - 21, 2013. 


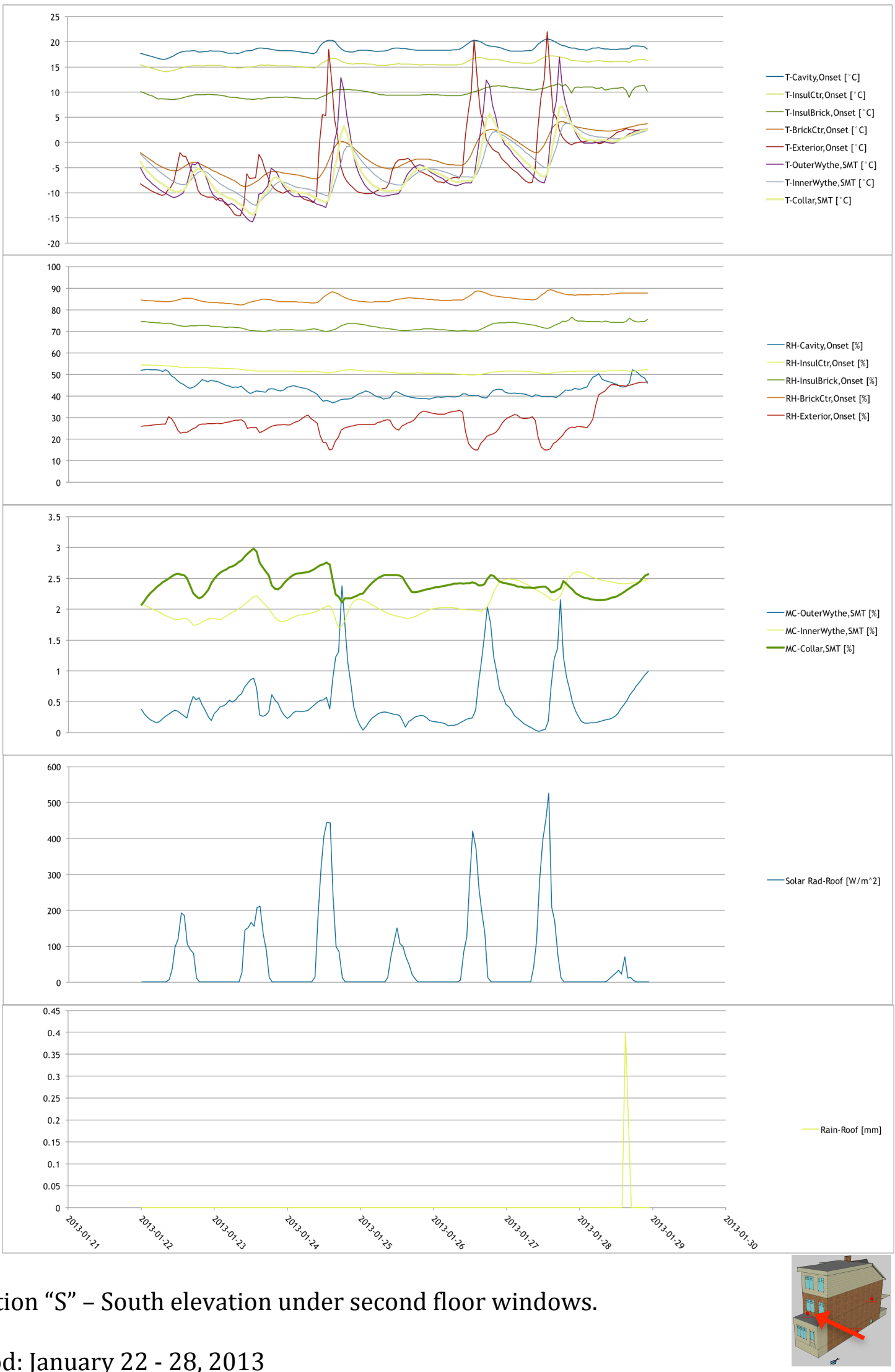

Period: January 22 - 28, 2013

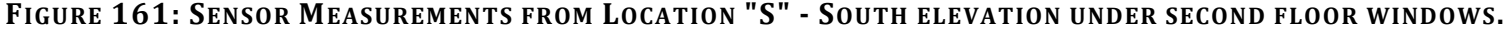
JANUARY 22 - 28, 2013. 


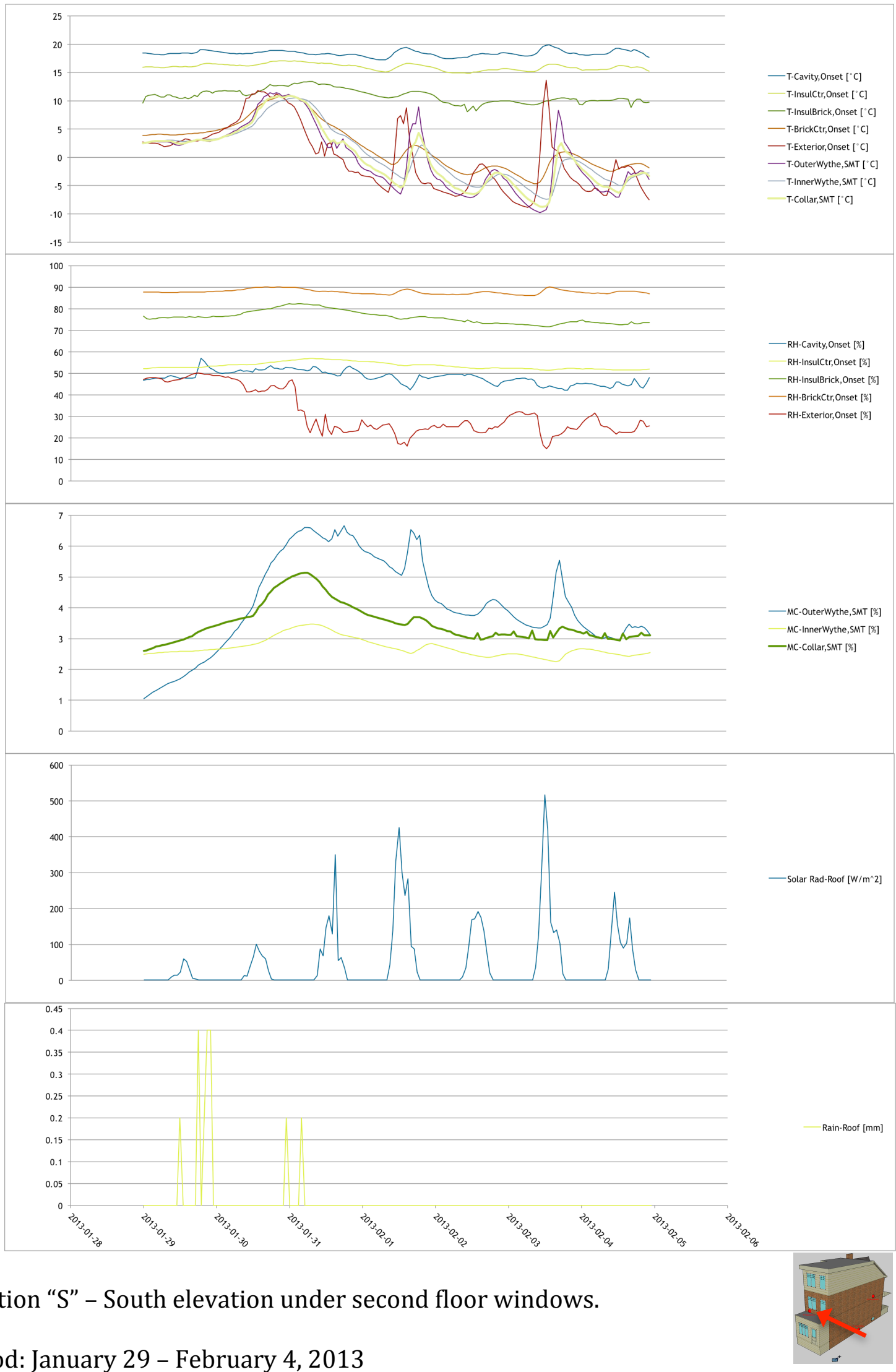

Period: January 29 - February 4, 2013

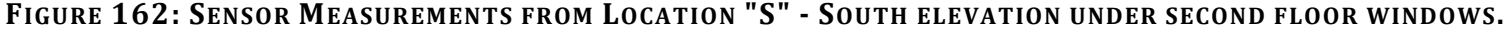
JANUARY 29 - FEBRUARY 4, 2013. 


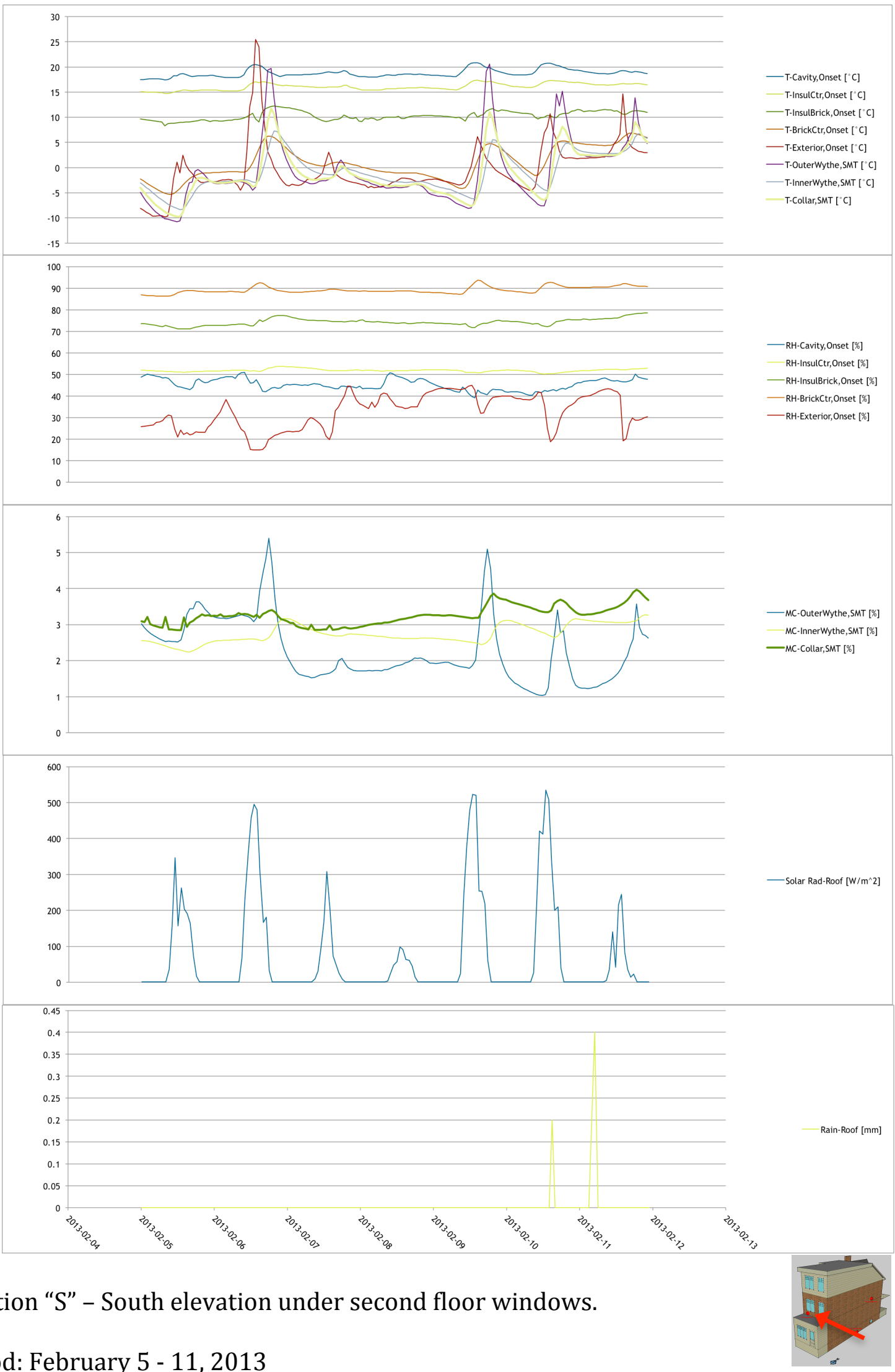

Period: February 5 - 11, 2013

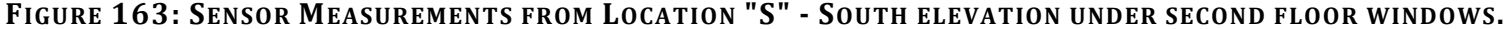
FEBRUARY 5 - 11, 2013. 


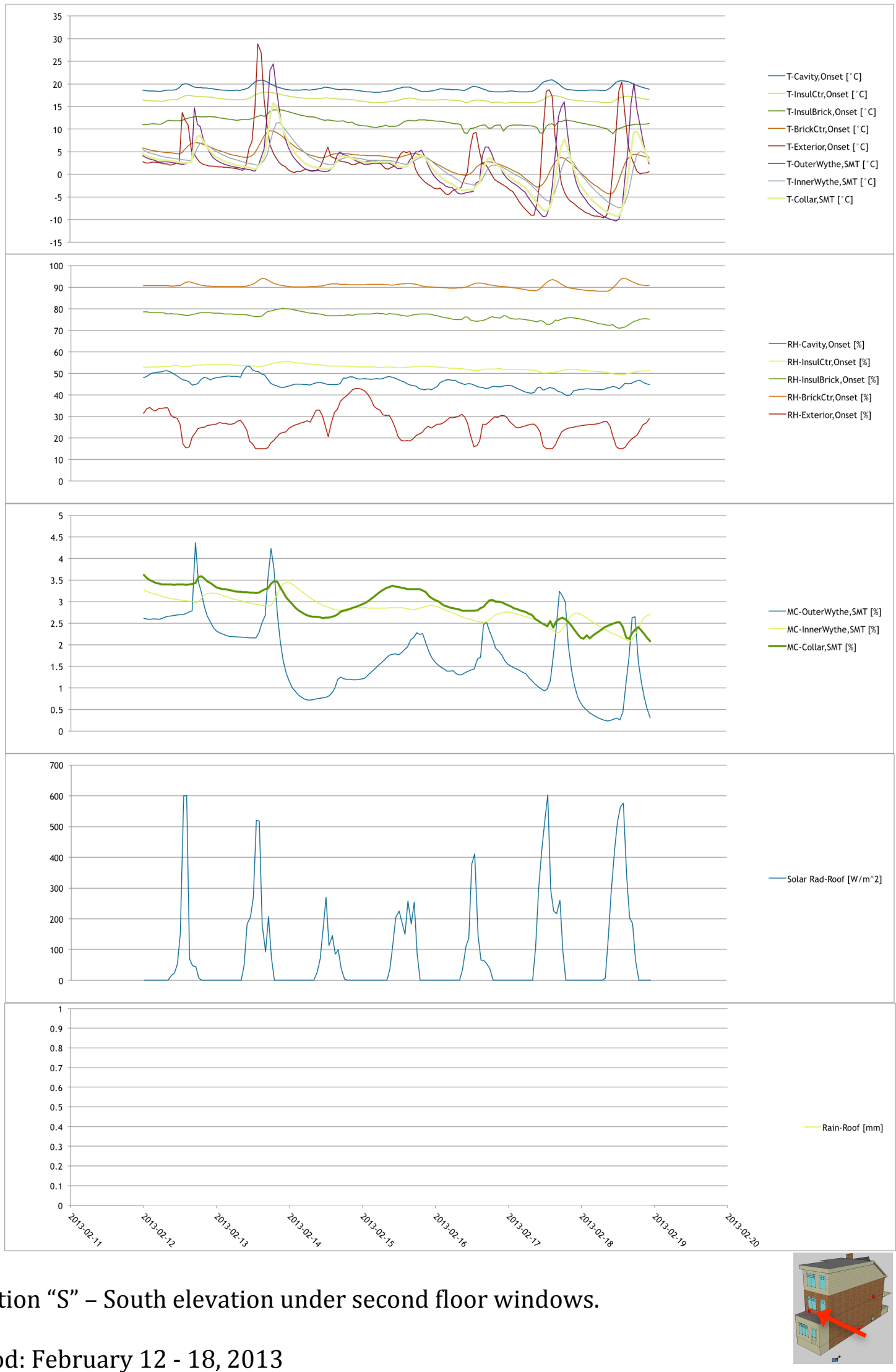

Period: February 12 - 18, 2013

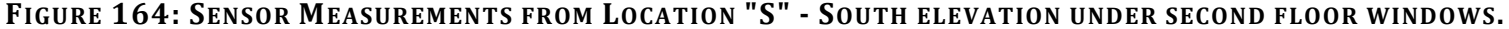
FEBRUARY 12 - 18, 2013. 


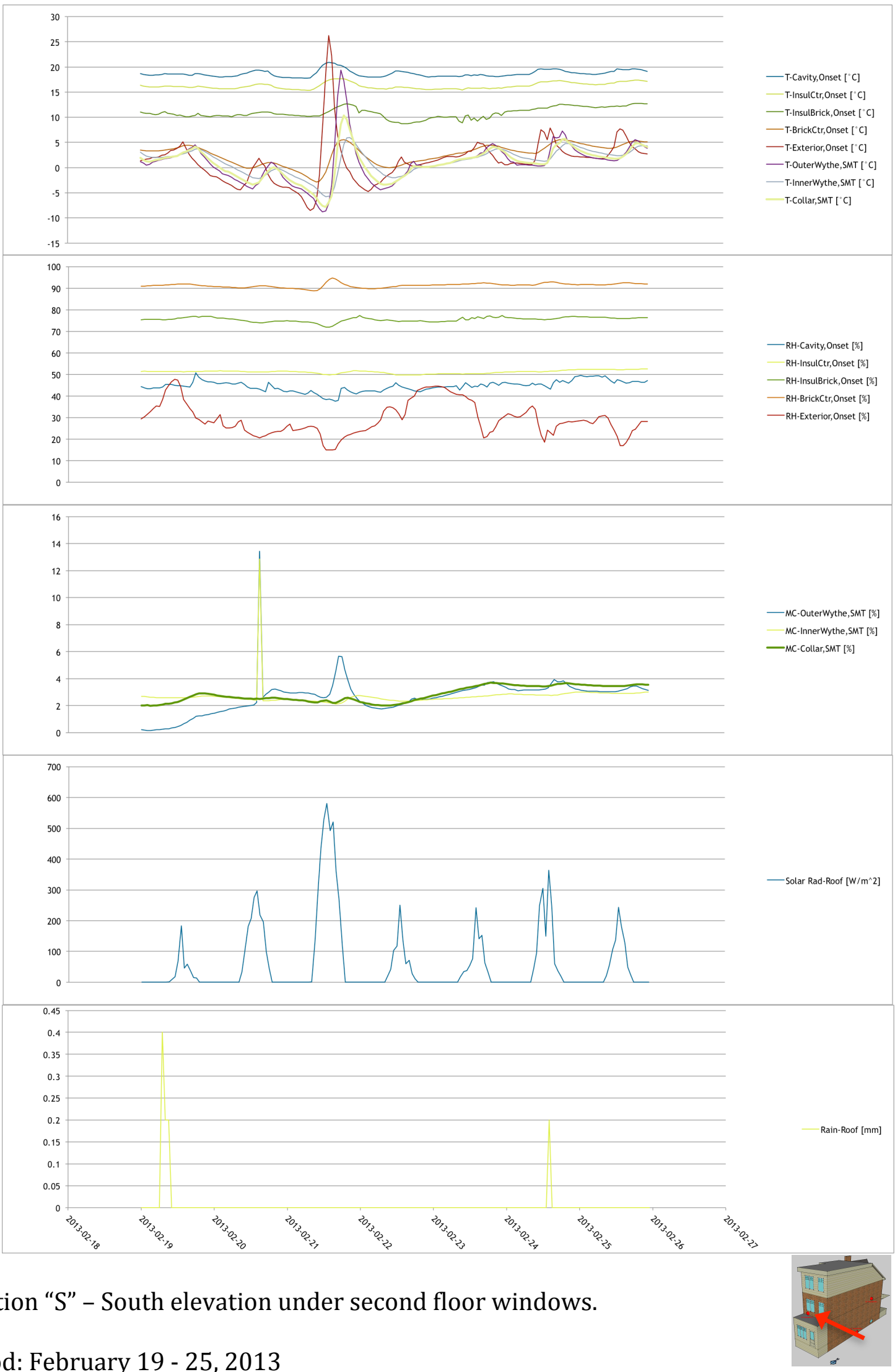

Period: February 19 - 25, 2013

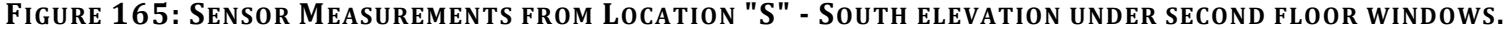
FEBRUARY 19 - 25, 2013. 


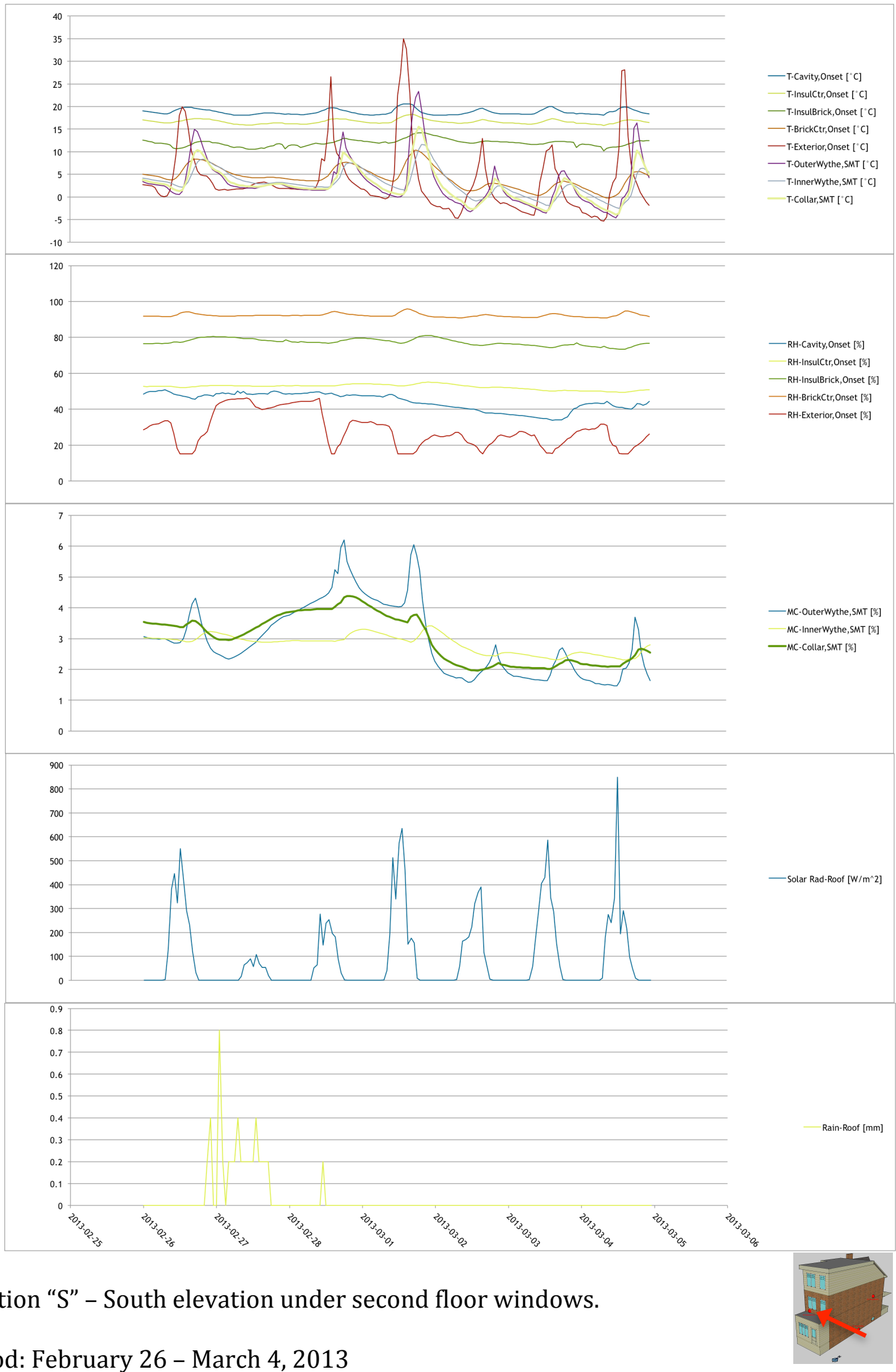

Period: February 26 - March 4, 2013

Figure 166: Sensor Measurements from location "S" - South Elevation Under SECond floor Windows. FEBRUARY 26 - MARCH 4, 2013. 


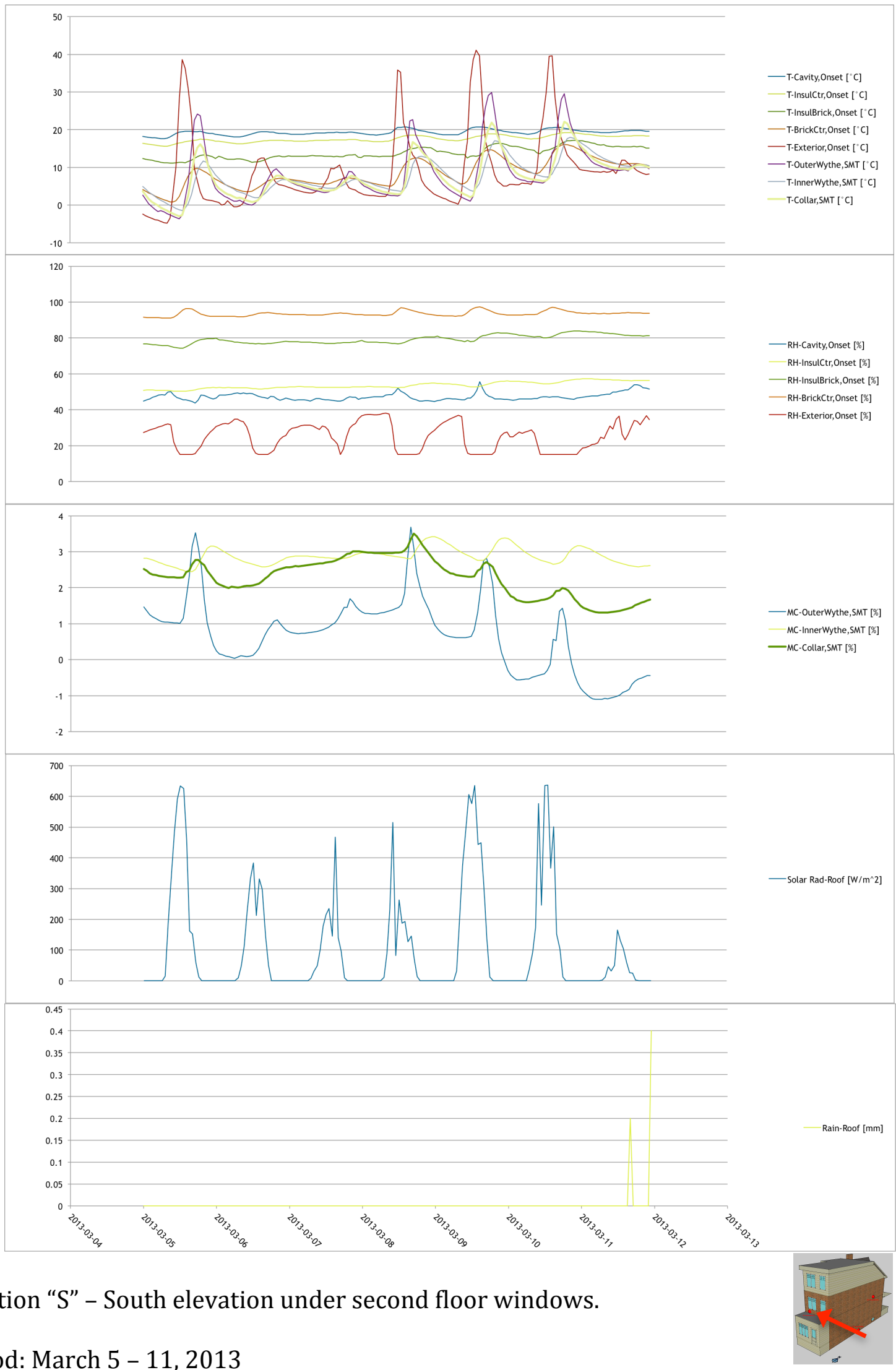

Period: March 5 - 11, 2013

Figure 167: Sensor Measurements from Location "S" - South EleVation Under SECond floor WindoWs. March 5 - 11, 2013. 


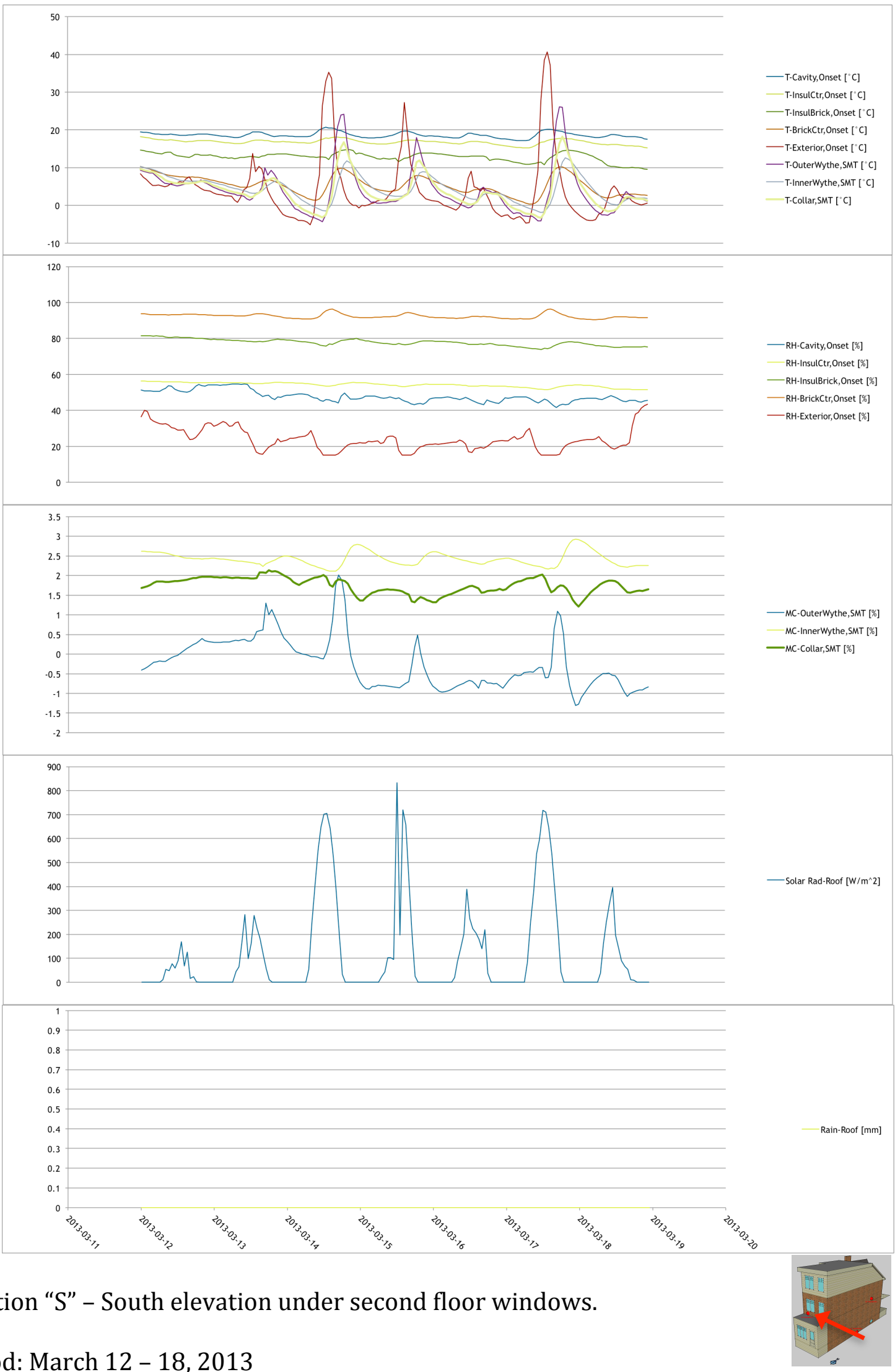

Period: March 12 - 18, 2013

Figure 168: Sensor Measurements from Location "S" - South EleVation Under SECond floor WindoWs. March $12-18,2013$. 


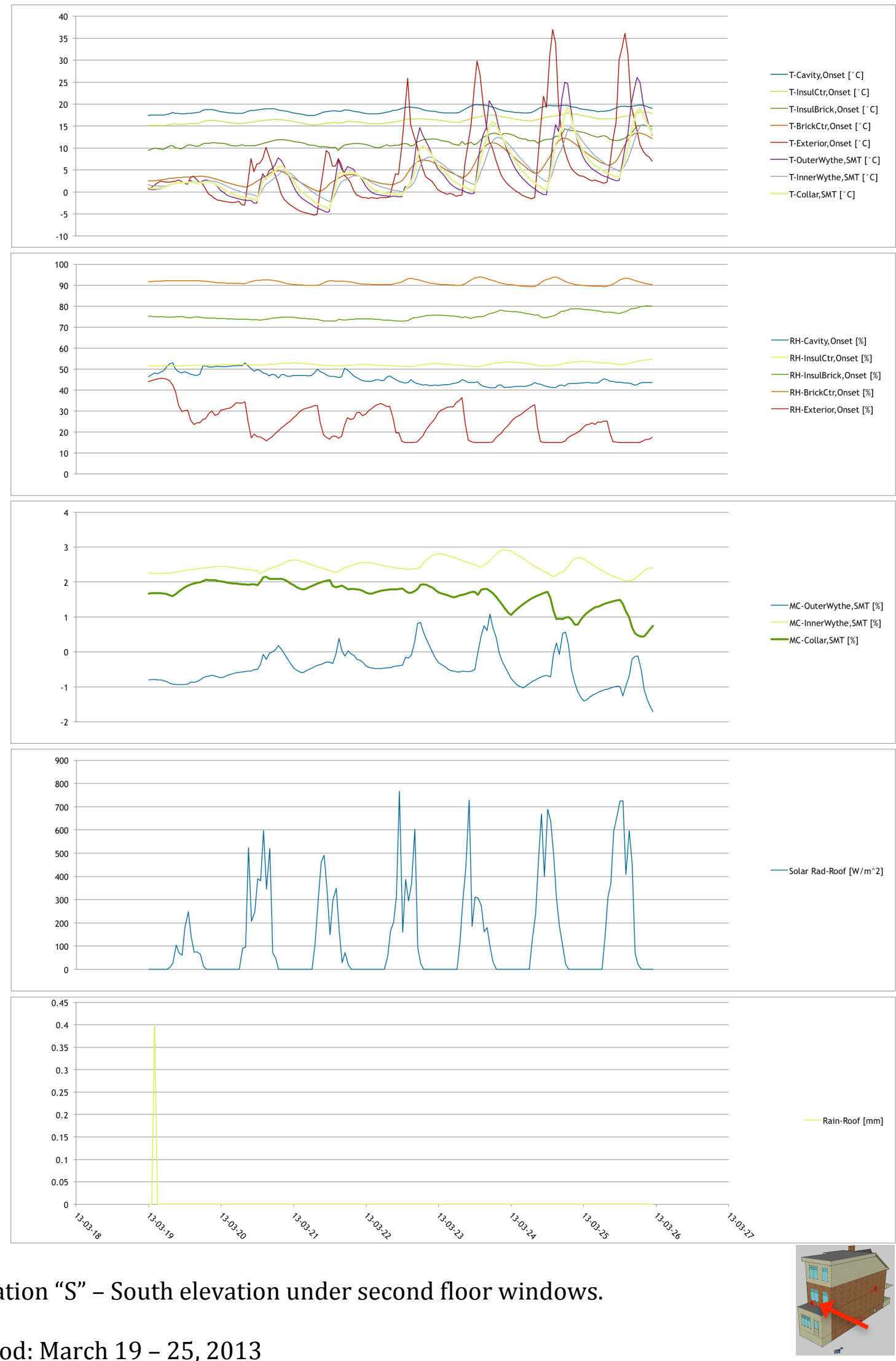

Period: March 19 - 25, 2013

Figure 169: Sensor Measurements from Location "S" - South EleVation Under SECond floor Windows. March 19 - 25, 2013. 


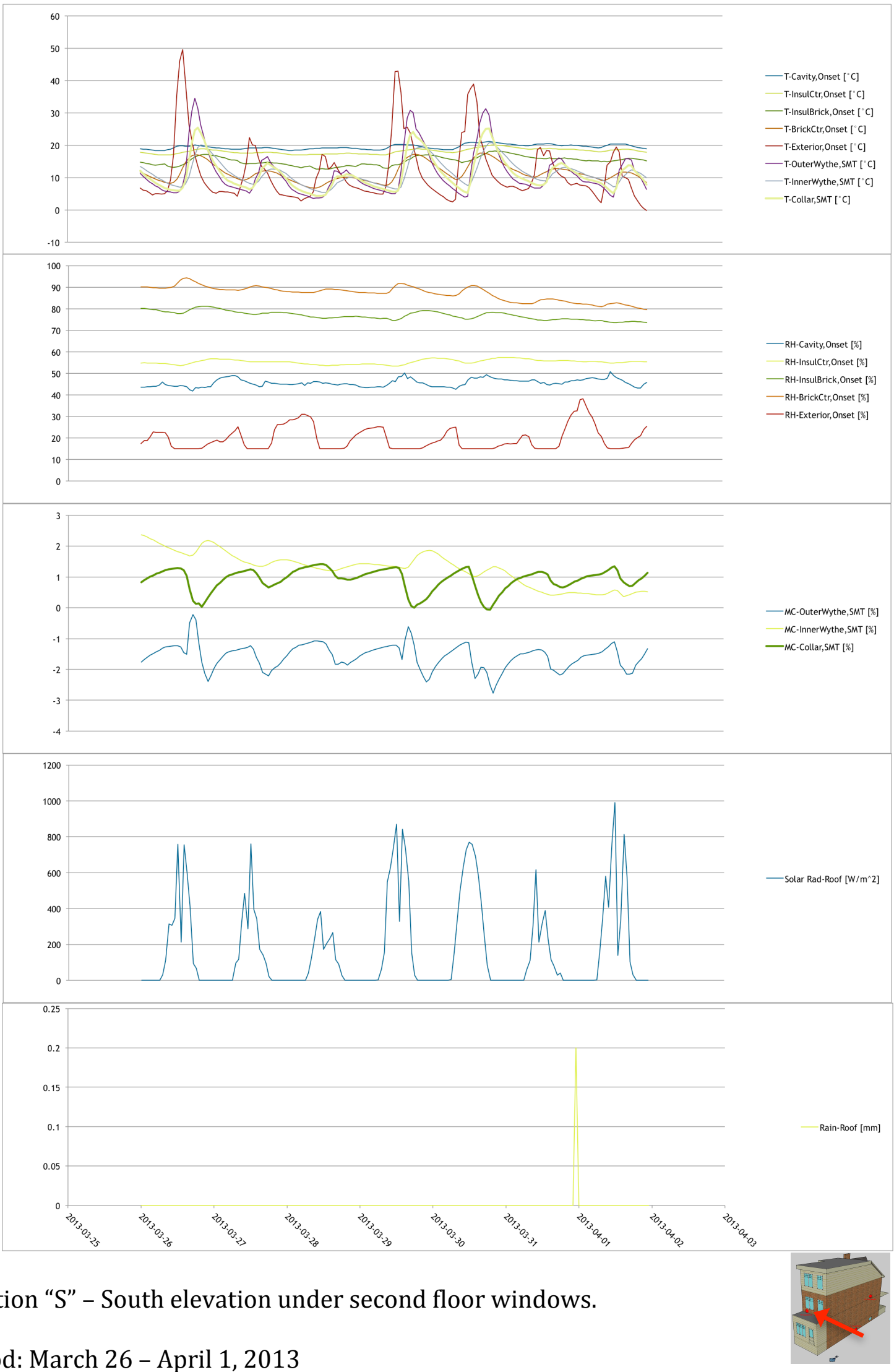

Period: March 26 - April 1, 2013

Figure 170: Sensor Measurements from Location "S" - South EleVation Under SECond floor Windows. March 26 - APRIL 1, 2013. 


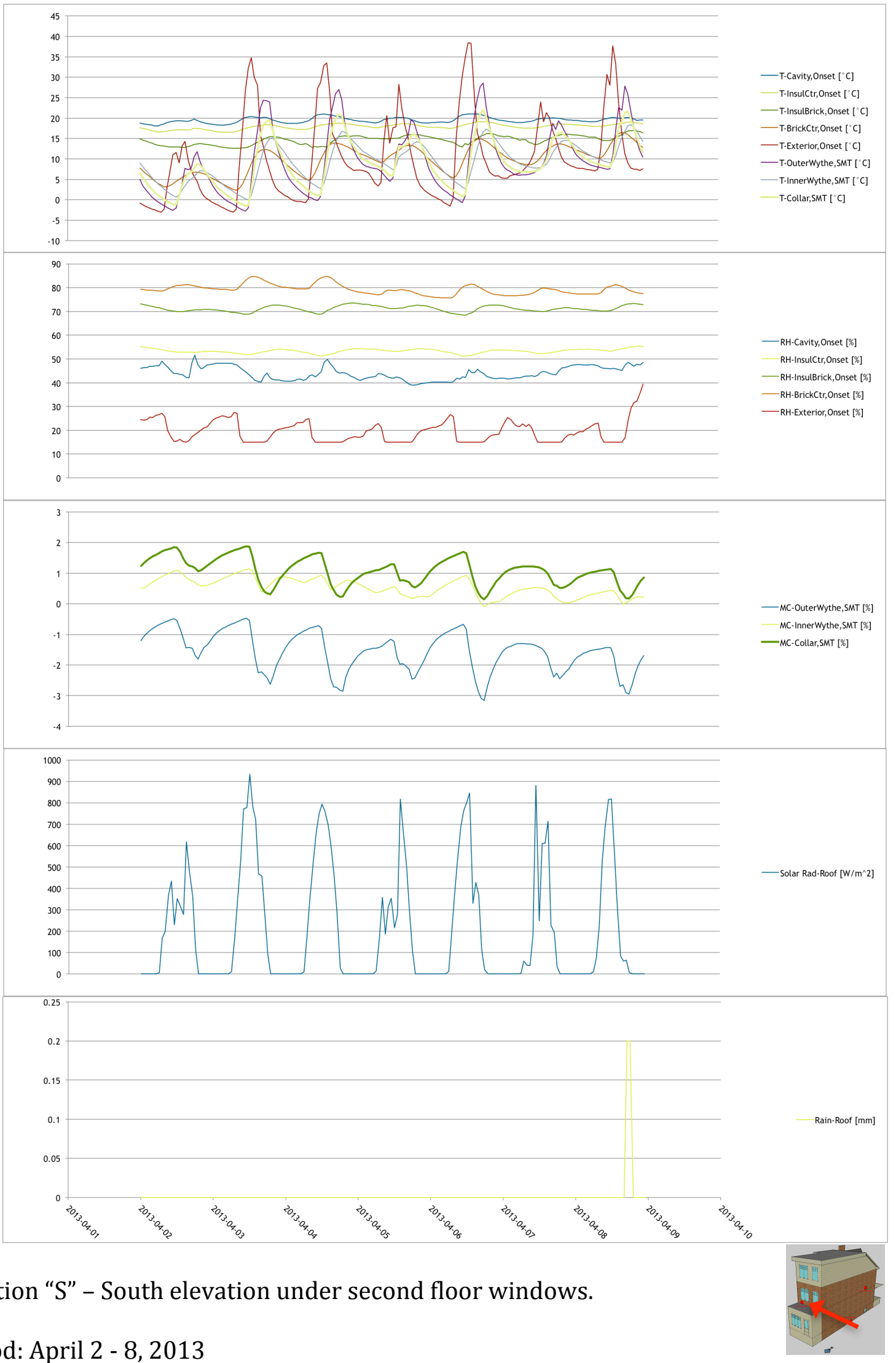

Period: April 2 - 8, 2013

Figure 171: Sensor Measurements from location "S" - South eleVation Under Second floor Windows. April 2 $-8,2013$. 


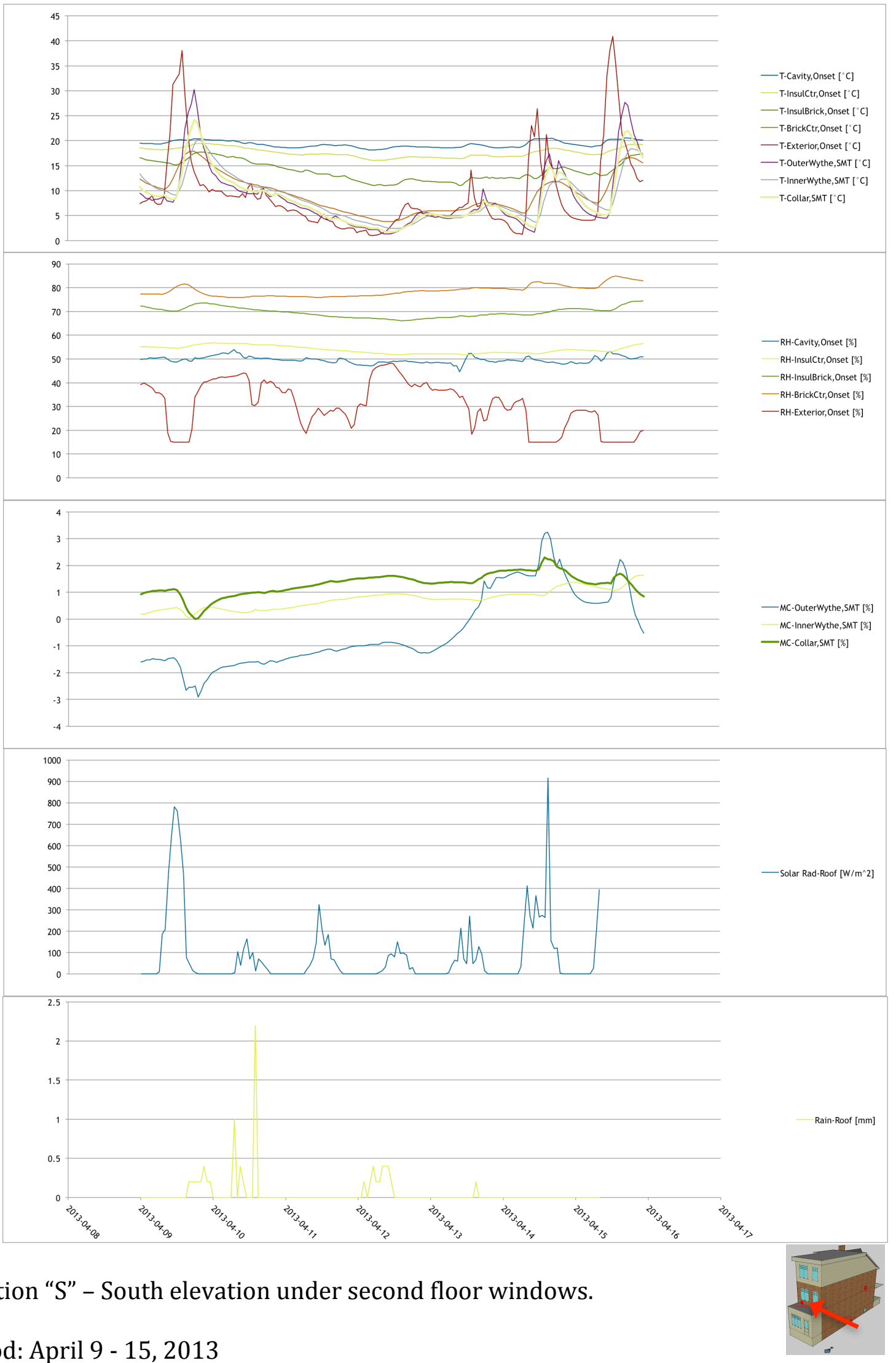

Period: April 9 - 15, 2013

Figure 172: Sensor Measurements from location "S" - South eleVation Under Second floor Windows. April 9 $-15,2013$. 


\section{APPENDIX C - MOISTURE CONTENT SENSOR CORRECTION COEFFICIENTS}

The table below lists the coefficients supplied by the Moisture Content Sensor

manufacturer for each of the tuned sensors.

TABLE 11: MoISTURE CONTENT SENSOR CALIBRATION COEFFICIENTS.

\begin{tabular}{|c|c|c|c|c|}
\hline Sensor Number & Mfg's Label No. & $\underline{\mathbf{A}}$ & $\underline{\mathbf{B}}$ & Notes: \\
\hline 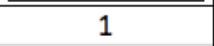 & 2 & 1.0122 & 9.4551 & R - Exterior Wythe \\
\hline 2 & 6 & 1.0107 & 9.8496 & P - Inner Wythe \\
\hline 3 & 7 & 1.0329 & 9.4721 & Q - Collar Joint \\
\hline 4 & 8 & 1.1091 & 8.7700 & RH-to-MC Curve Development \\
\hline 5 & 10 & 0.9782 & 10.1812 & P - Collar Joint \\
\hline 6 & 11 & 1.0388 & 9.3575 & Q - Inner Wythe \\
\hline 7 & 12 & 0.9195 & 11.1679 & S - Exterior Wythe \\
\hline 8 & 14 & 0.9188 & 10.0590 & $P$ - Exterior Wythe \\
\hline 9 & 15 & 1.1607 & 8.0490 & Q - Exterior Wythe \\
\hline 10 & 17 & 1.2834 & 7.2109 & $\mathrm{X}$ - Exterior \\
\hline 11 & 18 & 0.9573 & 10.9409 & X-Inner \\
\hline 12 & 20 & 1.0284 & 8.8352 & R - Inner Wythe \\
\hline 13 & 21 & 1.0743 & 8.5377 & R - Collar Joint \\
\hline 14 & 22 & 0.8557 & 9.4601 & X-Collar \\
\hline 15 & 25 & 1.0974 & 8.5709 & S - Collar Joint \\
\hline 16 & 30 & 1.0795 & 9.2572 & S - Inner Wythe \\
\hline$\sim$ & "Western Hemlock" & 0.8220 & 0.2020 & (for informational purposes only.) \\
\hline
\end{tabular}

The instructions indicated to use the calibrated values for best accuracy, or to use the "western hemlock" values for relative readings. The calibrated values were programmed into the instrumentation for best accuracy of measurements. 


\section{REFERENCES}

Abuku, M., Janssen, H., \& Roels, S. (2009). Impact of wind-driven rain on historic brick wall buildings in a moderately cold and humid climate: Numerical analyses of mould growth risk, indoor climate and energy consumption. Energy and Buildings, 41(1), 101-110. doi:10.1016/j.enbuild.2008.07.011

Adan, O., Brocken, H., Carmeliet, J., Hens, H., Roels, S., \& Hagentoft, C.-E. (2004). Determination of Liquid Water Transfer Properties of Porous Building Materials and Development of Numerical Assessment Methods: Introduction to the EC HAMSTAD Project. Journal of Thermal Enviromental \& Building Science, 27(4), 253-260. doi:10.1177/1097196304042323

American Society for Testing and Materials. (2007). ASTM D4442-07 - Standard Test Methods for Direct Moisture Content Measurement of Wood and Wood-Base Materials (pp. 1-6). West Conshohocken, PA. doi:10.1520/D4442-07.

American Society for Testing and Materials. (2010). ASTM C62-05 - Standard Specification for Building Brick (Solid Masonry Units Made From Clay or Shale) (pp. 10-13). West Conshohocken, PA. doi:10.1520/C0062-10

American Society for Testing and Materials. (2011a). ASTM C67-11 - Standard Test Methods for Sampling and Testing Brick and Structural Clay Tile (pp. 1-12). West Conshohocken, PA. doi:10.1520/C0067-11

American Society for Testing and Materials. (2011b). ASTM F2170-11 - Standard Test Method for Determining Relative Humidity in Concrete Floor Slabs Using in situ Probes (pp. 1-6). West Conshohocken, PA. doi:10.1520/F2170-11

American Society for Testing and Materials. (2014a). ASTM C62-13a Standard Specification for Building Brick (Solid Masonry Units Made From Clay or Shale), 4. doi:10.1520/C0062-13A.2

American Society for Testing and Materials. (2014b). ASTM C67-13a Standard Test Methods for Sampling and Testing Brick and Structural Clay Tile, 13. doi:10.1520/C0067-13A.2

Brocken, H. J. P. (1998). Moisture transport in brick masonry: the grey area between bricks (p. 151).

Carmeliet, J., \& Roels, S. (2002). Determination of the Moisture Capacity of Porous Building Materials. Journal of Thermal Enviromental \& Building Science, 25(3), 209-237. doi:10.1106/109719602022835

City of Toronto. (2011a). James Pears Brick Manufacturer. Retrieved December 12, 2011, from https://gencat4.eloquentsystems.com/webcat/request/DoMenuRequest?SystemName=City+of+Toronto+Archi 
ves\&UserName=wa+public\&Password=\&TemplateProcessID=6000_1580_11104\&bCa chable=1\&MenuName=City+of+Toronto+Archives\&eloquentref=toronto

City of Toronto. (2011b). Robert Goodings Brick Works.

CMHC. (2004). Renovating for Energy Savings - Pre-World War ll Houses. CMHC, (1), 1-6. Retrieved from http://www.cmhc-schl.gc.ca/odpub/pdf/63643.pdf

CSA Standards. (2007). CAN/CSA-A82-06 Fired masonry brick made from clay or shale (p. 45). Mississauga.

Delghust, M., Janssens, A., \& Rummens, J. (2010). Retrofit cavity-wall insulation: performance analysis from in-situ measurements. In 1st Central European symposium on Building Physics (CESBP) (pp. 297-304). Technical University of Lodz.

Evergreen Brick Works. (2013). Historical Timeline. Retrieved May 09, 2013, from http://ebw.evergreen.ca/about/site/history

Fagerlund, G. (1977). The critical degree of saturation method of assessing the freeze/thaw resistance of contrete. Materials and Structures, 10.58(1), 217-230.

Finch, G., Straube, J. F., \& Richmond, M. (2007). Field Performance of Spray Polyurethane Foam : The Role of Vapour Diffusion Control. In 11th Canadian Conference on Building Science and Technology. Banff, Alberta.

Google Maps. (2014). Google Maps Streetview Image. Retrieved August 13, 2014, from https://www.google.com/maps/@43.67009,-

79.35148,3a,37.5y,159.53h,81.99t/data=!3m4!1e1!3m2!1sNcRFYqZroAeSjw579tp$\mathrm{zQ} ! 2 \mathrm{e} 0$

Guadagnoli, A. (2014). Evaluation of In-Situ Cooling Performance at Renovation 2050: Comparing Zone vs, Central Based Cooling Systems for Single Family Dwellings. Ryerson University.

Hall, C. (1977). Water Movement in Porous Building Materials--I . Unsaturated Flow Theory and its Applications. Buildings and Environment, 12, 117-125.

Hall, C., \& Hoff, W. (2012). Water Transport in Brick, Stone and Concrete (Second Edi., p. 370). Oxon: Spon Press.

Hanson Building Products. (2014). Northern Collection. Retrieved August 12, 2014, from http://www.hansonbrick.com/english/products/bricks.php?col=nor

Hens, H. (1998). Performance Predictions for Masonry Walls with Inside Insulation Using Calculation Procedures and Laboratory Testing. Journal of Building Physics, 22(1), 3248. doi:10.1177/109719639802200104

Hens, H. (2007). Building Physics - Heat, Air and Moisture : Fundamentals and Engineering Methods with Examples and Exercises (p. 270). Berlin: Ernst \& Sohn. 
Hutcheon, N. B., \& Handegord, G. O. (1995). NRC-CNRC Building Science for a Cold Climate. Institute for Research in Construction.

Ibstock. (2005). How Bricks Are Made. Retrieved August 02, 2014, from http://www.ibstock.com/pdfs/technical-support/TIS16Howbricksaremade.pdf

Johansson, P., Geving, S., Hagentoft, C.-E., Jelle, B. P., Rognvik, E., Kalagasidis, A. S., \& Time, B. (2014). Interior insulation retrofit of a historical brick wall using vacuum insulation panels: Hygrothermal numerical simulations and laboratory investigations. Building and Environment, 79, 31-45. doi:10.1016/j.buildenv.2014.04.014

Kavenagh, C., \& Wheeler, G. (2003). Evaluation of Cleaning Methods for the Exterior Brick at the Brooklyn Historical Society. Retrieved August 04, 2014, from http://cool.conservation-us.org/jaic/articles/jaic42-01-006_2.html

Klõšeiko, P., Arumägi, E., \& Kalamees, T. (2003). Hygrothermal performance of internally insulated brick wall in cold climate: field measurement and model calibration. co2olBricks.com, (Scheffler). Retrieved from http://co2olbricks.com/fileadmin/Redaktion/Dokumente/Publications/WP4OP09_ES_Hygrothermal_performance_pdf

Kolor SARL. (2014). Kolor Autopano Giga. Retrieved August 03, 2014, from http://www.kolor.com/image-stitching-software-autopano-giga.html

Künzel, H. M. (1998). Effect of interior and exterior insulation on the hygrothermal behaviour of exposed walls. Materials and Structures, 31, 99-103.

Laefer, D. F., Boggs, J., \& Cooper, N. (2004). Engineering Properties of Historic Brick: Variability Considerations as a Function of Stationary versus Nonstationary Kiln Types. Journal of the American Institute for Conservation, 43(3), 255-272. doi:10.2307/4129639

Mensinga, P. (2009). Determining the critical degree of saturation of brick using frost dilatometry. University of Waterloo. Retrieved from http://www.uwspace.uwaterloo.ca/handle/10012/4638

OmniSense LLC. (2014). OmniSense S-900. Retrieved August 12, 2014, from https://www.omnisense.com/help/sensor1_brief.asp

Onset Computer Corporation. (2006). HOBO U10 Temp/RH Data Logger. Retrieved August 12, 2014, from http://www.onsetcomp.com/products/data-loggers/u10-003

Onset Computer Corporation. (2014a). HOBO Micro Station Data Logger - H21-002. Retrieved August 12, 2014, from http://www.onsetcomp.com/products/dataloggers/h21-002

Onset Computer Corporation. (2014b). HOBO U-Shuttle - U-DT-1. Retrieved August 12, 2014, from http://www.onsetcomp.com/products/communications/u-dt-1 
Onset Computer Corporation. (2014c). Hobo U30-NRC Weather Station Starter Kit (U30NRC-SYS-B). Retrieved August 12, 2014, from

http://www.onsetcomp.com/products/kits/u30-nrc-sys-b

Onset Computer Corporation. (2014d). Temperature/RH Smart Sensor (S-THB-M00x). Retrieved August 12, 2014, from http://www.onsetcomp.com/products/sensors/sthb-m002

OSHA, U. (2001). Canadian WHMIS Standards. doi:001033

Pfaff, F., \& Garrahan, P. (1988). New Temperature Correction Factors for the Portable Resistance-Type Moisture Meter. In Workshop on In-Grade Testing of Structural Lumber (pp. 39-43). Ottawa. Retrieved from http://scholarsarchive.library.oregonstate.edu/xmlui/bitstream/handle/1957/5469/ New_Temp_ocr.pdf?sequence $=1$

Richman, R. (2009). Renovation 2050. Retrieved July 29, 2014, from http://renovation2050.wix.com/renovation2050

Roels, S., Carmeliet, J., Hens, H., Adan, O., Brocken, H., Cerny, R., ... Plagge, R. (2004). Interlaboratory Comparison of Hygric Properties of Porous Building Materials. Journal of Thermal Envelope and Building Science, 27(4), 307-325. doi:10.1177/1097196304042119

Russell Richman Consulting Limited. (2010). Proposed Site Plan Drawing (p. 7). Toronto.

Smits, A., Gregoire, Y., Tirlocq, J., Lefort, V., \& Andre, S. (2010). Frost Resistance of Clay Masonry Units: In-Depth Experimental Study of the European Method. In 8th International Masonry Conference 2010 in Dresden (pp. 1-10).

SMT Research Ltd. (n.d.). Embedded Moisture Sensor. Retrieved May 14, 2013, from http://www.smtresearch.ca/products/embedded-moisture-sensor-ems

Straube, J. F. (2006). Building Science Digest 138 Moisture and Materials. Building Science Digest, 138(Oct 24), 1-7.

Straube, J. F., \& Burnett, E. (2005). Building Science for Building Enclosures (1st ed., p. 549). Westford, Massachusetts: Building Science Press Inc. Retrieved from www.buildingsciencepress.com

Straube, J. F., Onysko, D., \& Schumacher, C. (2002). Methodology and Design of Field Experiments for Monitoring the Frame Enclosures. Journal of Thermal Enviromental \& Building Science, 26(2), 123-151.

Straube, J. F., \& Schumacher, C. (2007). Interior Insulation Retrofits of Load-Bearing Masonry Walls in Cold Climates. Building Science Digest, (114), 16. 
Straube, J. F., Schumacher, C., \& Mensinga, P. (2010). Assessing the Freeze-Thaw Resistance of Clay Brick for Interior Insulation Retrofit Projects. Building Science Digest, RR1013(15 December 2010), 1-11.

Straube, J. F., Ueno, K., \& Schumacher, C. (2011). Internal Insulation of Masonry Walls : Final Measure Guideline. Building Science.com, RR-1105(21 December 2011), 1-99.

Ueno, K., \& Straube, J. F. (2008). Laboratory Calibration and Field Results of Wood Resistance Humidity Sensors (Vol. ??, pp. 1-19). Retrieved from http://c.ymcdn.com/sites/www.nibs.org/resource/resmgr/BEST/BEST1_004.pdf?hh SearchTerms=ueno

Wexler, A., \& Hasegawa, S. (1954). Relative Humidity-Temperature Relationships of Some Saturated Salt Solutions in the Temperature. Journal of Research of the National Bureau of Standards, 53(1), 19-26.

Wilkinson, J., DeRose, D., Straube, J. F., \& Sullivan, B. (2009). Measuring the Impact of Interior Insulation on Solid Masonry Walls in a Cold Climate. 12th Canadian Conference on Building Science and Technology, 1-14. 
